DOE/BC/14431-1 (Vol. 3)

Distribution Category UC-122

\title{
AN EVALUATION OF KNOWN REMAINING \\ OIL RESOURCES IN THE STATE OF LOUISIANA \\ Project on Advanced Oil Recovery and the States
}

Volume III

November 1994

Work Performed Under Contract DE-FG22-89BC14431

Prepared for

U.S. Department of Energy

Assistant Secretary for Fossil Energy

R. Michael Ray, Project Manager

Bartlesville Project Office

P.O. Box 1398

Bartlesville, OK 74005

Prepared by

Interstate Oil Compact Commission

900 N.E. 23rd Street

Oklahoma City, OK 73152

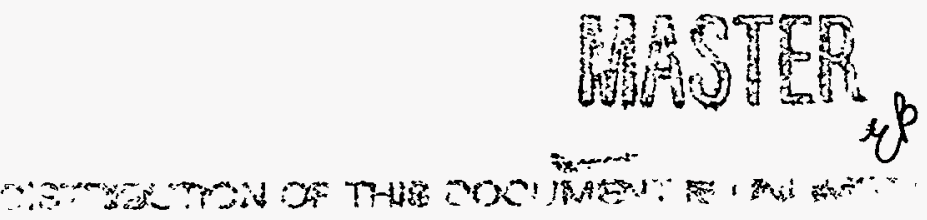


-_ 


\section{DISCLAIMER}

This report was prepared as an account of work sponsored by an agency of the United States Government. Neither the United States Government nor any agency thereof, nor any of their employees, make any warranty, express or implied, or assumes any legal liability or responsibility for the accuracy, completeness, or usefulness of any information, apparatus, product, or process disclosed, or represents that its use would not infringe privately owned rights. Reference herein to any specific commercial product, process, or service by trade name, trademark, manufacturer, or otherwise does not necessarily constitute or imply its endorsement, recommendation, or favoring by the United States Government or any agency thereof. The views and opinions of authors expressed herein do not necessarily state or reflect those of the United States Government or any agency thereof. 


\section{DISCLAIMER}

Portions of this document may be illegible in electronic image products. Images are produced from the best available original document. 


\section{Table of Contents}

$\underline{\text { Page }}$

LIST OF FIGURES $\ldots \ldots \ldots \ldots \ldots \ldots \ldots \ldots \ldots \ldots \ldots \ldots \ldots \ldots \ldots \ldots \ldots$

LIST OF TABLES $\ldots \ldots \ldots \ldots \ldots \ldots \ldots \ldots \ldots \ldots \ldots \ldots \ldots \ldots \ldots$ vii

ACKNOWLEDGEMENTS $\ldots \ldots \ldots \ldots \ldots \ldots \ldots \ldots \ldots \ldots \ldots \ldots \ldots$ viii

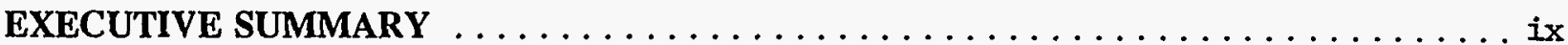

I. OVERVIEW

A. THE PROBLEM: DECLINING LOUISIANA OIL PRODUCTION . . . . . . . . I-1

B. THE OPPORTUNITY: OLL RECOVERY THROUGH ADVANCED

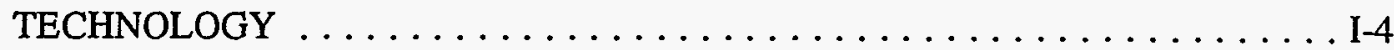

C. BENEFITS DERIVED FROM IMPROVED OIL RECOVERY $\ldots \ldots \ldots \ldots \ldots$ I-5

D. CONCLUSIONS ......................... $1-10$

II. BACKGROUND AND OBJECTIVES

A. TRENDS IN LOUISIANA PRODUCTION AND RESERVES . . . . . . . . II- I

B. IMPROVED RECOVERY ACTIVITIES TARGETING THE REMAINING

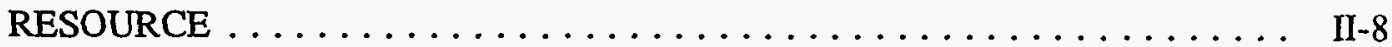

1. Enhanced Oil Recovery $\ldots \ldots \ldots \ldots \ldots \ldots \ldots \ldots \ldots$ II 8

2. Advanced Secondary Recovery ................. II-13

C. OBJECTIVES OF THE PRESENT STUDY $\ldots \ldots \ldots \ldots \ldots \ldots \ldots \ldots$ II -15

III. APPROACH TO THE ANALYSIS

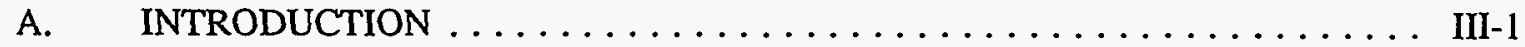

B. GENERAL METHODOLOGY: THE NPC BASIS $\ldots \ldots \ldots \ldots \ldots \ldots$ III- 1

C. BUILDING ON TORIS: THE EVALUATION OF UNRECOVERED MOBILE

OIL RESOURCES $\ldots \ldots \ldots \ldots \ldots \ldots \ldots \ldots \ldots \ldots \ldots$ III-6

D. SCOPE OF THE ANALYSIS $\ldots \ldots \ldots \ldots \ldots \ldots \ldots \ldots \ldots \ldots \ldots$ III-9

E. ADAPTATIONS FOR THE PRESENT STUDY $\ldots \ldots \ldots \ldots \ldots \ldots \ldots$ III -11

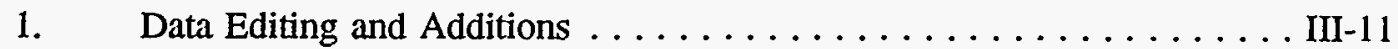

2. State and Federal Taxes . . . . . . . . . . . . . . . . III-11

3. Cost and Price Data ....................... III-12

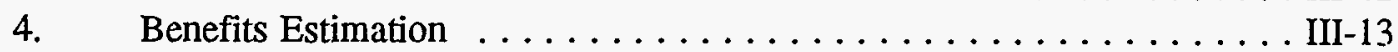

5. Project Timing . . . . . . . . . . . . . . . . . . . . 13

F. ESTIMATION OF BENEFITS, COSTS, AND ECONOMIC IMPACTS . . . . III-14

1. Benefits to State and Local Treasuries . . . . . . . . . . . . III-15

2. Direct State Economic Effects . . . . . . . . . . . . . III-15

3. National Effects . . . . . . . . . . . . . . . . . . . . III-16

G. LIMITATIONS TO THE ANALYTICAL APPROACH $\ldots \ldots \ldots \ldots \ldots \ldots$ III-18 
IV. INCREASED RECOVERY FROM THE KNOWN REMAINING OIL RESOURCE IN LOUISIANA UNDER IMPLEMENTED TECHNOLOGY

A. INTRODUCTION $\ldots \ldots \ldots \ldots \ldots \ldots \ldots \ldots \ldots \ldots \ldots \ldots \ldots$ IV -1

B. RECOVERY OF THE REMAINING IMMOBILE OL RESOURCE . . . . . . IV-1

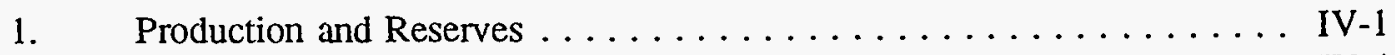

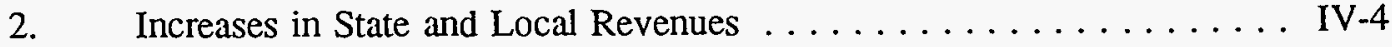

3. Effects on the State Economy $\ldots \ldots \ldots \ldots \ldots \ldots \ldots \ldots \ldots \ldots$ IV-4

4. Effects on the National Economy . . . . . . . . . . . . . IV-7

C. RECOVERY OF THE REMAINING MOBILE OIL RESOURCE . . . . . . . IV-10

1. Production and Reserves . . . . . . . . . . . . . . IV-10

2. Increases in State and Local Revenues .............. IV-11

3. Effects on the State Economy .................. IV-14

4. Effects on the National Economy and Budget $\ldots \ldots \ldots \ldots \ldots$ IV -16

D. CONCLUSIONS ........................ IV -16

V. BENEFITS OF INCREASED RECOVERY FROM THE KNOWN REMAINING OIL RESOURCE IN LOUISIANA WITH TECHNOLOGY ADVANCES

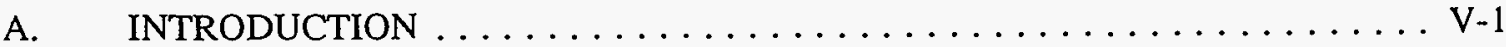

B. RECOVERY OF THE REMAINING IMMOBILE OLL RESOURCE . . . . . . V-1

1. "Advanced" Technology Defined .................... . . 1

2. Production and Reserves . . . . . . . . . . . . . . . . V-2

3. Effects on State Revenues and Economic Activity . . . . . . . . . . V-5

4. Effects on the National Economy and Budget . . . . . . . . . V-8

C. RECOVERY OF THE REMAINING MOBILE OIL RESOURCE . . . . . . . . V-9

1. "Advanced" Technology Defined . . . . . . . . . . . . . V

2. Production and Reserves . . . . . . . . . . . . . . . . V V 11

3. Effects on State Revenues and Economic Activity .......... V-12

4. Effects on the National Economy and Budget ........... V-15

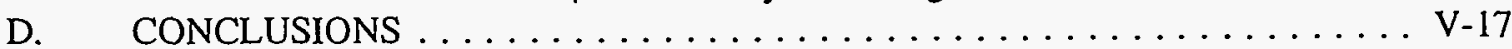




\section{List of Figures}

Figure

Page

I-1

I-2

I-3

I -4

I-5

II-1

II-2

II-3

II-4

II-5

II-6

II-7

II-8

II-9

II-10

IV-1

IV-2

IV-3

IV-4

IV-5

IV -6

IV-7

IV-8

IV-9

IV-10

IV-II

$\mathrm{V}-1$

V-2

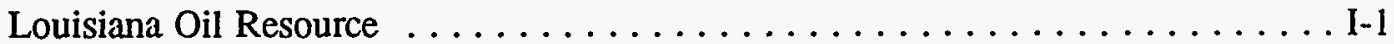

Louisiana Production and Reserves .................... I-3

Louisiana Oil Resource: Data Coverage of EOR and ASR Analyses . . . . . . I-6

Potential Impact of Advanced Technology . . . . . . . . . . . . . . . I-7

Remaining Oil Resource After Advanced Technology Recovery ........... I-11

Louisiana Crude Oil Production $(1950-1991) \ldots \ldots \ldots \ldots \ldots \ldots$. . . . . . . II-2

Louisiana Crude Oil Reserves $(1950-1991) \ldots \ldots \ldots \ldots \ldots \ldots$. . . . . . . . II-2

Louisiana Producing Wells $(1960-1991) \ldots \ldots \ldots \ldots \ldots \ldots \ldots$. . . . . . . . . II-4

Louisiana Stripper Well Production and Abandonments $(1970-1990)$. . . . . . . II-4

Total Oil and Gas Employment in Louisiana (1970-1991) . . . . . . . . . . . . . II-5

Annual Wellhead Value of Louisiana Oil and Gas Production (1961-1991) . . . . II-5

Louisiana Oil and Gas Severance Taxes (FY1971-1990) . . . . . . . . . . . II-6

Louisiana Oil and Gas Severance Taxes as a Percent of Total

State Taxes (FY1971-1990) . . . . . . . . . . . . . . . . II-6

Louisiana Oil Resource . . . . . . . . . . . . . . . . . II-7

Louisiana Remaining Oil Resource After Conventional Operations ........ II-16

Reserves and Production Response from EOR Techniques

Implemented Technology $\ldots \ldots \ldots \ldots \ldots \ldots \ldots \ldots$ IV -5

Direct State and Local Revenues from EOR Production

Implemented Technology . . . . . . . . . . . . . . IV-6

Direct State Economic Activity from EOR Production

Implemented Technology $\ldots \ldots \ldots \ldots \ldots \ldots \ldots \ldots$ IV-8

Jobs and Wages from EOR Production Implemented Technology . . . . . . . . IV-8

National Impact of EOR Production Implemented Technology . . . . . . . . . . IV-9

Reserves and Production Response from ASR Techniques Implemented Technology $\ldots \ldots \ldots \ldots \ldots \ldots \ldots \ldots \ldots \ldots$ IV -13

Direct State and Local Revenues from ASR Production Implemented Technology .................. IV-14

Direct State Economic Activity from ASR Production Implemented Technology $\ldots \ldots \ldots \ldots \ldots \ldots \ldots \ldots \ldots$ IV-15

Jobs and Wages from ASR Production Implemented Technology $\ldots \ldots \ldots \ldots \ldots \ldots \ldots \ldots \ldots \ldots \ldots \ldots \ldots \ldots$ IV-15

National Impact of ASR Production Implemented Technology . . . . . . . IV-17

Louisiana Remaining Oil Resource After Implemented Technology Recovery .................... IV-19

Incremental Reserves by EOR Process

Implemented Technology vs. Advanced Technology $\ldots \ldots \ldots \ldots \ldots$ V-3

Annual Production from EOR

Implemented Technology vs. Advanced Technology $\ldots \ldots \ldots \ldots \ldots$ V-6 


\section{List of Figures (continued)}

$\underline{\text { Figure }}$

Page

V-3 State Impact of EOR Production

Implemented Technology vs. Advanced Technology $\ldots \ldots \ldots \ldots \ldots$ V-7

V-4

National Impact of EOR Production

Implemented Technology vs. Advanced Technology $\ldots \ldots \ldots \ldots \ldots$ V-10

$\mathrm{V}-5$

Incremental Reserves by ASR Process

Implemented Technology vs. Advanced Technology $\ldots \ldots \ldots \ldots \ldots$ V-12

V-6

Annual Production from ASR

Implemented Technology vs. Advanced Technology $\ldots \ldots \ldots \ldots \ldots$ V-14

V-7 State Impact of ASR Production

Implemented Technology vs. Advanced Technology $\ldots \ldots \ldots \ldots$ V-16

V-8

National Impact of ASR Production

Implemented Technology vs. Advanced Technology $\ldots \ldots \ldots \ldots \ldots$ V-18

V-9 Louisiana Remaining Oil Resource After Advanced

Technology Recovery . . . . . . . . . . . . . . . . V-20 


\section{List of Tables}

Table

Page

I-1

Summary of Benefits from Technology Advances in EOR and ASR

in Louisiana $\ldots \ldots \ldots \ldots \ldots \ldots \ldots . \ldots \ldots$ I $9 . \ldots \ldots$

III-1

Key Elements in the Current TORIS Reservoir Data Base . . . . . . . . . . III-3

III-2

Screening Criteria for EOR Candidates - Implemented Technology Case . . . . . III-4

III-3

Screening Criteria for EOR Candidates - Advanced Technology Case . . . . . . III-5

III-4

Screening Criteria for Advanced Secondary Processes . . . . . . . . . . . . III-8

III-5

Screening and Approach for Advanced Technology Infill Drilling . . . . . . . . . . III-9

III-6

Risk Premium for Implemented and Advanced EOR and ASR Processes . . . . . . III-10

III-7

Labor and Materials as Percentage of Total Cost In EOR Projects . . . . . . . . III-17

IV-1A

Incremental Reserves from EOR by Process Implemented Technology . . . . . IV-3

IV-1B

Estimated Number of Economic EOR Projects by Process

Implemented Technology . . . . . . . . . . . . . . . IV -3

IV-2A

IV-2B

Incremental Reserves from ASR by Process Implemented Technology . . . . . IV-12

Estimated Number of Economic ASR Projects by Process

Implemented Technology $\ldots \ldots \ldots \ldots \ldots \ldots \ldots \ldots \ldots$ IV -12

V-1A Incremental Reserves from EOR by Process

Implemented Technology vs. Advanced Technology $\ldots \ldots \ldots \ldots \ldots$ V-4

V-1B Estimated Number of Economic EOR Projects by Process

Implemented Technology vs. Advanced Technology $\ldots \ldots \ldots \ldots$ V-4

$\mathrm{V}-2 \mathrm{~A}$

Incremental Reserves from ASR by Process

Implemented Technology vs. Advanced Technology $\ldots \ldots \ldots \ldots \ldots$ V-13

$\mathrm{V}-2 \mathrm{~B}$

Estimated Number of Economic ASR Projects By Process

Implemented Technology vs. Advanced Technology 


\section{ACKNOWLEDGMENTS}

An Evaluation of the Known Remaining Oil Resource in the State of Louisiana is one in a series of reports of the Project on Advanced Oil Recovery and the States, conducted by the Interstate Oil and Gas Compact Commission (IOGCC). The overall project was initiated by "seed money" grants from the States of Oklahoma and New Mexico in 1985. This report was prepared under grant number FG2289BC14431 from the U.S. Department of Energy, Bartlesville Project Office (BPO) to the IOGCC.

The analysis presented in this report is based on an updated and upgraded version of the databases and models developed by the National Petroleum Council (NPC) in 1984. The NPC models and data, as well as computer time, were made available for this study by BPO. Special acknowledgment to Mr. R. Michael Ray, Deputy Director of BPO, is extended for his valuable technical advice and guidance and to Mr. Thomas C. Wesson, BPO Director, for his encouragement and assistance.

Special recognition is due to those who directly performed the work of the project. ICF Resources Incorporated of Fairfax, Virginia, served as the IOGCC's principal contractor, responsible for the study design, computer modeling, analysis, interpretation, and report preparation. ICF's Project Director was Dr. Jerry P. Brashear; Mr. Khosrow Biglarbigi was the Project Manager; and the critical project staff included Mr. Hugh D. Guinn, and Mr. Donald J. Remson (engineering and computer modeling); Mr. Karl Lang, Dr. Frank Morra (Consultant), and Mr. Jeff Enright (analysis and report generation); Mr. Marc Greenberg, Ms. Sohinaz Sotoudeh, and Mr. Mike Schildkraut (editing, research, and analytical support); Mr. Alan B. Becker (Final Review); Ms. Barbara Jones (Administrator), Ms. Cheryl A. Labrecque (Senior Staff Assistant), Ms. Mary Bowers (Staff Assistant) and Ms. Barbara Gillen (word processing support).

Special recognition is also due to the members of the DOE/IOGCC Peer Review Committee; Mr. Lloyd Elkins, Dr. Alan Emanuel, Dr. Lee Gerhard, Dr. Donald Green, Dr. John D. Haun, Mr. Joseph E. King, Dr. Charles Mankin, Dr. David Martin, Dr. Donald Oltz, Dr. Fred H. Poettmann, Mr. William C. Stewart, and Dr. G. Paul Willhite.

This analysis was conceived and commissioned by W. Timothy Dowd, Executive Director of the IOGCC through June 1993. Mr. Dowd's keen interest in promoting the development of the nation's resource base has been the guiding force behind this study. To the degree that the results of this work help to improve the recovery of oil from U.S. reservoirs, Mr. Dowd's goals for of the IOGCC will have been furthered. Mr. Bob Cooper, former Associate Director of the IOGCC, and Mr. Jerry Simmons (Associate Director) provided liaison and coordination among the participating organizations.

While acknowledging the assistance of all these contributors, error of fact, analysis, or interpretation are the responsibility of the IOGCC and the principal contractor's project director.

Christine Hansen

Executive Director

November 1993 


\section{EXECUTIVE SUMMARY}

The Interstate Oil and Gas Compact Commission (IOGCC) has conducted a series of studies to evaluate the known, remaining oil resource in twenty-three (23) states. The primary objective of the IOGCC's effort is to examine the potential impact of an aggressive and focused program of research, development, and demonstration (RD\&D) and technology transfer on future oil recovery in the United States. As a part of this larger effort by the IOGCC, this report focuses on the potential economic benefits of improved oil recovery in the state of Louisiana. Individual reports for seven other oil producing states and a national report have been separately published. Several major technical insights for state and Federal policymakers and regulators can be reached from this analysis.

- At the conclusion of conventional recovery operations, three-fifths of the known originaloil-in-place will remain in Louisiana oil reservoirs.

- The remaining resource, over 19 billion barrels, is the target for future improved oil recovery techniques. However, a significant portion of this remaining oil resource has already been abandoned. An even greater portion is in imminent danger of abandonment if cost-effective and efficient recovery techniques are not applied.

- Resource abandonment will significantly impact the economic producibility of future production and reserves under improved oil recovery techniques. This is because major capital investments will be required to reacquire the leases, rebuild the infrastructure, and more importantly, drill new wells to regain access to the Louisiana target resource.

- Louisiana's future as a premier energy producing state depends strongly on the development of efficient and cost-effective oil recovery technologies, technology transfer to domestic producers, and the timely and successful application of such technologies, given the gradual decline in Louisiana's production and reserves and the accelerated level of well abandonment over the past decade.

- The effective transfer of existing technology could result in 960 million to 1.1 billion barrels of new reserves from analyzed Louisiana reservoirs at oil prices ranging from $\$ 20 / \mathrm{B}$ to $\$ 28 / \mathrm{B}$, potentially increasing the state's current proved reserves by $50 \%$.

- Technology advances resulting from a focused RD\&D effort could result in additional post-conventional reserves of 1 and 2 billion barrels for a total of 2 to 3 billion barrels. The effective transfer of existing technology, coupled with the development and application of new technologies, could more than replace current proved reserves in Louisiana.

- Public sector revenues from future improved oil recovery activity would total between $\$ 4.4$ and $\$ 6.8$ billion given currently available recovery practices and oil prices of $\$ 20 / \mathrm{B}$ to $\$ 28 / \mathrm{B}$. Technology advances could increase these totals by $\$ 2.4$ to $\$ 6.4$ billion over the same price range, with roughly $50 \%$ of the total flowing to the state treasury. 
Potential improved oil recovery would replace imports of foreign oil, keeping between $\$ 19$ billion and $\$ 30$ billion in the U.S. economy, given currently available recovery practices and oil prices at $\$ 20 / \mathrm{B}$ to $\$ 28 / \mathrm{B}$. This figure is only the direct cost of imports avoided due to increased domestic activity. The true value to the country is actually much higher due to multiplier effects as this money circulates in the economy.

The analysis presented in this report is based on the databases and models available in the Tertiary Oil Recovery Information System (TORIS). TORIS is a tested and verified system maintained and operated by the Department of Energy's Bartlesville Project Office. The TORIS system was used to evaluate 342 of Louisiana's major reservoirs in a consistent manner and on an individual basis, the results of which have been aggregated to arrive at the statewide total.

Overall, well abandonments and more stringent environmental regulations could limit economic access to Louisiana's known, remaining oil resource. The high risk of near-term abandonment and the significant benefits of future application of improved oil recovery technology, clearly point to a need for more aggressive transfer of currently available technologies to oil producers. Development and application of advanced oil recovery technologies could have even greater benefits to the state and the nation. A collaborative, focused RD\&D effort, integrating the resources and expertise of industry, state and local governments, and the Federal government, is clearly warranted. With effective RD\&D and a program of aggressive technology transfer to widely disseminate its results, Louisiana oil production could be maximized. The resulting increase in production rates, employment, operator profits, state and Federal tax revenues, and energy security will benefit both the state of Louisiana and the nation as a whole. 


\section{OVERVIEW}

\section{A. THE PROBLEM: DECLINING LOUISIANA OIL PRODUCTION}

Over three-fifths of the oil discovered in the state of Louisiana will remain trapped in the reservoir at the conclusion of conventional oil recovery operations. The total known original oil-in-place in Louisiana has been estimated at about 32 billion barreis (Figure I-1). Almost 12 billion barrels had already been produced at the end of 1991. Roughly 535 million barrels of onshore proved reserves are still producible under existing economic conditions, using currently available technologies. The remaining 19.3 billion barrels is the target for newer, more efficient recovery technologies and advances in geoscientific understanding that must be developed through an integrated public and private research effort.

Figure I-1

\section{Louisiana Oil Resource}

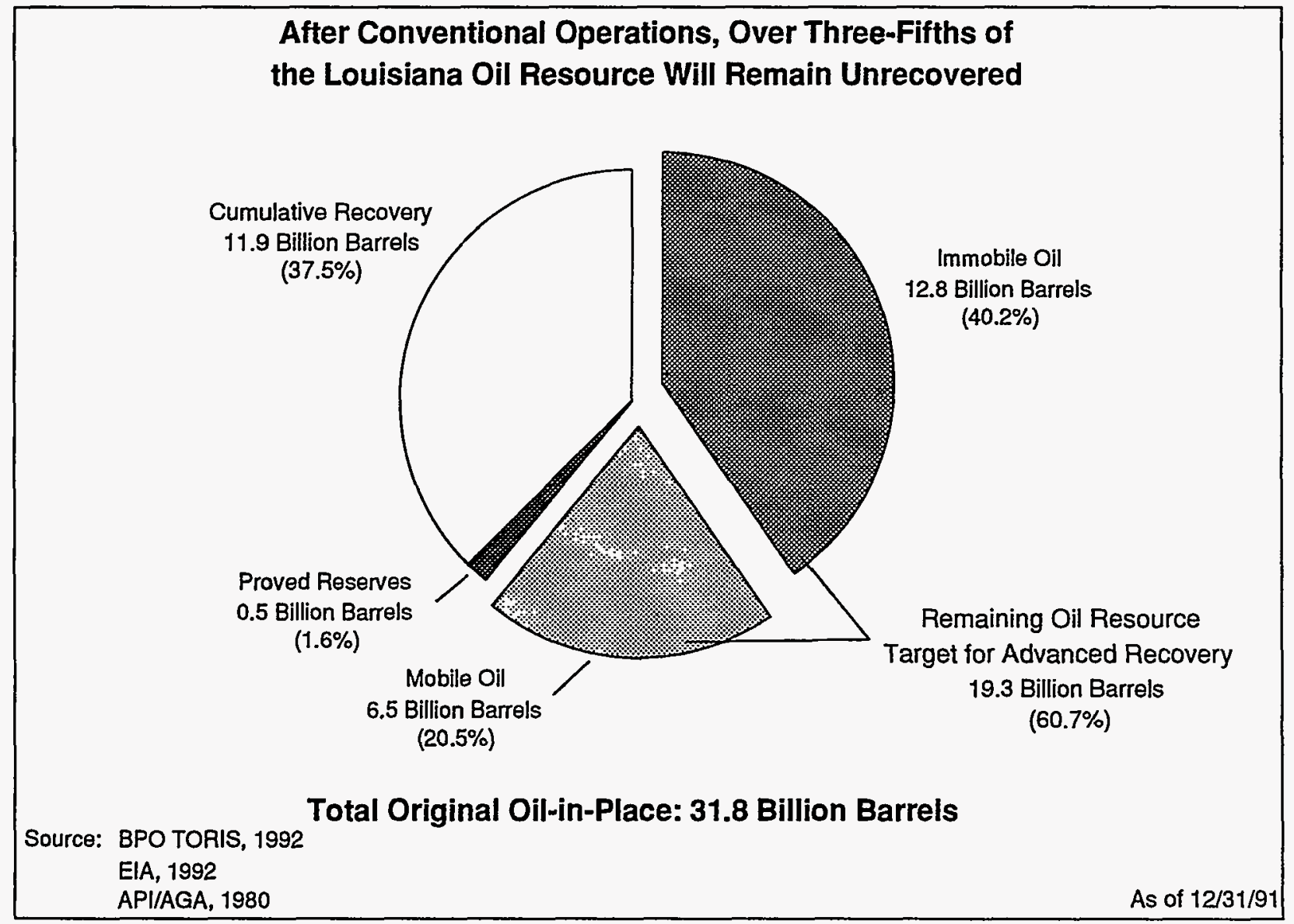


The urgency for technology development and its effective application by Louisiana oil producers has never been greater. The two factors that have combined to make technology development critical are:

- Declining state production and reserves. Louisiana oil production has declined by $74 \%$ from 1970 to 1991 (Figure I-2A). Crude oil reserves decreased by roughly 50\% between 1970 and 1985 (Figure I-2B). (Note: An accounting change in 1986 removed a large portion of Louisiana offshore reserves to a distinct category resulting in the abrupt change seen in Figure I-2B.) Although this decline has almost leveled off in recent years, reserve additions have not been quite sufficient to replace production volume. The average size of new field discoveries has been relatively small and reserves per well have decreased.

- Increased level of well abandonment. The state of Louisiana currently produces oil from roughly 27,000 wells. Many of these wells are "marginal" wells producing at or near their economic limits. In a period of high production costs and low oil price, many of these wells are being abandoned. A recent analysis by the Department of Energy (DOE) has concluded that from $37 \%$ to $45 \%$ of the nation's remaining oil resources had been abandoned by the end of 1991. ${ }^{1}$ Well abandonments will have a significant impact on economic access to the remaining resource for application of future improved recovery techniques. It is estimated that once a lease is abandoned, it will require an oil price increase of $\$ 10 / B$ to $\$ 25 / B$ to rebuild the infrastructure and drill replacement wells. ${ }^{2}$ Such an economic burden will not likely be justified by the incremental oil revenues from future improved recovery techniques.

The future of Louisiana oil production and reserves depends strongly on the development and application of cost-effective and efficient technology. In the past, technology advances have made substantial contributions to Louisiana oil production. The development of new exploration techniques, secondary recovery technology, and offshore drilling technology has acted to reverse past production declines and has allowed Louisiana to maintain and increase its producible oil and gas resources. The opportunity exists for a program of RD\&D, combined with an integrated program of technology transfer to all sectors of the Louisiana petroleum community, to arrest the decline in production and maximize recovery of the state's oil resource.

1 "Abandonment Rate of the Known Domestic Oil Resource", U.S. Department of Energy, Bartlesville Project Office, Bartlesville, OK (June 1990).

2 Brashear, J.P. et al. "Effect of Well Abandonments on EOR Potential," JPT, December 1991. 
Figure I-2

\section{Louisiana Production and Reserves}

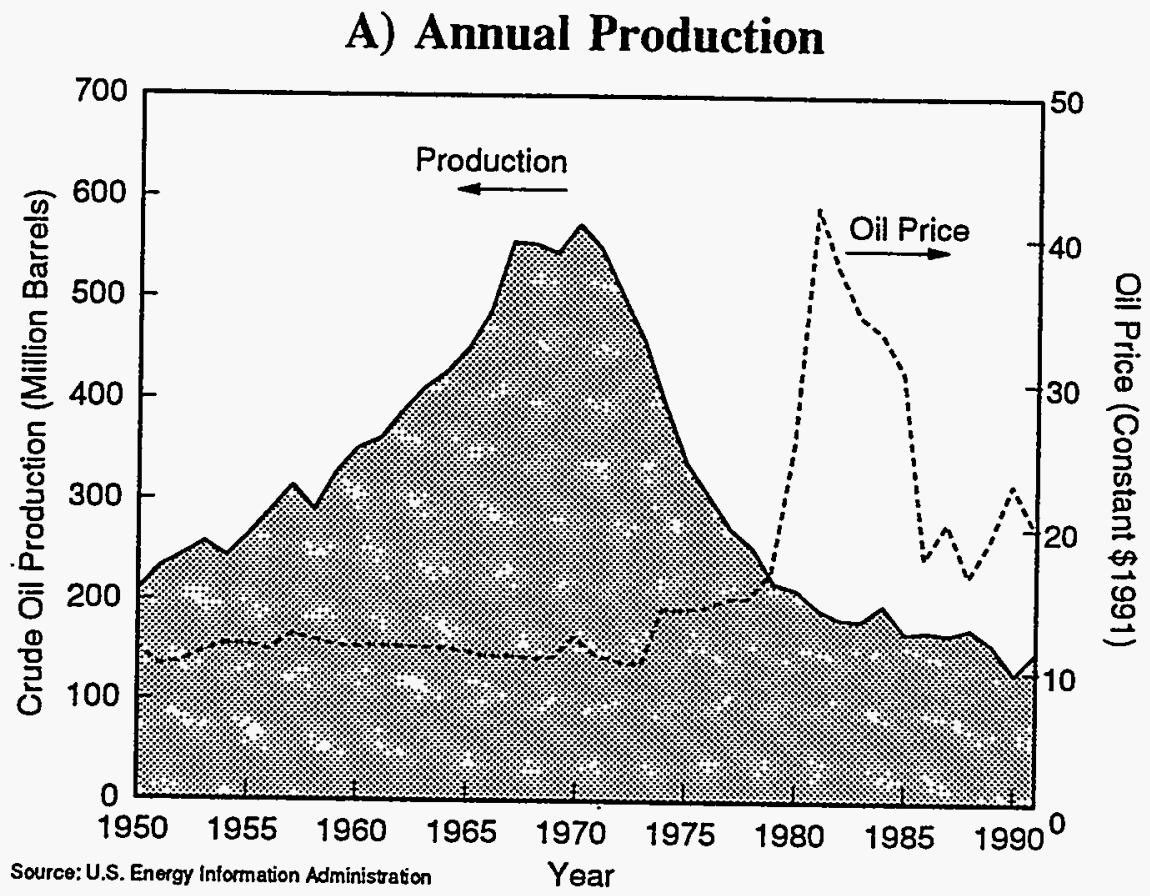

B) Reserves

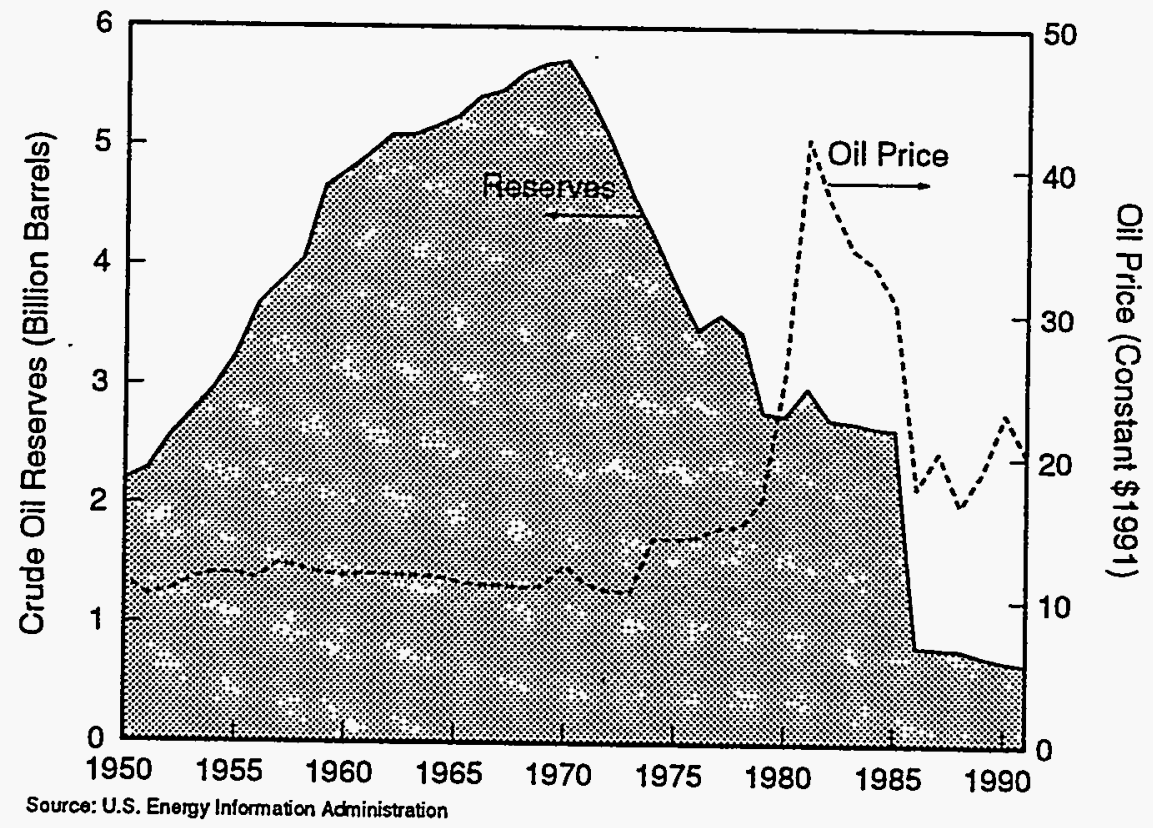




\section{B. THE OPPORTUNITY: OIL RECOVERY. THROUGH ADVANCED TECHNOLOGY}

The remaining oil resource constitutes a huge target for future recovery operations. The 19 billion barrels of known unrecovered oil in the state of Louisiana is of two types: mobile oil and immobile oil. Even though mobile oil is displaceable by water, it has been uncontacted or bypassed during conventional primary production or water flooding and thus remains unrecovered. Immobile oil is oil that is trapped in the reservoir pores by viscous and capillary forces and cannot be displaced by water.

The estimated unrecovered mobile oil (UMO) resource in Louisiana is 6.5 billion barrels. This oil is an important target for future improved recovery efforts. Several improved primary and secondary recovery processes (infill drilling, profile modification, and polymer flooding), collectively referred to as advanced secondary recovery (ASR), could be used in innovative ways to produce a substantial portion of this resource. Processes such as these are relatively low in cost and could increase production levels quickly. While such techniques have already been used by some operators in selected reservoirs, continued research and aggressive technology transfer are critically needed to improve, streamline, and adapt these techniques to site-specific reservoir conditions and broaden their applications.

The 12.8 billion barrels of remaining immobile oil resource in Louisiana is the target of a number of other recovery techniques. Miscible, chemical, and thermal recovery processes directed at producing immobile oil are referred to as enhanced oil recovery (EOR). While these processes generally require larger investments and higher operating costs in comparison to methods of conventional recovery, they are capable of producing substantial volumes of incremental oil with great economic benefit. Further advances in EOR technology are foreseeable if a focused, research-intensive approach is adopted to make process improvements ready for field application.

\section{Technology Assessment Method}

The benefits of RD\&D in oil recovery technology assessed in this report are based on the models and databases available through the Tertiary Oil Recovery Information System (TORIS). The TORIS methodology and analytical tools were originally developed by the National Petroleum Council (NPC) ${ }^{3}$ for its 1984 evaluation of nationwide EOR potential. DOE has since maintained and updated the system

3 National Petroleum Council, Enhanced Oil Recovery, Washington, DC, 1984. 
through its Bartlesville Project Office (BPO). ${ }^{4}$ DOE has also upgraded the capability of the system to evaluate the nation's unrecovered mobile oil through ASR techniques. In this report, the future potential of EOR and ASR techniques are examined with the following key assumptions and considerations:

- A total of 342 Louisiana reservoirs, accounting for 20.5 billion barrels of original oil-inplace, were individually analyzed for their EOR and ASR potential.

- Two levels of technology are considered: (1) implemented technology -- defined as the application of currently available post-conventional techniques; and (2) advanced technology -- defined as the improvements in process performance and applicability which are likely to occur over the next decade as the result of ongoing RD\&D efforts.

- For each technology level, benefits were evaluated at several oil prices ranging from $\$ 16 / \mathrm{B}$ to $\$ 36 / \mathrm{B}$ (1991 dollars).

- All economic analyses reflect the current Federal tax structure and the oil production and income tax situation in Louisiana. The Fiscal Year (FY) 1991 Federal EOR tax credit, as well as state EOR tax incentives, are included in this analysis.

- The results presented in this report reflect only the benefits and reserve potential associated with the 342 analyzed reservoirs (over $64 \%$ of total known Louisiana OOIP as shown in Figure I-3). No attempt is made to extrapolate the results to the remaining Louisiana resource not available in the TORIS database.

- All recovery potential evaluated in this report are for future new projects only, and they do not include reserves from existing EOR projects. However, any expansion to the existing projects, if technically and economically feasible, are reported as future new projects in this report.

\section{BENEFITS DERIVED FROM IMPROVED OIL RECOVERY}

Potential incremental reserve volumes and resulting direct state and local revenues that could be generated through improved oil recovery (EOR and ASR) techniques under both the implemented and advanced technology cases are shown in Figure I-4. Implemented technology, if more widely applied, could add between 0.9 and 1.2 billion barrels of incremental reserves across the entire oil price range. Advanced technology applied to the same resource base could stimulate an additional 0.7 to 1.8 billion barrels of incremental resources for a total of 1.6 to 3.1 billion barrels beyond currently proven reserves. In effect, improvements in process performance and application could more than double the reserves possible under implemented technology conditions for the analyzed reservoirs. This clearly provides a

4 Producing Unrecovered Mobile Oil: Evaluation of Potential Economically Recoverable Reserves in Texas, Oklahoma, and New Mexico, DOE, May 1990. 


\section{Louisiana Oil Resource}

Data Coverage of EOR and ASR Analyses

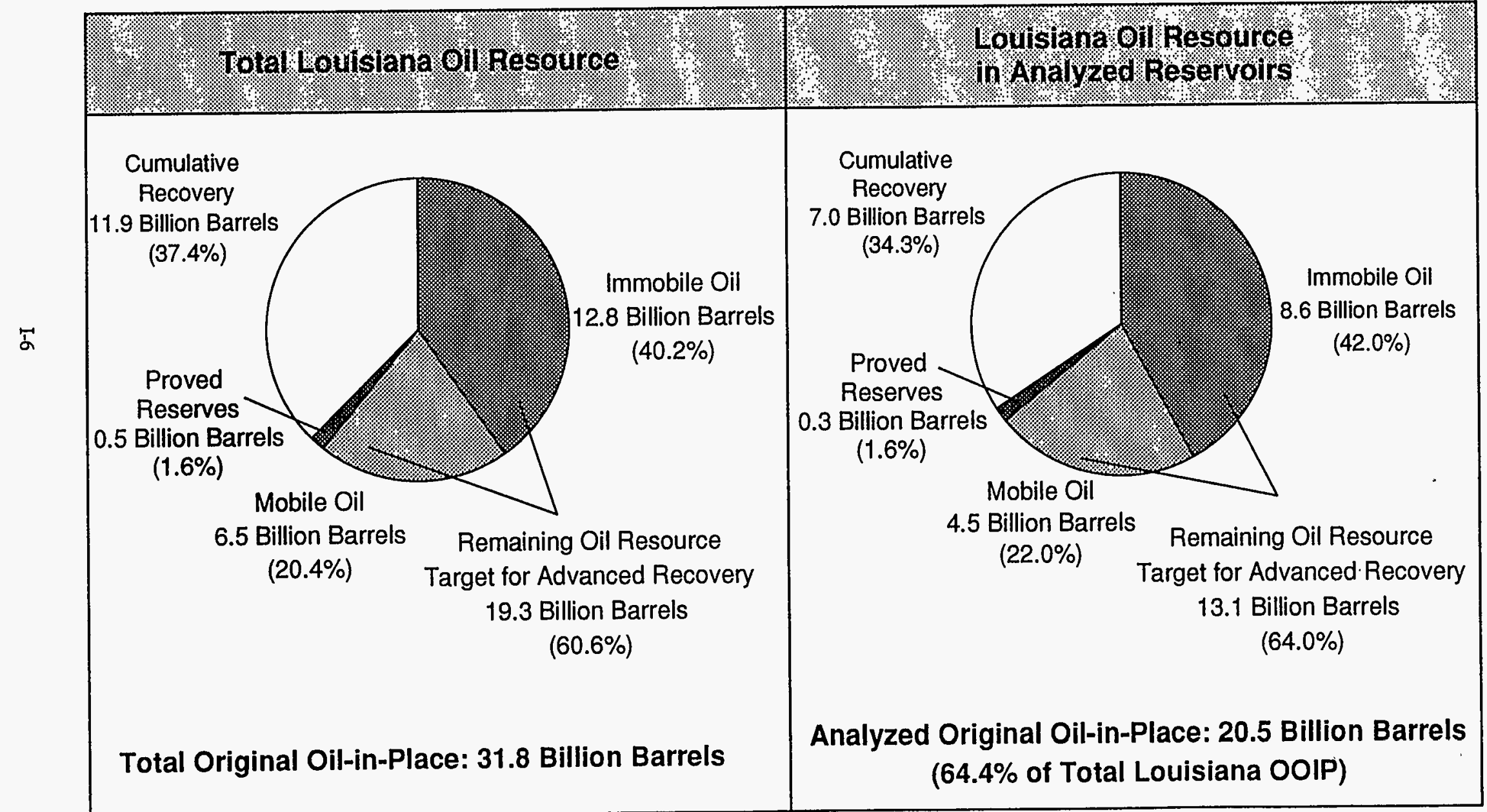

Source: BPO TORIS, 1992

EIA, 1992

API/AGA, 1980 
Figure I-4

\section{Potential Impact of Advanced Technology}

\section{A) Reserve Additions}

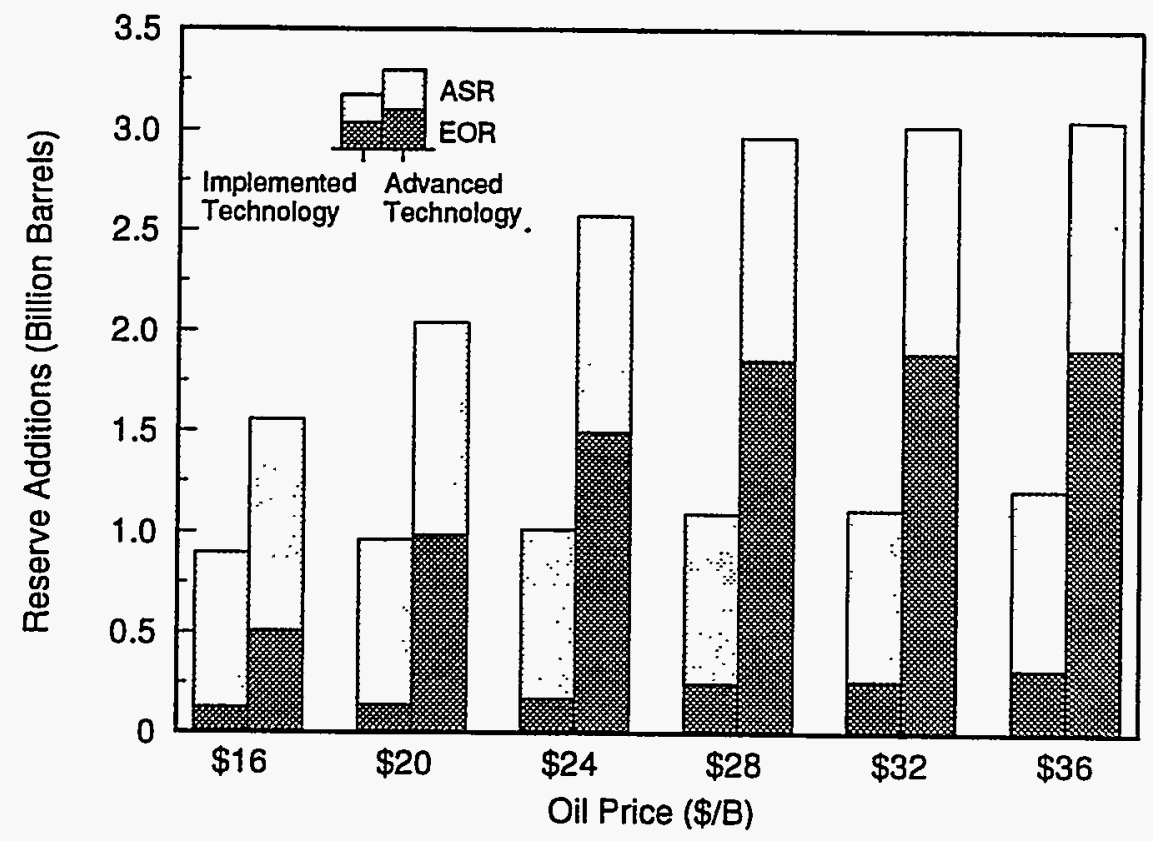

B) Direct State and Local Revenues

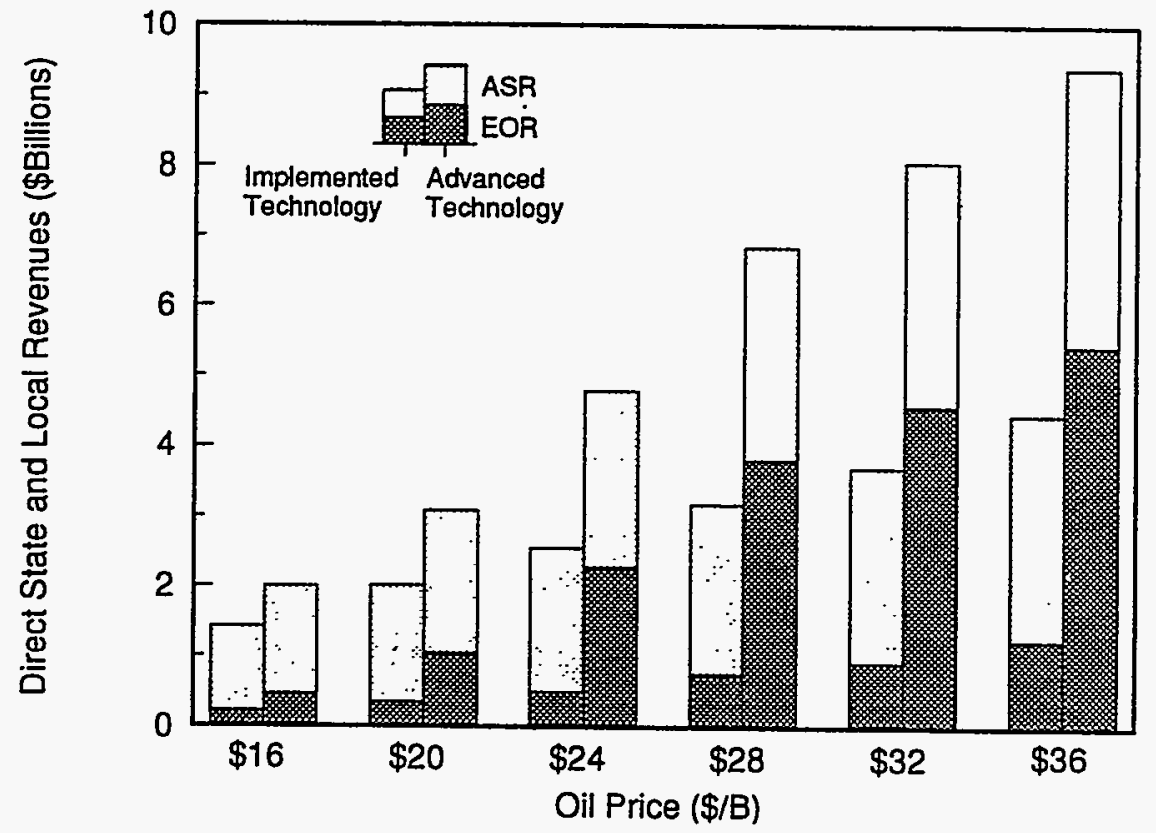


major justification for a focused RD\&D and technology transfer program.

The potential for expanded application of EOR techniques alone using implemented technology is very limited if prices remain at or below $\$ 20 / \mathrm{B}$; incremental recovery at this price would total only about 140 million barrels. However, implemented technology EOR could add 250 million barrels of reserves at a higher oil price of $\$ 28 / \mathrm{B}$. At this oil price, advances in EOR technology could stimulate an additional 1.6 billion of incremental reserves. This means that a total of 1.9 billion barrels of potential EOR recovery exists at $\$ 28 / \mathrm{B}$ prices under the two levels of technology.

Reserve additions attributed to ASR techniques only are also substantial but are impacted much less by oil price changes than EOR. About 820 million barrels of ASR reserves could be added in the implemented technology case at an oil price of $\$ 20 / \mathrm{B}$, growing only slightly to 890 million barrels as oil prices increase to $\$ 36 / \mathrm{B}$. Research on process improvements, specifically improved polymer flooding and profile modification combined with geologically targeted infill drilling, could increase ASR potential by $21 \%$ to $27 \%$. With advances in technology, incremental ASR reserve additions could total about 250 million barrels more than implemented technology over the price range analyzed, for a total of about 1.1 billion barrels of potential ASR reserves.

Future advanced oil recovery activities will generate revenues for Louisiana and the Federal treasury through increased production taxes and oil industry-related sales taxes. The revenue estimates in this study consider only direct revenues from recovery activities in the analyzed reservoirs, and exclude any additional indirect benefits from multiplier or "ripple" effects within the state or national economy. Under implemented technology at $\$ 20 / \mathrm{B}$, newly implemented improved oil recovery projects in Louisiana could directly generate $\$ 2$ billion in state revenues. At the same oil price, advanced technology could generate an additional $\$ 1.1$ billion, for a total of $\$ 3.1$ billion in public sector revenues (Figure I-4). At an oil price of $\$ 28 / \mathrm{B}$, application of currently available EOR and ASR technology could contribute $\$ 3.2$ billion to the Louisiana public treasury while the application of advanced methods could increase these revenues by an additional $\$ 3.6$ billion to a total of $\$ 6.8$ billion.

Increased production from EOR and ASR could offset oil imports, which in turn would reduce the national trade deficit, and increase national economic activity. The value of the oil produced, the product of reserves and their effective oil price, is a simple measure of Louisiana's contribution to reducing imports. As shown in Table $\mathrm{I}-1$, this figure could total between $\$ 19$ billion and $\$ 30$ billion under the implemented technology scenario, over the $\$ 20 / \mathrm{B}$ to $\$ 28 / \mathrm{B}$ range. Advanced technology could further decrease imports by an additional $\$ 21$ billion to $\$ 52$ billion. The additional value of domestically 


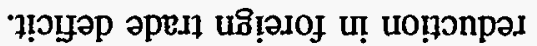

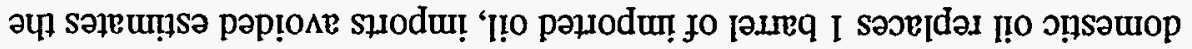

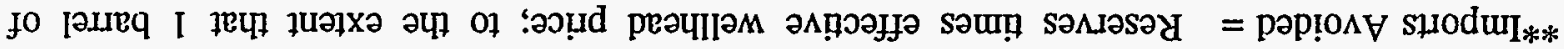

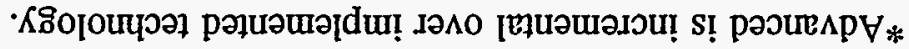

\begin{tabular}{|c|c|c|c|c|}
\hline $\begin{array}{l}\frac{6^{\circ} \varepsilon I}{\not{ }^{\circ} L} \\
\varsigma^{*} 9\end{array}$ & $\begin{array}{l}\frac{8^{\circ} \angle 0 I}{6 t 59} \\
6 \cdot 2 t\end{array}$ & $\begin{array}{l}\frac{76}{6 t} \\
s t\end{array}$ & $\begin{array}{l}\frac{9 \cdot 6}{6 \cdot 1} \\
2 \cdot 1\end{array}$ & 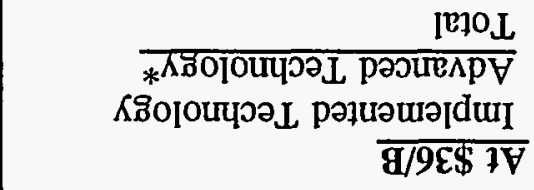 \\
\hline $\begin{array}{l}\frac{S^{*} 0 I}{\varepsilon^{*} S} \\
\tau \cdot S\end{array}$ & $\begin{array}{l}\frac{0.56}{0.09} \\
0^{*} \varsigma \mathcal{E}\end{array}$ & $\begin{array}{l}\frac{1 \cdot 8}{D^{\circ} \mathrm{t}} \\
L^{\circ} \mathcal{E}\end{array}$ & $\frac{1 \cdot \varepsilon}{6.1}$ & 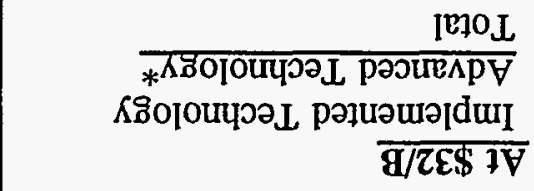 \\
\hline $\begin{array}{l}\frac{t^{\circ} 9}{7 * 2} \\
0 * t\end{array}$ & $\begin{array}{l}\frac{L I 8}{L \cdot I S} \\
0.0 E\end{array}$ & $\begin{array}{l}\frac{8^{\circ} 9}{9^{\circ} \varepsilon} \\
\tau^{\circ} \varepsilon\end{array}$ & $\begin{array}{l}\frac{0^{\circ} \varepsilon}{6^{\circ} \mathrm{I}} \\
\mathrm{I}^{\circ} \mathrm{I}\end{array}$ & 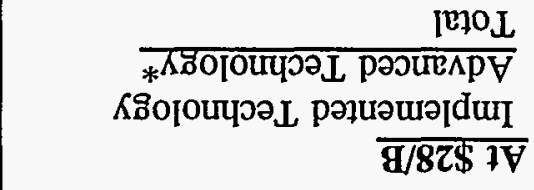 \\
\hline $\begin{array}{l}\frac{0 .}{8^{\circ} \mathrm{I}} \\
\tau^{\circ} \mathcal{\varepsilon}\end{array}$ & $\begin{array}{l}\frac{609}{\varepsilon L \varepsilon} \\
9^{\circ} \varepsilon \tau\end{array}$ & $\begin{array}{l}\frac{8 * t}{\varepsilon^{\circ} z} \\
s z\end{array}$ & $\begin{array}{l}\frac{9^{\circ} Z}{9^{\circ} I} \\
0^{\circ} \mathrm{I}\end{array}$ & 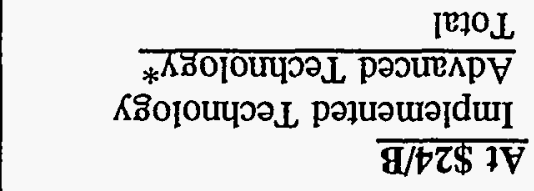 \\
\hline $\begin{array}{l}\frac{L \mathcal{L} \varepsilon}{\mathcal{E} T} \\
\dot{\nabla} Z\end{array}$ & $\begin{array}{l}\frac{Z 0 t}{S \cdot I Z} \\
\angle \cdot 8 I\end{array}$ & $\begin{array}{l}\frac{I^{\circ} \varepsilon}{I^{\prime} T} \\
0^{\circ} \tau\end{array}$ & $\begin{array}{l}\frac{0 \%}{0.1} \\
0.1\end{array}$ & 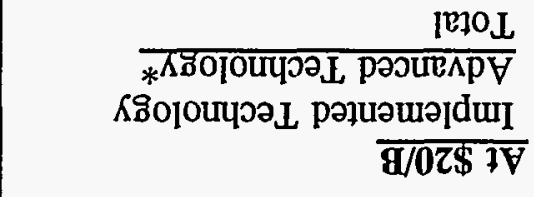 \\
\hline $\begin{array}{l}\frac{0^{\circ} Z}{t^{*} 0} \\
9 \cdot 1\end{array}$ & $\begin{array}{l}\frac{S^{\circ} \dagger \tau}{90^{\circ} 0 I} \\
6^{\circ} \varepsilon I\end{array}$ & $\begin{array}{l}\frac{0^{\circ} \tau}{90^{\circ} 0} \\
\nabla^{\circ} 1\end{array}$ & $\begin{array}{l}\frac{9^{\circ} I}{L^{\circ} 0} \\
6^{\circ} 0\end{array}$ & 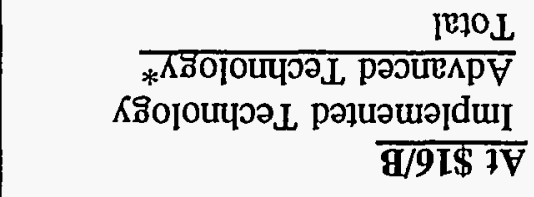 \\
\hline 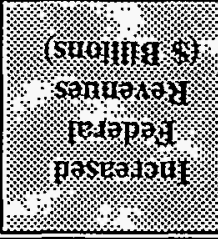 & 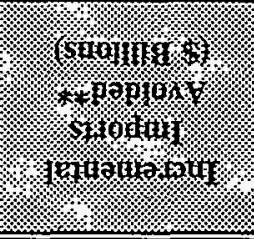 & : & (1) & ris \\
\hline
\end{tabular}

eue!s!noT u! \&SF pue YOA U!

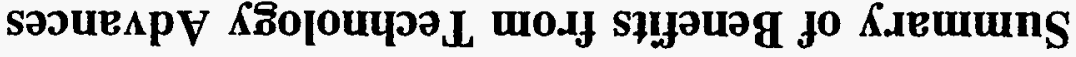

I-I əIqe $_{\mathbf{L}}$ 
produced oil by EOR and ASR generates significant direct economic activities as capital spending, profits, royalties, and taxes are circulated through the U.S. economy rather than spent abroad to buy foreign oil.

\section{CONCLUSIONS}

The development, testing, and wide-scale application of currently available improved oil recovery technologies could stimulate incremental reserves of roughly 1.0 billion barrels from Louisiana's largest, most mature reservoirs at oil prices of $\$ 16 / \mathrm{B}$ to $\$ 24 / \mathrm{B}$. With the technology advances resulting from focused RD\&D, an additional 0.7 to 1.9 billion barrels to 3 billion barrels could be produced over this price range using EOR and ASR techniques. Even with the successful development and application of these technologies, however, about 6.7 billion barrels of immobile oil would still remain in the analyzed reservoirs as a long-term target for future advances in EOR, and 3.4 billion barrels of mobile oil would remain as a long-term target for future advances in ASR processes (Figure 1-5). While this target is substantial, it unfortunately will not remain a target indefinitely. Well abandonments have already limited economic access to a portion of the resource. The timely development and application of new recovery technology is crucial to maintain economic access to the remaining domestic oil resource.

The results of this analysis have important policy implications. Domestic oil production generates significant direct revenues to Louisiana and to the Federal government and substantial additional indirect benefits to both the state and national economies. In addition to stimulating reserves, production, and economic activity, the application of improved oil technology would enhance the nation's energy security. However, integrated efforts and initiatives are needed to achieve these goals. These efforts should include:

- Collaborative RD\&D;

- $\quad$ Aggressive technology transfer; and

- Applicable tax and regulatory policies at state and Federal levels.

A collaborative RD\&D effort between the oil industry, universities, state and local governments, and the Federal government focused on improving advanced oil recovery technology and its application in key geologic settings would benefit operators, the state of Louisiana, and the entire nation. With sound planning and clear, attainable goals, state policies can be effectively integrated with Federal and private programs to dramatically increase production to the benefit of both Louisiana's and the nation's treasuries, economies, and citizens. State and Federal tax incentives can be instituted, or where already in place, could be modified to improve their effectiveness, in order to help domestic EOR/ASR projects compete with foreign investment opportunities. In addition, regulatory policy makers could design regulations 
which reflect both the true risks to health, safety and the environment and the economic risk of resource loss through abandonment.

Figure I-5

\section{Remaining Oil Resource After Advanced Technology Recovery}

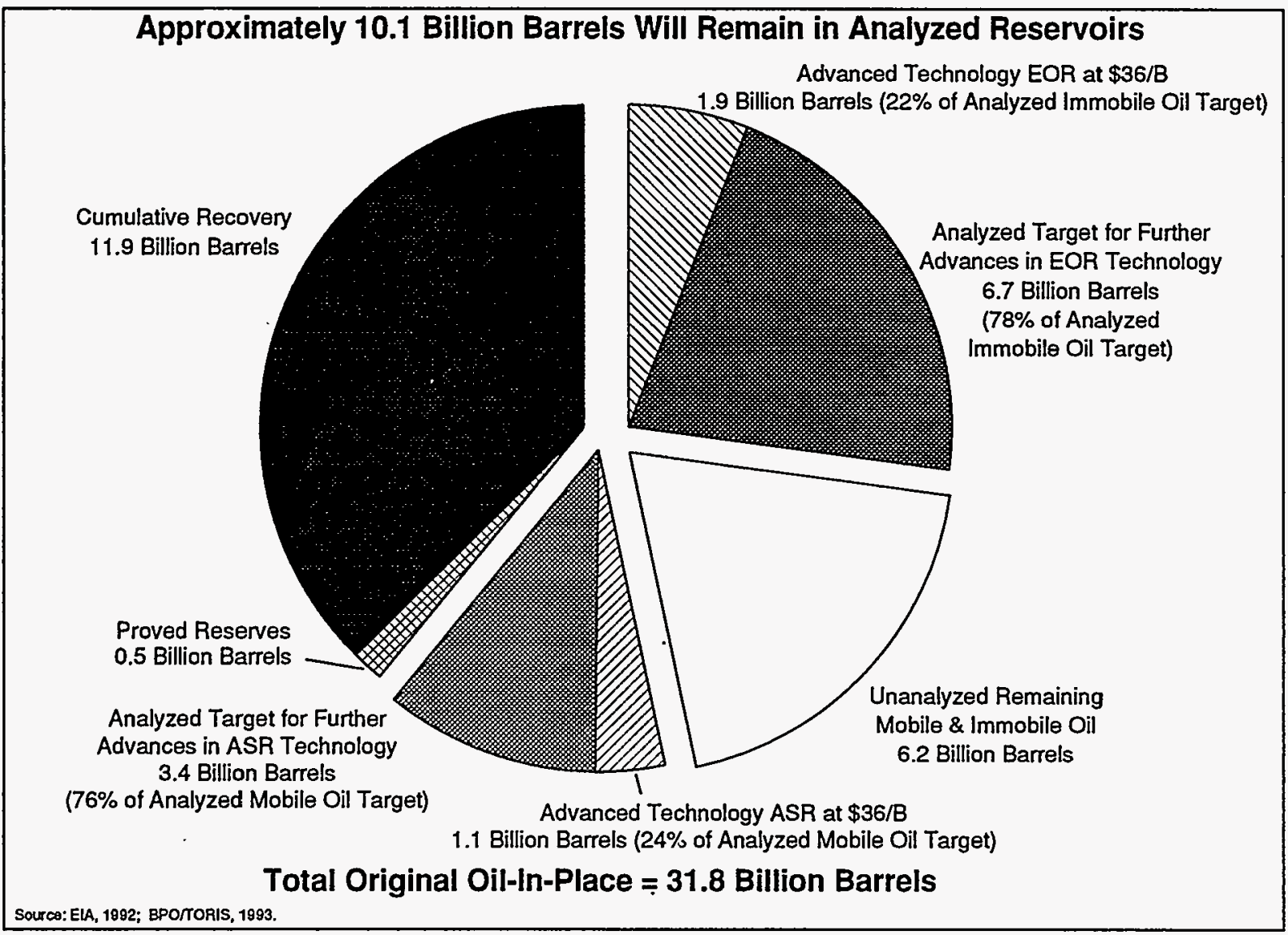




\section{BACKGROUND AND OBJECTIVES}

\section{A. TRENDS IN LOUISIANA PRODUCTION AND RESERVES}

Over the past thirty years, few oil producing states can match the rapid gain and dramatic decline in production that Louisiana has experienced (Figure II-1). Louisiana began the 1960s with a healthy production level of just over 300 million barrels. As oil production moved offshore and more efficient primary and secondary techniques were implemented, Louisiana production soared to 574 million barrels in 1970. This figure became a high-water mark that was never matched, as statewide production entered into a ten year decline; losses of greater than $10 \%$ per year resulted in a production level of under 200 million barrels in 1981. Unprecedented high world oil prices helped reduce the rate of decline in Louisiana production, but the fall in oil prices in 1985-1986 ended this production resurgence and sparked a four year slide that saw the year 1990 end with Louisiana's production at fewer than 130 million barrels, the lowest rate of production since the 1940s. Although 1991 production was up by $18 \%$, the recent loss of production potential has jeopardized Louisiana's long-standing position as the second-largest lower-48 oil producing state. Louisiana's share of lower-48 production now stands at 7\%, down from $17 \%$ in 1970 .

Louisiana's reserve losses have been even more dramatic (Figure II-2). Reserves additions posted moderate, but steady, gains over production through the 1960s even as production was rapidly increasing. By 1970 , reserves stood at a peak level of 5.7 billion barrels, but then went into a protracted decline that saw reductions in 18 of the next 20 years. As of 1991, reserves in Louisiana stood at just 679 million barrels. While a great proportion of this decrease was due to a failure to replace production, a portion was also the result of downward revisions in formerly optimistic reservoir and field reserve estimates made in times of higher oil prices. Also, prior to 1986, the reserves associated with the Federal OCS areas off the coast of Louisiana were included in EIA state reserves estimates. The dramatic reduction in 1986 reserves reflects the exclusion of these reserves from subsequent yearly totals. Given 1991 reserves and production levels, Louisiana reserves could be exhausted in as little as four and one-half years should no further reserves replacement occur. The state with the next lowest reserves-to-production ratio is Kansas, with a ratio of 5.2 years. This situation is a dramatic warning that Louisiana reservoirs are approaching the end of their conventional production life.

Louisiana producing wells in 1991 numbered fewer than 24,000, down from nearly 30,000 in 1987 (Figure II-3), an indication that lower oil prices have caused the abandonment of marginal wells and a 
Figure II-1

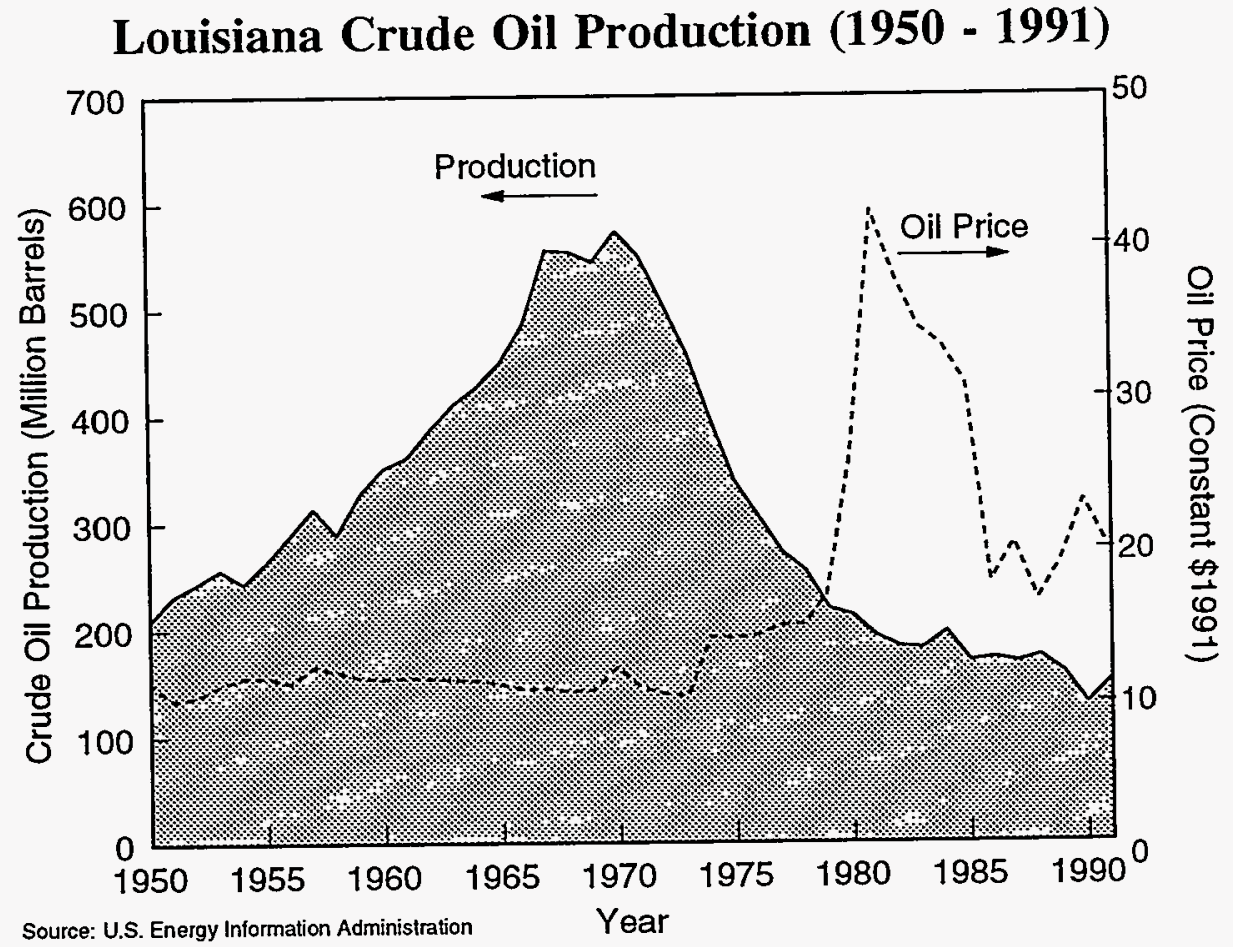

Figure II-2

\section{Louisiana Crude Oil Reserves (1950 - 1991)}

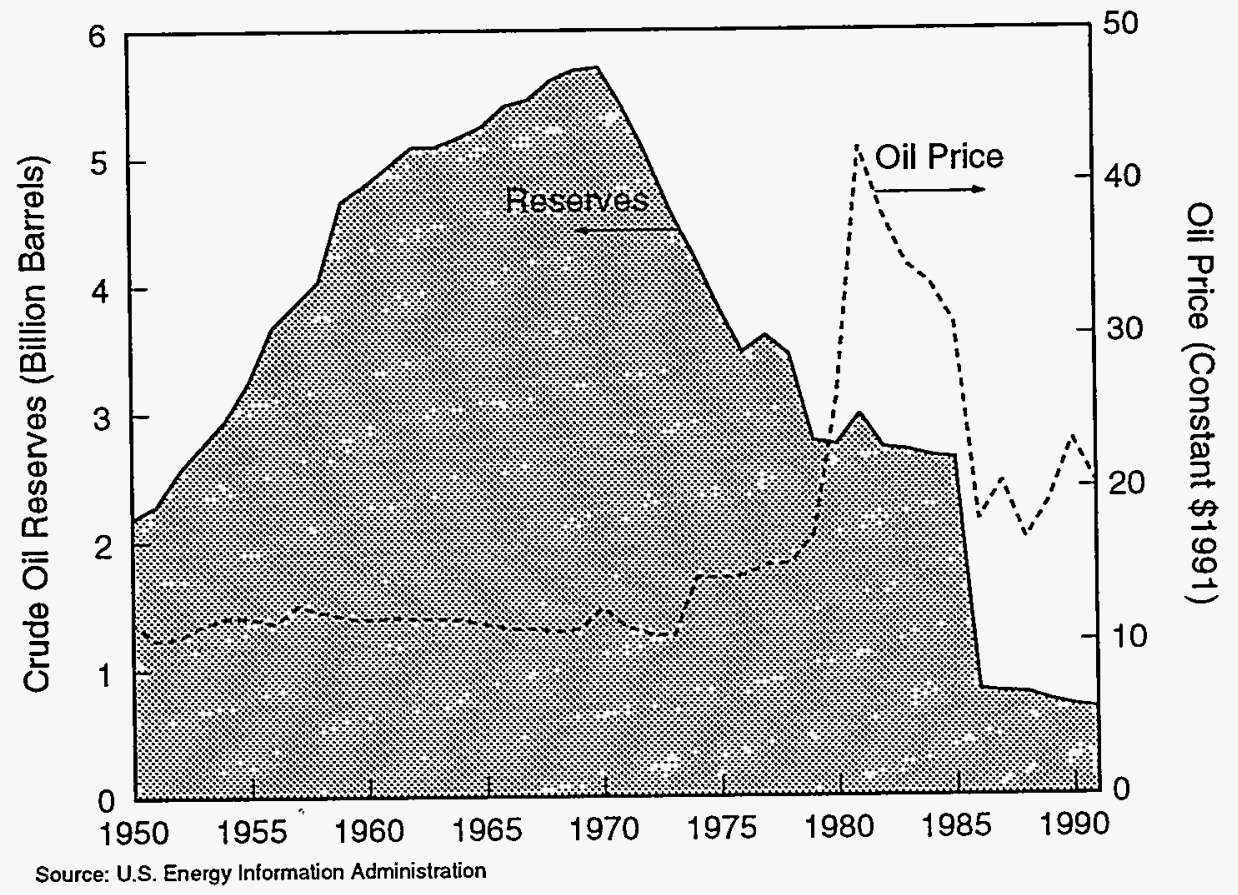


reduction in exploration activity. Even at these reduced well numbers, the reserves per producing well have been declining precipitously. In 1970, the average Louisiana well had reserves estimated at more than 200,000 barrels. By 1991, that figure had dwindled to fewer than 33,000 barrels, even though the net number of wells had also decreased. Clearly, Louisiana has entered into a very mature stage in its production history, and future production can no longer be guaranteed.

Although well numbers are declining, Louisiana continues to produce most of its oil from relatively high rate wells, rather than from stripper wells. Louisiana's stripper wells produce just less than $2 \%$ of the statewide annual production (Figure II-4), and although this is double what it was twenty years ago, it still is not a significant percentage. This is a result of the character of production in southem Louisiana - relatively deep, high-rate wells which produce with strong natural water drives and water out fairly quickly. Since 1980, 7,600 stripper wells have been abandoned, and while this may have reduced Louisiana production figures, it has not made the state more reliant on economically marginal wells. However, abandonments will continue to limit access to the remaining resource.

As Louisiana's onshore oil industry fades in importance, its decline adversely affects employment and economic activity in Louisiana. In 1981, the oil and gas industry accounted for over 130,000 jobs in Louisiana. Ten years later in 1991 , over 40,000 oil and gas related jobs were lost leaving fewer than 90,000 full time positions (Figure II-5). These employment figures include jobs associated with Federal OCS offshore production as well as state production, since all of the offshore production is managed from shore bases in Louisiana and Texas. In part, then, the loss of jobs can be explained by the decline in exploration and development activity in the Federal OCS area. The gross annual value of the oil produced in Louisiana has similarly declined (Figure II-6). The total drop off between 1981 and 1991, in constant 1991 dollars, has been nearly $\$ 20$ billion, an overall reduction of $56 \%$. These job losses and revenue reductions have had a severe effect upon the Louisiana economy, and these losses stand to grow in years to come if production continues to decline.

Revenues from production taxes on Louisiana oil and gas production reached a peak of $\$ 1.15$ billion in 1982 , only to decline by $62 \%$ to $\$ 431$ million in fiscal year 1990 (Figure $11-7$ ). This significant Ioss in state revenues has been caused by the dual effect of lower product prices and declining oil and gas production. In fiscal year 1982, when oil prices were at their peak, oil and gas production taxes made up more than $34 \%$ of all state tax revenues (Figure II-8). This percentage has fallen dramatically to $11 \%$ of total tax revenues in fiscal year 1990. Oil severance taxes represent as much as $50 \%$ of the total state tax 
Figure II-3

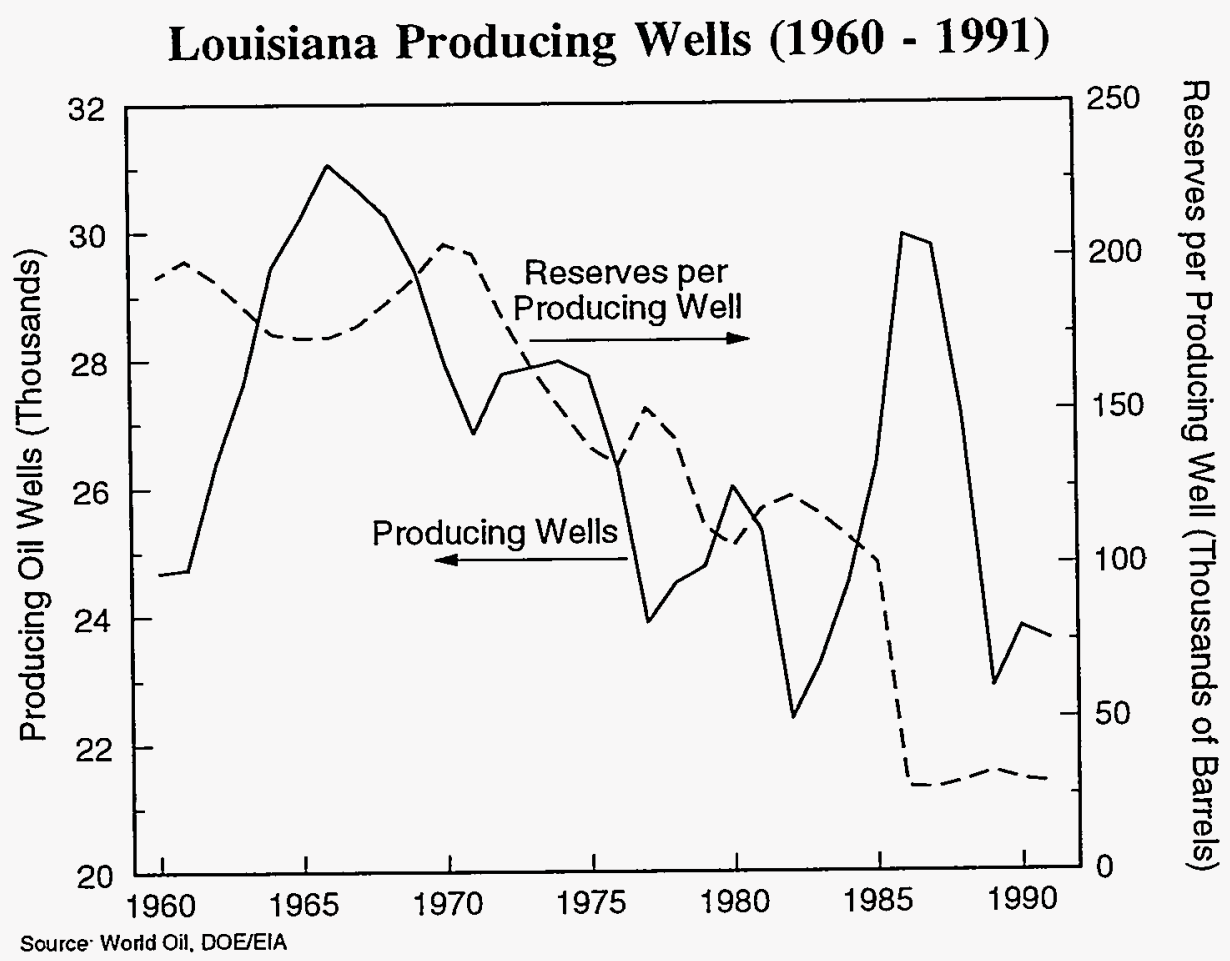

Figure II-4

Louisiana Stripper Well Production and Abandonments (1970 - 1990)

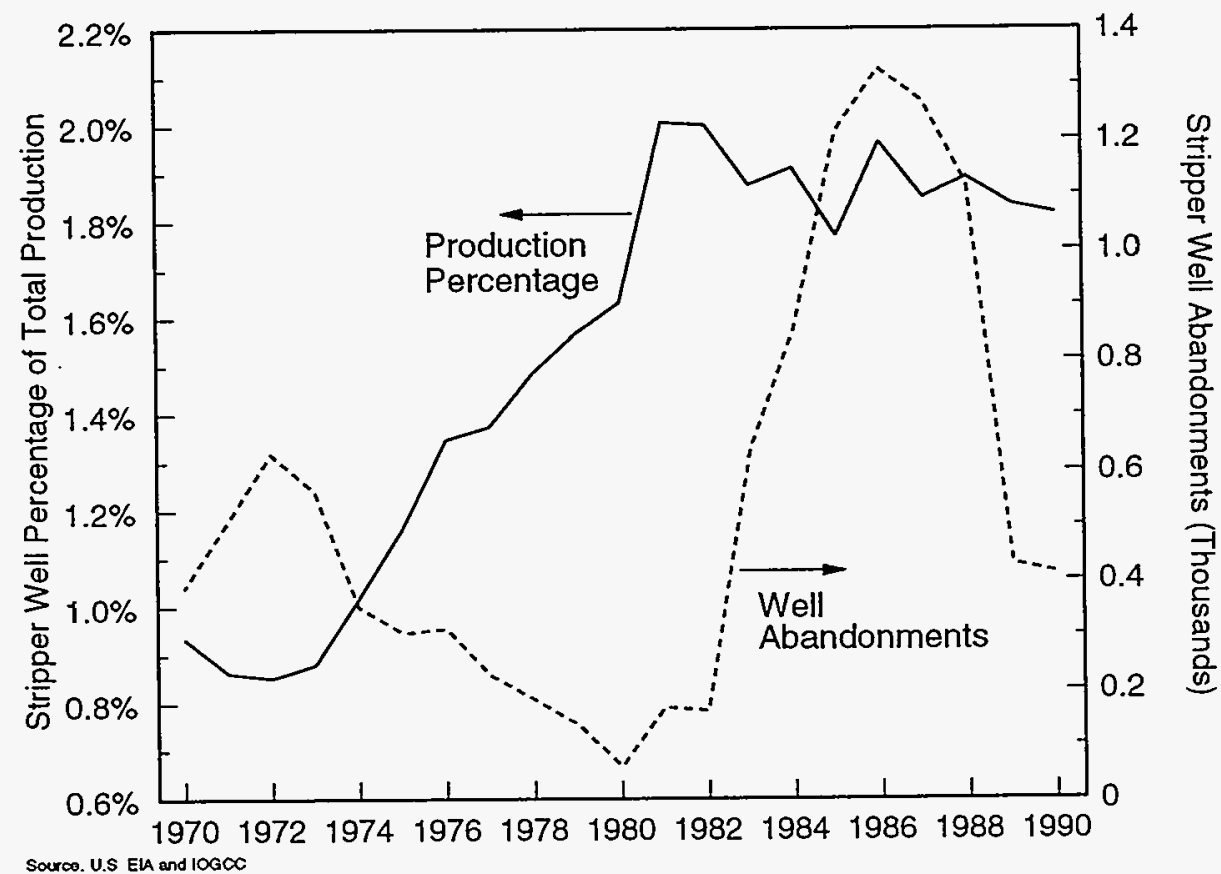



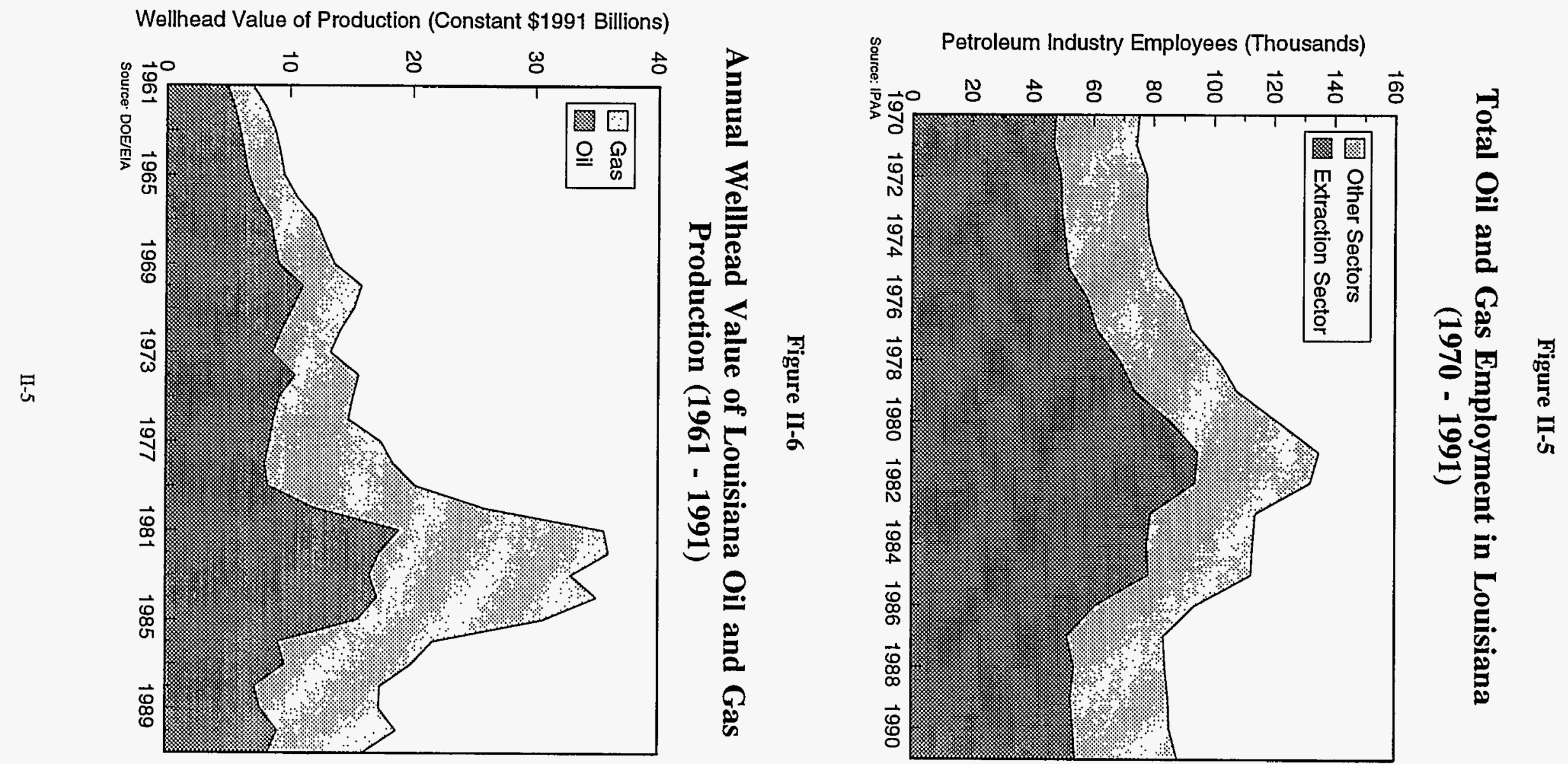
Figure II-7

Louisiana Oil and Gas Severance Taxes

(FY1971 - 1990)

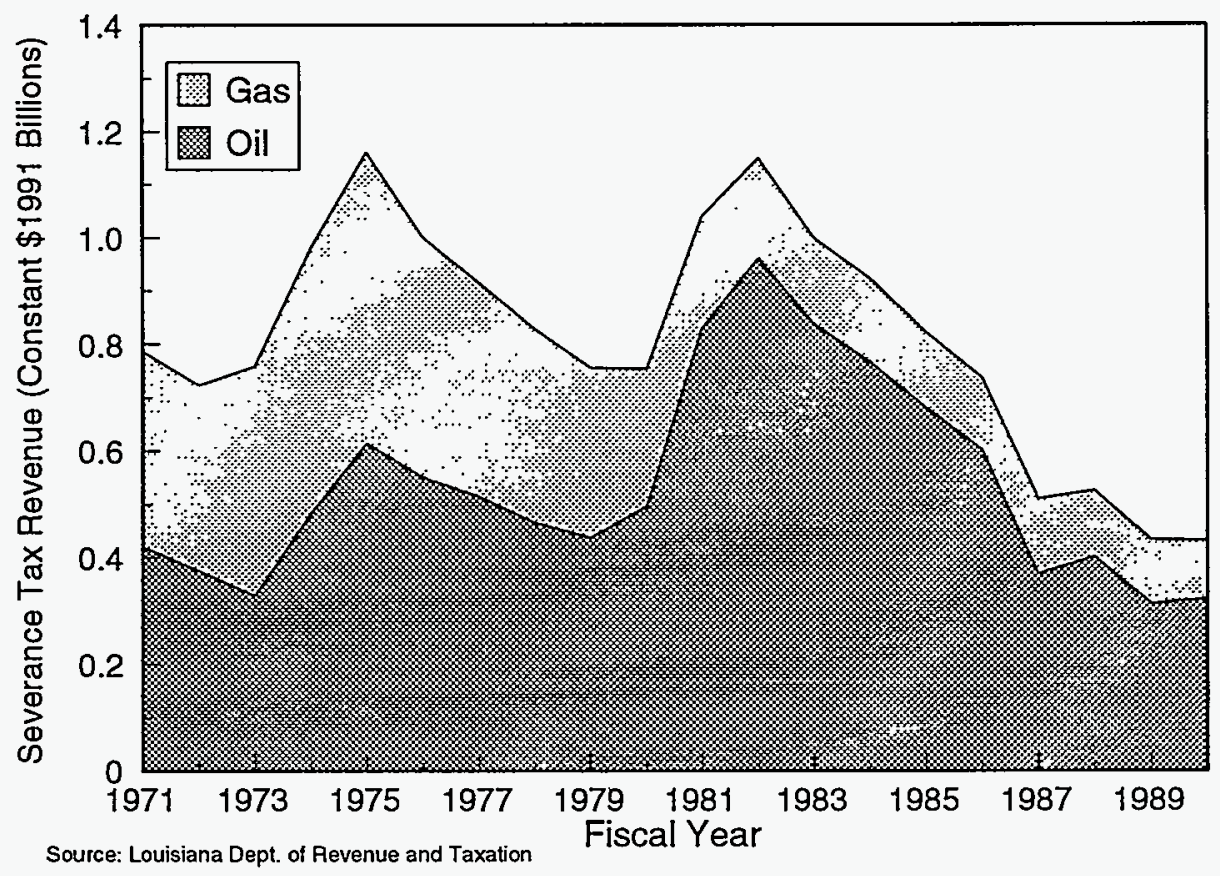

Figure II-8

\section{Louisiana Oil and Gas Severance Taxes as a Percent of Total State Taxes (FY1971 - 1990)}

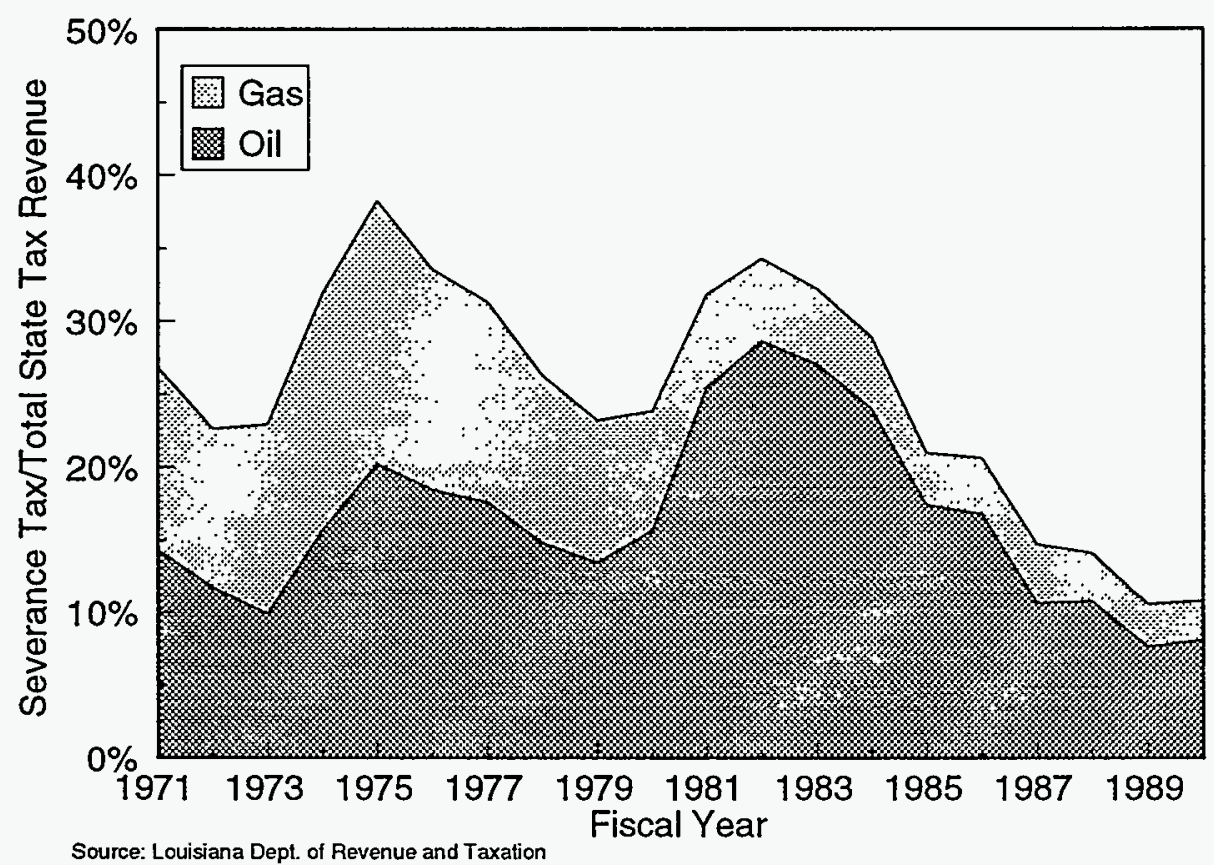


revenues from oil and gas activity. Despite significant revenue losses caused by the decline in oil and gas production, revitalization of the Louisiana economy is beginning to occur on some fronts by diversifying the industrial base in the state. However, oil and gas production continue to play a vital role in the state's economy.

Even as Louisiana's conventional. production nears its end, over three-fifths of the original Louisiana oil resource in presently developed reservoirs will remain (Figure II-9). Louisiana has cumulatively produced nearly 12 billion barrels as of 1991 and onshore proved reserves were estimated to be 535 million barrels, for a total ultimate recovery of 12.4 billion. Louisiana was estimated to have had an original oil-in-place (OOIP) of 32 billion barrels, leaving the remaining 19 billion barrels, amounting to over $60 \%$ of the OOIP, as the target for advanced extraction technologies.

Figure II-9

\section{Louisiana Oil Resource}

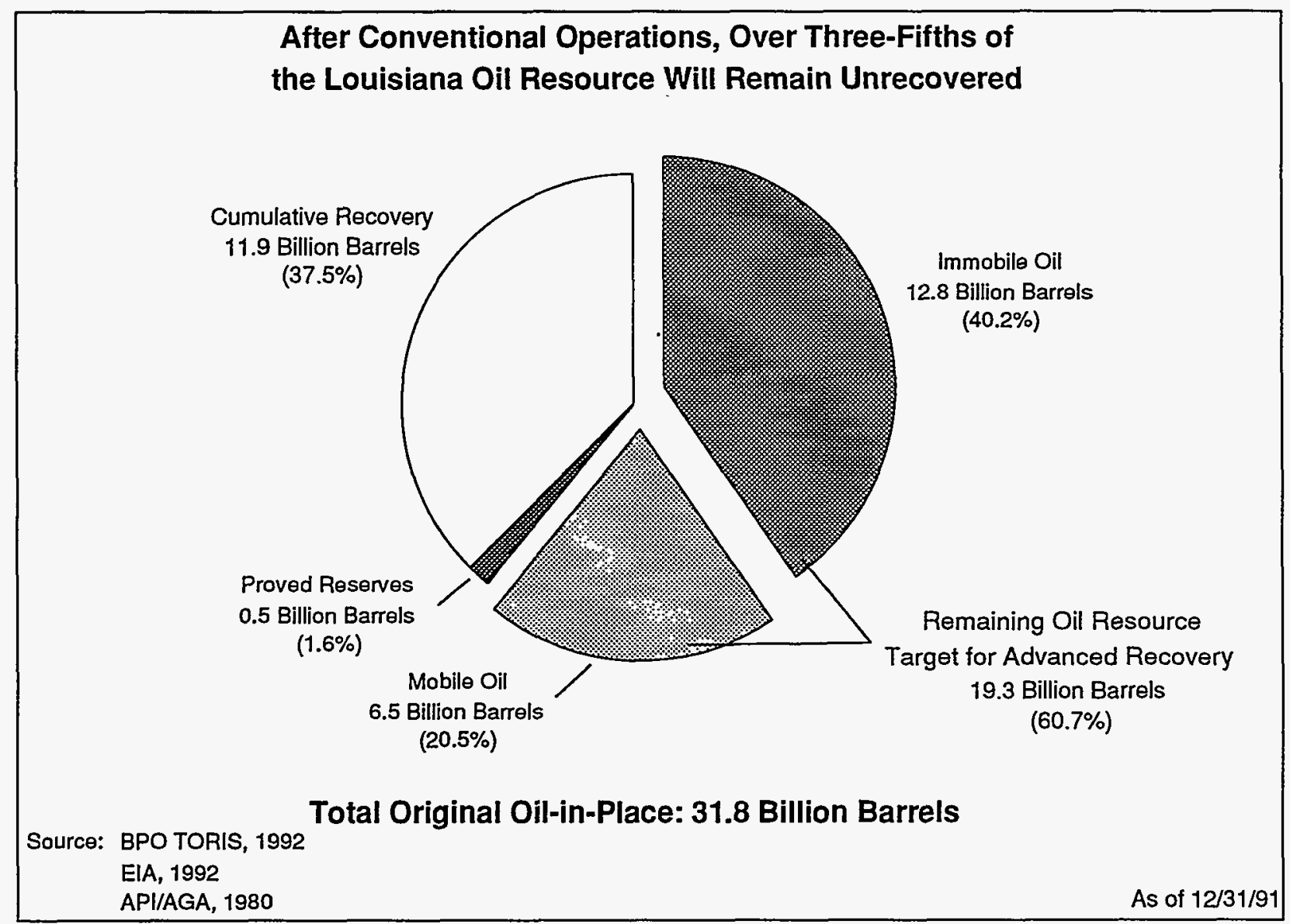


This unrecovered resource can be divided into two components: mobile and immobile oil. Roughly 6.5 billion barrels of the Louisiana remaining resource is unrecovered mobile oil (UMO), oil that is outside the water swept zone of conventional primary and secondary efforts. This oil is the target for advanced secondary recovery (ASR). The remaining resource of nearly 13 billion barrels of oil in Louisiana is immobile oil, the target for any one of a series of tertiary extraction techniques that are known as enhanced oil recovery (EOR). If Louisiana were to undergo an aggressive effort aimed at recovering these quantities of unrecovered oil, significant additional quantities could be recovered and the productive life of Louisiana wells could be extended for a greater length of time than would otherwise be possible.

\section{B. IMPROVED RECOVERY ACTIVITIES TARGETING THE REMAINING RESOURCE}

The oil remaining after conventional primary and secondary recovery lies in two defined regions within each reservoir: the swept and the unswept zones. In the swept zone of the reservoir, conventional operations have recovered a significant portion of the original concentration of oil. The oil remaining in this swept zone is trapped in the reservoir pore spaces or on the surface of the pores by capillary and surface tension forces. Additional flooding with water can produce very little of this oil; the swept zone is at the "waterflood residual" level of oil saturation.

In the unswept zone of the reservoir, conventional recovery processes have not swept the pore space, and the oil saturation can range from low to high, depending upon the primary recovery mechanism (e.g., high saturation for pressure depletion or lower saturations for water drive). The objective of many infill drilling programs, improved waterflooding projects (profile modification), and other reservoir management techniques is to contact the oil in the unswept zones.

\section{Enhanced Oil Recovery}

Proven enhanced recovery projects designed to displace immobile oil targets are classified into three categories: gas-miscible, chemical, and thermal. The majority of the EOR projects undertaken in Louisiana reservoirs have been gas-miscible projects. To date, there have been eight reported projects in five fields: four reservoirs in Texaco's Paradis field in St. Charles parish and Bay St. Elaine field in Terrebonne parish, two reservoirs in Oryx's Fordoche field in Point Coupee parish, one reservoir in Chevron's Timbalier Bay field in Lafourche parish, and one in Chevron's Quarantine Bay field in 
Plaquemines parish. ${ }^{1}$ The two Oryx projects utilize hydrocarbon gas, while the rest are carbon dioxide injection projects. In addition, there have been several immiscible gas injection projects undertaken at various south Louisiana fields.

Texaco began a carbon dioxide injection project at Paradis in 1982 in a 300 acre reservoir, and another in 1988 in a 44 acre reservoir with only one injector and one producer. Similarly, Chevron's pilot projects at Quarantine Bay and Timbalier Bay, begun in 1981 and 1984 respectively, are less than 60 acre projects with two producers and a single injector each. None of these projects are considered to have been profitable, although they did result in incremental oil production and are thought to have provided useful information about a technically promising process application. Texaco is reportedly considering two more similarly sized projects in nearby reservoirs in 1993.

Texaco also implemented a gravity-stable miscible $\mathrm{CO}_{2}$ flood in the 8,000 foot sand of the Bay St. Elaine field in $1981 .^{2} \mathrm{~A} \mathrm{CO}_{2}$ slug equal to one-third of the reservoir pore volume was injected over a nine month period and an estimated 75,000 barrels of incremental oil was expected to be produced from two downdip producers. Further reports on the success of this small-scale project have not been published. Chevron's Quarantine Bay project involved the injection of an $18.9 \%$ of hydrocarbon pore volume slug (483 million cubic feet) of carbon dioxide to recover an estimated $15.8 \%$ of the OOIP (175,000 barrels of oil) in a 57 acre pilot consisting of one injector and seven producers. ${ }^{3}$ Oryx's two hydrocarbon gas injection projects in the Fordoche field are larger projects which target the deeper Wilcox sand rather than the Miocene-Pliocene sands of the other projects. Both of these projects, which Sun Oil Co. began in 1980 are nearly complete and considered to be technically and economically successful. Oryx has determined that only $30 \%$ of the volatile oil in the Wilcox reservoirs of the Fordoche field would

1 Moritis, Guntis, 1992 "EOR Increases 24\% Worldwide; Claims 10\% of U.S. Production," Oil and Gas Joumal, (April 20) p. 51-79.

2 Palmer, F.S., Nute, A.J., Peterson, R.C., "Implementation of a Gravity-Stable Miscible $\mathrm{CO}_{2}$ Flood in the 8000 Foot Sand, Bay St. Elaine Field. JPT, January 1984, p. 101-110.

3 Hsie, J.C., Moore, J.S., "The Quarantine Bay 4RC CO${ }_{2}$-WAG Pilot Project: A Post-Flood Evaluation." SPE15498 61st Technical Conference, New Orleans, LA Oct. 5, 1986. 
be recovered by primary recovery and that injecting a 30/70 mixture of nitrogen and natural gas could boost recovery as high as $50 \%$ of OOIP. ${ }^{4}$

In addition to these miscible projects, several immiscible carbon dioxide projects have been implemented. While immiscible carbon dioxide injection was not modeled in this study, ongoing efforts are reported here. In 1985, Chevron began an immiscible "huff and puff" $\mathrm{CO}_{2}$ injection project, at their Timbalier Bay field. Chevron believes they have produced incremental oil through $\mathrm{CO}_{2}$ related oilswelling and viscosity-reduction, rather than as a result of miscible gas displacement. An incremental oil volume of more than 14,000 barrels was recovered over a four month period following the injection of $\mathrm{CO}_{2}$ in two wells. ${ }^{5}$ Chevron considers the process to be economically successful at oil prices below $\$ 20 / B$. Texaco has also tested the feasibility of "huff and puff" $\mathrm{CO}_{2}$ stimulation on wells in their Paradis, Bayou Sale, Lake Barre, Lafitte and West Cote Blanche Bay fields. ${ }^{6}$ The process was considered effective in at least two of the fields, but the economics were not reported.

Shell has discontinued its immiscible $\mathrm{CO}_{2}$ injection project in the "S" Sand Reservoir B at Weeks Island in New Iberia parish. Started in 1978, this project used a gravity stable, immiscible displacement of oil via injection of $\mathrm{CO}_{2}$ just above the gas-oil contact. The project has recovered an estimated $8.9 \%$ OOIP; although technically successful, this project is considered economically marginal. ${ }^{7,8}$

4 Eckles, W.W., Jr., Prihoda, C., Holden, W.W., 1981, "Unique Enhanced Oil and Gas Recovery for Very High-Pressure Wilcox Sands Uses Cryogenic Nitrogen and Methane Mixture," JPT, June, p. 971-984.

5 Simpson, M.R., 1988, "The $\mathrm{CO}_{2}$ Huff " $n$ ' Puff Process in a Bottomwater-Drive Reservoir," JPT (July) p. 887-893.

6 Palmer, F.S. et al "Design and Implementation of Immiscible $\mathrm{CO}_{2}$ Displacement Projects in South Louisiana," SPE 15497, presented October 5-8, 1986 at 61st Annual Technical Conference, New Orleans, LA.

7 Johnston, J.R.: "Weeks Island Gravity Stable $\mathrm{CO}_{2}$ Pilot," SPE/DOE 17351 presented at the SPE/DOE EOR Symposium, Tulsa, OK, April 17-20, 1988.

8 Cole, E.L., Ferrell, H.H., Miller, D.E.: "An.Evaluation of the Weeks Island "S" Sand Reservoir B Gravity Stable $\mathrm{CO}_{2}$ Displacement Project, Iberia Parish, LA," Report for DOE by K\&A Energy Consultants, February 1989, DOE/BC/10830-11. 
Only one reported miscible EOR project has been implemented in the offshore state waters of Louisiana - ARCO's hydrocarbon miscible injection project in Chandeleur Sound Block 25. This 950 acre project had 16 injection wells and began injection in $1983 .^{9}$

Although the Federal OCS area of the Gulf of Mexico is not covered by the TORIS reservoir database used in this study, some EOR efforts have been undertaken in recent years. Thirteen miscible injection projects have been reported as having been implemented in the Federal OCS areas of offshore Louisiana. ${ }^{10}$ Of these, ten are ARCO operated hydrocarbon miscible projects in the South Pass 61 field, two are Texaco operated $\mathrm{CO}_{2}$-miscible projects at South Marsh Island Block 6 and West Delta Block 105, and one is an Exxon operated hydrocarbon miscible project at South Pass Block 89. While the Exxon project was fairly large (204 acres, 16 producers, and 10 injectors), all but three of the others were less than 100 acres, generally with only one or two injectors. ${ }^{11}$ Initiated about ten years ago, many of these projects have been reported as "profitable," but the details of each project's performance and current status have not been published.

A total of only about 1,500 BOPD, about half a million barrels per year, is reported as incremental EOR production from miscible gas injection projects in Louisiana in the Oil and Gas Journal 1992 EOR Database. However, there are many reservoirs which might be considered candidates given the technical success of the many projects mentioned above.

As currently understood and implemented, chemical flooding has limited potential in Louisiana. However, small-scale alkaline injection projects have been reported in the Clovelly, Perry Point, Whitecastle, and Quarantine Bay fields of the coastal parishes. ${ }^{12}$ The most recent, Shell's small-scale pilot in the Whitecastle field of Iberville parish, was initiated in 1987 and subsequently discontinued.

9 Pautz, J.F., Sellers, C.A., Nautigal, C., Allison, E.; "Enhanced Oil Recovery Projects Database," Report prepared by NIPER for U.S. Department of Energy, April 1992, NIPER-583 (DE92001039).

10 Ibid.

11 Ibid.

12 Pautz, J.F. et al., "Enhanced Oil Recovery Projects Data Base," NIPER, Bartlesville, OK, April 1992. 
Shell also reported initiating a very small scale surfactant flood pilot (2.8 acres) in 1980 in an offshore reservoir at the South Pass 27 field. ${ }^{13}$

Although several thermal projects are underway in Louisiana, they are not nearly as prevalent in the state as miscible projects. Shell has operated two steam injection projects in their Whitecastle field since 1976. These two projects, encompassing a total of 42 producers and 13 injectors, are considered technical and economic successes, producing 1,700 barrels of oil per day of incremental oil from shallow $\left(1,400 \mathrm{ft}\right.$.) low gravity $\left(16^{\circ} \mathrm{API}\right)$ sands. ${ }^{14}$ Mobil also had a steam injection project at Bayou Bleu field in Iberville parish. This 120 acre, 26 producer and 7 injector project began in 1988, but was discontinued due to its lack of success. ${ }^{15}$

There have been four in situ combustion projects reported in Louisiana. ${ }^{16}$ While they have been spread among four fields and five operators, they have all focused on the Nacatoch Sand of northwest Louisiana. Bayou State Oil Company currently operates one 200 acre project which began in 1970 in the Nacatoch, a very shallow (400 ft.) low gravity (19 ${ }^{\circ} \mathrm{API}$ ) reservoir. ${ }^{17}$ Texaco has discontinued injection in a second project in the same sand that began in 1963 and encompassed 385 acres with 200 producers and 30 injectors. Both of these projects were considered technically and economically successful. Cities Service began a pilot test at Bellevue in 1971 and expanded it to eight patterns during the 1970 s. $^{18}$ Texaco also undertook an in situ combustion project in the Nacatoch at Caddo Pine Island field, also in northwest Louisiana, and was successful in applying the process to a thin oil column underlain by

13 Ibid.

14 Moritis, Guntis, 1992 "EOR Increases 24\% Worldwide; Claims 10\% of U.S. Production," Oil and Gas Journal, (April 20) p. 51-79.

15 Ibid.

16 Pautz, J.F. et al., "Enhanced Oil Recovery Projects Data Base," NIPER, Bartlesville, OK, April 1992.

17 Moritis, Guntis, 1992 "EOR Increases 24\% Worldwide; Claims 10\% of U.S. Production," Oil and Gas Journal, (April 20) p. 51-79.

18 Joseph, C., Pusch, W.H. 1980 "A Field Comparison of Wet and Dry Combustion" JPT September, p. 1523-1528. 
water. ${ }^{19}$ According to the results of this study, thermal recovery (both steam and in situ combustion), could ultimately have wider application in northern Louisiana and selected southern Louisiana reservoirs.

\section{Advanced Secondary Recovery}

Mobile oil remains in the reservoir after conventional recovery for a variety of reasons. Foremost of these is reservoir heterogeneity, the complex variation of rock properties among zones in the producing interval. Reservoirs may consist of a large number of individual compartments, reflecting internal heterogeneity. These compartments are formed by depositional processes that originally formed the reservoir, or by diagenesis or tectonic activity that later altered the rock bodies. Exceedingly complex reservoirs may have compartments formed by all of these processes. At a given well spacing, some compartments containing oil are not in pressure communication with existing producing wells. At wide well spacings, much of the rock volume in a heterogeneous reservoir will not be contacted by existing wells, leaving large volumes of oil at or near original pressure and saturation. These compartments provide a major target for infill drilling and future recovery operations conducted at closer well spacing.

Mobile oil also remains in reservoir compartments that have been contacted, but inefficiently swept by secondary recovery methods that utilize existing well configurations. At wide well spacings, significant volumes of oil are areally bypassed due to small-scale variations in reservoir continuity, to the higher viscosity of oil than injected water, and to permeability variations within the reservoir. The effectiveness of water injection is further limited by vertical layering in the reservoir. Water preferentially enters the more permeable layers of the reservoir, leaving the less permeable rock layers unswept at relatively high remaining oil saturations.

Several geologic factors influence the volume, distribution, and potential future production of unrecovered mobile oil (UMO). A major factor commonly influencing recovery potential is reservoir genesis, or the type of system that originally deposited the reservoir rock. Internal reservoir architecture is profoundly affected by the depositional system of the initial reservoir sediment, which controls the distribution of different types of rock "packages," and by the pore structure that plays host to later

19 Horne, J.S. et al, 1982 "Initiation of an In-Situ Combustion Project in a Thin Oil Column Underlain by Water," JPT October 1982, p. 2233-2243. 
diagenetic rock and fluid alterations. Other important geologic factors include trap style and source rocks. Reservoirs that have common depositional histories may have very similar internal reservoir architecture, but will be modified by post-depositional diagenesis. That modification will vary from basin to basin depending on geohistory.

Recovery of remaining mobile and immobile oil from known fields is a highly cost effective method for increasing oil production and reserves. A large portion of these new reserves result from implementation of waterflooding and pressure maintenance programs, drilling of additional wells to improve reservoir contact, and selective recompletion of existing wells to improve performance. Several distinct methods for producing UMO have emerged: infill drilling to tap uncontacted reservoir compartments, recompletion of production and injection wells to contact and sweep previously bypassed portions of the reservoir, polymer flooding to overcome unfavorable waterflood injection fluid characteristics, and profile modification to reduce the permeability contrast between reservoir layers. These techniques are all tested and proven methods for producing mobile oil remaining in the reservoir.

Clearly, some portion of the oil bypassed at current spacing can be recovered by well-designed, advanced waterflooding techniques, and significant portions of this oil could be recovered with the combined application of both polymer injection and infill drilling. Eight polymer projects have been reported in Louisiana. ${ }^{20}$ Two of these have been initiated by Chevron at West Bay in Plaquemines parish. Both of these small (less than 100 acres) projects began in 1981, and their status has not been well reported in the literature. ${ }^{21}$ Few infill drilling and.profile modification projects (applied alone) have been reported in the literature.

Taken alone, infill drilling, polymer flooding, and profile modification are effective processes for producing mobile oil; they are often even more effective when applied in combination, which allows the processes to complement one another. For example, polymer injection and profile modification can be used to increase the waterflood sweep efficiency not only in previously contacted compartments, but also in compartments newly contacted by infill drilling. These synergies maximize the cost-effectiveness of

Pautz, J.F. et al, loc. cit.

21

Ibid. 
mobile oil recovery and encourage the coordinated, multiple application of techniques in selected reservoir settings.

There are several other processes and recovery techniques which were not included in this analysis which may have potential in Louisiana. Application of these techniques would further increase potential recovery and add to the estimates contained in this analysis. Immiscible gas and nitrogen gas EOR projects could enhance Louisiana oil recovery. Recently, as part of DOE's cost-shared research projects, Amoco initiated a double displacement air process (gas displacement of a water invaded oil column) and production by gravity drainage using down structure wells to produce remaining oil in a watered out reservoir in the west Hackenberry field of Cameron Parish. These processes could enhance potential reserves. In addition, improvements in reservoir management and improvements in waterflood patterns, waterflood rates of injection, and the timing of inception of waterfloods show significant potential as recovery techniques. To the extent that these techniques and others currently being transferred (i.e., injection water compatibility) improve potential oil recovery, the results presented in this report will be understated.

\section{OBJECTIVES OF THE PRESENT STUDY}

The present study analyzes the incremental reserves, public sector revenues, and statewide economic activity that could result from the implementation of the improved EOR and ASR techniques described above. The potentials for EOR and ASR production are evaluated separately, and each is considered for two technology levels: implemented technology, which assesses recovery potential given the statewide application of currently available technology, and advanced technology, which assesses the impact of the statewide application of potential technological advances. Comparison of the results of these two evaluations provides the basis for assessing the benefits of improved technology provided by RD\&D. All of the analyses are conducted over a range of crude oil prices from $\$ 16$ to $\$ 36$ per barrel (in constant 1991 dollars). This price range encompasses the long-term prices likely to prevail over approximately the next 30 years.

Three hundred and forty-two reservoirs, accounting for 20.5 billion barrels of original oil-in-place (64\% of the total known resource in Louisiana), were included in this analysis. These reservoirs contain over 13 billion barrels of remaining oil resource (Figure II-10). The 4.5 billion barrels of UMO is the 
target for application of ASR processes and 8.6 billion barrels is the target for application of EOR processes. To achieve the required level of application, and therefore receive the maximum benefits of both levels of technology assessed in this report, it is critical that state and local governments, the Federal government, and the oil industry work collaboratively to: (1) effectively transfer to operators currently available technology (implemented technology), and (2) develop a focused RD\&D program to improve recovery methods (advanced technology) and subsequently transfer those methods to a broad public-private audience. The results and conclusion will provide valuable insights for state and Federal policymakers in their efforts to maximize domestic production and improve the nation's energy security.

Figure II-10

\section{Louisiana Remaining Oil Resource After Conventional Operations}

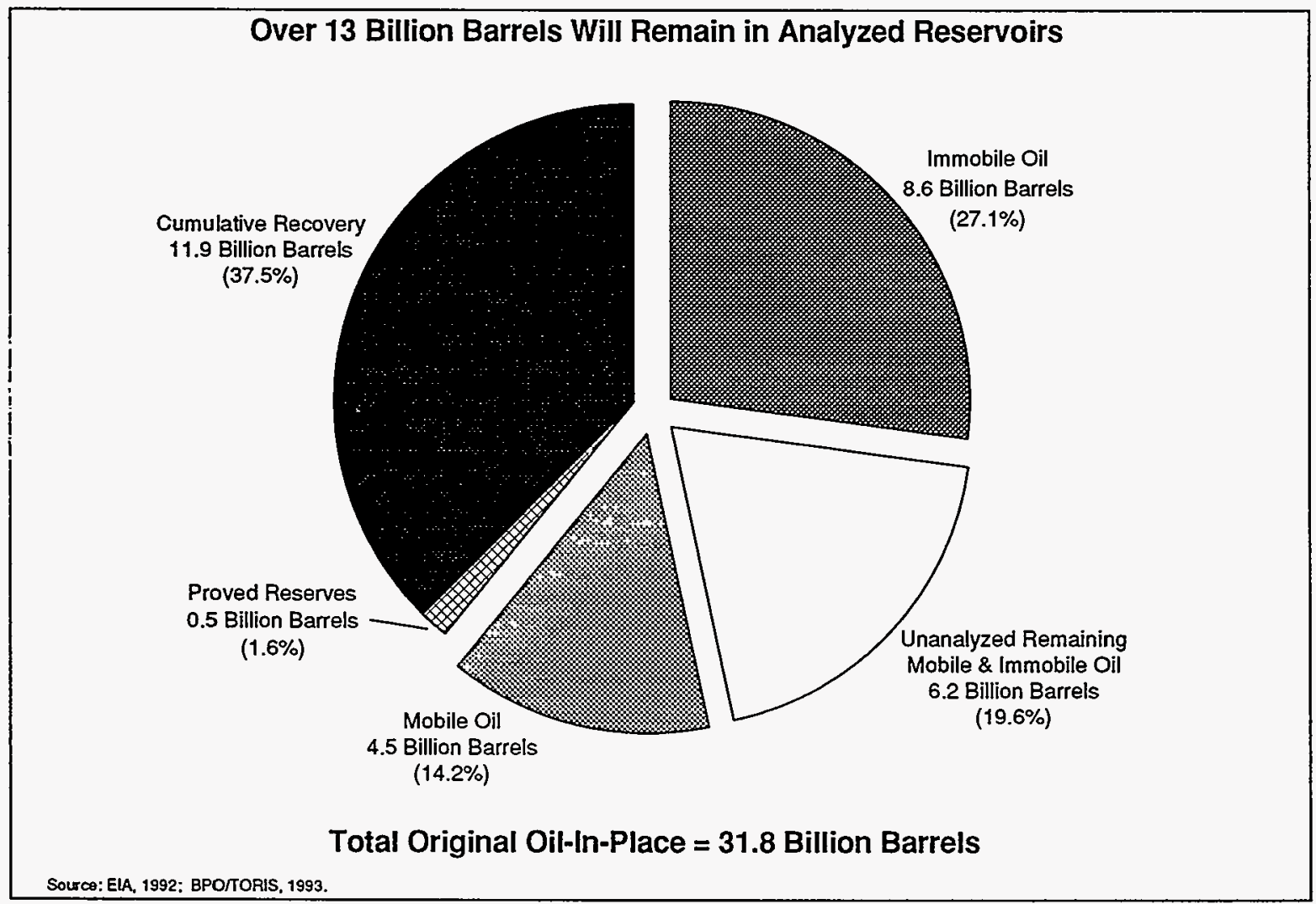




\section{APPROACH TO THE ANALYSIS}

\section{A. INTRODUCTION}

This analysis was performed using the Department of Energy's Tertiary Oil Recovery Information System (TORIS) developed for the 1984 National Petroleum Council (NPC) analysis of the nation's enhanced oil recovery (EOR) potential. ${ }^{1}$ Although TORIS was originally designed to evaluate EOR potential only, the system's capabilities have since been expanded to incorporate evaluations of the unrecovered mobile oil (UMO) resource, the target for advanced secondary recovery (ASR). The upgraded TORIS system assessed the recovery potential of immobile oil and.UMO in the United States. The following sections in this chapter will briefly discuss the:

- Development of TORIS;

- $\quad$ Enhancement of TORIS to evaluate the UMO resource;

- $\quad$ Scope of the current analysis;

- $\quad$ Adaptations to TORIS for this analysis;

- Estimation of benefits, costs, and economic impacts; and

- Limitations of the analytical approach.

\section{B. GENERAL METHODOLOGY: THE NPC BASIS}

In March 1982, the U.S. Secretary of Energy requested that the NPC prepare a report on the nationwide potential and the economics of incremental EOR. The NPC is the official petroleum industry advisory committee to the Secretary. Members of NPC, who are appointed by the Secretary, represent all segments of petroleum interest, such as production, refining, marketing, and environmental, and include many chief executive officers. The NPC is supported entirely by the voluntary contributions of its members.

In response to the Secretary's request, the NPC mounted a two-year effort that consumed more than 50 professional man-years and nearly $\$ 7$ million of in-kind services. EOR experts from industry (majors, independents, service companies and consulting firms), universities, government, and private, non-profit organizations participated. The NPC EOR study committee utilized and built upon data bases

1 National Petroleum Council, Enhanced Oil Recovery, Washington, DC, 1984. 
of individual reservoir characteristics and computer models that were under development by the U.S. Department of Energy's (DOE), Office of Fossil Energy. After augmentation, adaptation, and validation, the data bases and models were remanded to the DOE's Bartlesville Project Office (BPO) for maintenance, updating, and subsequent application. These data bases and models are components of a larger system, the Tertiary Oil Recovery Information System (TORIS).

By the agreement of the Assistant Secretary for Fossil Energy, the present study enjoys access to TORIS and the assistance of BPO, although its participation is limited strictly to providing the data base, models, and assistance for the technical analysis. The BPO and DOE neither contribute to nor endorse the study design or the interpretations presented in this report. The approach used by the NPC and in the present study to evaluate the EOR resource consists of the major phases listed below.

1. Reservoir Data Compilation. Detailed data describing the properties of the individual, significant oil reservoirs are compiled. Numerous public and private sources of information are consulted to complete and validate the reservoir data base. The principal elements of the TORIS data base are displayed in Table III-1. Representatives of the operating companies review the data elements of each reservoir at least three times for consistency and accuracy; automated validity checks are performed on the entire data base.

2. Resource Screening Models. Each reservoir is subjected to a screening process designed to identify the technical applicability of the respective EOR processes under what the NPC defined as "implemented," or currently available, technology. The specific criteria applied to screen each EOR process are shown in Table III-2. In addition, the reservoirs are screened under what the NPC defined as "advanced" technology, available through concerted research and development. Table III-3 displays the technical criteria for "advanced" EOR technology.

3. Process Performance Models. Each reservoir that satisfies the technical criteria is then analyzed by a detailed process performance model at each level of technical applicability. The models for each process have been previously reviewed in detail and calibrated to actual field results. NPC study committees review and test this calibration. The models are reservoir-specific and, therefore, estimate incremental oil production from EOR as a function of reservoir properties and process design for each reservoir independently. Incremental production is that which is recovered in excess of production by conventional primary and secondary techniques at current field conditions.

4. Economic Evaluation. Each reservoir is then evaluated for its economic feasibility by estimating the income attributable to the incremental EOR production and the investment, operating costs, and taxes required to support the implementation of the process as designed and installed in the field. Detailed costing algorithms reflect EOR design (both "implemented" and "advanced"), reservoir depth, region, and other factors. The energy component of each cost element is adjusted to reflect the oil price being analyzed. A 
Table III-1

\section{Key Elements in the Current TORIS* Reservoir Data Base}

- Original Volumetrics

-- Original Oil-in-Place

- Reservoir area

-- Net thickness

- Porosity

-- Initial water saturation

-- Initial oil saturation

- Initial formation volume factor

\section{- $\quad$ Current Volumetrics}

-- Current oil saturation (swept zone)

-- Current formation volume factor

- $\quad$ Fluid Data

-- Oil gravity and viscosity

-- Connate water viscosity

-- Connate water salinity

-. Initial GOR

-- Current GOR

-- Injection water salinity

-- Crude oil fractions \& properties (being added)
- Geologic Variables

-- Lithology

-- Depth

-- Temperature

-- Original and current pressure

-- Permeability

-- Permeability variation index

-- Clay content

-- Gross thickness

-- Dip angle

-- Geologic age code

-- Presence of gas cap, faults, shale breaks

-- Geologic play, depositional system, trap type

-- Areal and vertical heterogeneity descriptors

-- Pay continuity (estimated)

\section{- Development \& Performance Data}

-- Recovery efficiency

-- Cumulative production

-- Annual production

-- Current injection rate

-- Cumulative volume of injectant by type

-- Well spacing

-- Number of producing \& injecting wells

-- Water cut

*Tertiary Oil Recovery Information System, maintained and operated by the Bartlesville Project Office of the U.S. Department of Energy 
Table III-2

\section{Screening Criteria for EOR Candidates-Implemented Technology Case}

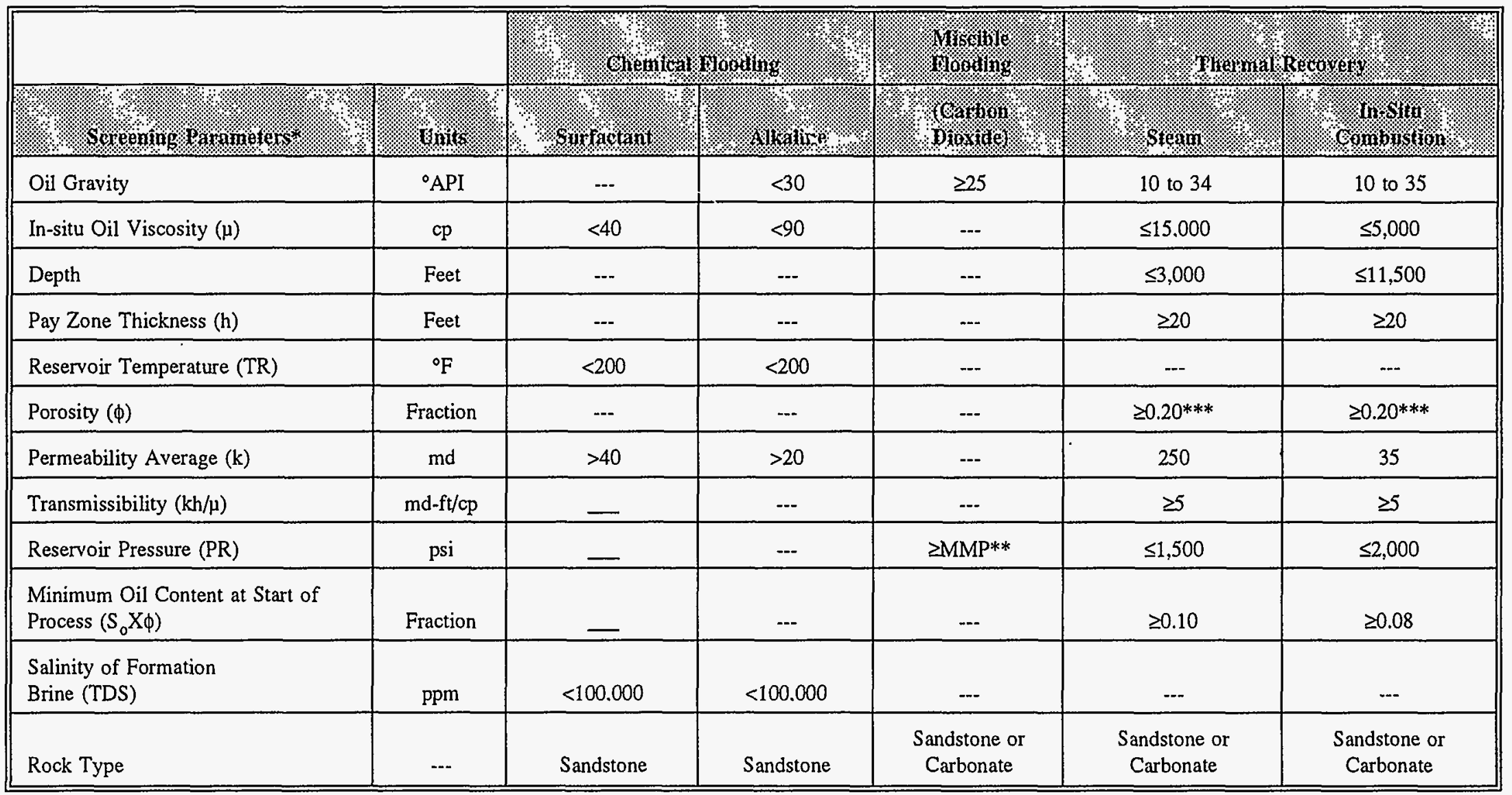

* Other criteria of a geological and depositional nature were also considered. Generally, reservoirs with extensive faulting. lateral discontinuities. or overlying gas caps are not prime candidates for field-wide EOR application. These factors were considered during the manual screening step when they could be identified.

** MMP denotes minimum miscibility pressure. which depends on temperature and crude oil composition.

*** Ignored if oil saturation $\left(\mathrm{S}_{\mathbf{0}}\right) \mathrm{X}$ porosity $(\phi)$ criteria are satisfied.

Source: NPC. 1984. 
Table III-3

Screening Criteria for EOR Candidates-Advanced Technology Case

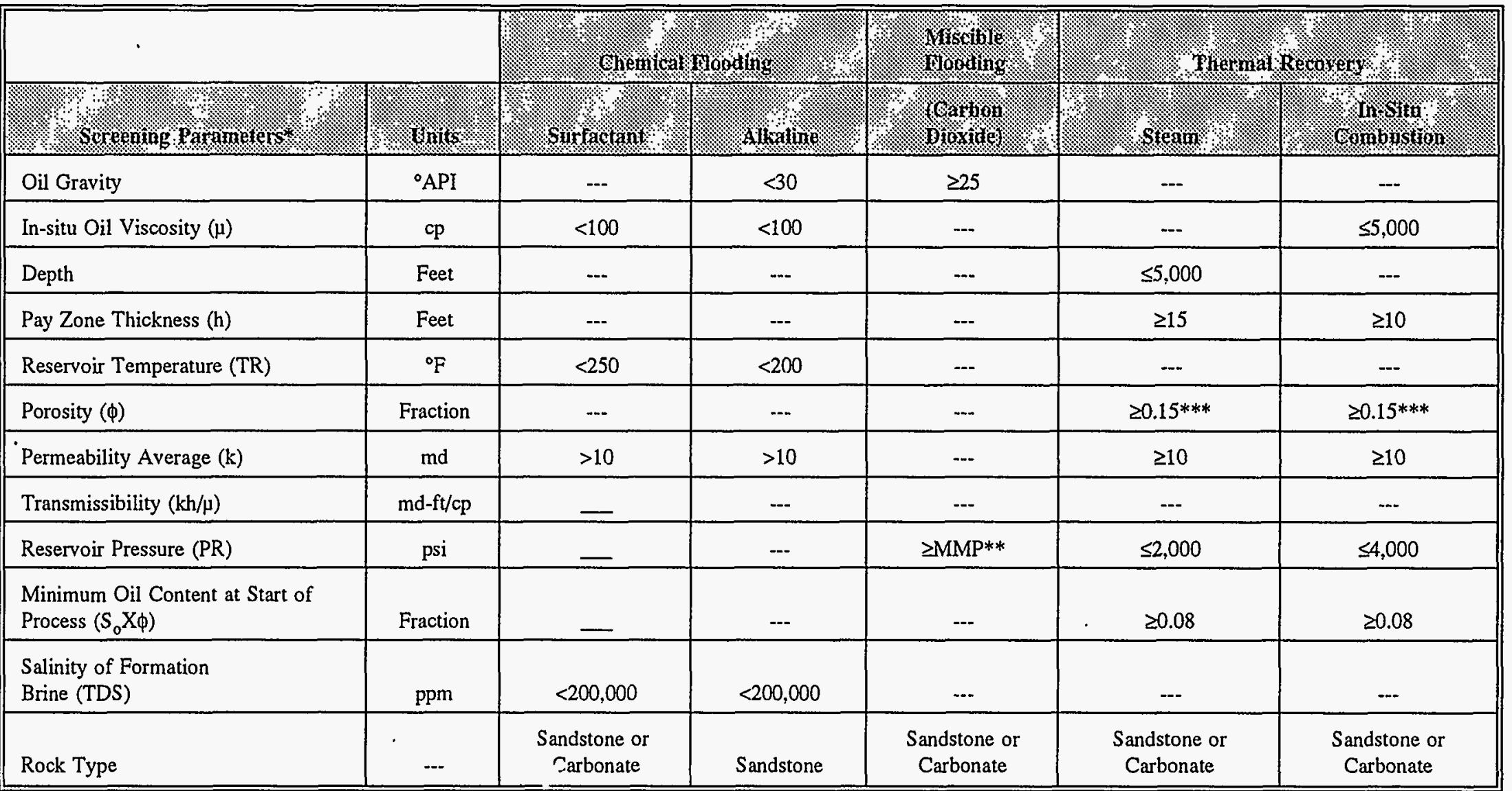

* Other criteria of a geological and depositional nature were also considered. Generally. re irvoirs with extensive fauiting, lateral discontinuities, or overlying gas caps are $n r^{*}$ prime candidates for field-wide E${ }^{\prime}$ n application. These factors were considered during the manual screening step whin. $: y$ could be identified.

** MMP denotes minimum miscibility pressure, which depends on temperature and crude ull .umposition.

*** Ignored if oil saturation $\left(S_{0}\right) \mathrm{X}$ porosity $(\phi)$ criteri:' are satisfied.

Source: NPC. 1984. 
discounted cashflow analysis is performed for each reservoir at a number of oil prices and minimum rates of return.

5. Technology Development. For each reservoir that is determined to be economic at a given price, the performances of the applicable EOR processes are compared. Each reservoir is then assigned the process producing the greatest quantity of incremental oil. In the NPC assessment, the reservoirs are then scheduled for development on the basis of their relative economic attractiveness and time-phased against a series of supply and environmental constraints. This procedure is modified somewhat in the present study, as described below.

The NPC reported its findings on a national basis for four oil prices, ranging from $\$ 20$ to $\$ 50$ per barrel, three minimum rates of return (zero, ten, and twenty percent), and two levels of technology performance -- "implemented," meaning available at present, and "advanced," meaning available in the future due to successful completion of currently ongoing RD\&D. The present study uses the NPC reservoir data base, models, and methodology just as the NPC developed them, except as described in sections $\mathrm{C}$ and $\mathrm{E}$. The NPC methodology is described at length in its final report. ${ }^{2}$

\section{BUILDING ON TORIS: THE EVALUATION OF UNRECOVERED MOBILE OIL RESOURCES}

TORIS evaluations have historically focused on the recovery of immobile or waterflood residual oil. In 1988, TORIS' capabilities were expanded to include an evaluation of the unrecovered mobile oil (UMO) resources in several states. ${ }^{3}$ This expansion was accomplished by enlarging the system to consider the recovery potential of extended primary and secondary recovery operations in unswept portions of the reservoir, in a manner consistent with the current capabilities to analyze the tertiary recovery target (residual oil in previously swept zones). The system development and initial limited applications that were completed under the DOE UMO study are reported in detail in a topical report by the DOE. ${ }^{3}$

Ibid.

3 ICF Resources Incorporated and the Bureau of Economic Geology, University of Texas at Austin, Producing Unrecovered Mobile Oil: Evaluation of Potential Economically Recoverable Reserves in Texas, Oklahoma, and New Mexico, prepared for: U.S. Department of Energy/Office of Planning and Environment/Office of Fossil Energy and Bartlesville Project Office, 1989. 
Since 1989, the TORIS ASR models have been upgraded to more accurately describe and evaluate the UMO resources. The enhancements included the following:

- Development of an infill drilling model which processes five-spot waterflood to five-spot infill as well as five-spot waterflood to nine-spot infill;

- Development of a methodology to determine key reservoir heterogeneity elements needed for modeling infill drilling potential. The heterogeneity elements are "reservoir continuity" and "Vertical Permeability Stratification Index" (Dykstra-Parson coefficient). The methodology relies on the history match of production data to determine the heterogeneity elements;

- Validation of the infill drilling model and history match methodology on nine actual field results as well as results of a black oil simulator;

- Integration of a newly developed infill model with other models in TORIS to process infill drilling in combination with polymer flooding or profile modification; and

- Validation of criteria for implemented as well as advanced technology infill drilling.

A preliminary draft report of all developmental work is available through the U.S. Department of Energy, Bartlesville Project Office. The draft report is currently being finalized, and it will be available to the general public in the near future.

UMO, the target for advanced primary and secondary recovery operations, consists of oil that is uncontacted or bypassed during conventional production that can be displaced from the reservoir by waterflooding. "Uncontacted oil" refers to oil trapped in isolated compartments in reservoirs uncontacted by wells at current spacing, while "bypassed" oil has been contacted by existing wells but unswept by secondary recovery processes. The volume, location, and properties of the UMO depend on the geologic history of the reservoir, the fluid characteristics of the oil, and the drilling and development history of the reservoir.

Potential incremental oil recovery and related economic benefits are estimated for the three processes currently used to improve mobile oil displacement. These processes are referred to as advanced secondary recovery (ASR) and include: infill drilling, profile modification treatments (permeability contrast reduction), and polymer-augmented waterflooding. A modified polymer-waterflood predictive model is used to evaluate each process. Selected combinations of these processes are also evaluated in this study. 
Consistent with TORIS EOR evaluations, the analysis of UMO considers both current technology and advanced technology. The advanced technology analysis estimates the potential improvement in recovery possible after successful research, development and demonstration (RD\&D). For polymer flooding and profile modification treatments, advances in technology are projected to increase both the reservoir temperature and the formation salinity thresholds that currently limit the application of these processes. Table III-4 shows the process technical screens that are used in evaluating reservoirs for polymer flooding and profile modification treatments under current and advanced technology scenarios.

\section{Table III-4}

\section{Screening Criteria for Advanced Secondary Processes}

\begin{tabular}{lcccc}
\hline \hline & \multicolumn{2}{c}{ Polymer $^{*}$} & \multicolumn{2}{c}{ Profile Modification } \\
\cline { 2 - 3 } & Current & Advanced & Advanced \\
$\begin{array}{l}\text { Reservoir Temperature } \\
\left({ }^{\circ} \mathrm{F}\right)\end{array}$ & $<200$ & $<250$ & $<180$ & $<250$ \\
$\begin{array}{l}\text { Formation Brine } \\
\text { Salinity (ppm) }\end{array}$ & $<100,000$ & $<200,000$ & $<100,000$ & $<200,000$ \\
$\begin{array}{l}\text { Permeability (md) } \\
\text { Oil Viscosity (cp) }\end{array}$ & $>20$ & $>10$ & $>20$ & $>10$ \\
N $_{\text {Source: NPC, } 1984}$ & $<100$ & $<150$ & $<100$ & $<150$ \\
\hline
\end{tabular}

Infill drilling potential is also evaluated under implemented and advanced technology scenarios. Current knowledge of reservoir heterogeneity limits drilling to highly favorable reservoirs where blanketpattern drilling at uniform spacing can yield a profit. Increased continuity in the implemented technology case is estimated by the reservoir-wide average improvement in continuity possible with a reduction in spacing to one-half the current level. The advanced technology scenario assumes that improved geologic description would target infill wells to more promising segments of each reservoir. The TORIS models represent this assumption by dividing the reservoir into two parts, a more continuous (homogeneous) region and a less continuous (heterogeneous) region. Each region is then separately analyzed to determine 
its economic potential for infill drilling at subsequent one-half reductions in well spacing down to five acre spacing, or one-eighth of current spacing, the maximum reduction evaluated in this study. The specific criteria for both the implemented technology and the advanced technology infill drilling is shown in Table III-5. The entire methodology (data, models, highgrading, and analytical systems) was developed and implemented in a manner fully compatible with the existing TORIS structure.

\section{Table III-5}

\section{Screening and Approach for Advanced Technology Infill Drilling}

\begin{tabular}{|c|c|}
\hline /. & 18 ritenis \\
\hline Implemented & $\begin{array}{l}\text { - } 5 \text {-spot waterflood to 5-spot infill } \\
\text { - } 15 \% \text { minimum real rate of retum } \\
\text { - } \quad \text { Minimum well spacing of } 10 \text { acres before infill drilling } \\
\text { - } \quad \text { One drill down }\end{array}$ \\
\hline Advanced & $\begin{array}{l}\text { - } \quad \text {-spot waterflood to } 5 \text {-spot infill } \\
\text { - } 10 \% \text { minimum real rate of return } \\
\text { - } \quad \text { Highgrade into homogenous and heterogeneous portions } \\
\text { - One drill down in homogeneous portion } \\
\text { - Up to three drill downs in heterogeneous portion } \\
\text { - Well spacing after infill greater than } 5 \text { acres }\end{array}$ \\
\hline
\end{tabular}

\section{SCOPE OF THE ANALYSIS}

The cases selected for this analysis include six oil price assumptions and two levels of technology application. The cases are run, first incorporating either EOR or ASR processes individually, and then in combination. TORIS selects from five EOR recovery methods and five ASR methods for each reservoir in the database. A reservoir could be assigned only one EOR process and/or one ASR method for each case considered.

The nominal crude oil prices (West Texas intermediate adjusted for transportation costs and gravities less than $40^{\circ} \mathrm{API}$ ) range from $\$ 16 / \mathrm{B}$ to $\$ 36 / \mathrm{B}$ in $\$ 4$ increments, all stated in constant 1991 dollars. The prices are selected to bracket the likely prices over the next 30 years. A minimum real (after inflation) rate of retum of $10 \%$ is used to estimate discounted cash flows and project profitability for all analyses. In addition, a risk premium is also considered depending on the EOR/ASR process and the level 
of technology. The risk premium is modeled as an increase in the hurdle rate as shown by the following table. The risk premium was recommended by the TORIS peer review committee.

Table III-6

\section{Risk Premium For Implemented and Advanced EOR and ASR Processes}

\begin{tabular}{|c|c|c|c|c|c|}
\hline & \multirow{2}{*}{ 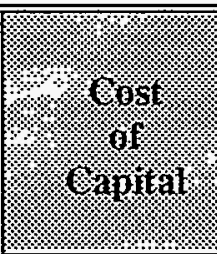 } & \multicolumn{2}{|c|}{ (1) } & \multicolumn{2}{|c|}{ (1) } \\
\hline & & 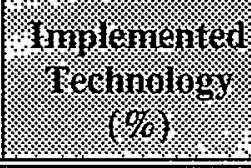 & 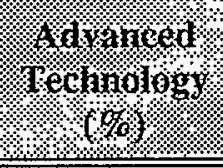 & Implenented & $\begin{array}{l}\% \text { d yanced } \\
\text { Pechnology } \\
.\end{array}$ \\
\hline Alkaline & 10 & 15 & 0 & 27 & 10 \\
\hline Surfactant & 10 & 15 & 0 & 27 & 10 \\
\hline In-Situ & 10 & 15 & 5 & 27 & 16 \\
\hline Polymer & 10 & 5 & 0 & 16 & 10 \\
\hline $\begin{array}{l}\text { Profile } \\
\text { Modification }\end{array}$ & 10 & 5 & 0 & 16 & 10 \\
\hline $\mathrm{CO}_{2}$ & 10 & 5 & 0 & 16 & 10 \\
\hline Steam & 10 & 5 & 0 & 16 & 10 \\
\hline Infill Drilling & 10 & 5 & 0 & 16 & 10 \\
\hline
\end{tabular}

At each oil price, two technology cases are analyzed; the "implemented" and the "advanced" case. Implemented technology reflects the applicability and level of performance of the respective processes (EOR or ASR) which are currently available. Advanced technology considers the likely improvements in process performance and applicability that can be achieved within the next decade if a focused, effective RD\&D program is successfully completed.

All cases are analyzed in detail to examine their impact on estimated oil reserves, oil production, state and Federal revenues, and the state and national economies. The results of these analyses, addressing the benefits from incremental production, are reported in Chapters IV and V which discuss the effects of EOR and ASR processes for implemented technology and advanced technology, respectively. 


\section{E. ADAPTATIONS FOR THE PRESENT STUDY}

Several adaptations to the NPC approach were necessary to conduct the present analysis. None is a significant departure from the NPC methodology.

\section{Data Editing and Additions}

Based on a lengthy data search using state and library sources, the NPC reservoir data have been reviewed and updated for 342 of the largest Louisiana reservoirs, accounting for $64 \%$ of the estimated original oil-in-place (OOIP) in Louisiana. The reservoirs represented in the data base include oil zones in every region of the state. The largest reservoirs are more completely represented in the data, but reservoirs as small as 5 million barrels are also analyzed in the study. The data base is, therefore, believed to be representative of the diverse oil producing formations across Louisiana. Data from the Energy Information Administration on the production of oil, gas, and water from 1970 to 1992 has been added for all reservoirs, thereby permitting decline curve analyses (used in the timing algorithm, discussed below) and validation of the estimated ultimate conventional recovery.

\section{State and Federal Taxes}

The present study uses current tax structure along with the actual tax rates in the TORIS economic models. The Federal taxes are estimated based on the new corporate tax rules established by Congress in the Tax Reform Act of 1986 and signed into law in October 1986. This law provides for a 34\% marginal rate on corporate income taxes and changes the depreciation schedules and expense rules. In addition, the present study includes the new Federal EOR tax credit as passed by Congress in FY91. The new Federal EOR tax credit provides a credit equal to $15 \%$ of all qualified enhanced oil recovery costs on projects that began or were significantly expanded after December 31, 1990. The "qualified enhanced oil recovery costs" are defined as tangible property investments, intangible drilling and development costs, and purchase costs of tertiary injectants. The tax credit is contingent upon professional certification, in advance, that the EOR project is capable of producing more than an insignificant increase in ultimate recovery. Because the goal of the incentive is to make the application of EOR techniques economic at lower oil prices, where project economics are most impacted, the incentive is gradually phased out at oil prices above $\$ 28 / \mathrm{B}$. For every $\$ 1 / \mathrm{B}$ that the average benchmark price for the preceding year exceeds 
$\$ 28 / \mathrm{B}$, the incentive is reduced by 2.5 percentage points for the subsequent year, so that a complete phasing out of the incentive would occur at an oil price of $\$ 34 / \mathrm{B}$.

The study also accounts for the current state tax incentive in Louisiana. This incentive forgives severance tax on incremental production until the point of project payback for all qualified EOR and ASR projects.

\section{3. $\quad$ Cost and Price Data}

An informal survey of industry representatives has determined that the NPC costing algorithms for investments are still valid for the present study, provided that prices analyzed are consistent with the year of the cost data. The only exception to the use of the NPC's cost algorithms is the cost of enhanced recovery injectants delivered to the field. The NPC assumed a $\mathrm{CO}_{2}$ purchase price in the Permian Basin of West Texas and Eastern New Mexico of $\$ 1.25$ per thousand standard cubic feet (Mcf) at an oil price of $\$ 30 / B$. The NPC adjusted for changes in oil price using the equation:

$$
\mathrm{CO}_{2} \text { Price }(\$ / \mathrm{Mcf})=\$ 0.50+\$ 0.025 \times \text { Oil Price }(\$ / \mathrm{B}) .^{4}
$$

However, the base price and adjustment equation were established at higher oil prices and before the completion of major $\mathrm{CO}_{2}$ pipelines or significant $\mathrm{CO}_{2}$ deliveries to the region. An informal poll of pipeline and field operators suggests that the $\mathrm{CO}_{2}$ prices at present and into the near future will be lower (relative to oil prices) than the NPC had assumed. The $\mathrm{CO}_{2}$ purchase price in West Texas has been adjusted for changes in oil price using the equation:

$$
\mathrm{CO}_{2} \text { Price }(\$ / \mathrm{Mcf})=\$ 0.50+\$ 0.02 \times \text { Oil Price }(\$ / \mathrm{B})
$$

This equation results in a $\mathrm{CO}_{2}$ price of $\$ 0.90 / \mathrm{Mcf}$ at the $\$ 20 / \mathrm{B}$ oil price. $\mathrm{CO}_{2}$ prices in other regions of the state are assumed to be double the West Texas price, based on previous NPC surveys.

Chemical injectant costs have also been adjusted based on a survey of operators and suppliers. Polymer costs, assumed to he $\$ 1.60$ per active pound by the NPC, have been reduced to $\$ 1.33$ per active

4 National Petroleum Council, Enhanced Oil Recovery, Washington, DC, 1984. 
pound based on the current cost of low temperature, low salinity polymers. The cost is increased where oil and reservoir properties dictate the use of high molecular weight polymers. Surfactant costs used by the NPC were based on a primary surfactant cost of $\$ 0.32$ per active pound and a secondary surfactant cost of $\$ 0.44$ per active pound. The surfactant slug cost based on these components was $\$ 7.00 / \mathrm{B}$. Prices paid by operators in recent field tests show this cost to be too low. Survey information shows that primary surfactant costs are higher ( $\$ 0.63 /$ active pound), resulting in a $\$ 10.17 / \mathrm{B}$ surfactant slug cost at a $\$ 30 / \mathrm{B}$ oil price..$^{5}$ Chemical costs have been adjusted for oil price changes as had been done in the NPC analysis, based on the energy component of the chemicals for different oil prices.

\section{Benefits Estimation}

The NPC did not calculate all of the individual items used in the present study's estimation of benefits. Special algorithms have been developed to estimate the number of jobs created, wages paid, and personal income taxes collected based on other elements already contained in the economic model. These algorithms are discussed further in Section $\mathrm{F}$ of this chapter.

\section{Project Timing}

The NPC's national perspective permitted a timing algorithm based principally on the assumption that the most economically attractive reservoirs would be developed first, given some broad constraints. A more detailed timing approach for both EOR and ASR was used in the present study. Timing for the application of EOR recovery techniques is estimated in two steps. First, project starting dates for EOR that are documented in the literature are used to time recently started operations. Second, when project start up dates are not available, the year that average well abandonment will occur for each reservoir under conventional recovery is estimated. This abandonment date is based on the projected rate of decline and economic limit of conventional recovery for each reservoir. EOR recovery is then phased in to occur reservoir-wide, at the latest, by three years following the estimated abandonment date. Projects that are not timed in by this data are assumed abandoned and are excluded from the analysis. The timing of ASR reserves development and production was accomplished using the Crude Oil Policy Model (COPM) hecause the TORIS timing model was not suited for ASR for technical reasons. COPM simulates the

5 Ray, et al., Potential Crude Oil Production from Enhanced Oil Recovery, U.S. Department of Energy, Bartlesville Project Office, 1986. 
development of an aggregate resource as a function of project economics, while simultaneously accounting for abandonment of the undeveloped portion of the resource and technology transfer constraints. Inputs to COPM include the total resource potential, development and production costs, technology availability dates, technology penetration rates, abandonments rates, and reserves development rates. Outputs from the model include annual production, reserve additions, abandonments, development costs, operating costs, wages, and taxes. Reserves estimates were supplied by TORIS.

Total reserves were disaggregated into two categories, reserves available with implemented technology and incremental reserves available through the application of advanced technology. Appropriate model parameters were selected for each of these resource categories. The technology availability dates were set to 1993 for implemented technology and 2000 for advanced technology. Technology penetration rates were set at $75 \%$ in 12 years for implemented technology and $75 \%$ in 8 years for advanced technology, with the advanced technology case representing an aggressive technology transfer effort. Abandonment rates for both implemented and advanced technology were set to $3 \%$ of the undeveloped resource per year prior to technology availability and $1.5 \%$ per year after technology becomes available. Reserves development rates corresponded to typical field development profiles.

\section{F. ESTIMATION OF BENEFITS, COSTS, AND ECONOMIC IMPACTS}

The NPC study analyzed each reservoir from the perspective of the operator deciding whether to implement advanced oil recovery processes. The present study does the same in evaluating the economic viability of each reservoir. Thus, the benefits and costs to the operators are explicitly captured in the net cash flow calculations of individual projects. Under each of the various cases analyzed, projects yielding a net present value greater than the hurdle rate are assumed to be developed. This assumption is the basis for the projection of potential incremental production and reserves.

The incremental benefits and costs of EOR and ASR are estimated and reported on an annual as well as a cumulative basis. As previously discussed, reservoir timing is based on the estimated abandonment of the resource due to production decline, except for major reservoirs in which activity suggests earlier project start dates. Projects are phased in over a 5- to 10-year period to achieve full project development before this abandonment would occur. Annual estimates of benefits are based on the total economic resource produced in a given year. These annual values are reported for a twenty-seven year period, 1993 to 2020 . Cumulative benefits include the sum of the annual benefits plus any additional 
benefits that would accrue after 2020. The total length of time for the life of all projects varies considerably depending on the process, oil price, and tax treatment. The vast majority of cumulative production and benefits occur in the twenty-seven year period of focus in this study. The additional benefits that occur after 2020 are small relative to the total benefit, but important to the overall aggregate analysis.

\section{Benefits to State and Local Treasuries}

The benefits to Louisiana state and local treasuries from advanced oil recovery processes are the additional tax revenues attributable to implementation of the projects. These taxes include gross production taxes on oil and sales tax on equipment and material purchases, and corporate and personal income taxes on wages paid and operator profits. Evaluating these benefits under the current tax structure involves estimating the sum of these revenues as they apply to the development of the projects and the activities associated with the incremental production from improved recovery projects.

\section{Direct State Economic Effects}

The effect on the state's treasury is only one segment of the benefits of advanced oil recovery processes. The citizens of Louisiana also gain from the increased economic activity. Only the direct effects of the incremental activity are included, not the economic "multiplier" or indirect "ripple effect" activities (e.g., pipeline construction, retail sales, etc.). The direct impact on the state economy is defined as the sum of net revenues to the state and local treasuries (as presented above); royalties to individuals, corporations, and the state; expendable (intangible) drilling materials and services; and operating costs excluding injectant purchases. It is assumed that these funds flow predominantly to the state of Louisiana and its citizens.

Excluded from this state economic activity definition are cashflows that generally benefit citizens of other states in larger proportion than they benefit citizens of Louisiana. These include costs for tubular steel products installed in wells, injection and production equipment, purchased tertiary injectants, and other oil field materials typically manufactured out-of-state. To the extent that these goods are marketed by distributors in Louisiana, the direct benefits of these "retail pass-through" to the state are omitted from the estimates of direct state economic activity. Similarly, while it is recognized that a portion of tertiary injectants, especially chemicals, may originate in Louisiana (generating royalties, employment, taxes, 
and/or other economic activity), estimating these quantities is outside the scope of the present study. Other excluded items include Federal taxes, corporate debt service, and return on capital. While the citizens of Louisiana obviously benefit from these excluded elements as U.S. citizens, or as employees and stockholders of companies providing services, they share them with a much larger population. Thus, the definition used for direct economic effects understates the actual benefits to the state of Louisiana and its citizens.

The additional jobs, wages, and benefits created by advanced oil recovery are also estimated. Labor costs (wages and fringe benefits) are calculated by isolating the labor component of all major cost elements. Table III-7 summarizes the major cost elements and their respective labor and material components. Labor costs are converted into estimated numbers of jobs by dividing total wages by the average oil field wages (including benefits) reported by the U.S. Department of Labor. ${ }^{6}$ Sales tax revenues are calculated based on the materials component of these costs, assuming purchasers would pay the appropriate state tax on these goods.

\section{National Effects}

The Federal government benefits substantially, both directly and indirectly, from increased recovery of the Louisiana oil resource. Direct Federal taxes total $5 \%$ to $20 \%$ of the value of each barrel of oil recovered. Each additional barrel of Louisiana oil produced can replace a barrel of imported oil. Therefore, each dollar used to purchase the incremental barrels of oil that would otherwise pay for imports is, potentially, a dollar reduction in the trade deficit. ${ }^{7}$ To estimate the direct effects on import replacement (i.e., excluding multiplier effects), the gross revenue from the additional production is used. This measure of gross revenues incorporates direct in-state economic activity and excludes elements discussed in the section above. In this sense, the estimated increase in import replacement represents a more complete measurement of direct economic impacts, excluding multiplier effects. In addition, corporate and individual Federal income taxes are estimated to assess the direct effects of incremental Louisiana oil recovery on the Federal treasury.

6 U.S. Department of Labor, Bureau of Labor Statistics, 1985.

7 Although constraints caused by limited financial or personnel resources may result in delayed national benefits due to short-term deferral of projects in other states, the aggregate benefits to the nation should be achieved as all economic projects will ultimately be developed. 
Table III-7

\section{Labor and Materials as Percentage of Total Cost in EOR Projects}

\begin{tabular}{|c|c|c|c|}
\hline Investments & \% Labor & \% Materials & $\%$ Other \\
\hline Drilling Wells & 18 & 55 & 27 \\
\hline Work-overs & 15 & 63 & 22 \\
\hline Equipping Wells & 10 & 50 & 40 \\
\hline Pipe Installation & 10 & 50 & 40 \\
\hline Plant Installation & 16 & 46 & 38 \\
\hline \multicolumn{4}{|l|}{ Expenses } \\
\hline Field Operations & 33 & 58 & 9 \\
\hline Plant Operations & 38 & 57 & 5 \\
\hline Production Treating & 0 & 100 & 0 \\
\hline Overhead & 100 & 0 & 0 \\
\hline
\end{tabular}

Sources:

Investments

- $\quad$ Drilling and Work-overs

-- NPC, 1984

-- $\quad$ EIA, 1984

-- $\quad$ Professor Neil J. Dikeman, University of Oklahoma, 1986

- $\quad$ Equipping Wells

-- Industry estimate

- $\quad$ Pipe Installation

-- Industry estimate

- $\quad$ Plant Installation

-- $\quad$ Modern Cost Engineering Technologies, Herbert Popper, page 82-83

Expenses

- $\quad$ Field Operations

-- $\quad$ EIA, 1984

- $\quad$ Plant Operations

-- NPC, 1984

-- $\quad$ EIA, 1984 (power and chemicals)

- $\quad$ Production Treating

-- $\quad$ By definition

- Overhead

-- NPC, 1984 


\section{G. LIMITATIONS TO THE ANALYTICAL APPROACH}

The approach followed by this study has limitations that should be considered in utilizing its results. Some of these follow from the adoption of the NPC methodology; others result from the need to limit the scope of the present effort. It is also important to note that the results of this analysis are not forecasts of future oil recovery; they are estimates of the recovery potential of selected EOR and ASR processes.

The NPC approach, while the most credible and flexible methodology available, has certain distinct limitations. One problem is the reliance on averaged reservoir and fluid properties. Oil reservoirs are actually highly heterogeneous, with erratic properties throughout the field. The use of averaged properties belies the fact that portions of an individual reservoir could be highly attractive as an advanced technology oil recovery prospect even if the whole reservoir, on average, is not economic. Given the present methodology, reservoirs must be economically accepted or rejected as whole units, unless advanced geoscientific knowledge allows the reservoir to be evaluated in segments. The methodologies of both the present study and the NPC assume that the least favorable $20 \%$ of any reservoir would not be developed under EOR or ASR operations.

A second limitation is the use of regional costing algorithms. Although developed from the best available data and explicitly adjusted for variations in energy costs and specific reservoir characteristics, they do not reflect site-specific cost variations applicable to specific operators. Thus, this study does not necessarily use the actual costs of individual projects. To the extent that the average costs used understate or overstate the true project costs, the actual results will be higher or lower than the analysis estimates.

A third limitation is the use of simplified process performance models. While the models used in this project are extensively calibrated, they are designed to analyze large numbers of individual reservoirs quickly and simultaneously. Therefore, while they incorporate all the relevant reservoir engineering concepts, they are relatively simplified and generalized. In this simplified state, the models cannot be as accurate as highly detailed reservoir simulators in which very specific reservoir features and process designs may be evaluated (such as assessments used in the actual design of specific projects). The present study assumes these models are appropriate for aggregate analyses but not necessarily for individual reservoirs. Further, these models are explicitly designed to estimate only incremental recovery 
resulting from advanced oil recovery processes after the completion of conventional production operations. Laboratory and limited field data suggest that the application of some of these techniques before the economic limit of conventional recovery could yield more than the sum of conventional and advanced oil recovery, but this is not reflected in the models.

An additional limitation arises from the methodological convention of "constant price" analysis. The use of this convention is consistent with the NPC's original nationwide study, conducted during a period of relatively stable, rising oil prices, and differentiates the effect of oil price from other effects. It can, however, cause a distortion, especially in times of declining or radically changing oil prices. The "hidden" assumption of this convention is that each of the respective oil prices analyzed must be attained by the time (and be expected to continue at that level after) the decision to commit specific reservoirs to enhanced recovery or advanced mobile oil recovery operations is made. This decision is generally made several years before the reservoir's final, actual economic limit is reached under conventional technology. To the extent this condition is not met, existing wells reaching their economic limits at lower prices will be shut-in and abandoned, making them unavailable for use in advanced oil recovery projects, as assumed. The economic model assumes that all existing wells will be utilized in future operations, although older wells may require workovers. Should "premature" abandonments occur, these wells would need to be redrilled, resulting in additional incremental investment not included in this analysis (although necessary workovers are included in the assumed cost). Redrilling would result in substantially increased costs and would thus increase the minimum oil price at which advanced oil recovery processes are profitable for certain reservoirs. The net effect of this analytic convention could overstate the economic reserves and production and the corresponding economic benefits. Under these conditions, the "constant price" convention introduces an optimistic bias to the present analysis.

Finally, the analysis follows the NPC approach, which assumed that project operation would be conducted by an integrated major oil company. This approach, in most cases, presents the least favorable corporate tax treatment for investments and revenues from advanced oil recovery projects and assumes a relatively high overhead on operations. Independent producers operate with a different corporate structure, tax situation, and overhead rate. Because most costs used in this analysis are not affected by total project size and some non-integrated operators would enjoy more favorable tax treatment, smaller independent producers should receive the same benefit as a major oil company from application of advanced oil recovery processes, possibly even at lower oil prices than projected in this evaluation. 
None of the above limitations invalidate the results of this analysis. Given the uncertainty of the size and combinations of the optimistic and pessimistic biases introduced by these limitations, it is assumed that the approach is valid and the resulting projections are reasonable. To avoid misinterpretation of particular reservoirs, and to respect the confidence in which some project and reservoir data were obtained, no reservoir specific date is provided in the reports generated from this analysis. However, in cases where the results seemed unusual, the modeling specifications for specific reservoirs were examined in-depth to ensure the validity of the results. 


\section{INCREASED RECOVERY FROM THE KNOWN REMAINING OIL RESOURCE IN LOUISIANA UNDER IMPLEMENTED TECHNOLOGY}

\section{A. INTRODUCTION}

This chapter discusses the post-conventional reserve additions and potential economic impacts attributable to the application of currently available (implemented technology) oil recovery methods in analyzed Louisiana reservoirs. Chapter $\mathrm{V}$ discusses the incremental reserves and benefits under advanced technology methods attainable through RD\&D. The TORIS reservoirs analyzed in this study are individually modeled to evaluate their potential for incremental production and reserves by tertiary and advanced secondary recovery techniques under a variety of oil prices and economic conditions. Some key technical assumptions and considerations regarding the analysis in this report are:

- The incremental production and reserves refers to future recovery estimated for the analyzed EOR and ASR techniques. Such production and reserves are above and beyond the recovery attainable by primary and secondary recovery techniques.

- Both light oil (API $>20$ degree) and heavy oil (API $\leq 20$ degree) resources are considered in this analysis.

- All EOR and ASR recovery potential evaluated in this report reflect future new projects only, and they do not include incremental reserves from existing (ongoing) EOR and ASR projects. However, the expansion to the ongoing projects, if technically and economically feasible, are evaluated as part of future new projects in this report.

All reservoirs are screened for technical criteria and are analyzed in detail using the process performance and economic models described in Chapter III. The results are based on the evaluation of 342 Louisiana reservoirs for their EOR and ASR potential. No effort is made to extrapolate the results of this analysis to the rest of the reservoirs making up the nation's resource.

\section{B. RECOVERY OF THE REMAINING IMMOBILE OIL RESOURCE}

\section{Production and Reserves}

Over the price range analyzed, EOR processes (carbon dioxide-miscible, chemical, and thermal) could stimulate from 126 million to over 320 million barrels of incremental reserves using implemented 
technology. This potential represents an increase of between $23 \%$ and $60 \%$ of Louisiana's 1991 onshore proved reserves (535 million barrels). As the oil price rises above $\$ 24 / \mathrm{B}$, EOR processes could become increasingly prolific, and substantial incremental reserves could become economically attainable (Figure IV-1A and Table IV-1A). The 170 million barrels of incremental EOR reserves at $\$ 24 / \mathrm{B}$ could increase by nearly 80 million barrels, almost $50 \%$, with a $\$ 4 / \mathrm{B}$ increase in the oil price. At an oil price of $\$ 36 / \mathrm{B}$, EOR techniques could generate total incremental reserves of over 320 million barrels.

Among the EOR processes considered in this analysis, thermal processes (steam and in situ combustion) could generate the largest incremental reserves at all oil prices. These additions are relatively insensitive to price increases, remaining at 125 million to 160 million barrels of incremental oil over the analyzed oil price range. At an oil price of $\$ 16 / \mathrm{B}$, thermal processes could account for all incremental EOR reserves. At $\$ 20 / \mathrm{B}$ and $\$ 24 / \mathrm{B}$, thermal processes could stimulate $99 \%$ and $83 \%$ of the estimated EOR reserve additions, respectively. At higher prices, other EOR processes, particularly $\mathrm{CO}_{2}$-miscible flooding, could become more attractive. At $\$ 36 / \mathrm{B}$, thermal processes could still generate $50 \%$ of the total incremental reserves from EOR in the analyzed Louisiana reservoirs. Given oil prices at or above $\$ 24 / \mathrm{B}$, thermal processes could recover over 142 million barrels, a resource equivalent to $27 \%$ of Louisiana's 1991 onshore proved reserves.

The recovery potential of other EOR processes is more limited in Louisiana. $\mathrm{CO}_{2}$-miscible flooding exhibits significant potential at higher oil prices. As shown in Figure IV-1A and Table IV-1A, $\mathrm{CO}_{2}$-miscible flooding could stimulate 90 million to 150 million barrels of incremental reserves over the oil price range from $\$ 28$ to $\$ 36 / \mathrm{B}$. At lower oil prices, however, $\mathrm{CO}_{2}$-miscible flooding potential under implemented technology would be small due to high $\mathrm{CO}_{2}$ costs; a threshold price of at least $\$ 28 / \mathrm{B}$ would be necessary to make $\mathrm{CO}_{2}$-miscible flooding a significant contributor to EOR potential in the analyzed Louisiana reservoirs under implemented technology. The application of chemical flooding would be also limited due to the high costs of chemicals, but chemical processes could still generate almost $10 \%$ of the incremental EOR reserves at prices in the $\$ 24 / \mathrm{B}$ to $\$ 32 / \mathrm{B}$ range.

Table IV-1B shows the number of EOR projects that could be implemented at different oil prices. Of the analyzed Louisiana reservoirs, only 5\% would be economic to develop with current EOR technology at oil prices of $\$ 36 / \mathrm{B}$ or below. $\mathrm{CO}_{2}$-miscible floods could account for $37 \%$ to $42 \%$ of the EOR projects considered economic at oil prices above $\$ 24 / \mathrm{B}$, and chemical processes could account for $15 \%$ to $25 \%$ of the economic projects. However, at oil prices of $\$ 20 / \mathrm{B}$ or less, thermal projects could 
Table IV-1A

Incremental Reserves from EOR by Process

Implemented Technology

(Million Barrels)

\begin{tabular}{|c|c|c|c|c|}
\hline 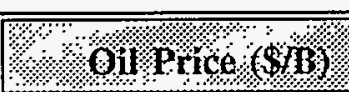 & \%O, niscuble: & Vytrinical & Hernal & Total \\
\hline$\$ 16$ & 0 & 0 & 126 & 126 \\
\hline$\$ 20$ & 2 & 0 & 137 & 139 \\
\hline$\$ 24$ & 14 & 15 & 142 & 171 \\
\hline$\$ 28$ & 87 & 20 & 143 & 250 \\
\hline$\$ 32$ & 96 & 20 & 146 & 262 \\
\hline$\$ 36$ & 149 & 13 & 161 & 323 \\
\hline
\end{tabular}

Table IV-1B

Estimated Number of Economic EOR Projects by Process Implemented Technology

(Project Counts)

\begin{tabular}{|c|c|c|c|c|}
\hline 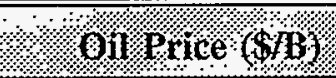 & $\mathrm{CO}_{2} \mathrm{Miscinile}$ & Cheninieal & MHennalt: & $1 \%$ Yoral \\
\hline$\$ 16$ & 0 & 0 & 3 & 3 \\
\hline$\$ 20$ & 1 & 0 & 5 & 6 \\
\hline$\$ 24$ & 4 & 3 & 6 & 13 \\
\hline$\$ 28$ & 6 & 4 & 6 & 16 \\
\hline$\$ 32$ & 7 & 4 & 6 & 17 \\
\hline$\$ 36$ & 8 & 3 & 8 & 19 \\
\hline
\end{tabular}


account for all but one of the economic Louisiana EOR projects. In most cases, the economic projects are in the large reservoirs, but size alone is not a major determinant of EOR economics.

The timing of project initiation in each reservoir that is economic at a specific price is scheduled according to that reservoir's projected conventional decline rate. The annual incremental production resulting from EOR is determined by phasing in economic projects based on the demonstrated economic limit of conventional production (as well as other constraints) as discussed in Chapter III. Figure IV-1B shows the expected annual production from all EOR processes for oil prices of $\$ 16 / \mathrm{B}$ and $\$ 32 / \mathrm{B}$. At $\$ 16 / \mathrm{B}$, EOR production generally stays within a range of 1 million to 4 million barrels per year, with a gradual increase beyond the year 2000 . The $\$ 32 / \mathrm{B}$ annual production curve peaks at over 10 million barrels per year in the year 2001, falling to about 5 million barrels per year by the year 2020 .

\section{Increases in State and Local Revenues}

EOR production could also increase state and local revenues through production taxes, corporate and personal income taxes, and sales taxes on purchased materials used in the projects. The estimated revenues are generated directly from oil production or operations in the analyzed Louisiana reservoirs. State and local revenues generated over the life of the EOR projects could vary considerably with oil prices, as shown in Figure IV-2. Despite a state tax incentive for EOR project (forgiveness of the 12.5\% severance tax for qualified projects), the most significant portion of these revenues could result from production taxes. At $\$ 20 / \mathrm{B}, \$ 350$ million in incremental state revenues could be generated, with production taxes contributing $75 \%$ of the total. Implemented EOR activities at a $\$ 24 / B$ oil price could stimulate production tax revenues of over $\$ 350$ million plus $\$ 140$ million in other tax receipts. At $\$ 28 / \mathrm{B}$, additional revenues could total nearly $\$ 750$ million, while at the highest price case of $\$ 36 / \mathrm{B}, \$ 1.2$ billion of additional state and local revenues could be generated.

\section{Effects on the State Economy}

In addition to the incremental state and local revenues, EOR activity would benefit Louisiana by increasing economic activity and by creating new jobs. The effects of EOR on the state economy are estimated conservatively: (1) only direct effects are included (i.e., no economic multiplier); and (2) the direct effects are limited to benefits believed to accrue predominantly to the state of Louisiana and its citizens. Only intangible drilling costs, royalties, state and local taxes, and operating costs, exclusive of 
Figure IV-1

Reserves and Production Response from EOR Techniques Implemented Technology

A) Incremental Reserves by EOR Process

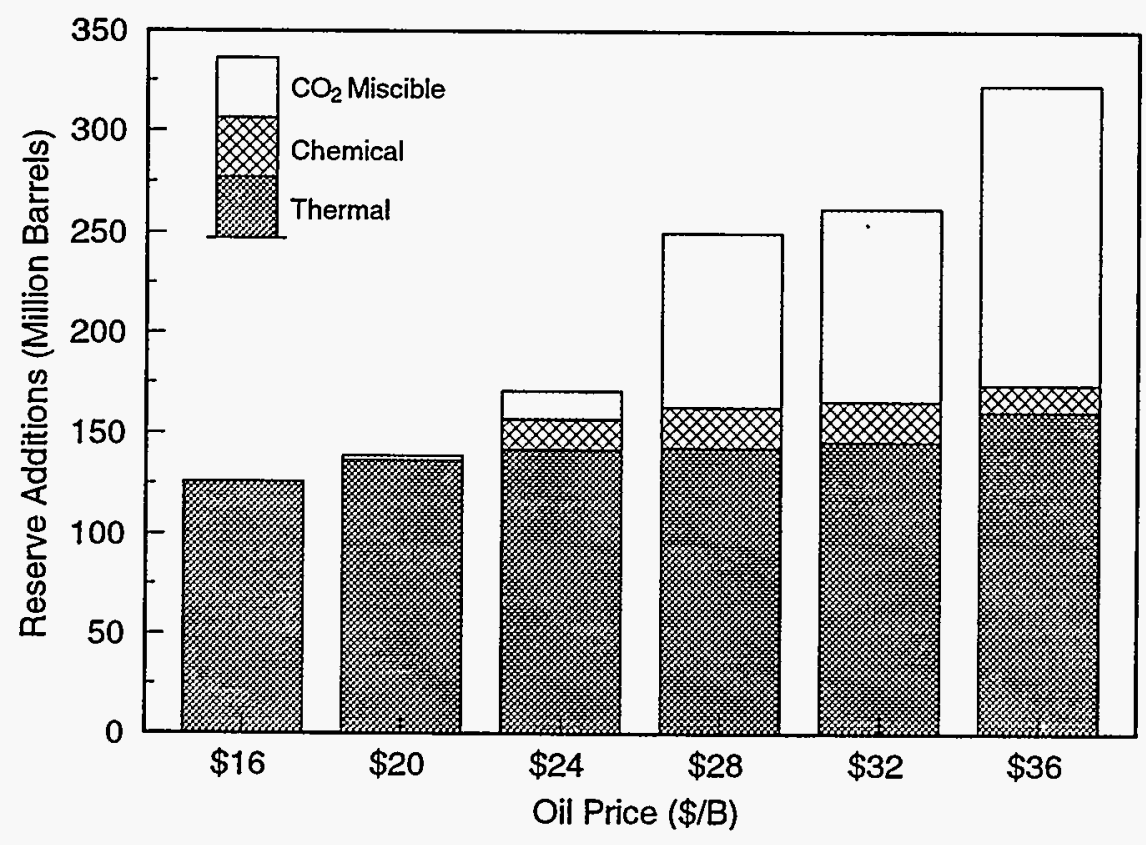

B) Annual Production from EOR Reserves

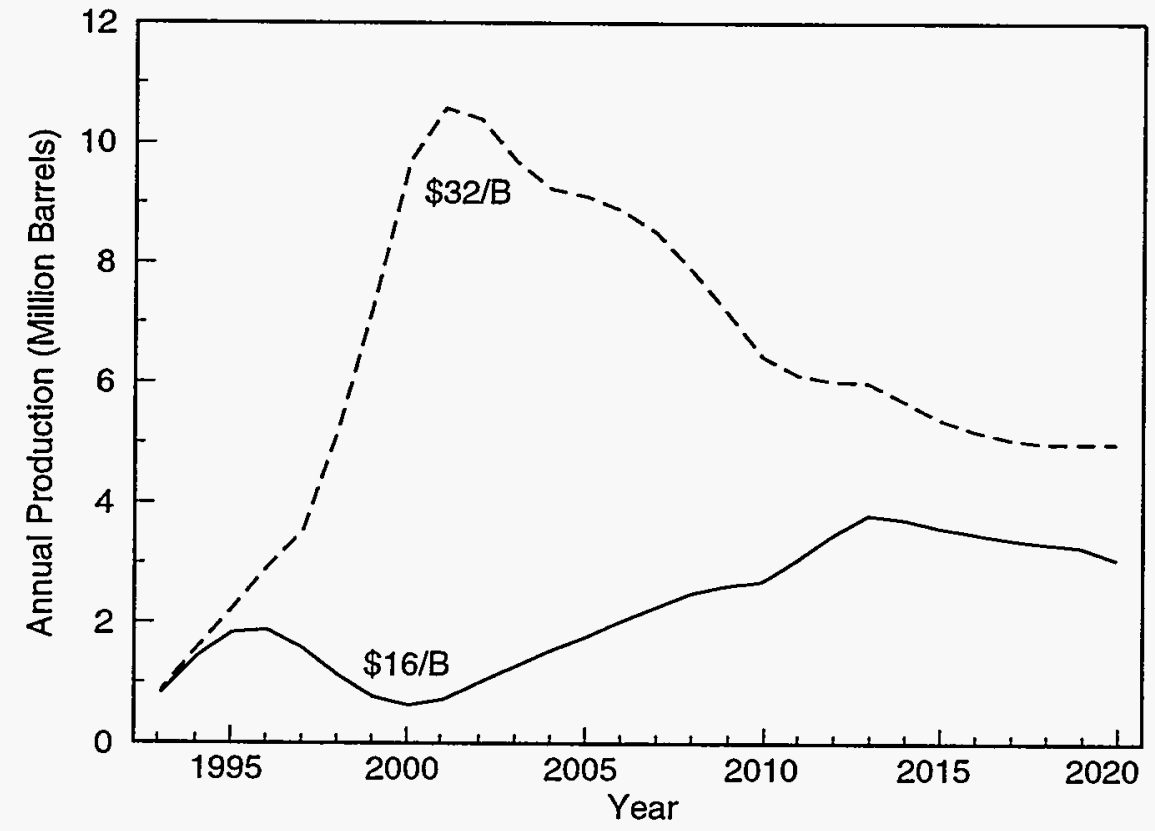


Figure IV-2

\section{Direct State and Local Revenues from EOR Production Implemented Technology}

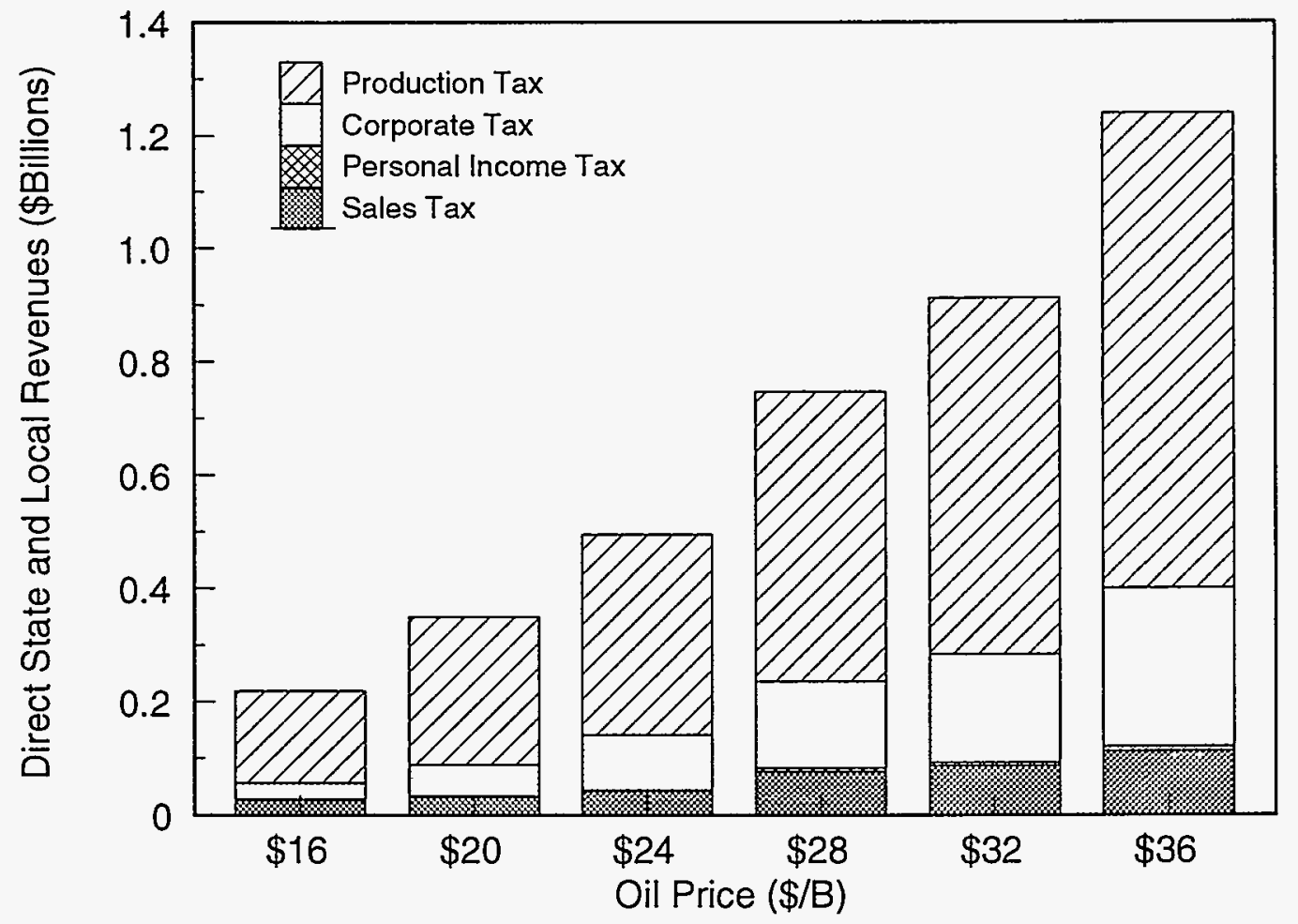

purchased injectants, are included in the calculation of state economic activity. Tubular steel products, injection and production equipment, purchased EOR injectants, corporate return on capital, and Federal taxes are all excluded from this definition of state economic activity. Royalties paid to the Federal government (i.e., from production on Federal lands) may cause the royalty portion of state economic activity to be overstated. While the excluded elements undoubtedly aid Louisiana's citizens to some degree, a substantial portion of the benefits will be enjoyed by citizens of other states. However, to the extent that the local manufacturing or retail sales of these items provides economic benefits within Louisiana, injectants produced or manufactured in Louisiana are employed, or economic "multipliers" are in effect, the calculated economic impacts are understated.

Figure IV-3 displays the total direct economic gains for the state over the oil price range analyzed. Operating costs could account for about $52 \%$ to $60 \%$ of these economic effects; state taxes could represent around $20 \%$; intangible investment could be about $1 \%$ to $2 \%$, and royalties about $20 \%$ to $25 \%$ of the total. At $\$ 16 / \mathrm{B}$, incremental benefits to the state economy would exceed $\$ 1.0$ billion. EOR activities could 
substantially increase economic activity at oil prices above $\$ 24 / \mathrm{B} ; \$ 4.1$ billion and $\$ 4.8$ billion could be generated at the oil prices of $\$ 28 / \mathrm{B}$ and $\$ 32 / \mathrm{B}$, respectively. At the highest oil price considered, $\$ 36 / \mathrm{B}$, over $\$ 6.5$ billion of statewide direct economic activity could be stimulated by EOR projects.

Successful EOR projects could create or maintain a substantial number of jobs statewide, as shown in Figure IV-4. At $\$ 16 / \mathrm{B}$, EOR projects could create or maintain 108 jobs per year in the year 2013. The number of jobs per year at $\$ 32 / \mathrm{B}$ could peak at over 1,140 by the year 2000 due to implemented technology EOR. Total incremental annual wages paid could reach over $\$ 50$ million.

\section{Effects on the National Economy}

Increased oil recovery from EOR in Louisiana would benefit the nation as a whole. National benefits would accrue in several ways: replacement of oil imports, increased Federal corporate and personal income tax revenues, and a reduced trade deficit. Of course, the addition of as many as 323 million barrels of incremental reserves in Louisiana would expand the nation's proved reserve base. As each additional barrel of domestic oil production replaces a barrel of imported oil, the nation's energy security and independence would be enhanced through the implementation of EOR in Louisiana.

EOR activity in Louisiana contributes to the Federal treasury through personal and corporate income taxes. As shown in Figure IV-5A, increases in Federal revenues attributable to EOR could range from $\$ 120$ million at $\$ 16 / \mathrm{B}$ to $\$ 1.2$ billion at $\$ 36 / \mathrm{B}$, over the life of the projects. Corporate income taxes would account for between $80 \%$ and $90 \%$ of this total depending on the oil price, and personal income taxes would make up the remainder. During the initial implementation phases of many EOR projects, negative Federal revenues could result from taxable losses as well as from the Federal EOR Tax Credit, both of which are assumed to be used as offsets to Federal income tax liabilities from other profitable activities. Federal corporate income taxes are evaluated at a marginal tax rate of $34 \%$.

As imports are replaced by increased production due to EOR in Louisiana, the foreign trade deficit could be reduced by the value of the avoided imports (reserves multiplied by the effective wellhead price of oil). Imports avoided, therefore, estimates the amount of money that could be circulated through the domestic economy rather than flowing to oil exporting countries. At oil prices from $\$ 16 / \mathrm{B}$ to $\$ 24 / \mathrm{B}$, EOR production could result in $\$ 1.9$ billion to $\$ 3.9$ billion in imports avoided. At higher oil prices, the gains could be more significant. Between $\$ 6.8$ billion and $\$ 11$ billion of avoided imports could be generated by implemented technology EOR activity at oil prices ranging from $\$ 28 / \mathrm{B}$ to $\$ 36 / \mathrm{B}$ (Figure IV-5B). 
Figure IV-3

\section{Direct State Economic Activity* \\ From EOR Production \\ Implemented Technology}

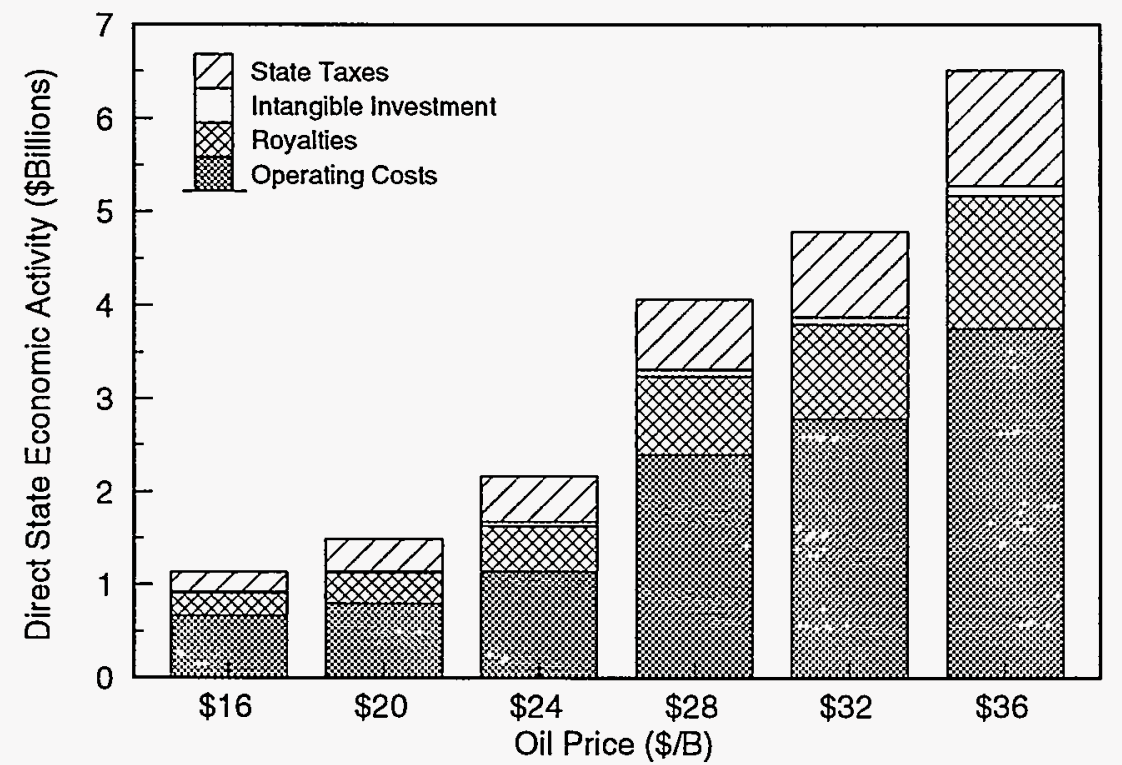

- To the extent that royalties go to the Federal government (i.e. fields on Federal lands), royalties as a portıon of state economic activity may be overstated.

Figure IV-4

\section{Jobs and Wages from EOR Production} Implemented Technology

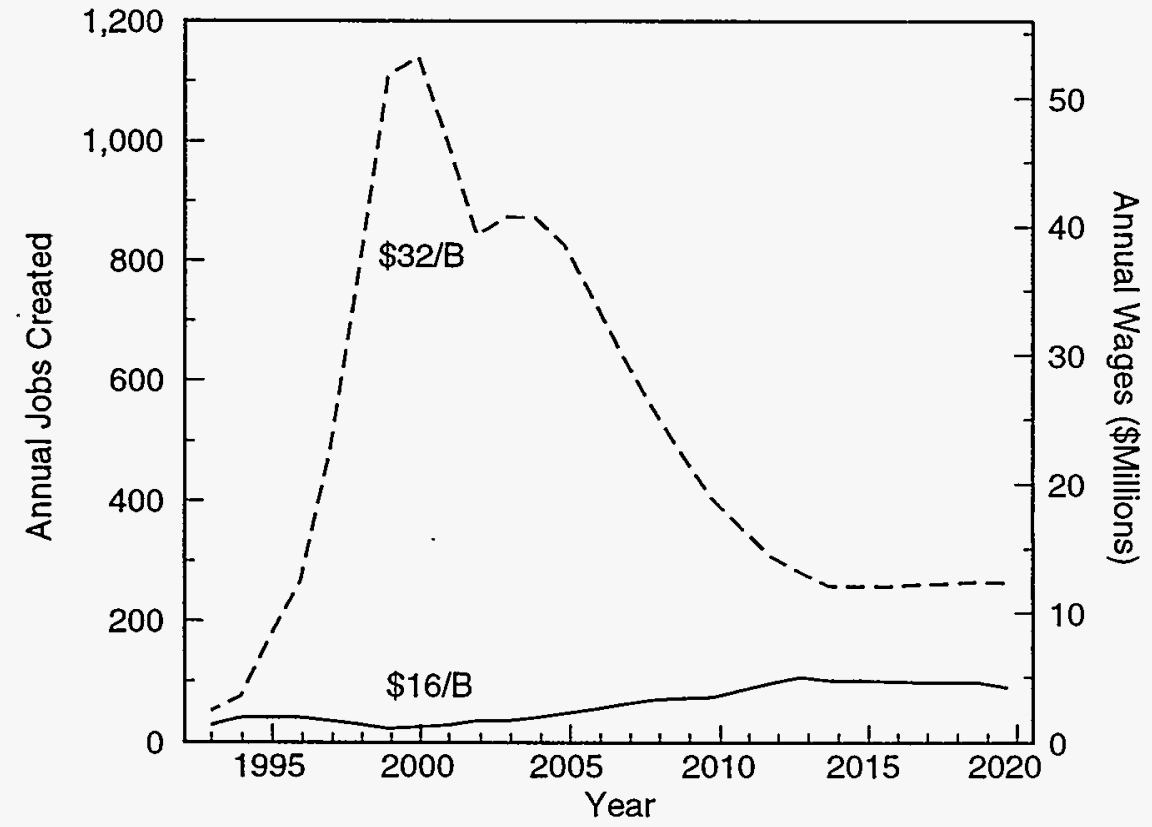


Figure IV-5

National Impact of EOR Production

Implemented Technology

A) Direct Federal Revenues

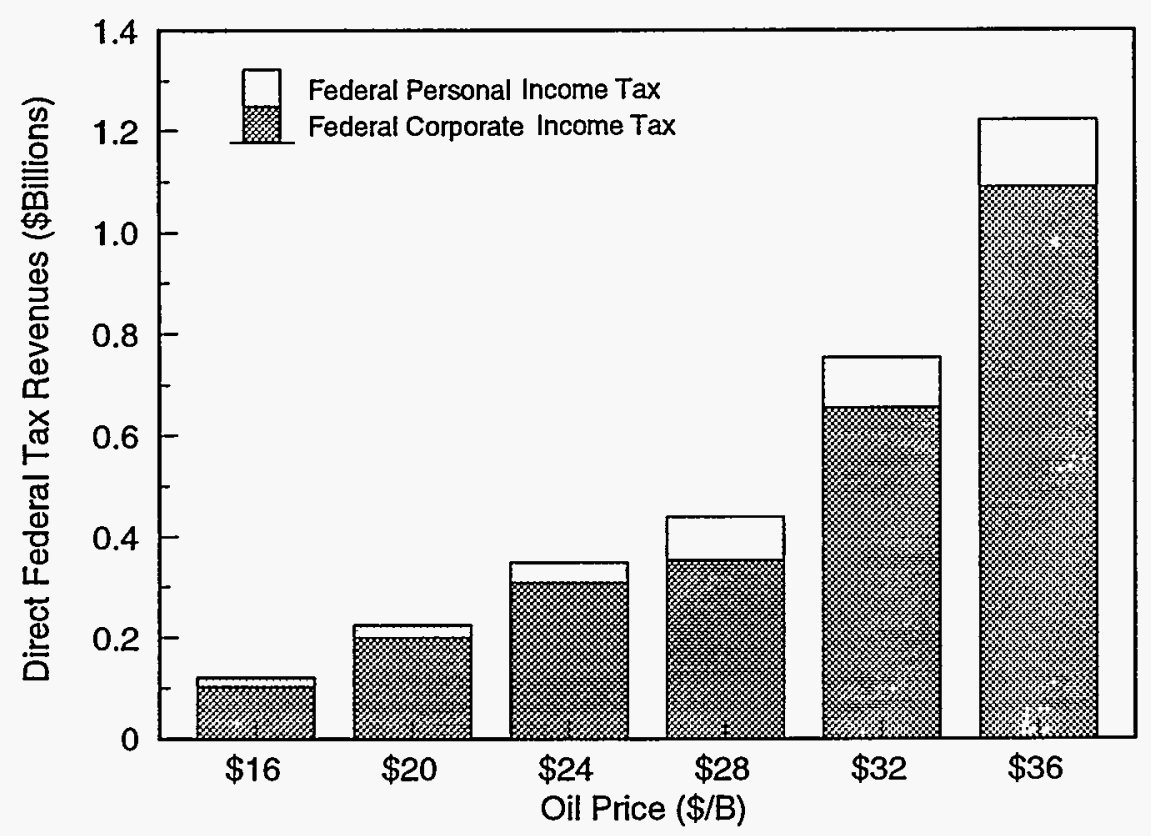

B) Imports Avoided*

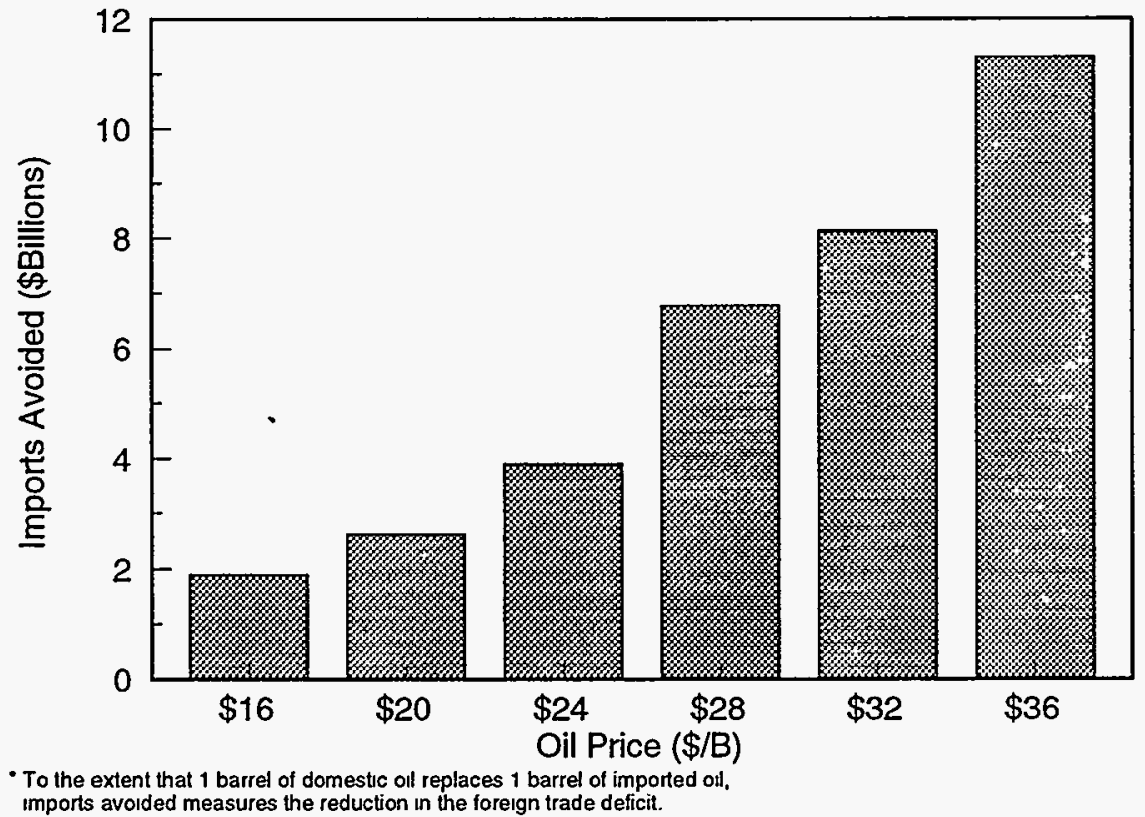




\section{RECOVERY OF THE REMAINING MOBILE OIL RESOURCE}

This section will discuss the application of currently available advanced secondary recovery (ASR) technology in the analyzed Louisiana reservoirs. These two distinct recovery technologies, EOR and ASR, have been addressed separately to illustrate the potential benefits of each. However, since the resource target of these two technologies is different, both could be simultaneously implemented, and the results would be independent and additive. Given the potential synergies in the simultaneous employment of EOR and ASR technologies, reserve additions and economic benefits could be even greater than the sum of the two.

\section{Production and Reserves}

Depending on the oil price, ASR processes applied in the reservoirs analyzed could stimulate 770 million to 900 million barrels of incremental reserves to current proved reserves in Louisiana (Figure IV6A). ASR is less costly to implement than EOR recovery processes, and therefore, incremental ASR reserves are less sensitive to changes in the oil price. At $\$ 20 / \mathrm{B}$, incremental ASR reserves could amount to over 820 million barrels, nearly $92 \%$ of the oil economically producible at $\$ 36 / \mathrm{B}$.

This analysis evaluates five advanced secondary recovery processes: polymer flooding, profile modification, infill drilling, and combinations of infill drilling with polymer flooding or profile modification. Polymer flooding and profile modification projects are grouped together in the following discussion, as are infill drilling combinations with polymer flooding and profile modification. As shown in Figure IV-6A and Table IV-2A, infill drilling, both by itself and in combination with the other processes, could play a predominant role in ASR recovery, accounting for essentially all of the incremental reserves at all prices. At $\$ 16 / \mathrm{B}$, the combination processes could contribute 425 million barrels of incremental reserves (55\% of the total potential), while infill drilling alone could contribute 331 million barrels ( $43 \%$ of the total potential). As oil prices increase, infill drilling becomes slightly more economical since revenues increase along with oil prices. At $\$ 28 / \mathrm{B}$, infill drilling by itself could contribute $45 \%$ of the 846 million barrels of potential incremental reserves, compared to the $54 \%$ contribution by the combination processes. At the highest oil price evaluated $(\$ 36 / \mathrm{B})$, infill drilling by itself and the combination processes make nearly equal contributions (47\% and $51 \%$, respectively) to 
incremental ASR reserves. Polymer flooding and profile modification techniques, applied alone, could contribute 11 million to 12 million barrels of incremental reserves across all oil prices considered in this analysis. Table IV-2B shows the number of projects expected to be economic at each price for individual recovery methods. At all prices above $\$ 16 / \mathrm{B}$, the number of economic projects in each category remains relatively constant.

Figure IV-6B displays the expected annual production from all ASR processes for oil prices of $\$ 16 / \mathrm{B}$ and $\$ 32 / \mathrm{B}$. Timing of the ASR potential has been carried out according to the methodology discussed in Chapter III. Annual ASR production at both prices is highest in 2015. The peak at $\$ 16 / \mathrm{B}$ is about 25 million barrels per year, and the peak at $\$ 32 / \mathrm{B}$ is about 28 million barrels per year. To put the potential contribution of ASR production into perspective, 30 million barrels per year is equivalent to almost $20 \%$ of current Louisiana annual production.

ASR projects are undertaken as reservoirs reach their economic limit. In this study, ASR projects are assigned initiation dates as a function of rig availability and technology transfer; projects are therefore phased in over time and some fields are abandoned before ASR is implemented. This abandonment, which is reflected in the annual production, is on the order of $25 \%$ of the potential resource over the life of the economic projects. Accelerated technology transfer can reduce this loss.

\section{Increases in State and Local Revenues}

Figure IV-7 shows the expected growth in state revenues from ASR production and the proportional contributions of production taxes, corporate and personal income taxes, and sales taxes to the total. Production tax receipts could account for the largest portion of total state revenues from ASR over all prices considered. Production taxes could generate $\$ 680$ million of the $\$ 1.2$ billion in additional direct state revenues from ASR activities at $\$ 16 / \mathrm{B}$. At moderate oil prices ( $\$ 20 / \mathrm{B}$ to $\$ 28 / \mathrm{B}$ ), nearly $\$ 1.7$ billion to $\$ 2.4$ billion in direct state and local revenues could be stimulated by implemented technology ASR, $55 \%$ of which would be due to production taxes. At $\$ 36 / \mathrm{B}, \$ 3.2$ billion could be generated for the state through ASR activities, with $54 \%$ of that amount from production taxes. 
Table IV-2A

\section{Incremental Reserves from ASR by Process Implemented Technology \\ (Million Barrels)}

\begin{tabular}{|c|c|c|c|c|}
\hline Oit. & 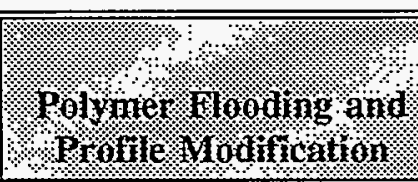 & Infill Drilling & $\begin{array}{l}\text { Inful oriling and } \\
\text { Poumer }\end{array}$ & (2) \\
\hline$\$ 16$ & 11 & 331 & 425 & 767 \\
\hline$\$ 20$ & 12 & 376 & 433 & 821 \\
\hline$\$ 24$ & 11 & 385 & 443 & 839 \\
\hline$\$ 28$ & 11 & 378 & 457 & 846 \\
\hline$\$ 32$ & 11 & 384 & 457 & 852 \\
\hline$\$ 36$ & 12 & 423 & 458 & 893 \\
\hline
\end{tabular}

Table IV-2B

Estimated Number of Economic ASR Projects by Process Implemented Technology

(Project Counts)

\begin{tabular}{|c|c|c|c|c|}
\hline Oit pries & 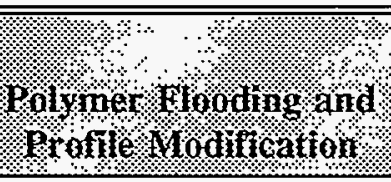 & Intull & 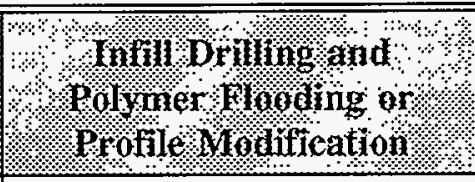 & $\begin{array}{l}\text { क } \\
\text { Totals }\end{array}$ \\
\hline$\$ 16$ & 12 & 43 & 31 & 86 \\
\hline$\$ 20$ & 16 & 46 & 34 & 96 \\
\hline$\$ 24$ & 15 & 50 & 37 & 102 \\
\hline$\$ 28$ & 16 & 52 & 38 & 106 \\
\hline$\$ 32$ & 18 & 55 & 38 & 111 \\
\hline$\$ 36$ & 17 & 59 & 38 & 114 \\
\hline
\end{tabular}


Figure IV-6

\section{Reserves and Production Response from ASR Techniques}

\section{Implemented Technology}

A) Incremental Reserves by ASR Process

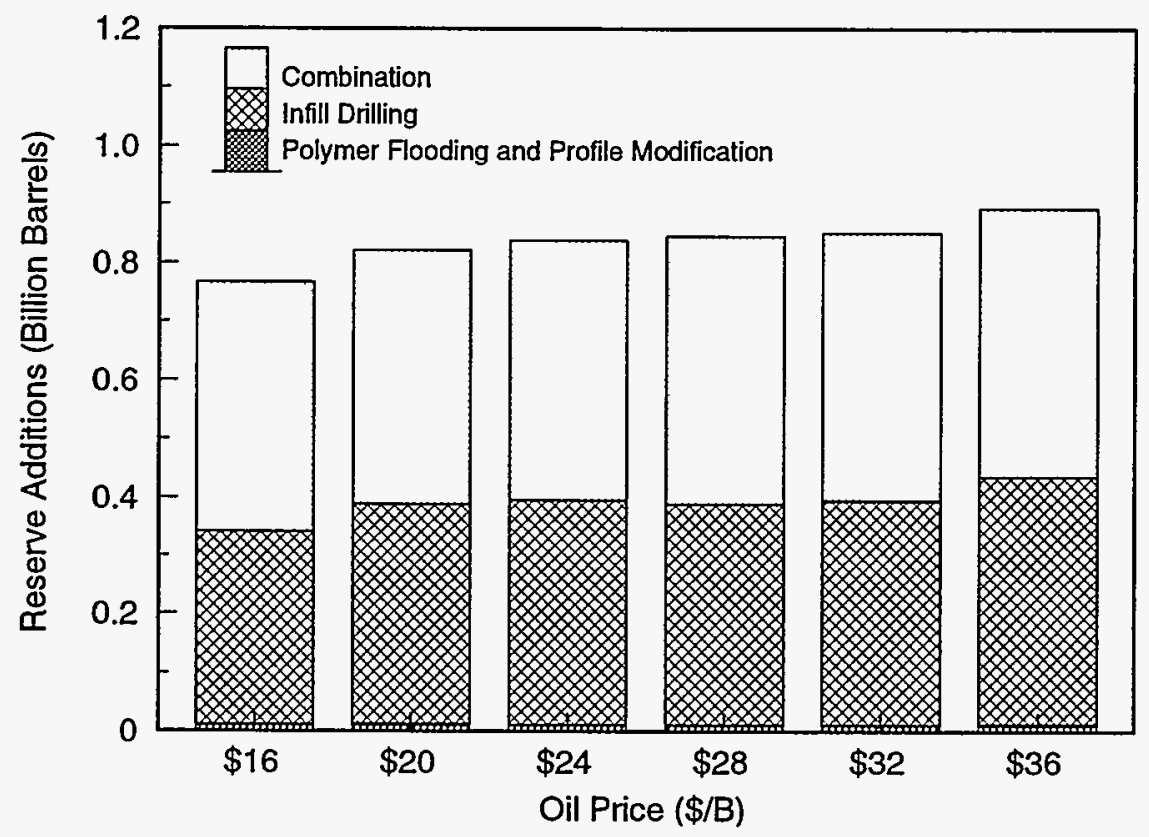

B) Annual Production from ASR Reserves

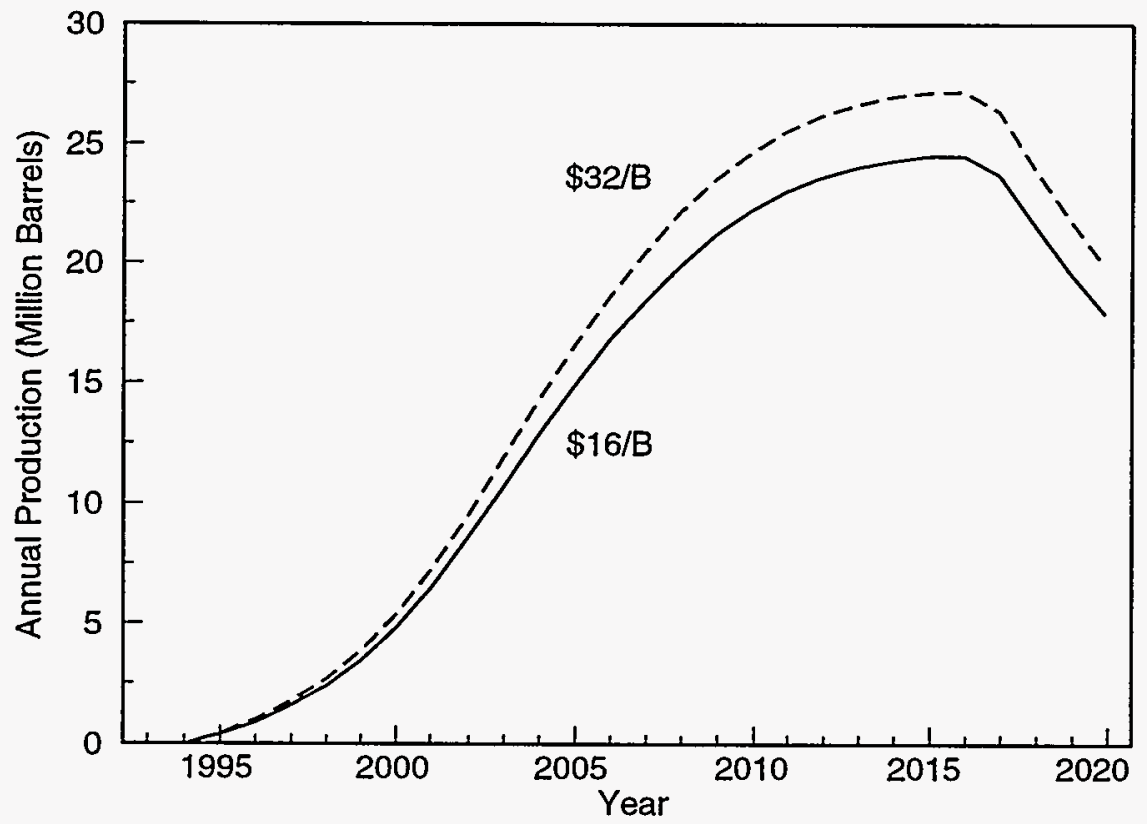


Figure IV-7

\section{Direct State and Local Revenues from ASR Production Implemented Technology}

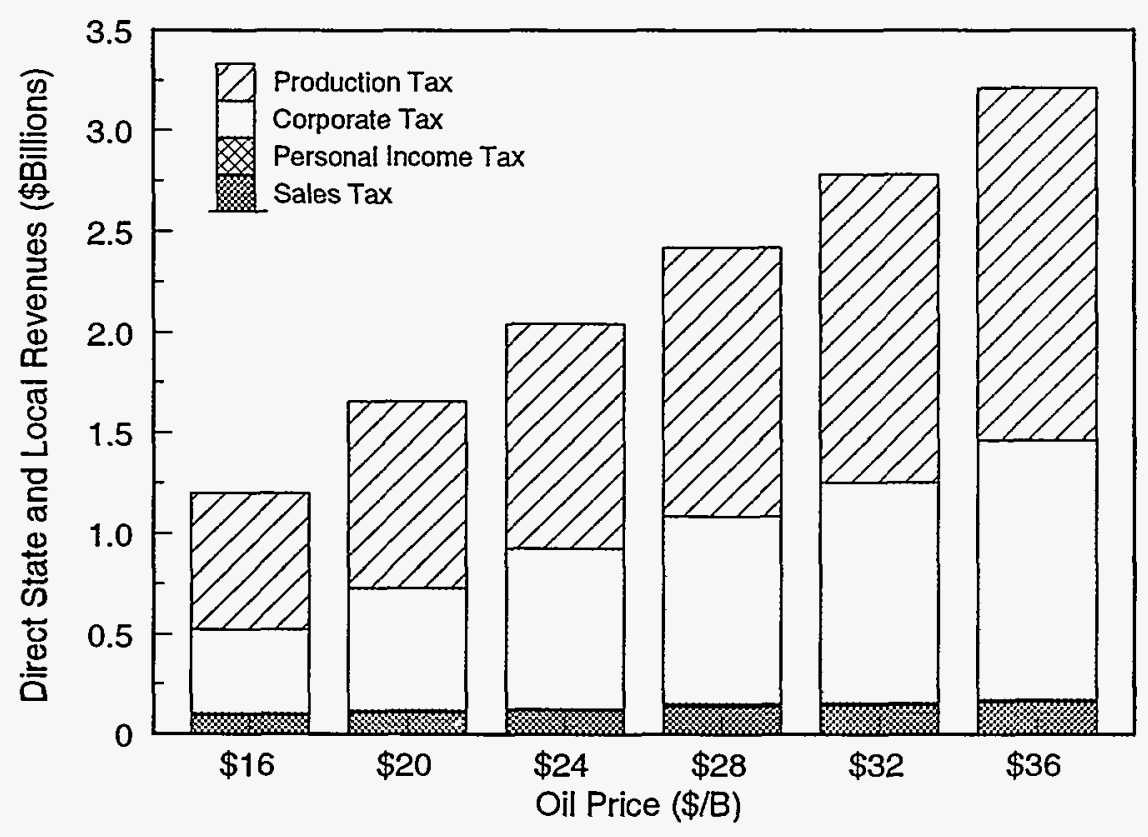

\section{Effects on the State Economy}

Figure IV-8 displays the total state economic activity associated with potential ASR production. Total state economic activity from the processes could range from about $\$ 7$ billion at $\$ 16 / \mathrm{B}$ to about $\$ 17$ billion at $\$ 36 / \mathrm{B}$. Intangible investments are the largest component of these increases in state economic activity, accounting for $40 \%$ of the total. These costs could approach $\$ 6.5$ billion at the $\$ 36 / \mathrm{B}$ oil price. Operating costs and royalties would be the next largest components of increased economic activity, each averaging a little over $20 \%$ of the total activity across all oil prices. State taxes would contribute the remaining $15 \%$ to $20 \%$. At moderate ( $\$ 20 / \mathrm{B}$ to $\$ 28 / \mathrm{B}$ ) oil prices, implemented technology ASR could generate $\$ 9.3$ billion to $\$ 13$ billion of additional direct economic activity in the state of Louisiana.

The implementation of ASR techniques could significantly increase employment in Louisiana. Figure IV-9 displays the annual number of jobs that could be created or maintained by ASR projects. The annual trend in jobs closely matches the production trend for ASR. At an oil price of $\$ 16 / \mathrm{B}$, job additions could peak in the year 2016 at nearly 730 per year. At $\$ 32 / \mathrm{B}$, the number of jobs created or maintained could peak in the year 2016 at 1,160 per year. At this price, almost $\$ 55$ million in wages could be paid in the peak employment year. 
Figure IV-8

\section{Direct State Economic Activity* From ASR Production Implemented Technology}

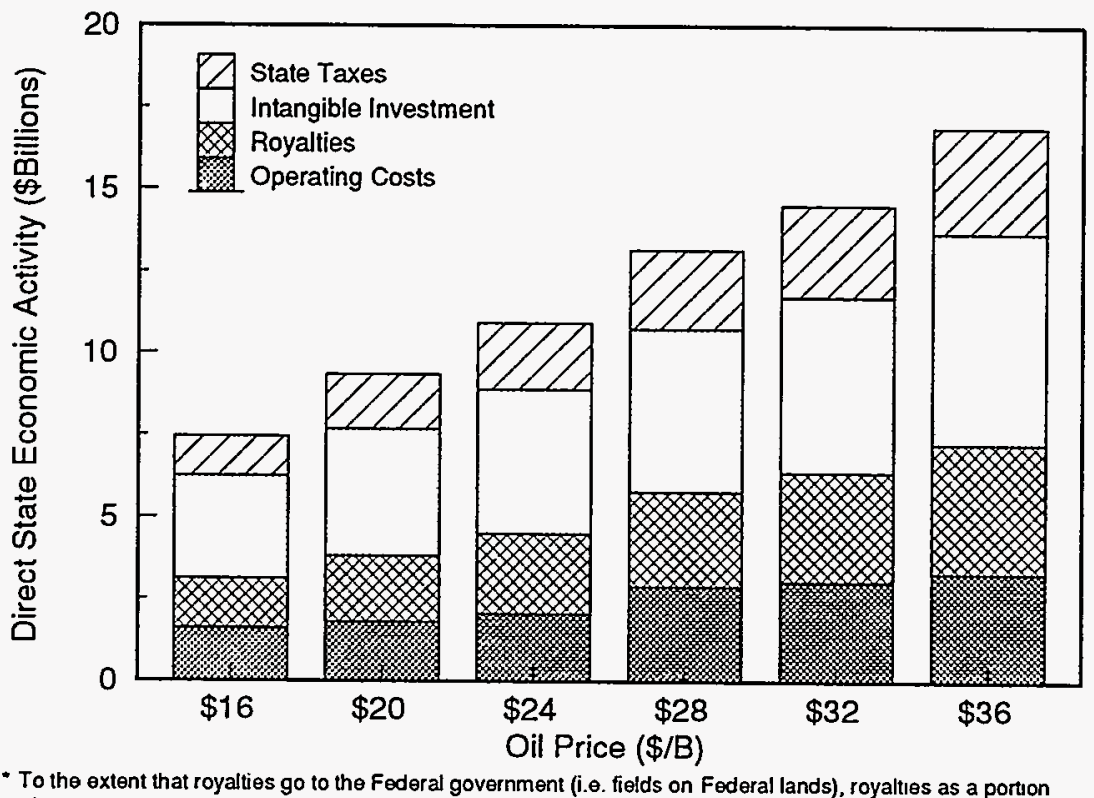
of state economic actuvity may be overstated

Figure IV-9

\section{Jobs and Wages from ASR Production} Implemented Technology

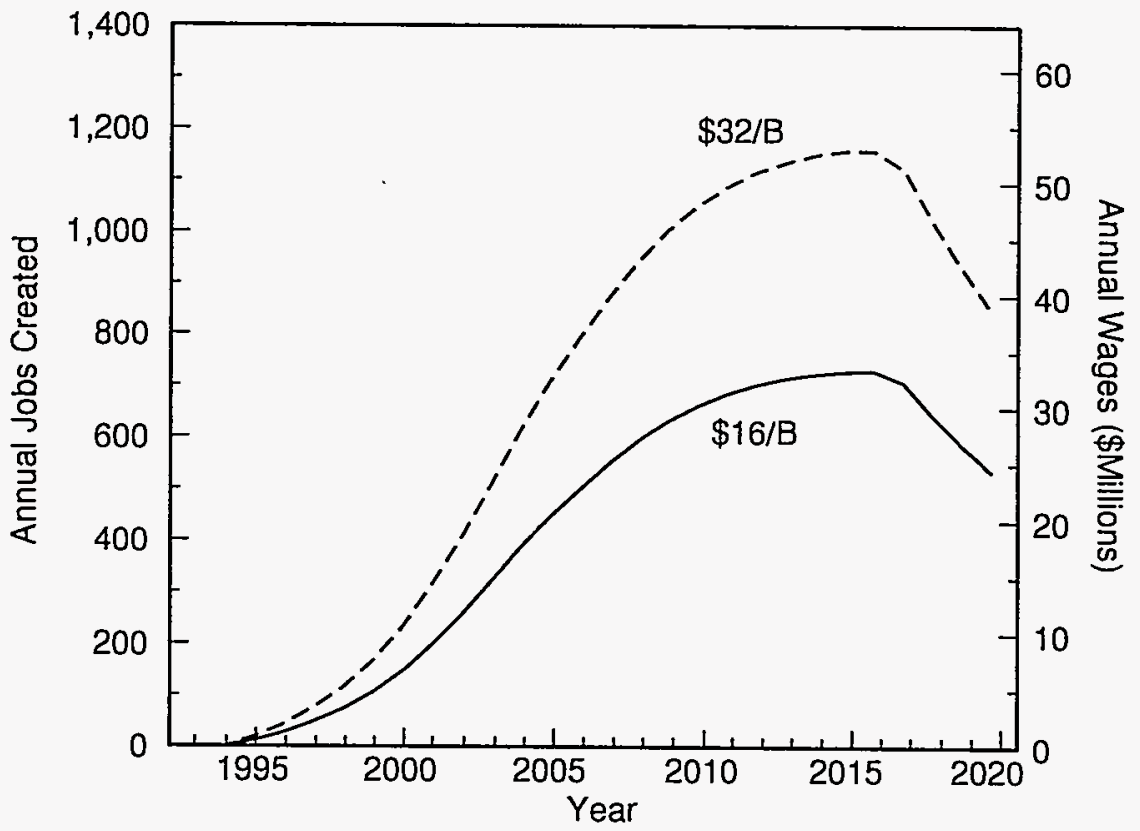




\section{Effects on the National Economy and Budget}

Figure IV-10A shows the national benefits of ASR production in Louisiana. Federal revenues from ASR production could range from about $\$ 1.4$ billion to $\$ 5.3$ billion over the price range analyzed. At oil prices ranging from $\$ 20 / \mathrm{B}$ to $\$ 28 / \mathrm{B}, \$ 2.2$ billion to $\$ 3.3$ billion in direct Federal revenues could be generated from implemented technology ASR production activities. Nearly all of these revenues would stem from corporate income taxes. At $\$ 36 / \mathrm{B}$, ASR activities could stimulate over $\$ 5.0$ billion in additional direct Federal revenues.

As the increased Louisiana production replaces oil imports, the U.S. trade deficit would be reduced and national security would be enhanced as the nation's vulnerability to future oil supply disruptions is diminished. At moderate oil prices, $\$ 16$ billion to over $\$ 23$ billion of avoided imports could be recirculated through the U.S. economy (Figure IV-10B). At $\$ 36 / \mathrm{B}$, nearly $\$ 32$ billion of avoided imports could result from implemented technology ASR production. As the value of avoided imports recirculates through the economy, its impact,could grow due to indirect effects stimulated by economic multipliers.

\section{CONCLUSIONS}

The existing level of EOR and ASR technologies could make small, but important, contributions to the reserve base and the Louisiana and national economies, as well as to domestic energy security. At a $\$ 24 / \mathrm{B}$ oil price, EOR processes could add 170 million barrels to Louisiana reserves while ASR techniques could add 840 million barrels of oil. The application of current EOR and ASR technologies, in concert, could potentially add over 1.0 billion barrels of reserves at this price, nearly doubling Louisiana's current onshore proved reserves. As discussed in the next chapter, improved geoscientific understanding of reservoirs and enhanced process performance could increase these benefits if the required research can be cost effectively completed and transferred to the producers.

The state of Louisiana and its citizens stand to gain significantly from the increased production resulting from incremental reserve additions. Production increases could generate $\$ 2.0$ billion to $\$ 3.7$ billion in additional state and local revenues over the life of the analyzed projects assuming oil prices of $\$ 20 / \mathrm{B}$ to $\$ 32 / \mathrm{B}$. Total state economic activity would be boosted by $\$ 11$ billion to over $\$ 19$ billion. Jobs would be created or maintained, and state economic activity would increase. The national economy would benefit through decreased oil imports, reductions in the trade deficit, and increased Federal corporate and 
Figure IV-10

National Impact of ASR Production

Implemented Technology

A) Direct Federal Revenues

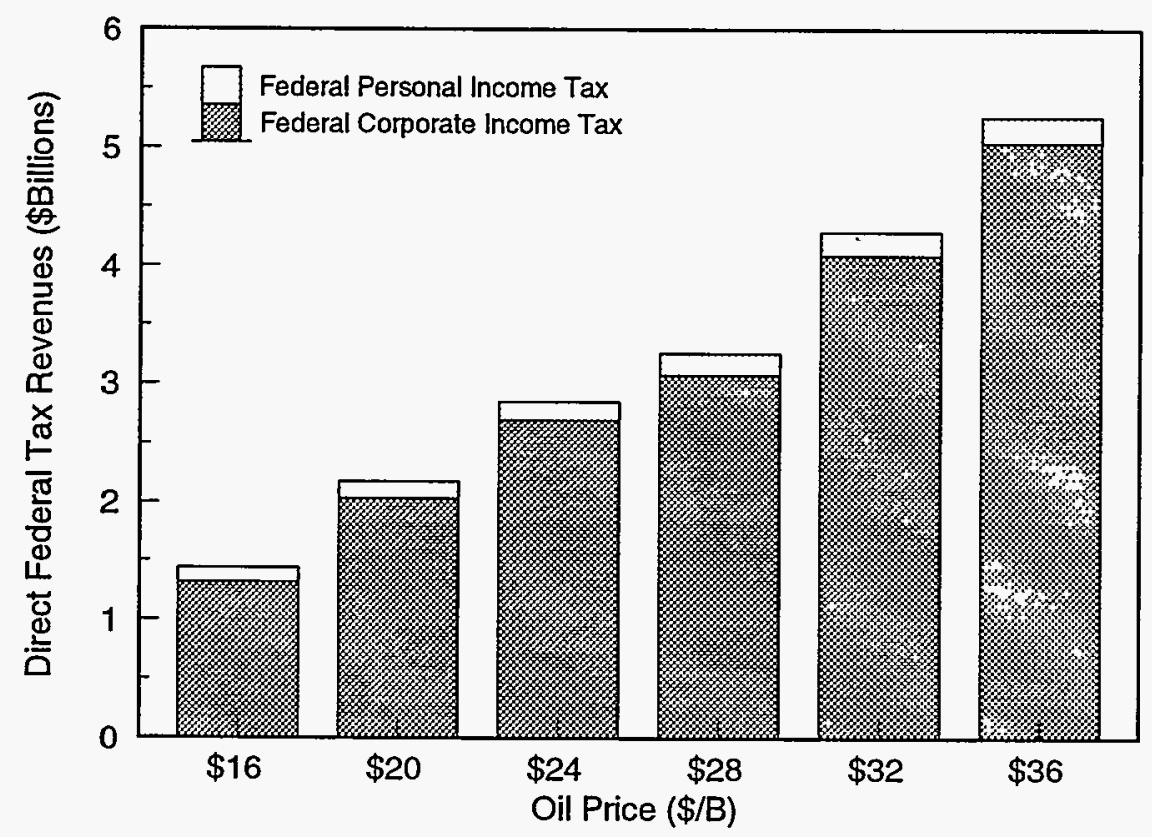

B) Imports Avoided*

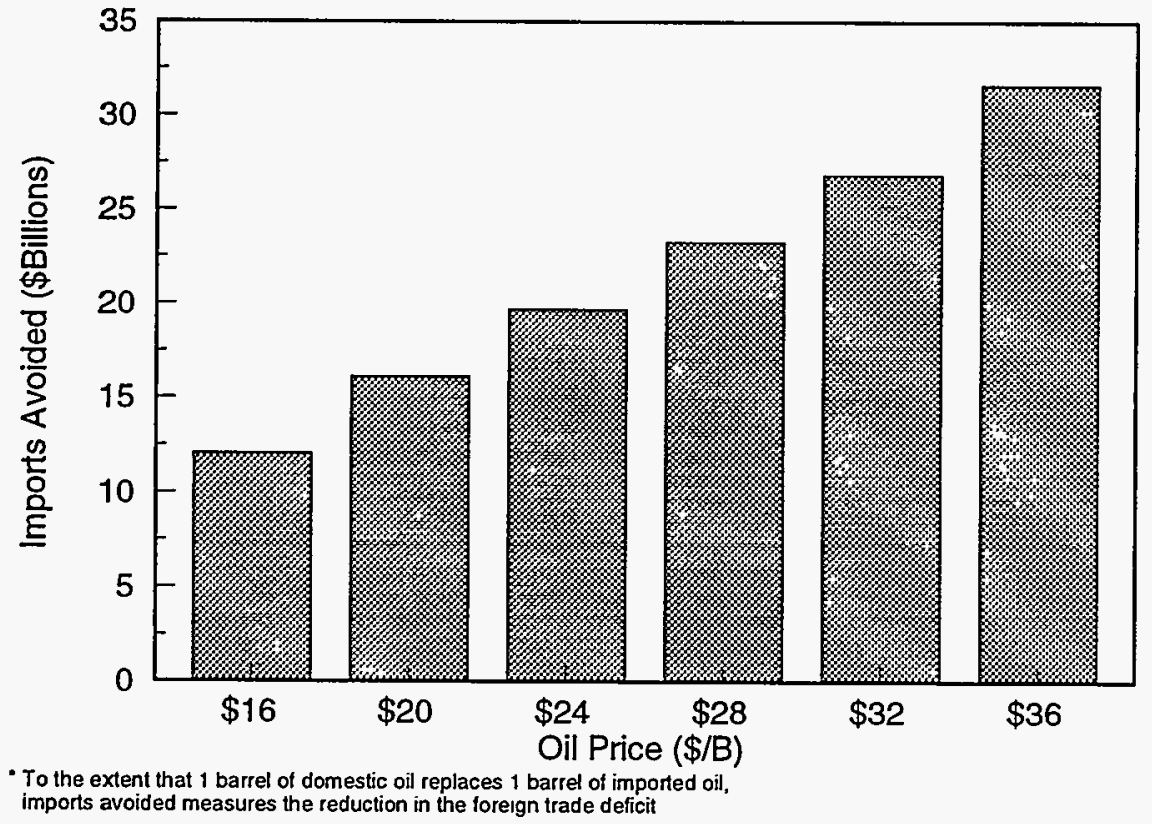


personal income tax revenues. Maximizing recovery of the known oil resource in Louisiana should be an important goal for state and Federal policy makers. While these benefits would be available using currently available technology, the true potential would not be realized without an aggressive program of technology transfer. The estimated potential assumes wide application of these technologies. A collaborative technology transfer effort between the public and private sectors is critical to the attainment of these estimated benefits.

As shown in Figure IV-11, the oil that will remain in the analyzed reservoirs after production by both current operations and by wide-scale application of currently available EOR and ASR processes constitutes an important resource target for improved recovery technologies. Of the 8.6 billion barrels of immobile oil resource analyzed in this study, implemented technology EOR practices as defined in this report could produce an estimated 323 million barrels at an oil price of $\$ 36 / \mathrm{B}$, leaving nearly 8.3 billion barrels of remaining immobile oil in these reservoirs. Of the 4.5 billion barrels of unrecovered mobile oil in the reservoirs analyzed, implemented technology practices could produce an estimated 890 million barrels at $\$ 36 / \mathrm{B}$, leaving 3.6 billion barrels in these reservoirs. The large size of the remaining resource clearly warrants a focused RD\&D program that will test and speed the implementation of advanced technology to capture additional oil reserves. 
Figure IV-11

\section{Louisiana Remaining Oil Resource After Implemented Technology Recovery}

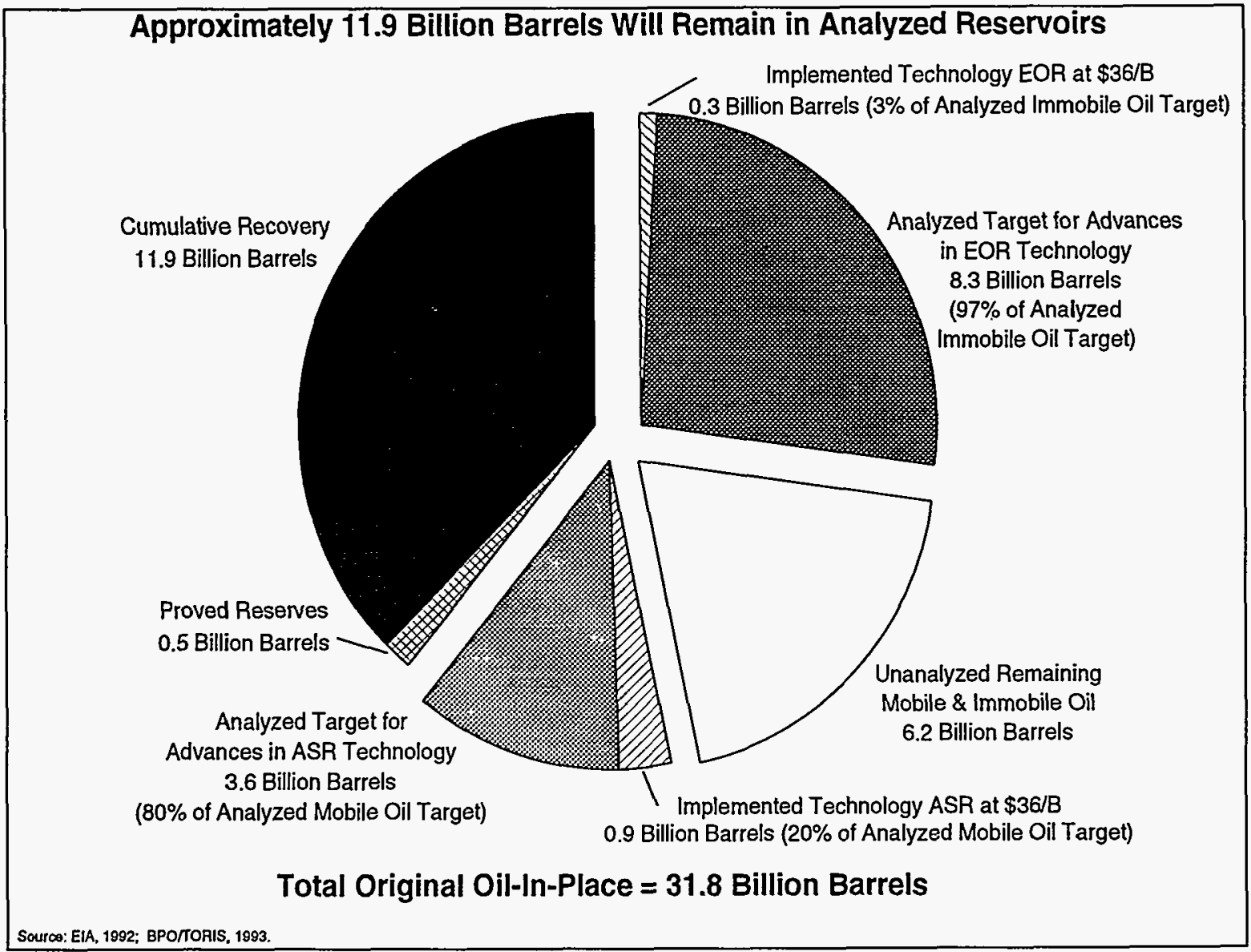




\section{BENEFITS OF INCREASED RECOVERY FROM THE KNOWN REMAINING OIL RESOURCE IN LOUISIANA WITH TECHNOLOGY ADVANCES}

\section{A. INTRODUCTION}

While currently available enhanced oil recovery (EOR) and advanced secondary recovery (ASR) techniques could contribute substantially to the Louisiana reserve base, technological advances in these processes resulting from a concerted RD\&D effort would have far more dramatic effects on the state's oil production. Development and wide-scale application of advanced methods could result in the recovery of a much greater portion of the remaining mobile and immobile oil resources in the state.

The present analysis evaluates the impact of advanced technology on oil recovery and the associated economic benefits. Evaluations of advanced technology EOR and ASR recovery potential in the state of Louisiana are presented separately. Given that the modeled advances in technology are conservatively defined, improvements in recovery processes resulting from research and development not envisioned in this report could add substantially to the estimated reserve potentials. However, well abandonments could limit access to the resource and increase project costs if EOR and ASR are not applied before conventional production ceases. Immediate actions are therefore necessary to realize the economic benefits of these advanced processes.

\section{B. RECOVERY OF THE REMAINING IMMOBILE OIL RESOURCE}

1. "Advanced" Technology Defined

Enhanced oil recovery processes, as currently applied, have severe limitations. Some current EOR techniques can only be applied in a limited number of reservoirs with properties which fall within a narrow range of suitable values (temperature, salinity, oil viscosity, etc.). The sweep efficiency of EOR processes is often relatively poor; only a small portion of the residual oil remaining in the previously waterflooded zone is contacted. Injectants are expensive, often approaching the value of the oil they are designed to recover, which places a burden on project economics. The National Petroleum Council (NPC) predicted gradual improvements in EOR performance and project economics as current processes are improved and tested in the lab and field. These advanced processes are predicted to gain operator 
acceptance as the research and development efforts of oil companies, universities, geologic surveys, and the Federal government proceed and as field applications prove commercial viability. In this report, the IOGCC delayed the advanced technology availability date from NPC's assumption of 1995 to the year 2000 to reflect the slower pace of RD\&D activities in recent years caused by relatively low oil prices.

The major improvements in technology that are likely to impact Louisiana enhanced oil recovery will be advances in chemical enhanced oil recovery applications. For advanced technology thermal recovery, the NPC modeled the effects of an improvement in the ability to inject steam at greater depths and into thinner, lower permeability reservoirs. For advanced technology chemical flooding, the NPC modeled the effects of increasing the salinity and temperature tolerance of injectants, thus enabling them to be applied in a larger number of reservoirs. This study also assumes that advances in chemical flood technology would result in improvements in injection rate, interfacial tension reduction, lower costs, and reduced chemical retention, thereby improving the recovery and economics of chemical projects. Additionally, the risk factors associated with current chemical and gas-miscible flooding are assumed to be substantially reduced by an RD\&D effort.

\section{2. $\quad$ Production and Reserves}

With technology advances, EOR could stimulate a substantial amount of incremental reserves over the analyzed oil price range. Figure V-1 and Table V-1A show the comparison between the incremental reserves potentially generated through the application of advanced technology EOR processes and implemented technology EOR processes as discussed in Chapter IV. At $\$ 20 / \mathrm{B}$, advances in EOR technology could increase implemented technology potential by over 840 million barrels for a total of 980 million barrels of incremental reserves. At $\$ 28 / \mathrm{B}$, technology advances could add over 1.6 billion barrels of incremental reserves, $87 \%$ of the 1.9 billion barrels of total incremental reserves.

The potential incremental reserves contributed by each of the analyzed advanced EOR processes are also shown in Figure V-1. Over the $\$ 16 / \mathrm{B}$ to $\$ 36 / \mathrm{B}$ range, advances in chemical flooding processes could contribute the largest amounts of incremental reserves. Under implemented technology, chemical flooding potential would be nominal (15 million to 20 million barrels of incremental reserves). Advanced technology, however, could increase the incremental reserves attributable to chemical EOR by 270 million

to 920 million barrels. Advances in technology could also significantly enhance thermal recovery potential. Between 110 million and 720 million barrels of incremental reserves could be stimulated over 
Figure V-1
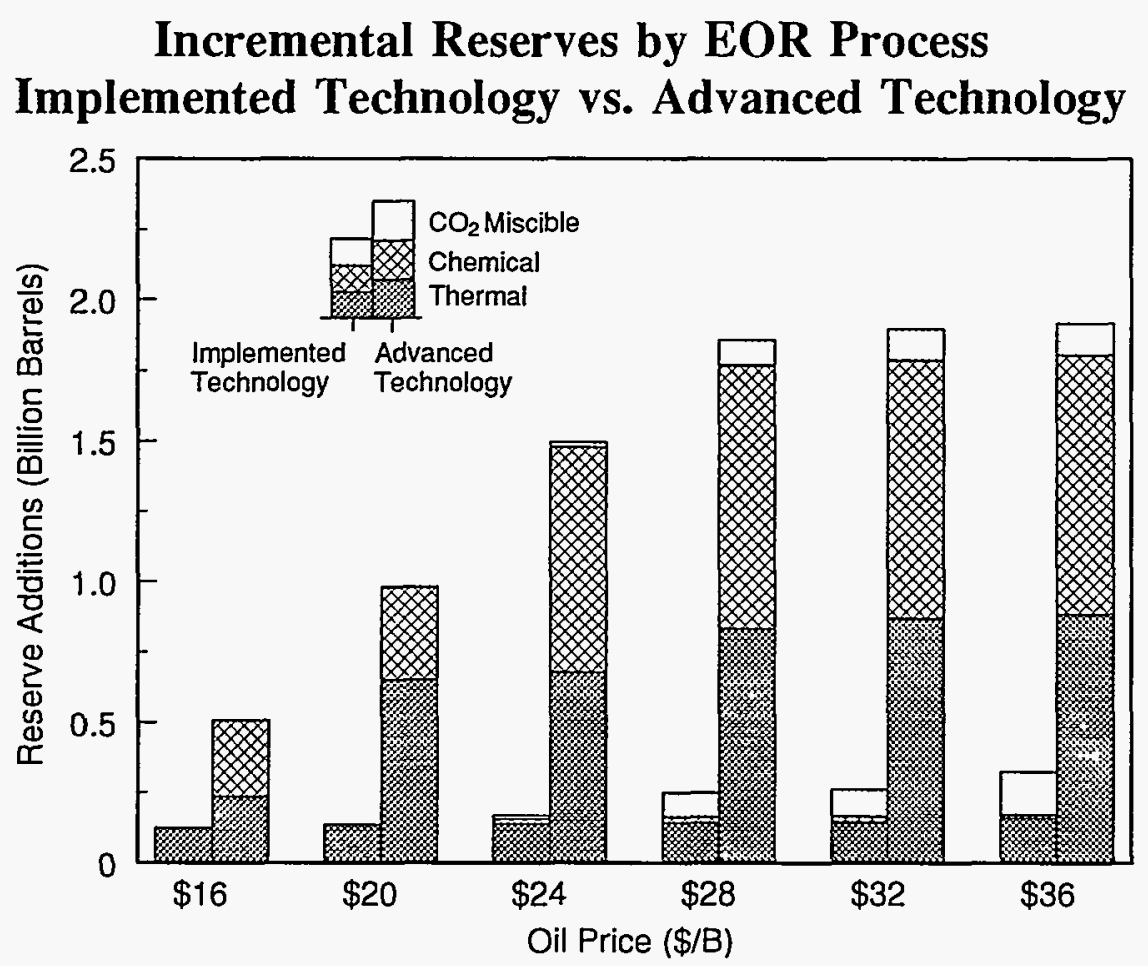

the analyzed price range due to advances in thermal recovery technology for a total potential of 240 million to 880 million barrels of incremental reserves. Advances in $\mathrm{CO}_{2}$-miscible flooding technology would not significantly increase reserves potential. In general, over $80 \%$ of the total thermal potential and nearly all of the total chemical potential at oil prices of $\$ 20 / \mathrm{B}$ and higher could be attributable to the impacts of a successful RD\&D effort.

The number of EOR projects for each process type is shown in Table V-1B. The comparison of the project count by process indicates the reasons for the increase in incremental reserves under advanced technology. The number of economic $\mathrm{CO}_{2}$-miscible projects does not change, indicating that advances in miscible flood technology would have a nominal impact in the analyzed Louisiana reservoirs. The number of chemical and thermal projects in the advanced case is three to fifteen times the number in the implemented technology case at $\$ 24 / \mathrm{B}$ and higher. This increase is roughly proportional to the increase in incremental reserves in the case of thermal processes, indicating that most of the reserves would be due to improved project economics. The additional reserve additions would be coming from reservoirs that were not technically or economically viable to develop under implemented technology. In the case of chemical flooding, the large increase in recovery per project indicates substantial additional improvements in recovery efficiency using advanced technology. 


\section{Table V-1A \\ Incremental Reserves from EOR by Process Implemented Technology vs. Advanced Technology (Million Barrels)}

\begin{tabular}{|c|c|c|c|c|c|c|c|c|}
\hline \multirow{2}{*}{$\begin{array}{l}\text { } \\
011 \\
\mathrm{putck} \\
(\mathrm{s} / \mathrm{B})\end{array}$} & \multicolumn{2}{|c|}{ 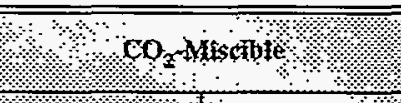 } & \multicolumn{2}{|c|}{ 1. } & \multicolumn{2}{|c|}{ Whimal } & \multicolumn{2}{|c|}{ \% } \\
\hline & Inplenented & Adrance & Hinpletrented & \%arparied: & Implenents & Nixpanced* & Iniptemetrted & Alvanced \\
\hline$\$ 16$ & 0 & 0 & 0 & 270 & 126 & 237 & 126 & 507 \\
\hline$\$ 20$ & 2 & 2 & 0 & 331 & 137 & 650 & 139 & 983 \\
\hline$\$ 24$ & 14 & 18 & 15 & 800 & 142 & 678 & 171 & 1,496 \\
\hline$\$ 28$ & 87 & 91 & 20 & 937 & 143 & 831 & 250 & 1,859 \\
\hline$\$ 32$ & 96 & 110 & 20 & 916 & 146 & 870 & 262 & 1,896 \\
\hline$\$ 36$ & 149 & 111 & 13 & 922 & 161 & 884 & 323 & 1,917 \\
\hline
\end{tabular}

* This is the total reserves with advanced technology -- implemented technology plus the increment due to technology advances.

Table V-1B

\section{Estimated Number of Economic EOR Projects by Process Implemented Technology vs. Advanced Technology (Project Counts)}

\begin{tabular}{|c|c|c|c|c|c|c|c|c|}
\hline ollorfes & \%. & . & Clten & & 政 & Mig & 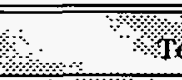 & ? \\
\hline (\$) & limbletnented & Huvanced & linplenensed. & Adpances & Himplene mut & Adyanced & Inplệnêtod & Adtraticed \\
\hline$\$ 16$ & 0 & 0 & 0 & 16 & 3 & 7 & 3 & 23 \\
\hline$\$ 20$ & I & 1 & 0 & 23 & 5 & 13 & 6 & 37 \\
\hline$\$ 24$ & 4 & 4 & 3 & 40 & 6 & 17 & 13 & 61 \\
\hline$\$ 28$ & 6 & 6 & 4 & 46 & 6 & 23 & 16 & 75 \\
\hline$\$ 32$ & 7 & 7 & 4 & 44 & 6 & 27 & 17 & 78 \\
\hline$\$ 36$ & 8 & 7 & 3 & 44 & 8 & 28 & 19 & 79 \\
\hline
\end{tabular}


Figure V-2 shows the expected annual EOR production for oil prices of $\$ 16 / \mathrm{B}$ and $\$ 32 / \mathrm{B}$ for both the implemented and advanced technology cases. At $\$ 32 / \mathrm{B}$, up to 20 million barrels per year could be added to Louisiana oil production within 10 years as a direct result of advanced EOR. By the year 2020, over 40 million barrels per year could be produced by advanced technology EOR processes. At $\$ 16 / \mathrm{B}$, advanced technology EOR could produce 11 million barrels per year in the year 2005, rising to over 30 million by the year 2012, the peak production year. Advanced technology could be four times more than that estimated to be produced using implemented technology.

\section{Effects on State Revenues and Economic Activity}

At all oil prices considered in this analysis, the direct revenues to the state of Louisiana attributable to EOR activities could significantly increase with advanced technology (Figure V-3A). Similar to the implemented case, state corporate income and production taxes make up most of the state's total direct revenues, and personal income and sales tax receipts contribute the remainder. At $\$ 20 / \mathrm{B}$, direct state revenues from advances in EOR technology could increase implemented technology potential by $\$ 230$ million, for a total of $\$ 450$ million. At $\$ 24 / \mathrm{B}$, advanced technology could generate incremental revenues from EOR of more than $\$ 2.2$ billion, $\$ 1.8$ billion of which could be due to the impacts of successful RD\&D. At the higher oil prices of $\$ 28 / \mathrm{B}$ to $\$ 36 / \mathrm{B}, 77 \%$ to $80 \%$ of the $\$ 3.8$ billion to $\$ 5.4$ billion in direct state revenues from advanced technology EOR activities could be attributed to technology advances.

Direct state economic activity generated by Louisiana EOR activities could also grow due to advanced technology. Figure V-3B displays the total potential incremental direct economic benefits to the state for both the implemented and advanced technology cases. The advanced case distribution of total economic benefits among the contributing components is similar to the trend shown for the implemented technology case. At $\$ 16 / \mathrm{B}$ and $\$ 20 / \mathrm{B}$, the incremental state economic gain due to advanced EOR technology is estimated at about four to six times the amount in the implemented technology case; $\$ 4.0$ billion to $\$ 9.4$ billion in economic activity could be stimulated by technology advances, for a total potential of $\$ 5.1$ billion to nearly $\$ 11$ billion. A $\$ 24 / \mathrm{B}$ oil price with advanced technology development could result in $\$ 21$ billion in economic activity, $90 \%$ from technology advances. At $\$ 28 / \mathrm{B}$, the direct state-wide economic gain could increase from $\$ 4.0$ billion under implemented technology to almost $\$ 30$ billion with full advanced EOR technology development. The difference estimates the impact of a successful RD\&D effort. Clearly, the state of Louisiana could accrue substantial benefits from the 
Figure V-2

\section{Annual Production from EOR}

\section{Implemented Technology vs. Advanced Technology}

A) At $\$ 16 / B$

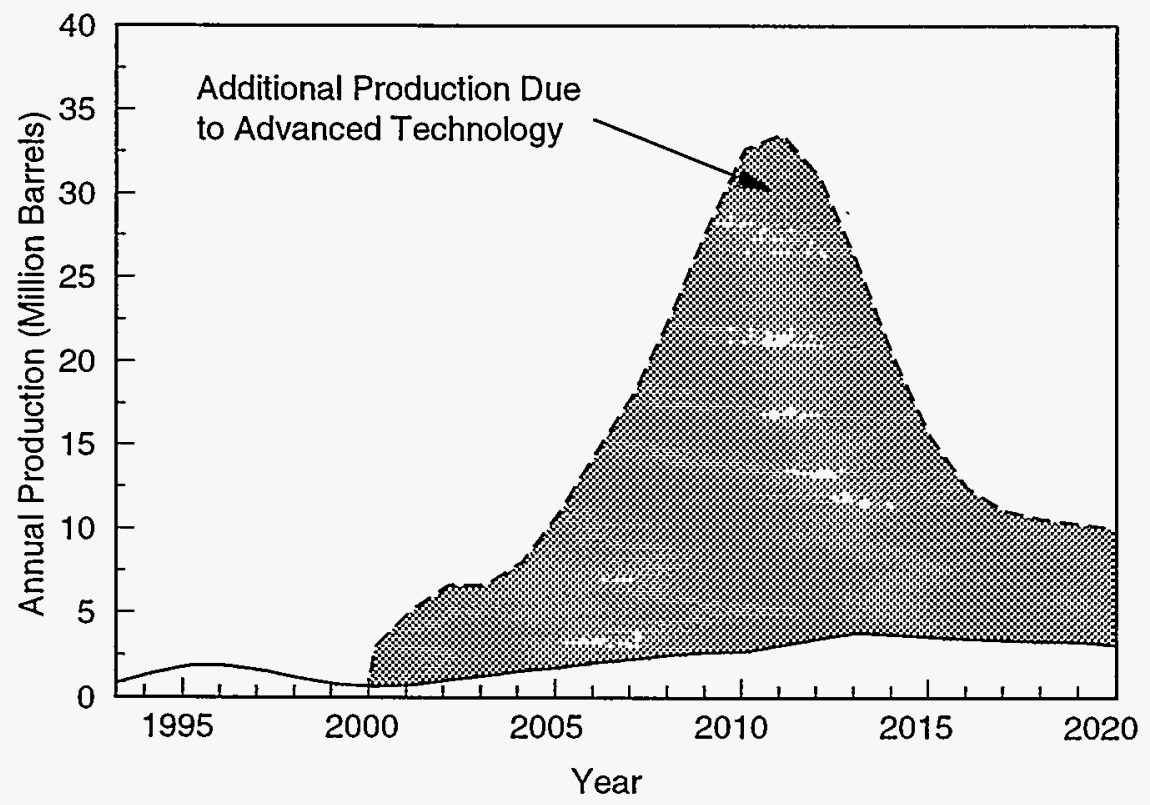

B) At $\$ 32 / B$

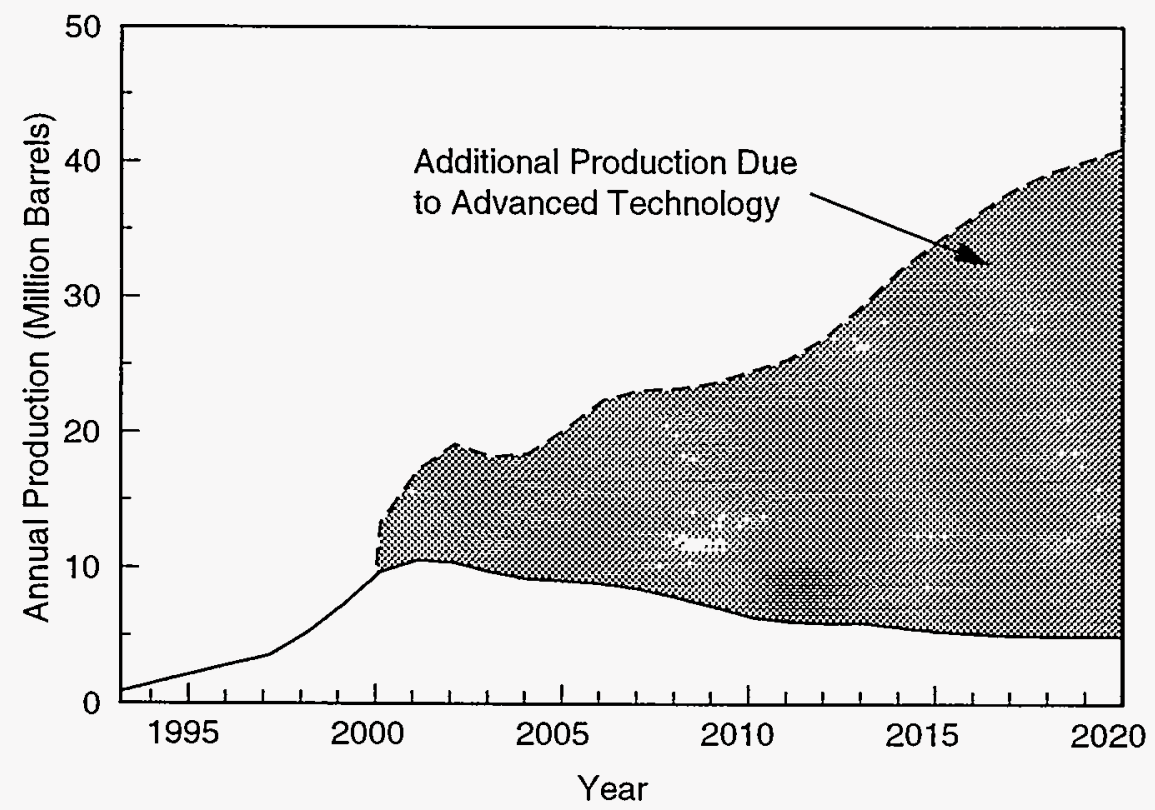


Figure V-3

State Impact of EOR Production

Implemented Technology vs. Advanced Technology

A) Direct State and Local Revenues

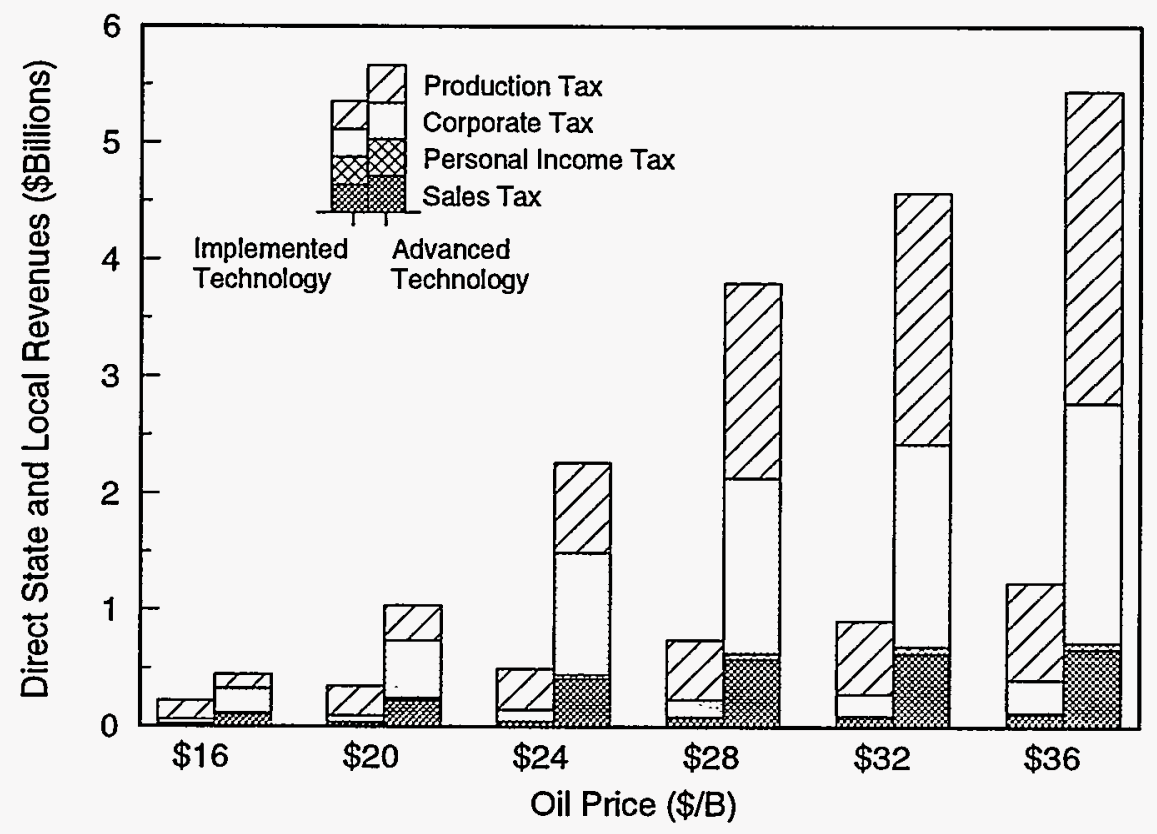

B) Direct State Economic Activity*

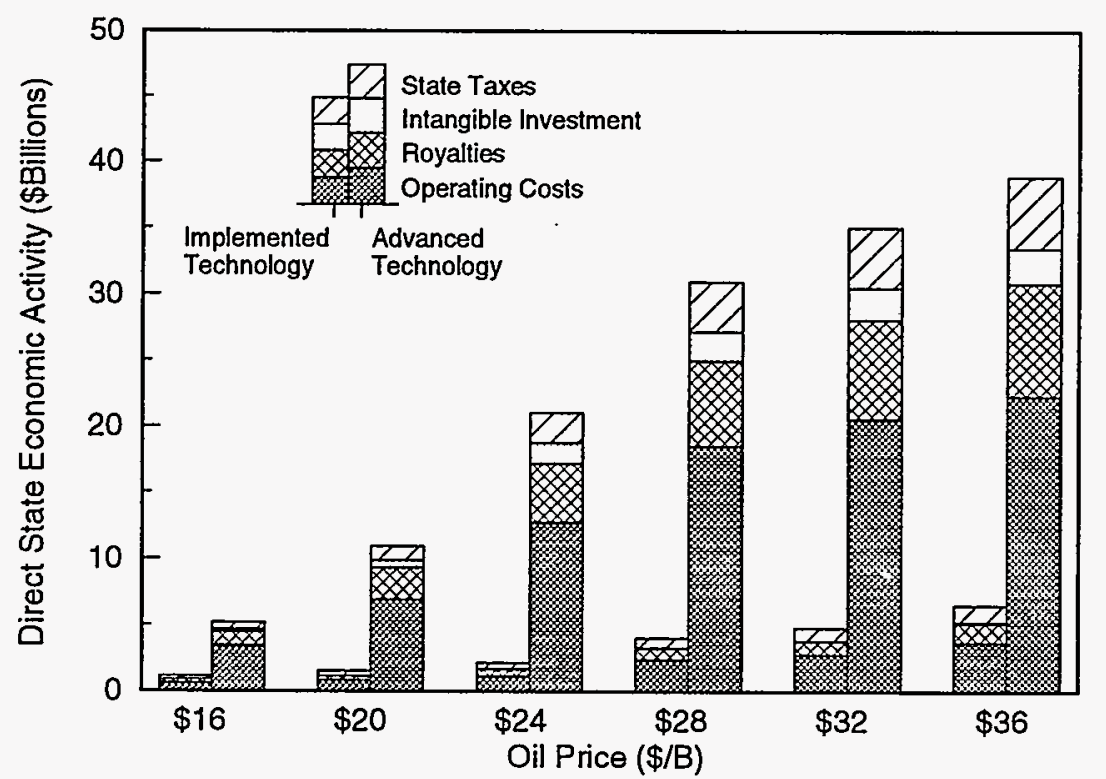

- To the extent that royalties go to the Federal govemment (i.e. folds on Federal lands), royaltes as a porton of state economic activity may be overstated. 
development and application of advanced EOR technology at all of the oil prices considered in this analysis.

Advanced technology could also have a substantial impact on the state's employment. Even at a relatively low oil price of $\$ 16 / \mathrm{B}$, the development of advanced technology could create nearly 1,800 new jobs per year by the year 2010 (not illustrated). At the higher oil price of $\$ 32 / \mathrm{B}$, over 2,000 jobs per year could result from development of advanced technology processes in the same time period. Peak wages at $\$ 16 / \mathrm{B}$ and $\$ 32 / \mathrm{B}$ with advanced technology EOR are estimated at $\$ 80$ and $\$ 100$ million, respectively, and would occur before the year 2010 .

\section{Effects on the National Economy and Budget}

As discussed in Chapter IV, increased oil recovery in the state of Louisiana would benefit the nation in the areas of enhanced energy security, import replacement, trade deficit reduction, and expanded direct revenues to the Federal treasury. The potential benefits are significantly more pronounced with the development of advanced technology. Up to 1.9 billion barrels of crude oil could be added to proved reserves due to advanced EOR technology, 1.6 billion barrels more than the reserve additions estimated under the implemented case.

Revenues to the Federal treasury, in the form of corporate and individual income taxes, would grow along with the increase in reserves as a result of advanced technology, as shown in Figure V-4A. EOR production under advanced technology could contribute from $\$ 290$ million up to $\$ 6.8$ billion to the Federal treasury over the price range analyzed. Nearly $\$ 170$ million to $\$ 5.6$ billion of the potential could be attributed to technology advances. At $\$ 24 / \mathrm{B}$ and $\$ 28 / \mathrm{B}$, roughly $80 \%$ of the additional direct Federal revenues from advanced technology EOR could be due to the impacts of successful RD\&D. Over $\$ 1.0$ billion to $\$ 1.5$ billion could be added to the Federal treasury at these prices.

As domestic production increases due to advanced technology EOR, imports of oil would decrease as each additional barrel of domestic production replaces a barrel of imports. The trade deficit would be reduced by the value of the avoided imports as money which would be spent on imports is instead recirculated through the U.S. economy. At moderate oil prices $(\$ 20 / \mathrm{B}$ to $\$ 28 / \mathrm{B}$, technology advances could stimulate $\$ 17$ billion to $\$ 44$ billion in avoided imports, for a total potential ranging from $\$ 19$ billion 
to $\$ 51$ billion of imports avoided. At $\$ 36 / \mathrm{B}, \$ 56$ billion $(81 \%)$ of the $\$ 68$ billion of avoided imports would be attributable to advances in EOR technology (Figure V-4B).

\section{RECOVERY OF THE REMAINING MOBILE OIL RESOURCE}

\section{1. "Advanced" Technology Defined}

The unrecovered mobile oil (advanced secondary recovery) advanced case analysis, designed to reflect the potential technological improvements possible from a focused RD\&D program in geological reservoir characterization, is conducted in a manner consistent with the implemented technology case analysis. A major assumption is that RD\&D will allow geologic reservoir characterization techniques to be widely applied, resulting in infill drilling that is targeted only into those portions of the reservoir where project economics will allow drilling at closer spacings. This will improve the project economics of advanced secondary recovery (ASR), resulting in more activity and much greater recovery under the advanced case than would be possible under the reservoir-wide, blanket drilling program assumed in the implemented technology case. Heterogeneous portions of reservoirs contain a proportionally larger amount of unrecovered mobile oil that is trapped in isolated compartments or bypassed by the injection fluids in conventional recovery operations. By contrast, the more homogenous portions of reservoirs exhibit more efficient conventional recovery and require less intensive drilling. In this study, infill drilling potential is evaluated by dividing each reservoir into two parts, a more continuous (homogeneous) segment and a less continuous (heterogeneous) segment. The economic recovery potential is evaluated independently in each segment, and the closest economic well spacing for each segment is independently selected.

The improved recovery methods discussed in this analysis could have a substantial impact on ASR reserve additions. Additional recovery could be stimulated as the chemical composition of polymer injectants is improved to withstand higher reservoir temperatures (up to $250^{\circ} \mathrm{F}$ ) and/or formation salinities (up to 200,000 parts per million). These improvements would increase the marginal impact of the profile modification and polymer flooding projected under the implemented technology case whether they are applied alone or in combination with infill drilling. Additional benefits are estimated from the reduction of the associated risk (modeled as a reduction in hurdle rates) of ASR processes with technology advances as discussed in Chapter III. 
Figure V-4

National Impact of EOR Production

Implemented Technology vs. Advanced Technology

A) Direct Federal Revenues

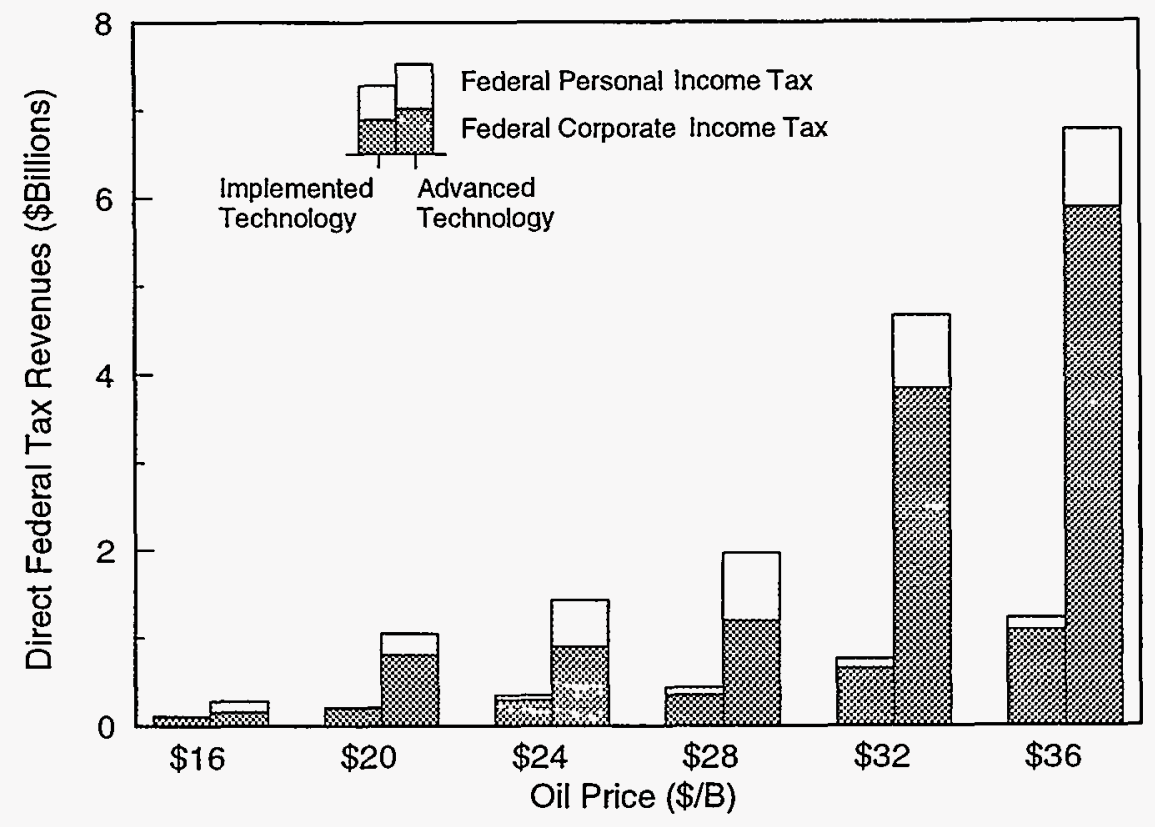

B) Imports Avoided*

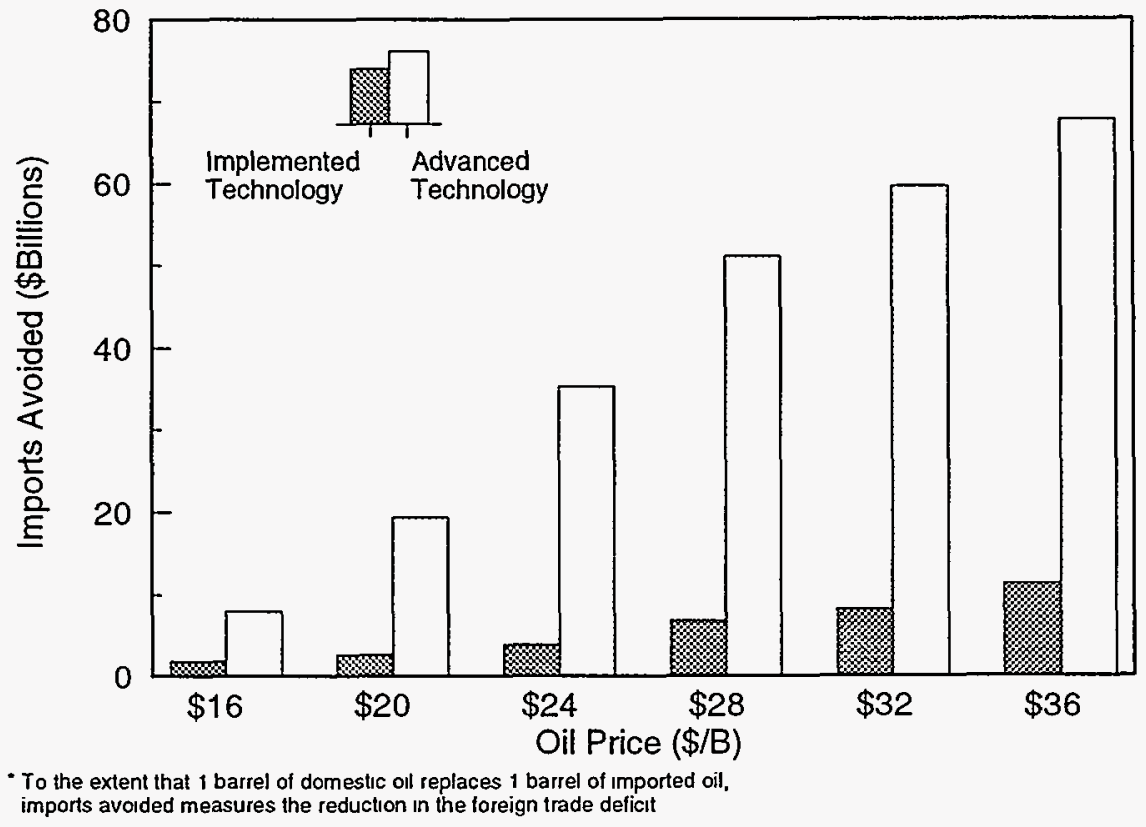




\section{2. $\quad$ Production and Reserves}

The development of advanced technology ASR methods through RD\&D could significantly increase the state's oil reserves. The incremental reserves from advanced technology ASR are estimated at 1.0 billion to 1.1 billion barrels in the analyzed Louisiana reservoirs, 240 million to 290 million barrels of oil over the reserves generated using implemented technology across the oil prices considered (Figure V-5). The increment over implemented technology would reflect the impact of a successful RD\&D effort. ASR is less sensitive than EOR to increases in oil price, and essentially the same increase is seen over the range of prices analyzed.

Table V-2A shows the distribution of incremental ASR reserves by process. Infill drilling in combination with profile modification or polymer flooding would be the most prolific advanced technology recovery method, contributing about $80 \%$ of the total incremental reserves. Infill drilling by itself decreases from about $50 \%$ of the total in the implemented technology case, to only about $20 \%$ in the advanced technology case. This occurs as more of the infill drilling projects are converted to combination projects, due to improvements in the polymer gels and foams.

Table V-2B shows the estimated number of economic ASR projects for both the implemented and advanced technology cases. At all oil prices analyzed, the number of infill drilling projects drops by twothirds while the infill drilling reserves drop by a little less than half in going from the implemented to the advanced technology case. This corresponds to a doubling of the number of combination projects (infill drilling with polymer flooding or profile modification) and a proportionate increase in combination project incremental reserves. This can be explained by a shift to combination projects from infill drilling alone by those infill projects which were less effective. Table V-2B also shows that the number of economic polymer and profile modification projects under the advanced case could increase significantly from the implemented case; this increase is proportional to the rise in incremental reserves at all oil prices considered. The number of economic projects increases as a result of assumed improvements in the chemical composition of polymer solutions that allow these solutions to withstand more severe reservoir conditions (e.g., higher temperature and higher salinity). Such technological advances would make more reservoirs technically and economically amenable to the application of chemical treatment processes. However, even with advanced technology, the number of polymer flooding and profile modification projects are not significant relative to the other two categories. The improvements in polymer solutions also lead to a move to combination processes from infill drilling applied alone. 
Figure V-5

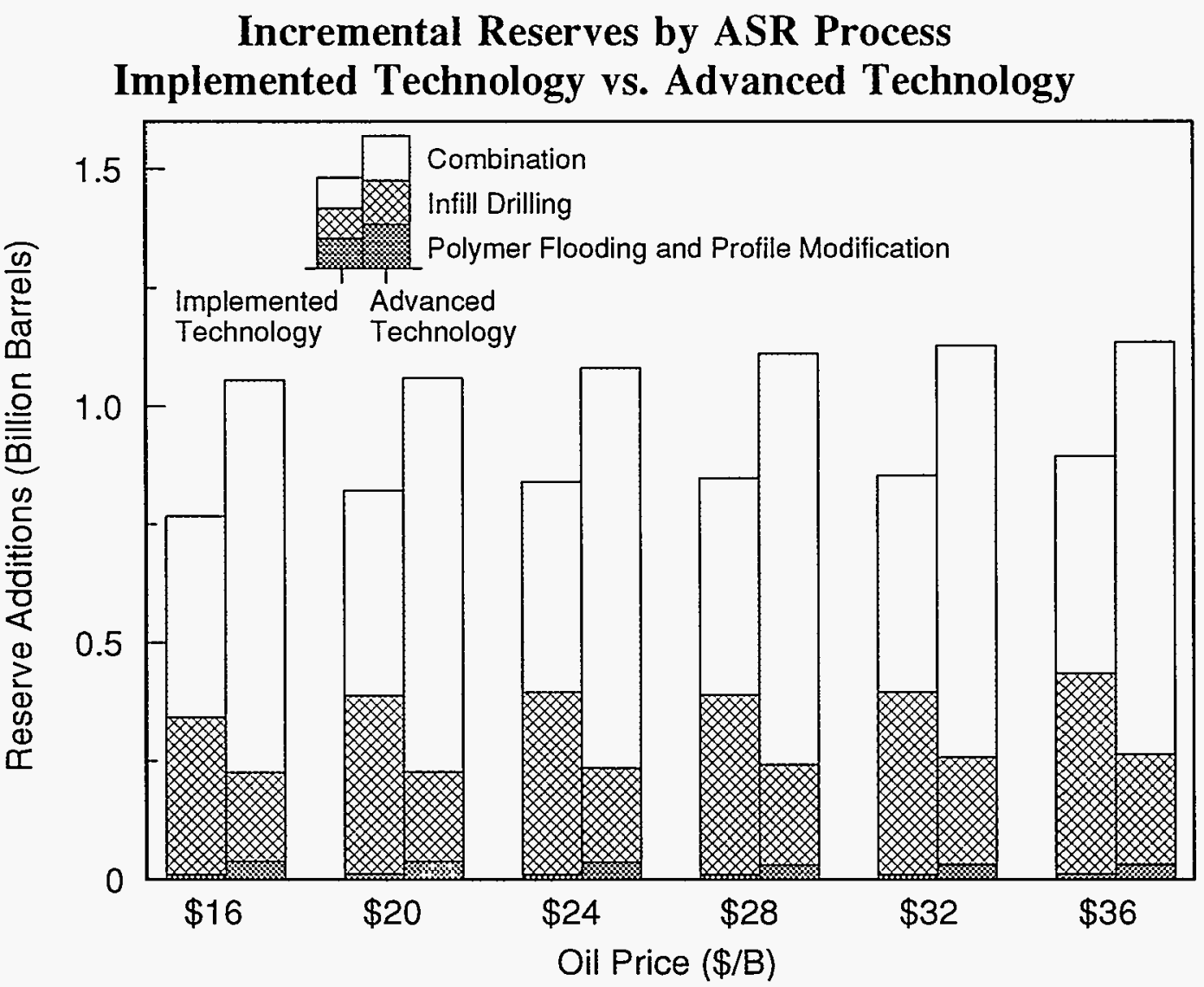

Figure V-6 displays the projected annual production that could result from ASR technology advances for oil prices of $\$ 16 / \mathrm{B}$ and $\$ 32 / \mathrm{B}$ from the analyzed Louisiana reservoirs. In both cases, a small, but important, incremental amount of oil could be added to the state's production over the next 25 years. Production could peak in the year 2016 in both cases, with a substantial volume of the incremental production occurring in the years beyond 2012. At $\$ 16 / \mathrm{B}$, over 32 million barrels of oil per year could be produced in the peak production year, an 8 million barrel per year increase over the implemented technology peak. With an oil price of $\$ 32 / \mathrm{B}$, production could peak at nearly 35 million barrels per year, $22 \%$ higher than the implemented technology peak.

\section{Effects on State Revenues and Economic Activity}

Under advanced technology, ASR activities could significantly increase the direct state and local revenues in Louisiana, but only about $20 \%$ of this increase would be attributable to technology advances 


\begin{tabular}{|c|c|c|c|c|c|c|c|c|}
\hline $6 \varepsilon 1$ & $\nabla I I$ & 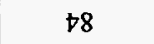 & $8 E$ & 61 & 65 & $9 \varepsilon$ & $\angle I$ & 9Es \\
\hline it & III & $\$ 8$ & $8 \varepsilon$ & $8 I$ & ss & $8 \varepsilon$ & 81 & zE\$ \\
\hline LEI & 901 & 98 & $8 \varepsilon$ & $\angle I$ & 25 & $\downarrow \varepsilon$ & 9I & $82 \$$ \\
\hline $9 \varepsilon I$ & 201 & 88 & $L E$ & LI & OS & $9 \varepsilon$ & SI & $t 2 \$$ \\
\hline$\langle Z I$ & 96 & $8 L$ & $\nabla E$ & $t I$ & $9 b$ & $\mathfrak{S E}$ & 91. & $02 \$$ \\
\hline 811 & 98 & $I L$ & IE & $t$ & $\varepsilon t$ & $\varepsilon \varepsilon$ & $Z I Z$ & $91 \$$ \\
\hline powapy & 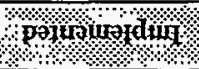 & poptroxpr & papuptsutur & א\%, & 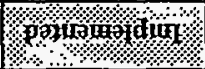 & pap4sopy & provinidut & \multirow{2}{*}{ 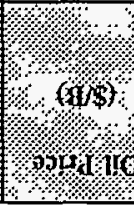 } \\
\hline \%. & 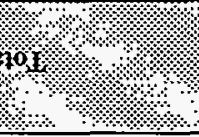 & \multicolumn{2}{|c|}{ W.10\% } & א. & \%orn & \multicolumn{2}{|c|}{ 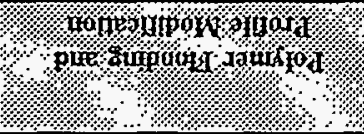 } & \\
\hline
\end{tabular}

\title{
(słunoว po?̣.dd)

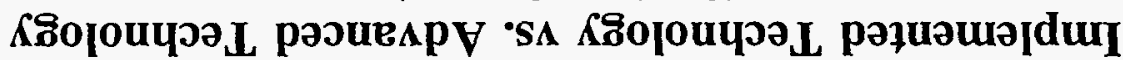

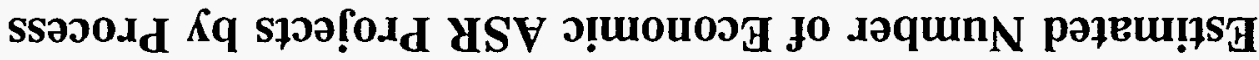

\author{
gz- $\Lambda$ गIQR $\mathbf{L}$
}

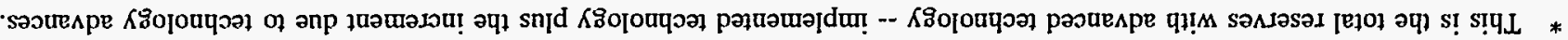

\begin{tabular}{|c|c|c|c|c|c|c|c|c|}
\hline$t \varepsilon I^{\prime} I$ & $\varepsilon 68$ & $1 \angle 8$ & $8 \mathfrak{S t}$ & 乙£乙 & $\varepsilon Z \downarrow$ & $I \varepsilon$ & $Z I$ & ges \\
\hline $9 Z I^{\prime \prime}$ & $2 \$ 8$ & 898 & $L S t$ & $\llcorner z Z$ & $58 \varepsilon$ & $I \varepsilon$ & II & zह\$ \\
\hline OII'I & $9+8$ & 898 & $\angle S t$ & $\tau \mathrm{I} Z$ & $8 L \mathcal{E}$ & $0 \varepsilon$ & II & $8 z \$$ \\
\hline I I & $6 \varepsilon 8$ & $S+8$ & $\varepsilon t t$ & 861 & S8E & $L \varepsilon$ & 11 & $t 2 \$$ \\
\hline $650^{\prime} \mathrm{l}$ & IZ8 & $\tau \varepsilon 8$ & $\varepsilon \varepsilon t$ & $68 I$ & $9 L \varepsilon$ & $8 \varepsilon$ & $Z \mathrm{I}$ & $02 \$$ \\
\hline$t S 0^{\circ} I$ & $\angle 9 L$ & 878 & $s Z_{t}$ & $88 \mathrm{I}$ & $I \varepsilon E$ & $8 \varepsilon$ & II & $91 \$$ \\
\hline$* \mathrm{p}+\mathrm{m} \times \mathrm{pl}$ & 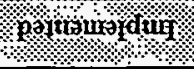 & \%prin & prown & proturp & 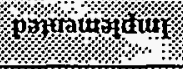 & 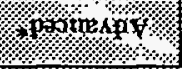 & grom & \multirow{2}{*}{$\begin{array}{l}\% \\
\% \\
\% \\
\%\end{array}$} \\
\hline का & 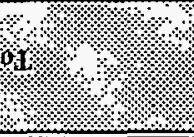 & 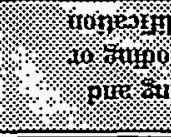 & 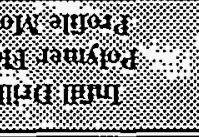 & \%. & mingy & \%ortoging & Horing, & \\
\hline
\end{tabular}

(s[ว.Jеg uo!!I!I)

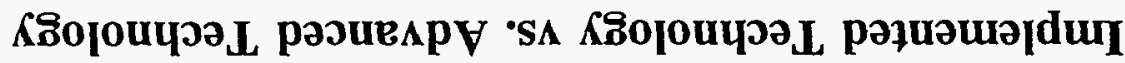

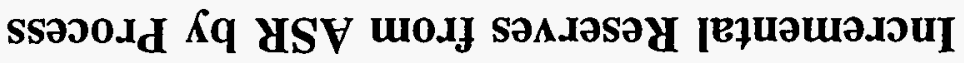

$\forall Z-\Lambda$ ә१ष्L 
Figure V-6

\section{Annual Production from ASR}

\section{Implemented Technology vs. Advanced Technology}

A) At $\$ 16 / B$

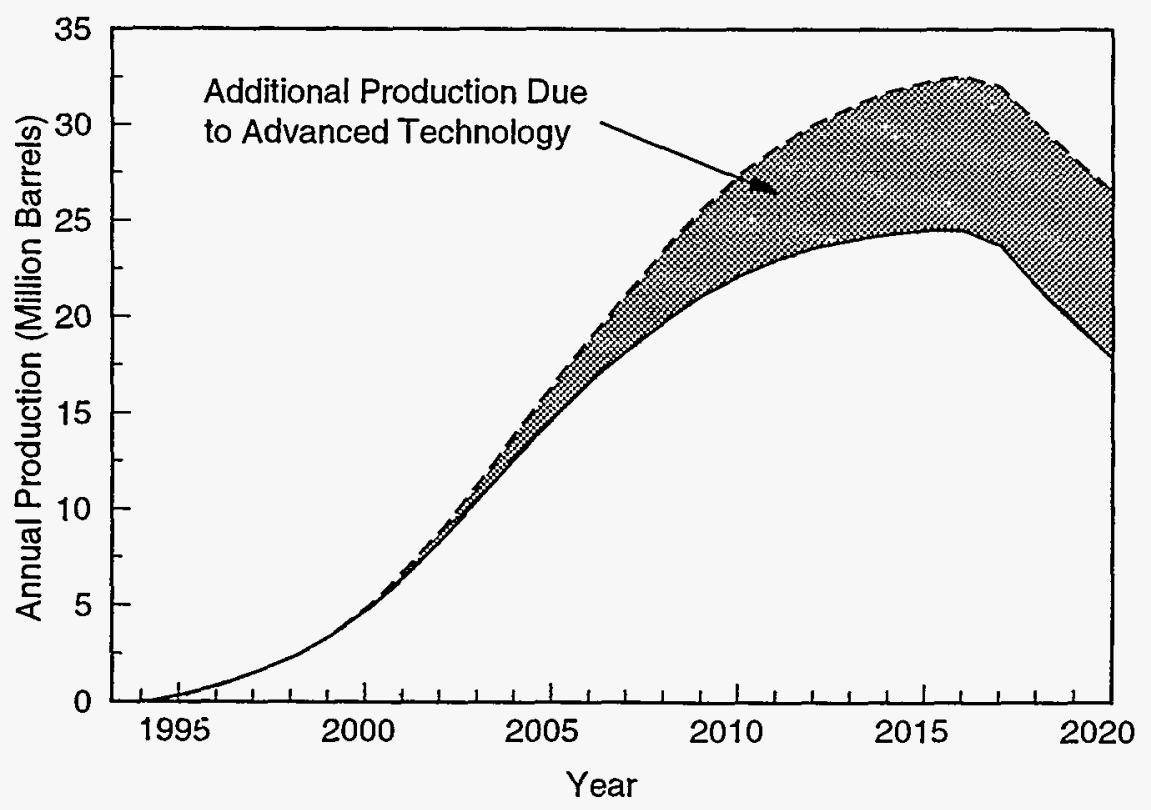

B) At $\$ 32 / B$

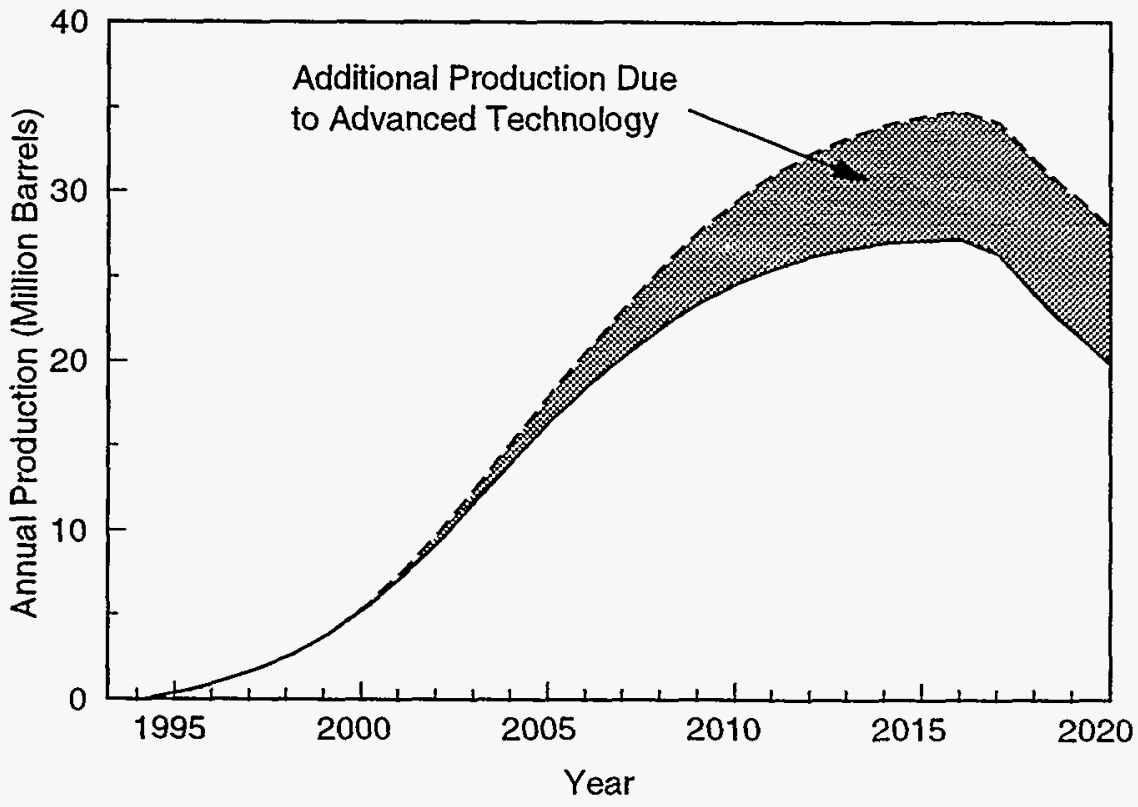


(Figure V-7A). At oil prices of $\$ 20 / \mathrm{B}$ to $\$ 28 / \mathrm{B}$, advanced technology ASR could stimulate $\$ 2.0$ billion to $\$ 3.0$ billion in additional direct state and local revenues, $19 \%$ of which would result from the impact of a successful RD\&D effort. At the historically high oil price of $\$ 36 / \mathrm{B}, \$ 750$ million (19\%) of the $\$ 4.0$ billion in state and local revenues generated by advanced technology ASR activities would be attributable to technology advances. As in the implemented technology case, the revenue is mostly generated from production taxes and state corporate income taxes. These taxes account for over $90 \%$ of the direct state tax revenues generated at each analyzed oil price.

In addition to increased tax revenues, Louisiana could also benefit from increased levels of economic activity stimulated by advanced technology ASR. At oil prices ranging from $\$ 16 / \mathrm{B}$ to $\$ 24 / \mathrm{B}$, advances in technology could account for $20 \%$ to $30 \%$ of the $\$ 11$ billion to $\$ 14$ billion of state economic activity from advanced technology ASR. At higher oil prices, the impact of successful RD\&D on potential economic activity decreases. Nearly $\$ 3.0$ billion $(15 \%)$ of the $\$ 20$ billion in advanced technology economic activity at $\$ 36 / \mathrm{B}$ would be attributable to technology advances (Figure V-7B).

At a price as low as $\$ 16 / \mathrm{B}$, advanced technology increases and accelerates the annual number of jobs created or maintained. Advanced ASR technology could result in an increase of about 200 to 300 jobs annually over implemented technology potential with an oil price of $\$ 16 / \mathrm{B}$ (not illustrated). Over 1,000 jobs per year could be created or maintained by the year 2016. A smaller number of incremental jobs are created by advanced technology applications at the higher price of $\$ 32 / \mathrm{B}$.

\section{Effects on the National Economy and Budget}

The development of advanced technology for the recovery of the known UMO resource in the state of Louisiana could also benefit the nation. Figure V-8A shows the increase in the incremental revenues to the Federal treasury from personal and corporate income taxes due to advanced technology. At moderate oil prices ( $\$ 20 / \mathrm{B}$ to $\$ 28 / \mathrm{B}$ ), technology advances could stimulate additional Federal revenues of $\$ 480$ million to $\$ 1.2$ billion in direct Federal revenues for a total potential of $\$ 2.6$ billion to $\$ 4.4$ billion in direct Federal revenues. At $\$ 36 / \mathrm{B}, \$ 1.8$ billion (26\%) of the $\$ 7.1$ billion in direct Federal revenues stimulated by advanced technology ASR activities would be attributable to advances in ASR technology.

The nation would also benefit from increased ASR production as imports are replaced on a barrelfor-barrel basis and the trade deficit is reduced. In addition to enhancing the nation's energy security and 
Figure V-7

\section{State Impact of ASR Production}

\section{Implemented Technology vs. Advanced Technology}

A) Direct State and Local Revenues

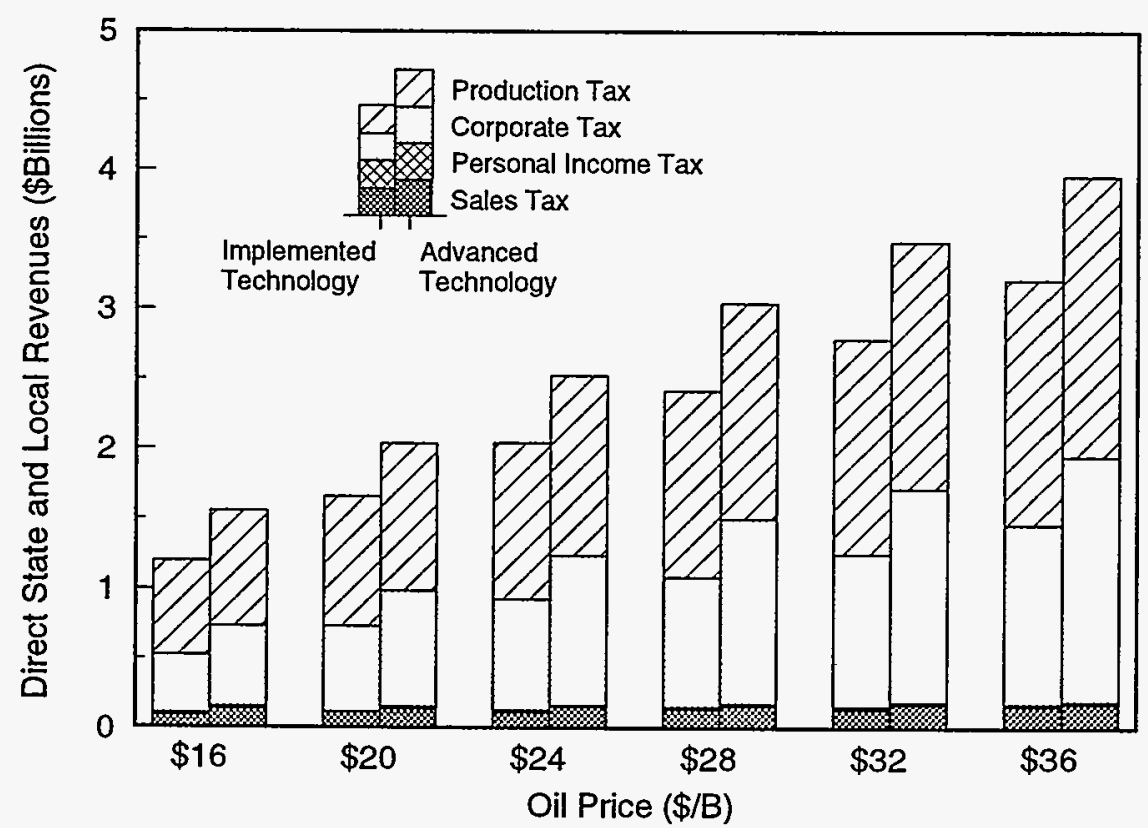

B) Direct State Economic Activity*

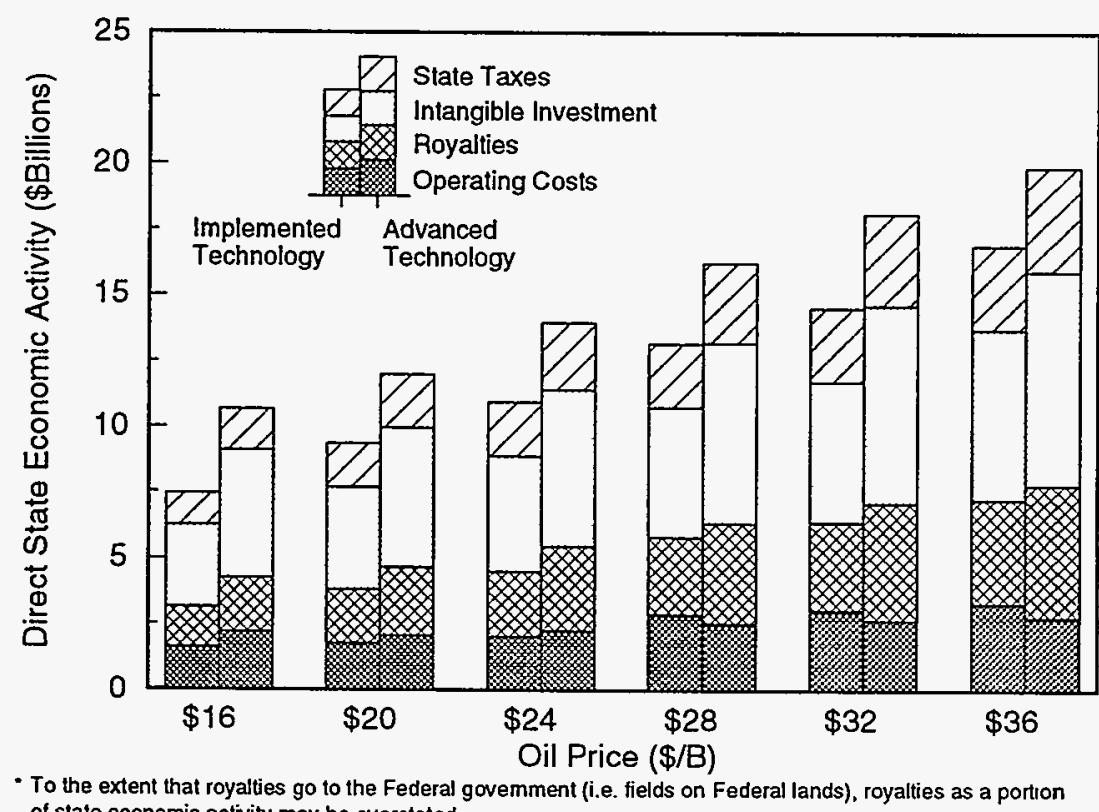

of state economic activity may be overstated. 
independence, replacing imports also keeps money within the U.S. economy rather than flowing to oil exporting countries. At $\$ 20 / \mathrm{B}$, technology advances could keep an additional $\$ 4.7$ billion of avoided imports circulating within the U.S. economy, for a total potential of nearly $\$ 21$ billion. Over $\$ 7.2$ billion of the $\$ 31$ billion in avoided imports at $\$ 28 / \mathrm{B}$ would be the result of a successful RD\&D effort. At $\$ 36 / \mathrm{B}$, over $\$ 40$ billion could be recirculated within domestic markets rather than abroad, $21 \%$ of which could be the result of the application of technology advances (Figure V-8B).

\section{CONCLUSIONS}

As discussed in Chapter IV, currently available EOR and ASR technologies have the potential to significantly increase reserves and provide substantial economic benefits to operators, the state of Louisiana, and the nation. An aggressive and efficient technology transfer program in both the public and private sectors would bring these available technologies to operators and expedite their field application. At an oil price of $\$ 20 / \mathrm{B}$, implemented technology EOR and ASR process could contribute 960 million barrels to Louisiana's reserves base. At $\$ 28 / \mathrm{B}$, potential reserve additions could reach over 1.0 billion barrels.

Advances in technology could significantly increase the potential reserves and associated economic benefits which are possible using implemented technology EOR and ASR. Technology advances could increase implemented technology incremental reserves by over 1.0 billion barrels of oil, at an oil price of $\$ 20 / B$. The total potential incremental reserves at this price, over 2.0 billion barrels, is nearly four times Louisiana 1991 onshore proved reserves. At an oil price of $\$ 28 / \mathrm{B}$, technology advances could add nearly 1.9 billion barrels of reserves additions for a total EOR and ASR reserves potential of almost 3.0 billion barrels. If this potential were to be realized, advanced technology EOR and ASR would be more than five times Louisiana 1991 onshore proved reserves.

The activities associated with advanced technology EOR and ASR would generate substantial direct state tax revenues. At $\$ 20 / \mathrm{B}, \$ 1.1$ billion of the $\$ 3.7$ billion of potential direct state revenues are attributable to technology advances. At an oil price of $\$ 28 / \mathrm{B}$, nearly $54 \%$ ( $\$ 3.7$ billion) of the $\$ 6.8$ million in total potential state revenues are due to advances in technology.

The potential benefits estimated in this analysis will not be possible, however, without effective technology transfer and RD\&D programs. Aggressive technology transfer needs to be undertaken by all 
Figure V-8

\section{National Impact of ASR Production}

\section{Implemented Technology vs. Advanced Technology}

A) Direct Federal Revenues

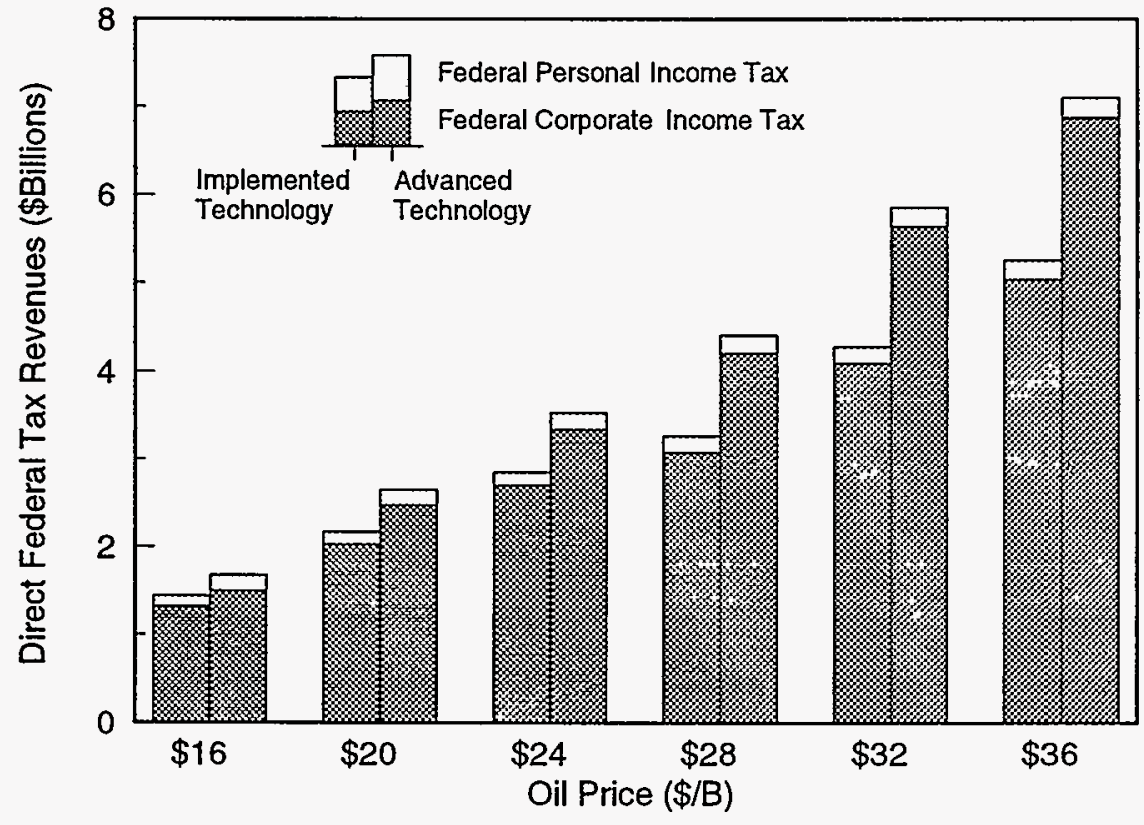

B) Imports Avoided*

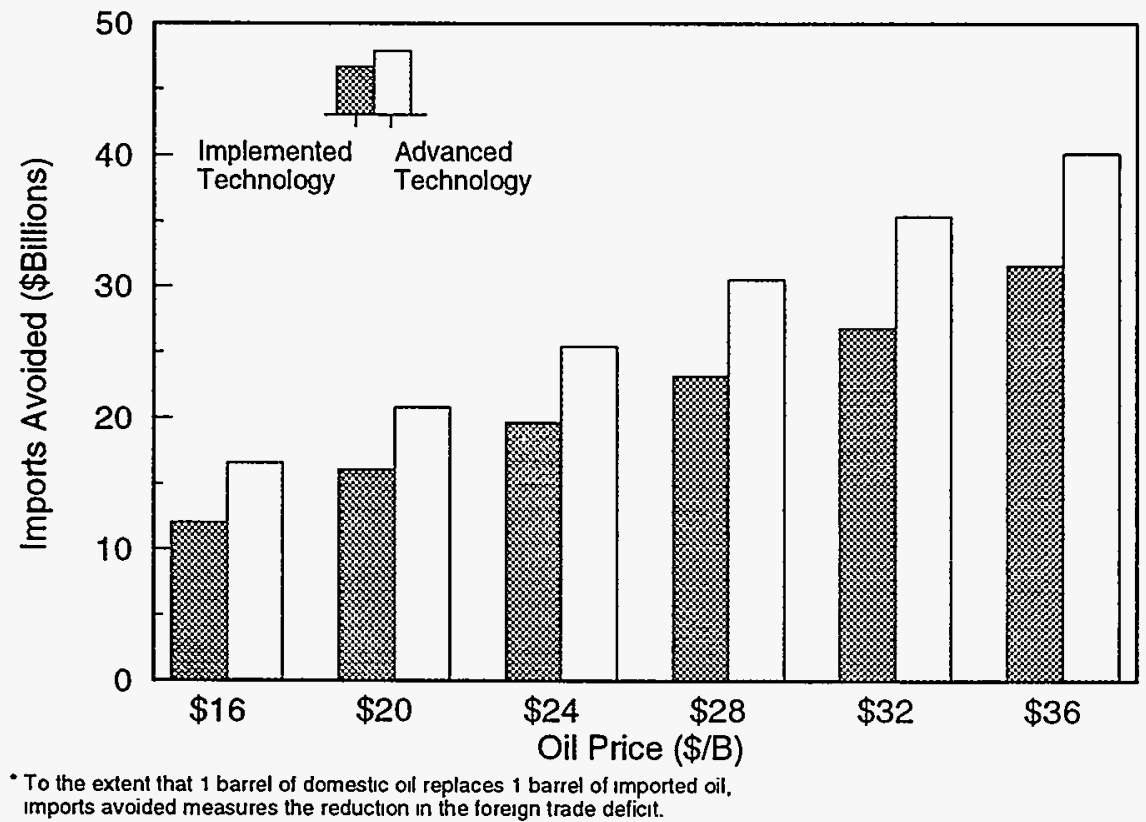


oil-related entities (operators, producer associations, research universities, state geologic surveys, and state and Federal government agencies) in order to ensure that currently available technologies are disseminated in the oil patch and widely applied in the field. The significant additional benefits derived from technology advances clearly warrant a focused RD\&D program to improve advanced oil recovery technologies.

A collaborative effort between the public and private sectors is essential to pool resources and expertise while leveraging risk. Operators, oil companies, research universities, and state geologic surveys need to join with state and local governments and the Federal government to identify the highest priority problems in reservoirs with the largest remaining resources and the greatest threat of abandonment. A focused RD\&D effort targeting the identified problems then needs to be undertaken. An RD\&D effort alone is not enough, however; the newly developed technologies need to be transferred to the field for wide-scale demonstration and application. The Department of Energy's Program Opportunity Notice (PON) process is currently applying some of these concepts. The PON process targets those classes of reservoirs with the largest potential resource and greatest threat of abandonments. Near- and mid-term RD\&D efforts, jointly funded by the Federal government and private industry, are directed towards the producing problems of these reservoirs. The results, once successfully developed and demonstrated, are to be transferred to other operators facing similar producing conditions. While they are a start, efforts like the PON process are not enough. A more aggressive and focused collaborative RD\&D effort will greatly increase domestic production, enhance national energy security, reduce imports, and increase economic benefits associated with oil recovery.

Even after application of advanced technology EOR and ASR, a significant portion of the oil resource will remain unrecovered in the analyzed reservoirs (Figure V-12). At the improbably high oil price of $\$ 36 / \mathrm{B}$, total ASR reserves potential would be 1.1 billion barrels while EOR reserves potential would total 1.9 billion barrels. If this reserves potential were realized, over 3.4 billion barrels of mobile oil (75\% of the mobile oil target) and 6.7 billion barrels of immobile oil (78\% of the immobile oil target) would remain in analyzed reservoirs. In addition, over 6.2 billion barrels of remaining oil not included in this analysis and any newly discovered oil would still be unrecovered after the application of advanced technology EOR and ASR. The known remaining oil-in-place of over 16 billion barrels is the target for further advanced in EOR and ASR technologies. 
Figure V-9

\section{Louisiana Remaining Oil Resource After Advanced Technology Recovery}

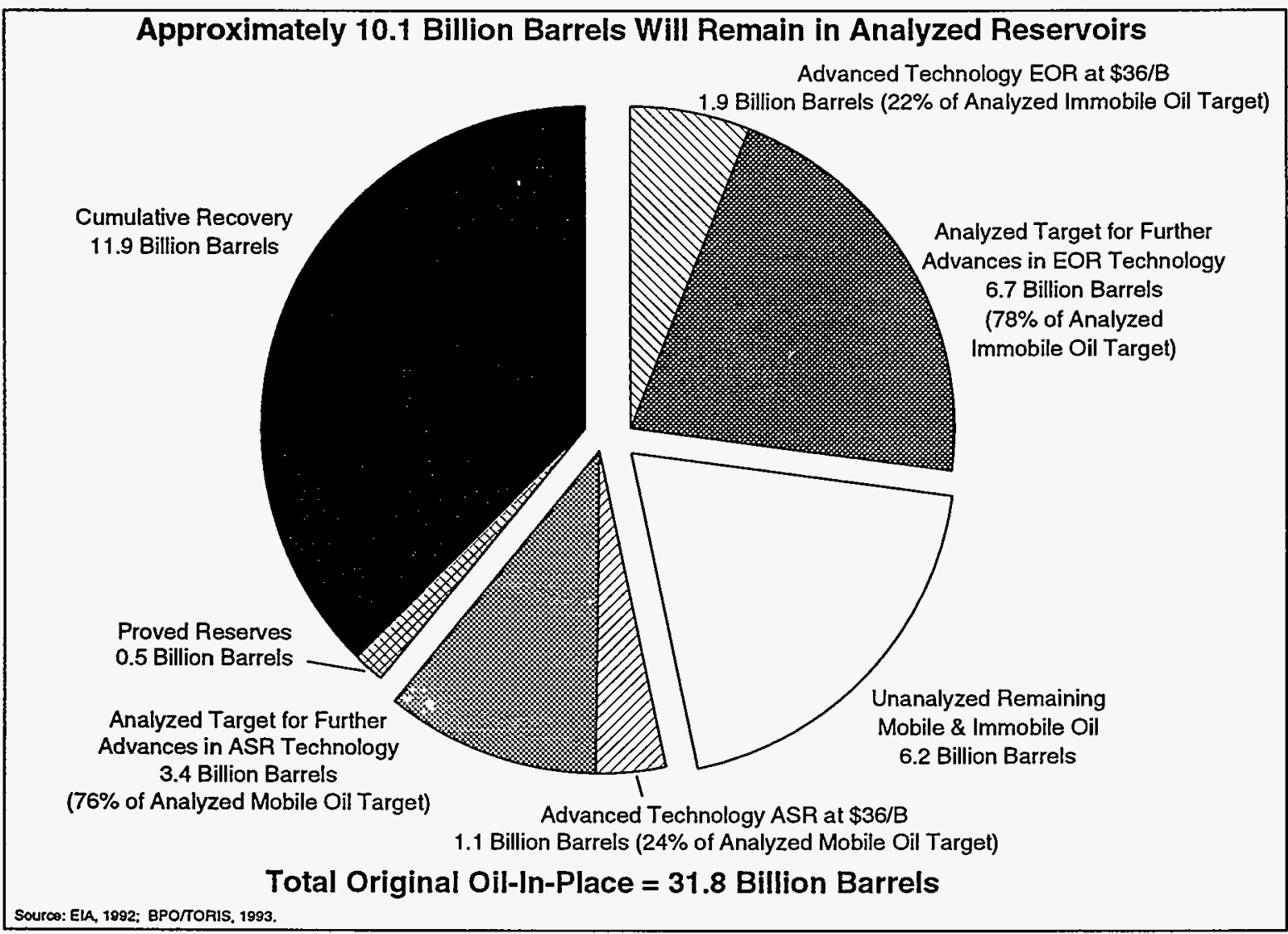


DOE/BC/14431-1 ( Vol. 3)

Distribution Category UC-122

\begin{abstract}
AN EVALUATION OF KNOWN REMAINING OIL RESOURCES IN THE STATE OF TEXAS
\end{abstract}

Project on Advanced Oil Recovery and the States

Volume III

November 1994

Work Performed Under Contract DE-FG22-89BC14431

Prepared for

U.S. Department of Energy

Assistant Secretary for Fossil Energy

R. Michael Ray, Project Manager

Bartlesville Project Office

P.O. Box 1398

Bartlesville, OK 74005

\author{
Prepared by \\ Interstate Oil Compact Commission \\ 900 N.E. 23 rd Street \\ Oklahoma City, OK 73152
}





\section{Table of Contents}

$\underline{\text { Page }}$

LIST OF FIGURES $\ldots \ldots \ldots \ldots \ldots \ldots \ldots \ldots \ldots \ldots \ldots \ldots \ldots \ldots \ldots \ldots$

LIST OF TABLES $\ldots \ldots \ldots \ldots \ldots \ldots \ldots \ldots \ldots \ldots \ldots \ldots \ldots$ vi

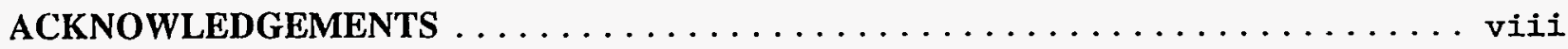

EXECUTIVE SUMMARY $\ldots \ldots \ldots \ldots \ldots \ldots \ldots \ldots \ldots \ldots \ldots \ldots \ldots$ ix

I. OVERVIEW

A. THE PROBLEM: DECLINING TEXAS OIL PRODUCTION . . . . . . . . I-1

B. THE OPPORTUNITY: OIL RECOVERY THROUGH ADVANCED

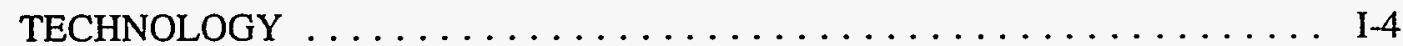

C. BENEFITS DERIVED FROM IMPROVED OIL RECOVERY $\ldots \ldots \ldots \ldots$ I-5

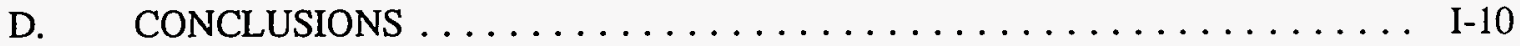

\section{BACKGROUND AND OBJECTIVES}

A. TRENDS IN TEXAS OIL PRODUCTION AND RESERVES $\ldots \ldots \ldots \ldots \ldots$ II-1

B. IMPROVED RECOVERY ACTIVITIES TARGETING THE REMAINING

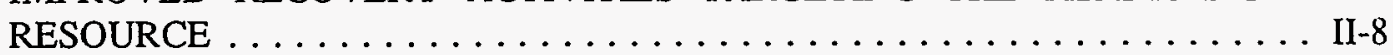

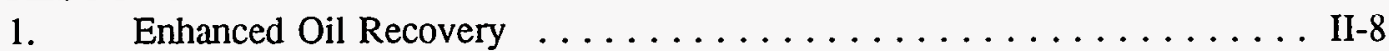

2. Advanced Secondary Recovery .................. II-11

C. OBJECTIVES OF THE PRESENT STUDY $\ldots \ldots \ldots \ldots \ldots \ldots \ldots \ldots$ II-14

\section{APPROACH TO THE ANALYSIS}

A. INTRODUCTION $\ldots \ldots \ldots \ldots \ldots \ldots \ldots \ldots \ldots \ldots \ldots \ldots \ldots \ldots \ldots \ldots \ldots \ldots \ldots$ III-1

B. GENERAL METHODOLOGY: THE NPC BASIS $\ldots \ldots \ldots \ldots \ldots \ldots \ldots$ III-1

C. BUILDING ON TORIS: THE EVALUATION OF UNRECOVERED MOBILE

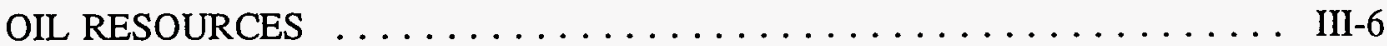

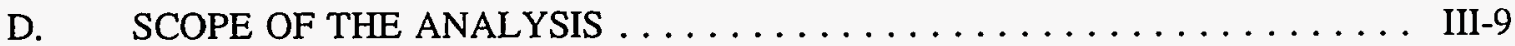

E. ADAPTATIONS FOR THE PRESENT STUDY $\ldots \ldots \ldots \ldots \ldots \ldots \ldots \ldots$ III-11

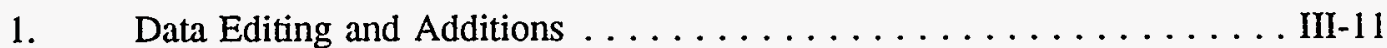

2. State and Federal Taxes ...................... III-11

3. Cost and Price Data ......................... III-12

4. Benefits Estimation ...................... . . . . . $\ldots \ldots$

5. Project Timing . . . . . . . . . . . . . . . . . III-13

F. ESTIMATION OF BENEFITS, COSTS, AND ECONOMIC IMPACTS . . . . III-14

1. Benefits to State and Local Treasuries ................ III-15

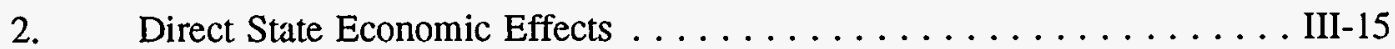

3. National Effects . . . . . . . . . . . . . . . . . III-16

G. LIMITATIONS TO THE ANALYTICAL APPROACH . . . . . . . . III-18 


\section{Table of Contents (Continued)}

$\underline{\text { Page }}$

IV. INCREASED RECOVERY FROM THE KNOWN REMAINING OIL RESOURCE IN TEXAS UNDER IMPLEMENTED TECHNOLOGY

A. INTRODUCTION $\ldots \ldots \ldots \ldots \ldots \ldots \ldots \ldots \ldots \ldots \ldots \ldots$ IV -1

B. RECOVERY OF THE REMAINING IMMOBILE OIL RESOURCE . . . . . . IV-1

1. Production and Reserves ..................... IV-1

2. Increases in State and Local Revenues . . . . . . . . . . . . IV-4

3. Effects on the State Economy .................. IV-6

4. Effects on the National Economy and Budget ........... IV-7

C. RECOVERY OF THE REMAINING MOBLE OIL RESOURCE . . . . . . . IV-9

1. Production and Reserves . . . . . . . . . . . . . . . IV-9

2. Increases in State and Local Revenues . . . . . . . . . . . IV-14

3. Effects on the State Economy .................. IV-15

4. Effects on the National Economy and Budget $\ldots \ldots \ldots \ldots \ldots$ IV-15

D. CONCLUSIONS ........................ IV -18

V. BENEFITS OF INCREASED RECOVERY FROM THE KNOWN REMAINING OIL RESOURCE IN TEXAS WITH TECHNOLOGY ADVANCES

A. INTRODUCTION $\ldots \ldots \ldots \ldots \ldots \ldots \ldots \ldots \ldots \ldots \ldots \ldots \ldots$

B. RECOVERY OF THE REMAINING IMMOBILE OIL RESOURCE $\ldots \ldots \ldots \ldots$ V-1

1. "Advanced" Technology Defined ................. V-1

2. Production and Reserves ..................... V-2

3. Effects on State Revenues and Economic Activity ............ V-7

4. Effects on the National Economy and Budget . . . . . . . . . . V V-9

C. RECOVERY OF THE REMAINING MOBILE OIL RESOURCE . . . . . . . . V-9

1. "Advanced" Technology Defined . . . . . . . . . . . . . . . V-9

2. Production and Reserves . . . . . . . . . . . . . . . . . V-11

3. Effects on State Revenues and Economic Activity ............ V-15

4. Effects on the National Economy and Budget . . . . . . . . . V-18

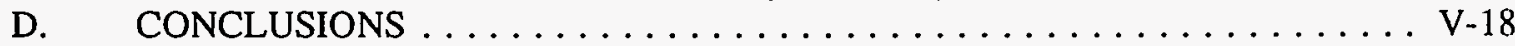




\section{List of Figures}

Figure

$\underline{\text { Page }}$

I-1

I-2

I-3

I -4

I-5

II-1

II-2

II-3

II-4

II-5

II-6

II-7

II-8

II-9

II- 10

IV-1

IV-2

IV-3

IV-4

IV-5

IV-6

IV-7

IV-8

IV-9

IV-10

IV-11

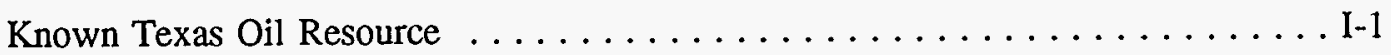

Texas Production and Reserves $\ldots \ldots \ldots \ldots \ldots \ldots \ldots \ldots \ldots \ldots$ I-3

Texas Oil Resource

Data Coverage of EOR and ASR Analyses .............. I-6

Potential Impact of Advanced Technology $\ldots \ldots \ldots \ldots \ldots \ldots \ldots \ldots \ldots$

Texas Remaining Oil Resource

After Advanced Technology Recovery ............... I-11

Texas Crude Oil Production $(1950-1991) \ldots \ldots \ldots \ldots \ldots \ldots \ldots$. . . . . . . II-2

Texas Crude Oil Reserves $(1950-1991) \ldots \ldots \ldots \ldots \ldots \ldots \ldots$. . . . . . . . II-2

Texas Producing Wells $(1960-1991) \ldots \ldots \ldots \ldots \ldots \ldots \ldots$. . . . . . . . . II-4

Texas Stripper Well Production and Abandonments (1970-1990) . . . . . . . . II-4

Total Oil and Gas Employment in Texas (1970-1991) . . . . . . . . . . . . . . II-5

Annual Wellhead Value of Texas Oil and Gas Production (1961-1991) . . . . . . II-5

Texas Oil and Gas Severance Taxes (FY1971-1992) . . . . . . . . . . . . . II-6

Texas Oil and Gas Severance Taxes as a Percent of Total

State Taxes (FY1971-1992) . . . . . . . . . . . . . . . . . . II-6

Texas Oil Resource . . . . . . . . . . . . . . . . . . . . II-7

Texas Remaining Oil Resource

After Conventional Recovery Operations . . . . . . . . . . II-15

Reserves and Production Response from EOR Techniques

Implemented Technology . . . . . . . . . . . . . IV-5

Direct State and Local Revenues from EOR Production

Implemented Technology $\ldots \ldots \ldots \ldots \ldots \ldots \ldots$ IV-6

Direct State Economic Activity from EOR Production

Implemented Technology $\ldots \ldots \ldots \ldots \ldots \ldots \ldots$ IV -8

Jobs and Wages from EOR Production

Implemented Technology $\ldots \ldots \ldots \ldots \ldots \ldots \ldots$ IV-8

National Impact of EOR Production

Implemented Technology . . . . . . . . . . . . . IV-10

Reserves and Production Response from ASR

Implemented Technology . . . . . . . . . . . . . . . IV-13

Direct State and Local Revenues from ASR Production

Implemented Technology $\ldots \ldots \ldots \ldots \ldots \ldots \ldots$ IV-14

Direct State Economic Activity from ASR Production

Implemented Technology $\ldots \ldots \ldots \ldots \ldots \ldots$ IV-16

Jobs and Wages from ASR Production

Implemented Technology $\ldots \ldots \ldots \ldots \ldots \ldots \ldots \ldots$ IV-16

National Impact of ASR Production

Implemented Technology . . . . . . . . . . . . . . . IV-17

Texas Remaining Oil Resource After Implemented Technology Recovery ... . IV-19 


\section{List of Figures (Continued)}

Figure

$\underline{\text { Page }}$

V-1 Incremental Reserves by EOR Process

Implemented Technology vs. Advanced Technology $\ldots \ldots \ldots \ldots \ldots$ V-3

$\mathrm{V}-2$

Annual Production from EOR Reserves

Implemented Technology vs. Advanced Technology $\ldots \ldots \ldots \ldots \ldots$ V-6

V-3 State Impact of EOR Production

Implemented Technology vs. Advanced Technology $\ldots \ldots \ldots \ldots \ldots$ V-8

V-4 National Impact of EOR Production

Implemented Technology vs. Advanced Technology . . . . . . . . V-10

V-5 Incremental Reserves by ASR Process

Implemented Technology vs. Advanced Technology . . . . . . . V V-12

V-6 Annual Production from ASR Reserves

Implemented Technology vs. Advanced Technology $\ldots \ldots \ldots \ldots$ V-16

V-7 State Impact of ASR Production

Implemented Technology vs. Advanced Technology $\ldots \ldots \ldots . \ldots \quad V-17$

V-8

National Impact of ASR Production

Implemented Technology vs. Advanced Technology . . . . . . . . . V-19

V-9 Texas Remaining Oil Resource After Advanced Technology $\ldots \ldots \ldots \ldots$. . . . 
Table

$\underline{\text { Page }}$

I-1

Summary of Benefits from Technology Advances in EOR and ASR in Texas . . . I-9

III-1

Key Elements in the Current TORIS Reservoir Data Base . . . . . . . . . . . III-3

III-2

Screening Criteria for EOR Candidates - Implemented Technology Case . . . . . III-4

III-3

Screening Criteria for EOR Candidates - Advanced Technology Case . . . . . . . III-5

III-4

Screening Criteria for Advanced Secondary Recovery Processes . . . . . . . . . . III-8

III-5

Screening and Approach for Advanced Technology Infill Drilling . . . . . . . . . III-9

III-6

Risk Premium for Implemented and Advanced EOR and ASR Processes . . . . . . III-10

III-7

Labor and Materials as Percentage of Total Cost In EOR Projects . . . . . . . . III-17

IV-1A Incremental Reserves from EOR by Process

Implemented Technology . . . . . . . . . . . . . IV-3

IV-1B Estimated Number of Economic EOR Projects by Process

Implemented Technology . . . . . . . . . . . . . . IV-3

IV-2A Incremental Reserves from ASR by Process

Implemented Technology $\ldots \ldots \ldots \ldots \ldots \ldots$ IV-12

IV-2B Estimated Number of Economic ASR Projects by Process

Implemented Technology $\ldots \ldots \ldots \ldots \ldots \ldots$ IV-12

V-1A Incremental Reserves from EOR by Process

Implemented Technology vs. Advanced Technology $\ldots \ldots \ldots \ldots \ldots$ V-5

$\mathrm{V}-1 \mathrm{~B}$

Estimated Number of Economic EOR Projects by Process

Implemented Technology vs. Advanced Technology $\ldots \ldots \ldots \ldots \ldots$ V-5

$\mathrm{V}-2 \mathrm{~A}$

$\mathrm{V}-2 \mathrm{~B}$

Incremental Reserve Additions from ASR by Process

Implemented Technology vs. Advanced Technology . . . . . . . . . V-14

Estimated Number of Economic ASR Projects By Process

Implemented Technology vs. Advanced Technology . . . . . . . V V-14 


\section{ACKNOWLEDGMENTS}

An Evaluation of the Known Remaining Oil Resource in the State of Texas is one in a series of reports on the Project of Advanced Oil Recovery and the States, conducted by the Interstate Oil and Gas Compact Commission (IOGCC). The overall project was initiated by "seed money" grants from the States of Oklahoma and New Mexico in 1985. This report was prepared under grant number DE-FG2289BC14431 from the U.S. Department of Energy, Bartlesville Project Office (BPO) to the IOGCC.

The analysis presented in this report is based on an updated and upgraded version of the databases and models developed by the National Petroleum Council (NPC) in 1984. The NPC models and data, as well as computer time, were made available for this study by BPO. Special acknowledgment to Mr. R. Michael Ray, Deputy Director of BPO, is extended for his valuable technical advice and guidance and to Mr. Thomas C. Wesson, BPO Director, for his encouragement and assistance.

Special recognition is due to those who directly performed the work of the project. ICF Resources Incorporated of Fairfax, Virginia, served as the IOGCC's principal contractor, responsible for the study design, computer modeling, analysis, interpretation, and report preparation. ICF's Project Director was Dr. Jerry P. Brashear, Mr. Khosrow Biglarbigi was the Project Manager, and the critical project staff included Mr. Hugh D. Guinn, and Mr. Donald J. Remson (engineering and computer modeling); Mr. Karl Lang, Dr. Frank Morra (Consultant), and Mr. Jeff Enright (analysis and report generation); Mr. Marc Greenberg, Ms. Sohinaz Sotoudeh, and Mr. Mike Schildkraut (editing, research, and analytical support); Mr. Alan B. Becker (Final Review); Ms. Barbara Jones (Administrator), Ms. Cheryl A. Labrecque (Senior Staff Assistant), Ms. Mary Bowers (Staff Assistant) and Ms. Barbara Gillen (word processing support).

Special recognition is also due to the members of the DOE/IOGCC Peer Review Committee; Mr. Lloyd Elkins, Dr. Alan Emanuel, Dr. Lee Gerhard, Dr. Donald Green, Dr. John D. Haun, Mr. Joseph E. King, Dr. Charles Mankin, Dr. David Martin, Dr. Donald Oltz, Dr. Fred H. Poettmann, Mr. William C. Stewart, and Dr. G. Paul Willhite.

This analysis was conceived and commissioned by W. Timothy Dowd, Executive Director of the IOGCC through June 1993. Mr. Dowd's keen interest in promoting the development of the nation's resource base has been the guiding force behind this study. To the degree that the results of this work help to improve the recovery of oil from U.S. reservoirs, Mr. Dowd's goals for the IOGCC will have been furthered. Mr. Bob Cooper, former Associate Director of the IOGCC, and Mr. Jerry Simmons (Associate Director) provided liaison and coordination among the participating organizations.

While acknowledging the assistance of all these contributors, error of fact, analysis, or interpretation are the responsibility of the IOGCC and the principal contractor's project director.

Christine Hansen

Executive Director

November 1993 


\section{EXECUTIVE SUMMARY}

The Interstate Oil and Gas Compact Commission (IOGCC) has conducted a series of studies to evaluate the known, remaining oil resource in twenty-three (23) states. The primary objective of the IOGCC's effort is to examine the potential impact of an aggressive and focused program of research, development, and demonstration (RD\&D) and technology transfer on future oil recovery in the United States. As a part of this larger effort by the IOGCC, this report focuses on the potential economic benefits of improved oil recovery in the state of Texas. Individual reports for seven other oil producing states and a national report have been separately published by the IOGCC. Several major technical insights for state and Federal policymakers and regulators can be reached from this analysis.

- At the conclusion of conventional recovery operations, three-fifths of the known originaloil-in-place will remain in Texas oil reservoirs.

- The remaining resource, over 100 billion barrels, is the target for future improved oil recovery techniques. However, a significant portion of this remaining oil resource has already been abandoned. An even greater portion is in imminent danger of abandonment if cost-effective and efficient recovery techniques are not applied.

- Resource abandonment will significantly impact the economic producibility of future production and reserves under improved oil recovery techniques. This is because major capital investments will be needed to reacquire the leases, rebuild the infrastructure, and more importantly, drill new wells to regain access to the Texas target resource.

- Texas' future as a premier energy producing state depends strongly on the development of efficient and cost-effective oil recovery technologies, technology transfer to domestic producers, and the timely and successful application of such technologies, given the steady decline in Texas production and reserves and the accelerating level of well abandonment over the past decade.

- The effective transfer of existing technology could result in 3.0 to 4.4 billion barrels of new reserves from analyzed Texas reservoirs at oil prices ranging from $\$ 20 / \mathrm{B}$ to $\$ 28 / \mathrm{B}$, potentially increasing the state's current proved reserves by $40 \%$ to $65 \%$.

- Technology advances resulting from a focused RD\&D effort could result in additional post-conventional reserves of 2.0 to 4.5 billion barrels for a total of 5.0 to 9.0 billion barrels. The effective transfer of existing technology, coupled with the development and application of new technologies, could more than replace current proved reserves in Texas.

- Public sector revenues from future improved oil recovery activity would total between $\$ 9$ and $\$ 20$ billion given currently available recovery practices and oil prices of $\$ 20 / \mathrm{B}$ to $\$ 28 / \mathrm{B}$. Technology advances could increase these totals by $\$ 4.4$ to $\$ 12$ billion over the same price range, with roughly $40 \%$ of the total flowing to the state treasury. 
Potential improved oil recovery would replace imports of foreign oil, keeping between $\$ 58$ billion and $\$ 120$ billion in the U.S. economy. This figure is only the direct cost of imports avoided due to increased domestic activity. The true value to the country is actually much higher due to multiplier effects as this money circulates in the economy.

The analysis presented in this report is based on the databases and models available in the Tertiary Oil Recovery Information System (TORIS). TORIS is a tested and verified system maintained and operated by the Department of Energy's Bartlesville Project Office. The TORIS system was used to evaluate over 850 major Texas reservoirs in a consistent manner and on an individual basis, the results of which have been aggregated to arrive at the statewide total.

Overall, well abandonments and more stringent environmental regulations could limit economic access to Texas' known, remaining oil resource. The high risk of near-term abandonment and the significant benefits of future application of improved oil recovery technology, clearly point to a need for more aggressive transfer of currently available technologies to oil producers. Development and application of advanced oil recovery technologies could have even greater benefits to the state and the nation. A collaborative, focused RD\&D effort, integrating the resources and expertise of industry, state and local governments, and the Federal government, is clearly warranted. With effective RD\&D and a program of aggressive technology transfer to widely disseminate its results, Texas oil production could be maximized. The resulting increase in production rates, employment, operator profits, state and Federal tax revenues, and energy security will benefit both the state of Texas and the nation as a whole. 


\section{OVERVIEW}

\section{A. THE PROBLEM: DECLINING TEXAS OIL PRODUCTION}

Over three-fifths of the oil discovered in the state of Texas will remain trapped in the reservoir at the conclusion of conventional oil recovery operations. The total known original oil-in-place in Texas has been estimated at nearly 161 billion barrels (Figure I-1). Almost 54 billion barrels had already been produced at the end of 1991 . Nearly 7 billion barrels of proved reserves are still producible under existing economic conditions, using currently available technologies. The remaining 100 billion barrels is the target for newer, more efficient recovery technologies and advances in geoscientific understanding that must be developed through an integrated public and private research effort.

Figure I-1

Known Texas Oil Resource

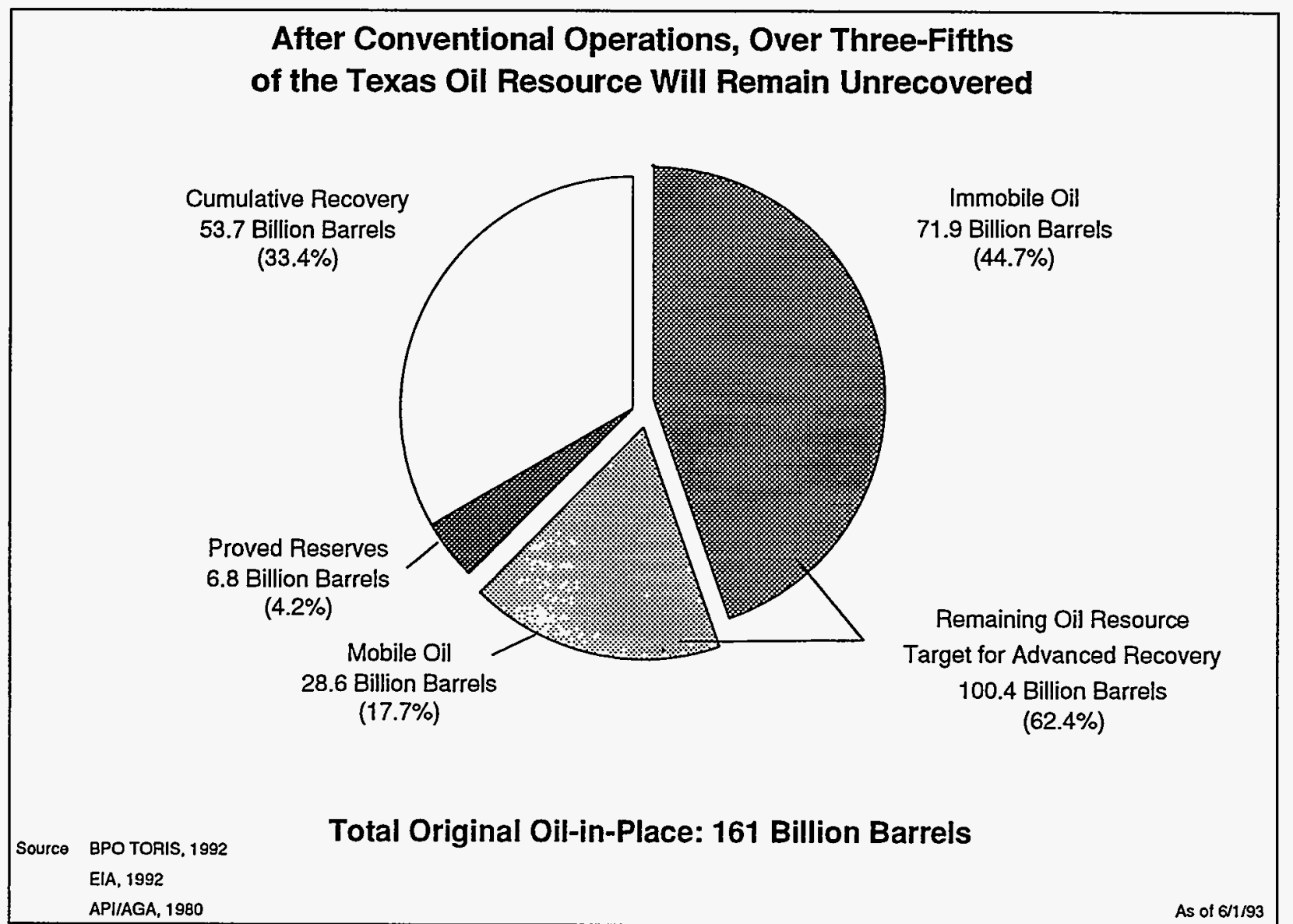


The urgency for technology development and its effective application by Texas oil producers has never been greater. The two factors that have combined to make technology development critical are:

Declining state production and reserves. Texas oil production has declined by $46 \%$ from 1972 through 1991 (Figure I-2A). Crude oil reserves decreased by roughly the same percentage (Figure I-2B). Although this decline has leveled off in recent years, reserve additions have not been quite sufficient to replace production volume. The average size of new field discoveries has been relatively small and reserves per well have decreased.

Increased level of well abandonment. The state of Texas currently produces oil from roughly 200,000 wells. Many of these wells are "marginal" wells producing at or near their economic limit. Once production ceases, these wells must be routinely tested to prove that they are not pollution hazards, and plugged and abandoned if they fail the test. In a period of high production costs and low oil price, many of these wells are being abandoned. A recent analysis by the Department of Energy (DOE) has concluded that from $37 \%$ to $45 \%$ of the nation's remaining oil resources had been abandoned by the end of 1991. ${ }^{1}$ Well abandonments will have a significant impact on economic access to the remaining resource for application of future improved recovery techniques. It is estimated that once a lease is abandoned, it will require an oil price increase of $\$ 10 / \mathrm{B}$ to $\$ 25 / \mathrm{B}$ to rebuild the infrastructure and drill replacement wells. ${ }^{2}$ Such an economic burden will not likely be justified by the incremental oil revenues from future improved recovery techniques.

The future of Texas oil production and reserves depends strongly on the development and application of cost-effective and efficient technology. In the past, technology advances have made substantial contributions to Texas oil production. The development of new exploration techniques, secondary recovery technology, and offshore drilling technology has acted to reverse past production declines and has allowed Texas to maintain and increase its producible oil and gas resources. Oil producers in the state of Texas have also pioneered much of the development of enhanced oil recovery technology, particularly in the case of carbon dioxide flooding and improved waterflooding techniques. The opportunity exists for a program of research, development and demonstration (RD\&D), combined with an integrated program of technology transfer to all sectors of the Texas petroleum community, to arrest the decline in production and maximize recovery of the state's oil resource.

1 "Abandonment Rate of the Known Domestic Oil Resource", U.S. DOE, Bartlesville Project Office, Bartlesville, OK (June 1990).

2 Brashear, J.P. et al "Effect of Well Abandonments on EOR Potential," JPT, December 1991. 
Figure I-2

\section{Texas Production and Reserves}

A) Annual Production

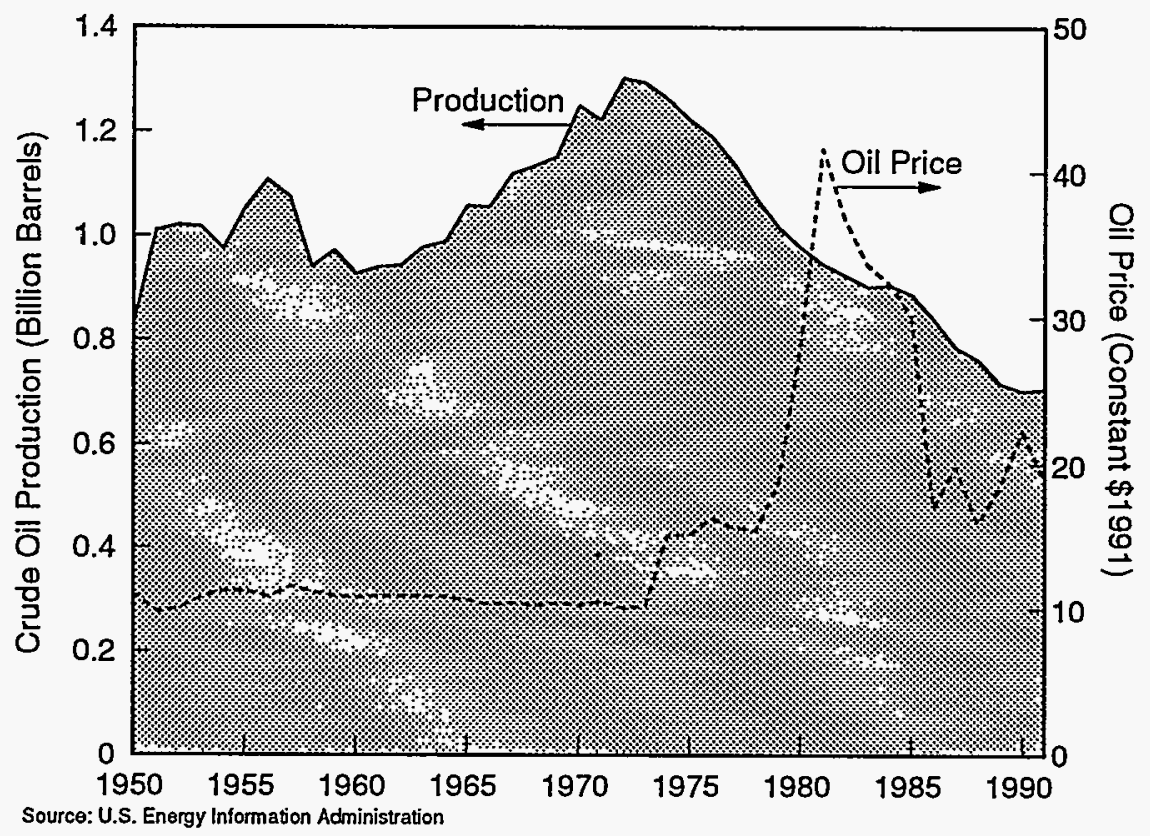

B) Reserves

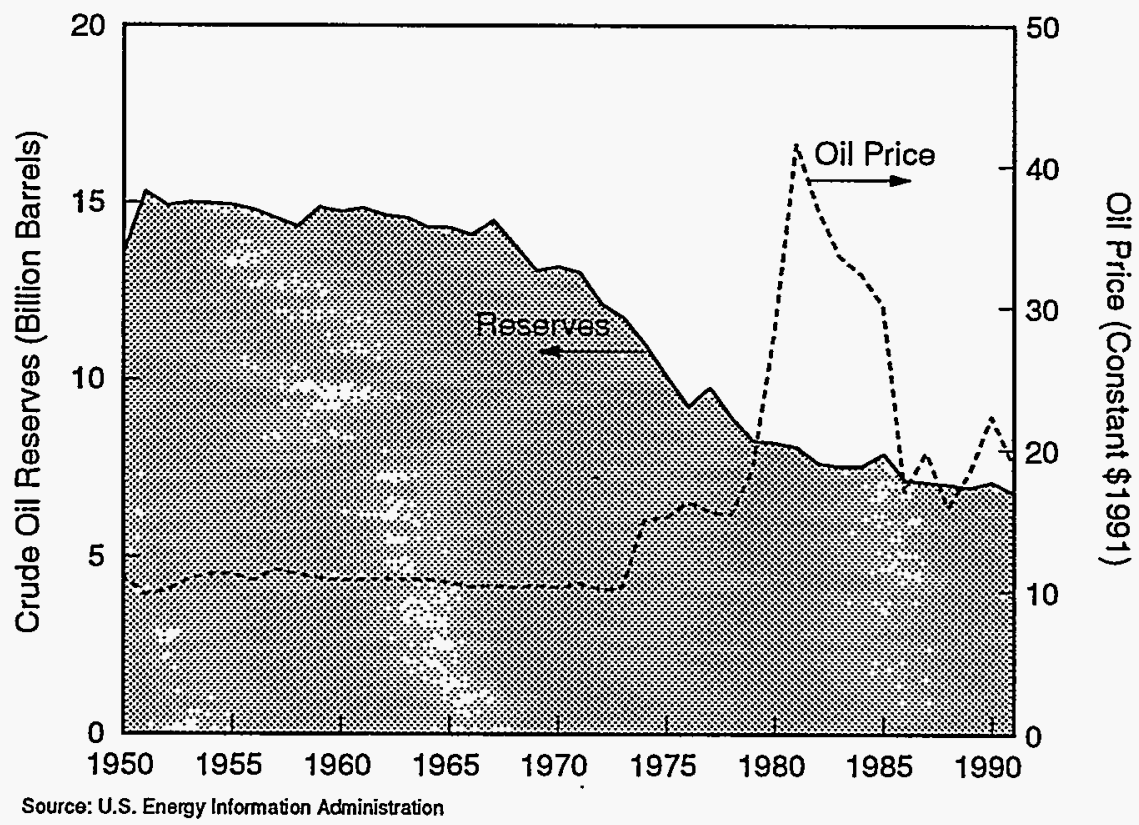




\section{B. THE OPPORTUNITY: OIL RECOVERY THROUGH ADVANCED TECHNOLOGY}

The remaining oil resource constitutes a huge target for future recovery operations. The 100 billion barrels of known unrecovered oil in the state of Texas is of two types: mobile oil and immobile oil. Even though mobile oil is displaceable by water, it has been uncontacted or bypassed during conventional primary production or water flooding and thus remains unrecovered. Immobile oil is oil that is trapped in the reservoir pores by viscous and capillary forces and cannot be displaced by water.

The estimated unrecovered mobile oil (UMO) resource in Texas is 29 billion barrels. This oil is an important target for future improved recovery efforts. Several improved primary and secondary recovery processes (infill drilling, profile modification, and polymer flooding), collectively referred to as advanced secondary recovery (ASR), could be used in innovative ways to produce a substantial portion of this resource. Processes such as these are relatively low in cost and could increase production levels quickly. While such techniques have already been used by some operators in selected reservoirs, continued research and aggressive technology transfer are critically needed to improve, streamline, and adapt these techniques to site-specific reservoir conditions and broaden their applications.

The 72 billion barrel remaining immobile oil resource in Texas is the target of a number of other recovery techniques. Miscible, chemical, and thermal recovery processes directed at producing immobile oil are referred to as enhanced oil recovery (EOR). While these processes generally require larger investments and higher operating costs than conventional recovery ones, they are capable of producing substantial volumes of incremental oil with substantial economic benefits. Further advances in EOR technology are foreseeable if a focused, research-intensive approach is adopted to make process improvements ready for field application.

\section{Technology Assessment Method}

The benefits of RD\&D in oil recovery technology assessed in this report are based on the models and databases available through the Tertiary Oil Recovery Information System (TORIS). The TORIS methodology and analytical tools were originally developed by the National Petroleum Council (NPC) ${ }^{3}$ for its 1984 evaluation of nationwide EOR potential. DOE has since maintained and updated the system

3 National Petroleum Council, Enhanced Oil Recovery, Washington, DC, 1984. 
through its Bartlesville Project Office (BPO). ${ }^{4}$ DOE has also upgraded the capability of the system to evaluate the nation's unrecovered mobile oil through ASR techniques. In this report, the future potential of EOR and ASR techniques are examined with the following key assumptions and considerations:

- A total of 853 Texas reservoirs accounting for nearly 128 billion barrels of original oil-inplace, were individually analyzed for their EOR and ASR potential.

- Two levels of technology are considered: (1) implemented technology -- defined as the application of currently available post-conventional techniques; and (2) advanced technology -- defined as the improvements in process performance and applicability which are likely to occur over the next decade as the result of ongoing RD\&D efforts.

- For each technology level, benefits were evaluated at several oil prices ranging from $\$ 16 / \mathrm{B}$ to $\$ 36 / \mathrm{B}$ (1991 dollars).

- All economic analyses reflect the current Federal tax structure and the specific oil production tax situation in Texas. The FY 1991 Federal EOR tax credit, as well as state EOR and ASR tax incentives are included in this analysis.

- The results presented in this report reflect only the benefits and reserve potential associated with the 853 analyzed reservoirs (almost $80 \%$ of total known Texas OOIP as shown in Figure I-3). No attempt is made to extrapolate the results to the remaining Texas resource not available in the TORIS database.

- All recovery potential evaluated in this report are for future new projects only, and they do not include incremental reserves from existing EOR projects. However, the expansion to the existing projects, if technically and economically feasible, are evaluated as part of future new projects in this report.

\section{BENEFITS DERIVED FROM IMPROVED OIL RECOVERY}

Potential incremental reserve volumes and resulting direct state and local revenues that could be generated through improved oil recovery (EOR and ASR) techniques under both the implemented and advanced technology cases are shown in Figure I-4. Implemented technology, if more widely applied, could add between 2 and 5 billion barrels of incremental reserves across the entire oil price range. Advanced technology applied to the same resource base could stimulate an additional 1.4 to 4.6 billion barrels of incremental resources for a total of 3.4 to 9.6 billion barrels beyond currently proven reserves. In effect, improvements in process performance and application could nearly double the reserves possible under implemented technology conditions. This clearly provides a major justification for a focused RD\&D and technology transfer program.

4 Producing Unrecovered Mobile Oil: Evaluation of Potential Economically Recoverable Reserves in Texas, Oklahoma, and New Mexico, DOE, May 1990. 


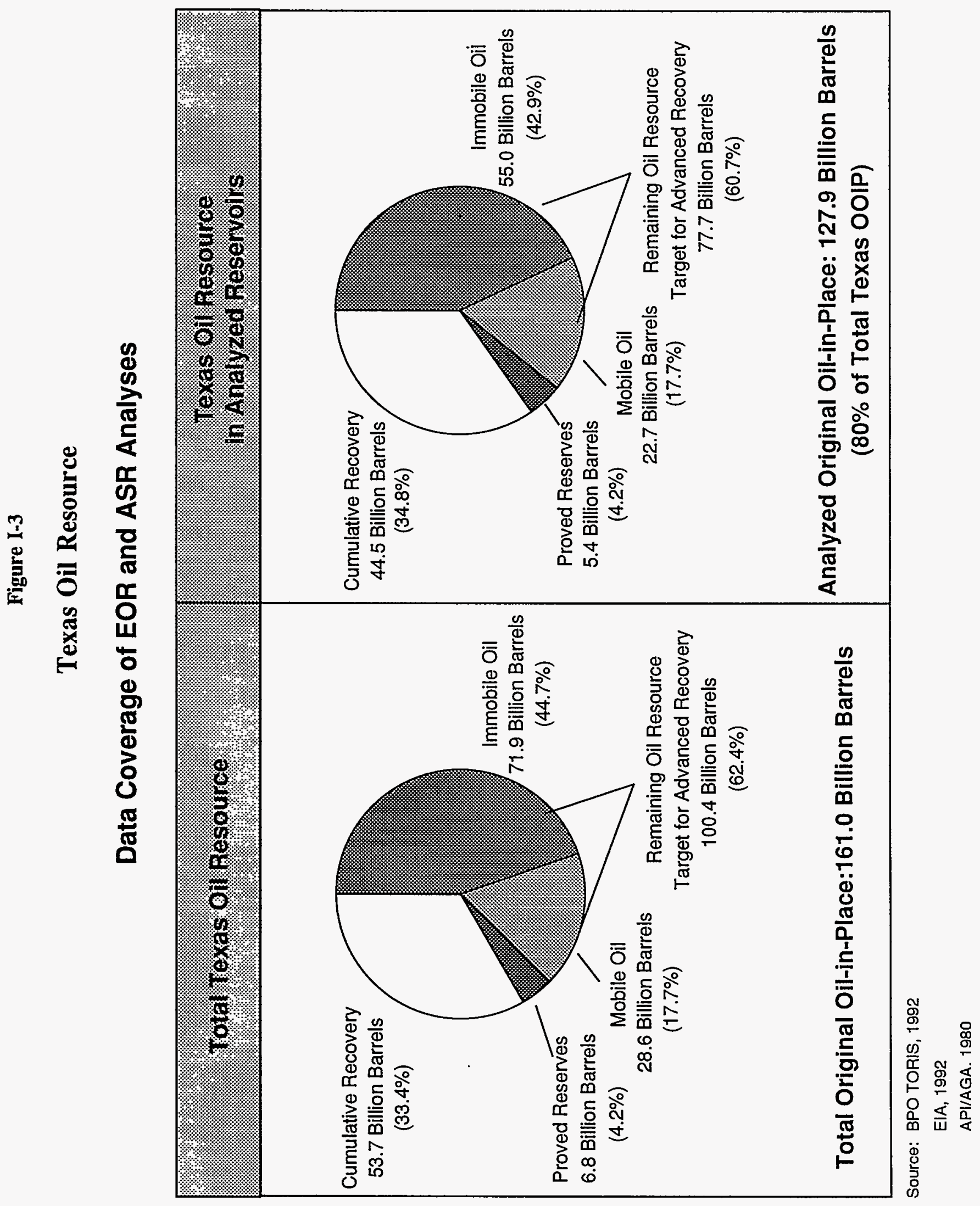


The potential for expanded application of EOR techniques using implemented technology is limited if prices remain at or below $\$ 20 / \mathrm{B}$; incremental EOR recovery at this price would total only about 880 million barrels. However, implemented technology EOR could add 2.1 billion barrels of reserves at a higher oil price of $\$ 28 / \mathrm{B}$. At this oil price, advances in EOR technology could stimulate an additional 3.1 barrels of incremental reserves. This means that a total of 5.2 billion barrels of potential EOR recovery exists under the two levels of technology for the analyzed reservoirs.

Reserve additions attributed to ASR techniques are also substantial but are impacted much less to oil price changes than EOR. About 2.1 billion barrels of ASR reserves could be added in the implemented technology case at an oil price of $\$ 20 / \mathrm{B}$, growing only slightly to 2.6 billion barrels as oil prices increase to $\$ 36 / \mathrm{B}$. Research on process improvements, specifically improved polymer flooding and profile modification combined with geologically targeted infill drilling, could increase ASR potential by $30 \%$ to $50 \%$. With advances in technology, incremental ASR reserve additions could total about 1 billion barrels more than implemented technology over the price range analyzed, for a total of 3.3 to 3.4 billion barrels of potential ASR reserves.

Future advanced oil recovery activities will generate revenues for Texas and the Federal treasury through increased production taxes and oil industry-related sales taxes. The revenue estimates in this study consider only direct revenues from recovery activities in the analyzed reservoirs, and exclude any additional indirect benefits from multiplier or "ripple" effects within the state or national economy. Under implemented technology at $\$ 20 / \mathrm{B}$, newly implemented improved oil recovery projects in Texas could directly generate $\$ 2.4$ billion in state revenues. At the same oil price, advanced technology could generate an additional $\$ 1.6$ billion, for a total of $\$ 4.0$ billion in state revenues (Figure $I-4$ ). At an oil price of $\$ 28 / B$, application of currently available EOR and ASR technology could contribute $\$ 5$ billion to the Texas public treasury while the application of advanced methods could increase these revenues by an additional $\$ 5$ billion to a total of $\$ 10$ billion.

Increased production from EOR and ASR could offset oil imports, which in turn would reduce the national trade deficit, and increase national economic activity. The value of the oil produced, the product of reserves and their effective oil price, is a simple measure of Texas' contribution to reducing imports. As shown in Table I-1, this figure could total between $\$ 58$ billion and $\$ 120$ billion under the implemented technology scenario, over the $\$ 20 / \mathrm{B}$ to $\$ 28 / \mathrm{B}$ range. Advanced technology could further decrease imports by an additional $\$ 41$ billion to $\$ 119$ billion. The additional value of domestically produced EOR and ASR generates significant direct economic activities as capital spending, profits, royalties, and taxes are circulated through the U.S. economy rather than exported to buy foreign oil. 
Figure I-4

Potential Impact of Advanced Technology

A) Reserve Additions

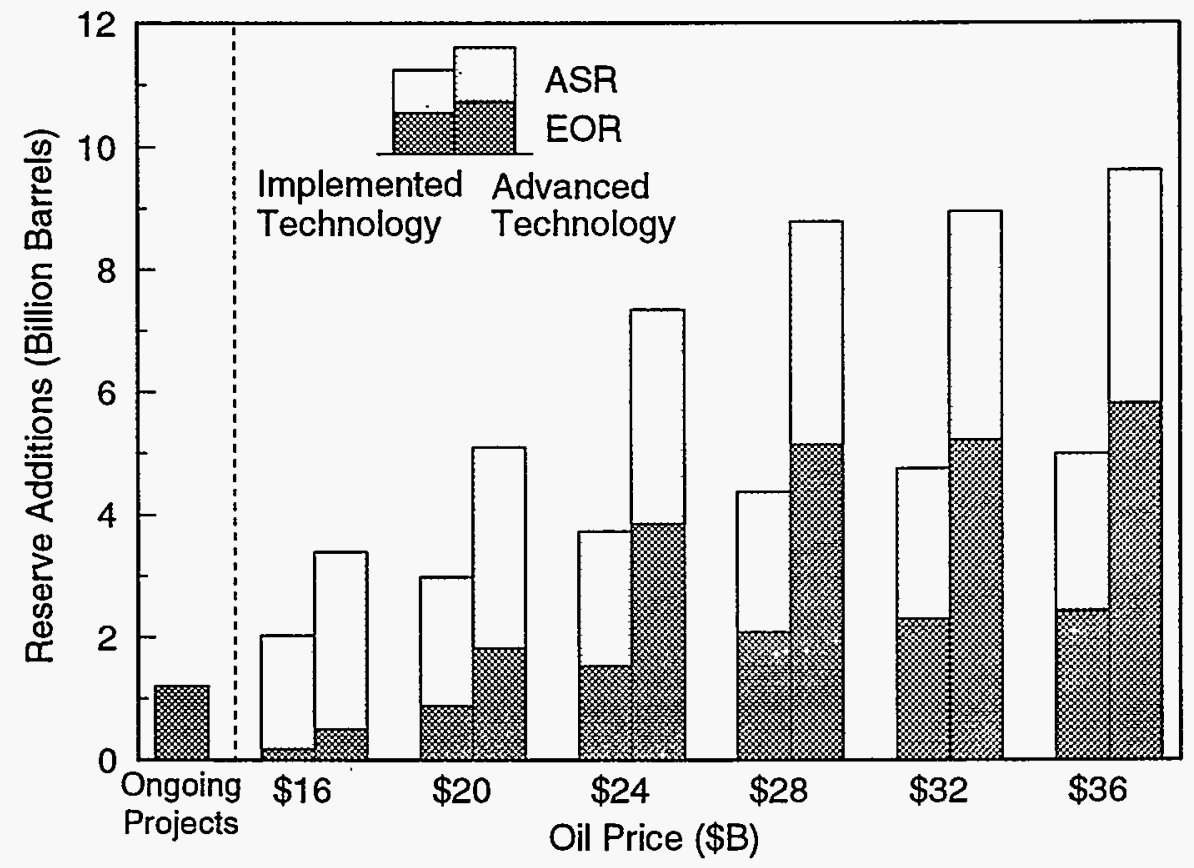

B) Direct State and Local Revenues

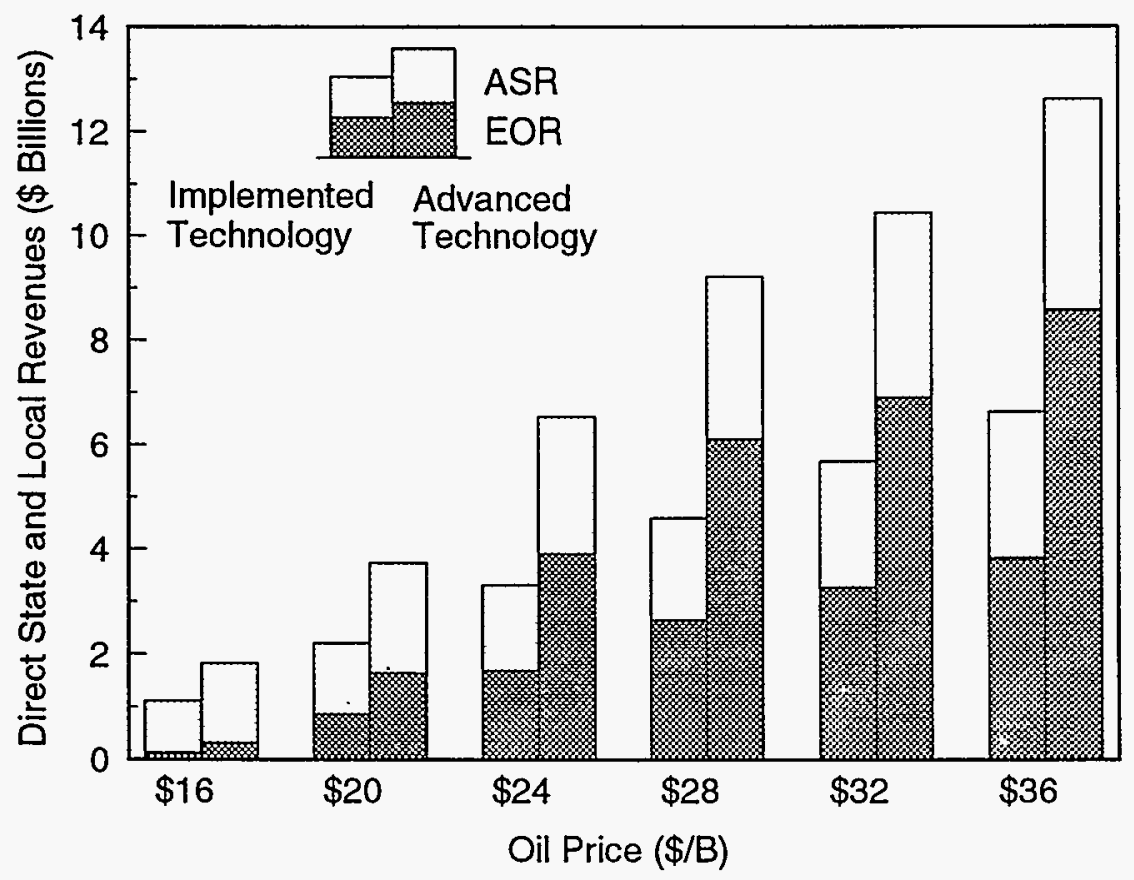


Table I-1

\section{Summary of Benefits from Technology Advances in EOR and ASR in Texas}

\begin{tabular}{|c|c|c|c|c|}
\hline 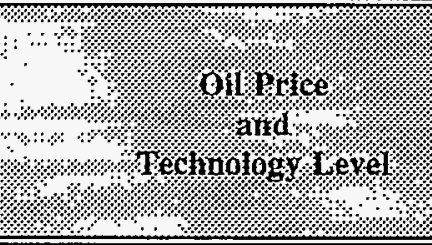 & Rotaritratl: & 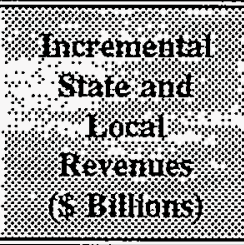 & 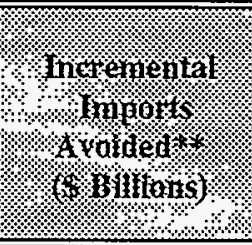 & (I) \\
\hline $\begin{array}{l}\frac{\text { At } \$ 16 / \mathbf{B}}{\text { Implemented Technology }} \\
\text { Advanced Technology* } \\
\text { Total }\end{array}$ & $\begin{array}{l}2.0 \\
\frac{1.4}{3.4}\end{array}$ & $\begin{array}{l}1.2 \\
\frac{0.8}{2.0}\end{array}$ & $\begin{array}{l}32.0 \\
21.0 \\
53.0\end{array}$ & $\begin{array}{l}3.9 \\
\frac{1.5}{5.4}\end{array}$ \\
\hline $\begin{array}{l}\frac{\text { At } \$ 20 / \mathbf{B}}{\text { Implemented Technology }} \\
\text { Advanced Technology* } \\
\text { Total }\end{array}$ & $\begin{array}{l}3.0 \\
\frac{2.1}{5.1}\end{array}$ & $\begin{array}{l}2.4 \\
\frac{1.6}{4.0}\end{array}$ & $\begin{array}{l}58.6 \\
41.1 \\
99.7\end{array}$ & $\begin{array}{l}6.8 \\
2.8 \\
9.6\end{array}$ \\
\hline $\begin{array}{l}\frac{\text { At } \$ 24 / \mathbf{B}}{\text { Implemented Technology }} \\
\text { Advanced Technology* } \\
\text { Total }\end{array}$ & $\begin{array}{l}3.7 \\
\frac{3.7}{7.4}\end{array}$ & $\begin{array}{l}3.6 \\
\frac{3.5}{7.1}\end{array}$ & $\begin{array}{r}87.8 \\
83.7 \\
171.5\end{array}$ & $\begin{array}{r}10.4 \\
\frac{5.1}{15.5}\end{array}$ \\
\hline $\begin{array}{l}\frac{\text { At } \$ 28 / \mathbf{B}}{\text { Implemented Technology }} \\
\text { Advanced Technology* } \\
\text { Total }\end{array}$ & $\begin{array}{l}4.4 \\
4.4 \\
8.8\end{array}$ & $\begin{array}{r}5.0 \\
5.0 \\
10.0\end{array}$ & $\begin{array}{r}120.1 \\
119.3 \\
239.4\end{array}$ & $\begin{array}{r}14.7 \\
6.9 \\
21.6\end{array}$ \\
\hline $\begin{array}{l}\frac{\text { At } \$ 32 / \text { B }}{\text { Implemented Technology }} \\
\text { Advanced Technology* } \\
\text { Total }\end{array}$ & $\begin{array}{l}4.8 \\
\frac{4.1}{8.9}\end{array}$ & $\begin{array}{r}6.1 \\
5.2 \\
11.3\end{array}$ & $\begin{array}{r}149.4 \\
128.9 \\
278.3\end{array}$ & $\begin{array}{l}21.7 \\
\frac{13.5}{35.2}\end{array}$ \\
\hline $\begin{array}{l}\frac{\text { At } \$ 36 / \mathbf{B}}{\text { Implemented Technology }} \\
\frac{\text { Advanced Technology* }}{\text { Total }}\end{array}$ & $\begin{array}{l}5.0 \\
\frac{4.6}{9.6}\end{array}$ & $\begin{array}{r}7.2 \\
6.4 \\
13.6\end{array}$ & $\begin{array}{l}176.5 \\
160.3 \\
336.8\end{array}$ & $\begin{array}{l}27.9 \\
22.0 \\
49.9\end{array}$ \\
\hline
\end{tabular}

*Advanced is incremental over implemented technology.

** Imports Avoided $=$ Reserves times effective wellhead price; to the extent that 1 barrel of domestic oil replaces 1 barrel of imported oil, imports avoided estimates the reduction in foreign trade deficit. 


\section{CONCLUSIONS}

The development, testing, and wide-scale application of currently available improved oil recovery technologies could stimulate incremental reserves ranging from 2 billion to nearly 4 billion barrels from the state of Texas' largest, most mature reservoirs at oil prices of $\$ 16 / \mathrm{B}$ to $\$ 24 / \mathrm{B}$. With the technology advances resulting from focused RD\&D, an additional 1.4 billion barrels to nearly 4 billion barrels could be produced over this price range using EOR and ASR techniques. Even with the successful development and application of these technologies, however, about 50 billion barrels of immobile oil would still remain in the analyzed reservoirs as a long-term target for future advances in EOR, and nearly 19 billion barrels of mobile oil would remain as a long-term target for future advances in ASR processes (Figure I-5). While this target is substantial, it unfortunately will not remain a target indefinitely. Well abandonments have already limited economic access to a portion of the resource. The timely development and application of new recovery technology is crucial to maintain economic access to the remaining domestic oil resource.

The results of this analysis have important policy implications. Domestic oil production generates significant direct revenues to Texas and to the Federal government and substantial additional indirect benefits to both the state and national economies. In addition to stimulating reserves, production, and economic activity, the application of improved oil technology would enhance the nation's energy security. However, integrated efforts and initiatives are needed to achieve these goals. These efforts should include:

- $\quad$ Collaborative RD\&D;

- $\quad$ Aggressive technology transfer; and

- Appropriate tax and regulatory policies at the state and Federal levels.

A collaborative RD\&D effort between the oil industry, universities, state and local governments, and the Federal government focused on improving advanced oil recovery technology and its application in key geologic settings would benefit operators, the state of Texas, and the entire nation. With sound planning and clear, attainable goals, state policies can be effectively integrated with Federal and private programs to dramatically increase production to the benefit of both the state and the nation's treasuries, economies, and citizens. State and Federal tax incentives can be instituted, or where already in place could be modified to improve their effectiveness, in order to help domestic EOR/ASR projects compete with foreign investment opportunities. In addition, regulatory policymakers could design regulations which reflect both the true risks to health, safety and the environment and the economic risk of resource loss through abandonment. 
Figure I-5

\section{Texas Remaining Oil Resource After Advanced Technology Recovery}

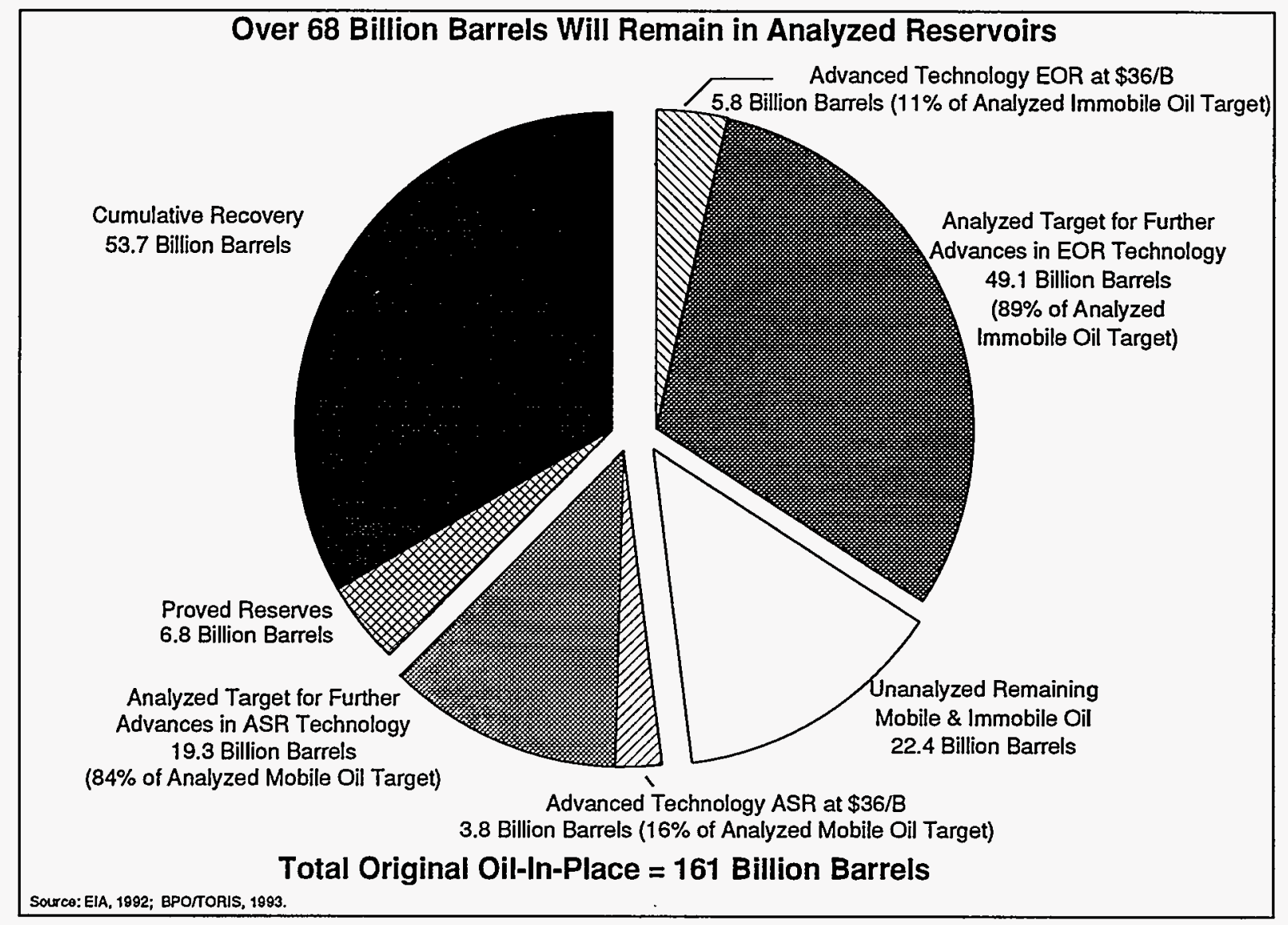




\section{BACKGROUND AND OBJECTIVES}

\section{A. TRENDS IN TEXAS OIL PRODUCTION AND RESERVES}

Oil production in Texas has alternated between distinct periods of rise and decline. Production increased dramatically during World War II; in 1945, the annual production reached 751 million barrels, nearly double the level of the depression years, ten years earlier. Technological advances, including the development and application of waterflooding, increased annual production to over 1.1 billion barrels by 1956. As the U.S. economy struggled during the late 1950s, the state's oil output fell over $12 \%$. After 1960, production increased relatively steadily for twelve years, peaking in 1972 when 1.3 billion barrels were produced; this was $38 \%$ of all domestic production that year (Figure II-1). Following that peak, Texas oil production entered a slow but steady decline that has continued to this day. Inflated world oil prices temporarily slowed the statewide production slide; after eighteen years of decline, production increased slightly in 1984. The collapse of oil prices in 1986 accelerated the decline, and that by 1990 Texas was only producing 702 million barrels, $46 \%$ of peak levels. Most of the decline in production since 1972 can be attributed to price changes and decreasing yields from conventional recovery. Even as its fields mature and many wells reach the point of abandonment, Texas still is the largest producer in the U.S., accounting for approximately 35\% of lower-48 production in 1990.

The decrease in Texas oil production has been accompanied by a major decline in reserves (Figure II-2). State crude oil reserves over the past thirty years peaked in 1961 at 14.8 billion barrels, but have since fallen to less than half that level by 1991 . The decline in reserves was especially steep during

the high production years of the 1970s when reserves dropped from 13.2 billion barrels in 1970 to 8.2 billion barrels in 1979 , an overall decline of $38 \%$. Total reserves continued to fall during the 1980 s despite higher oil prices. A brief resurgence took place in 1985, when reserves increased by 337 million barrels, but the dramatic drop in oil prices set off a decline in reserves that continued almost unabated until 1991, for a six year reduction of 1.1 billion barrels.

Although both production and reserves have declined, the number of producing wells steadily increased from 1973 to 1985 , largely led by the rise and fall of world oil prices. In 1973, Texas had 159,000 wells; major field development activity increased that number to 209,000 in 1985 (Figure II-3). In the past six years lower oil prices have reduced the number of producing wells as marginal wells have been abandoned and development activity has declined. As of 1991, Texas had 192,000 producing wells. 


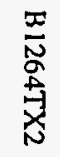
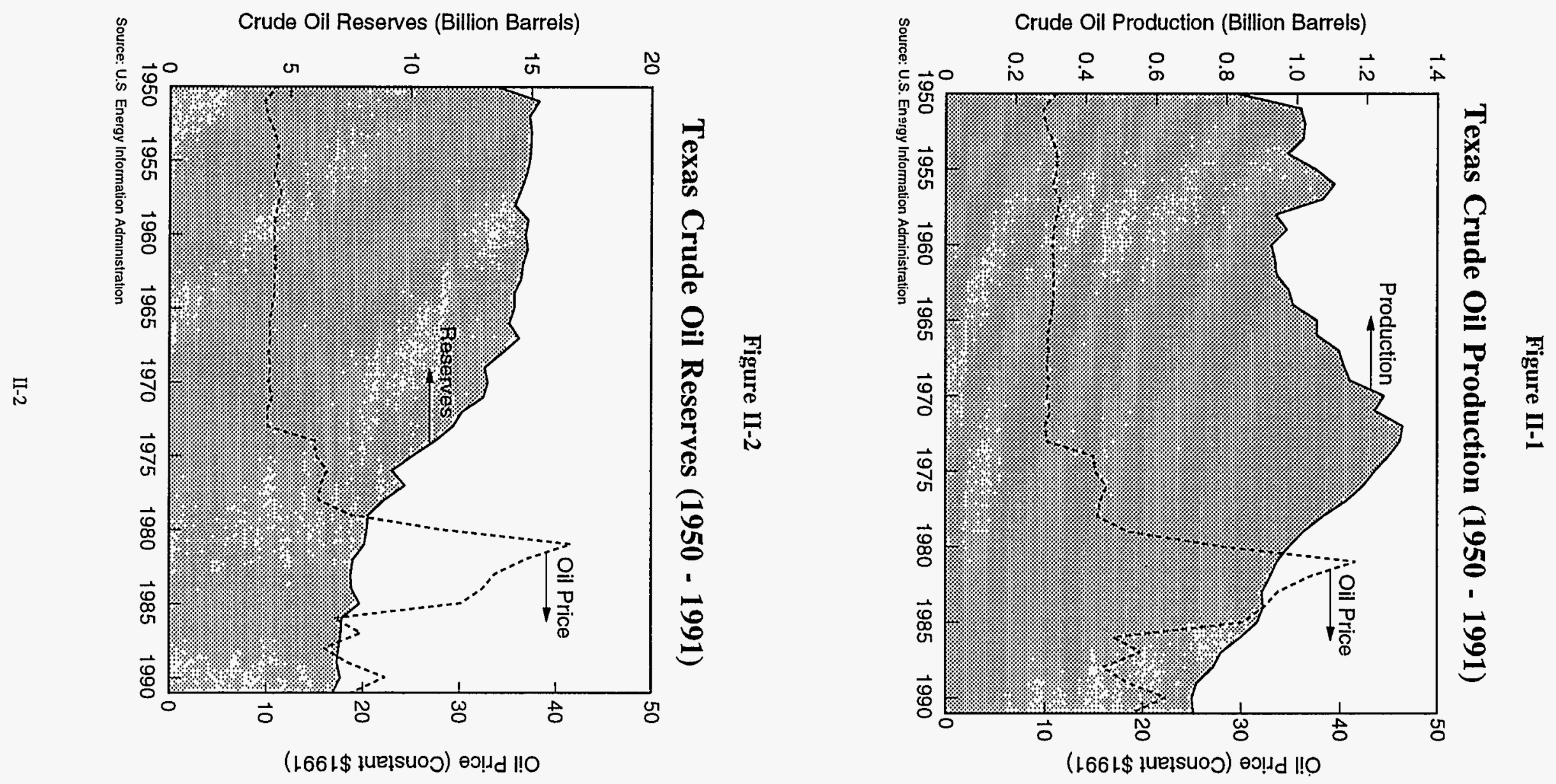
Reserves per producing well have plummeted even as the number of wells has increased. In 1973, nearly 74,000 barrels of reserves were associated with each producing well. That number has since dropped dramatically to about 35,000 barrels of oil per well in 1991 (Figure II-3).

Wells which produce very small quantities of oil are known as "stripper" wells; the number of these marginal wells has been growing and they accounted for more than $19 \%$ of Texas production in 1990, and an even greater percentage of Texas proved reserves (Figure II-4). Another oil price collapse, or other future economic events that might threaten the viability of continued production, would result in mass abandonment of stripper wells and would affect a large portion of the Texas resource. Between 1980 and 1990, over 52,000 Texas stripper wells were abandoned, limiting economic access to the oil resource remaining in older producing zones. From 1982 to the latter part of 1986, there was a sharp rise in the number of stripper well abandonments, with over 20,000 abandoned between 1985 and 1987 .

Clearly, this trend of declining production has significant implications for employment, economic activity, and the tax base of Texas. In 1973, the petroleum industry employed nearly 200,000 people in the state (Figure II-5). Employment rose to 433,000 in 1982, then decreased sharply to 289,000 in 1991. Over the same period, the gross annual value of the oil produced within the state increased from $\$ 13$ billion in 1973 (in constant 1991 dollars) to over $\$ 39$ billion in the peak year of 1981 , before decreasing to $\$ 15$ billion in 1990 (Figure II-6).

Revenues from production taxes on oil and gas increased from $\$ 940$ million in 1972 to a peak of nearly $\$ 2.8$ billion in 1981, only to decline by almost $65 \%$ to 1.0 billion in fiscal year 1992 (Figure II-7). This significant loss in state revenues has been caused by the dual effect of lower product prices and declining oil and gas production, trends which are expected to continue.

The loss of oil and gas revenue has had a significant impact on total state tax revenues. In fiscal year 1981, when oil prices were at their peak, oil and gas production taxes were nearly $27 \%$ of state tax revenues (Figure II-8). This percentage has fallen dramatically to $6.3 \%$ of total tax revenues in fiscal year 1992. Oil production (severance) taxes represent slightly more than half of the total. The state government ran deficits in fiscal years 1986 and 1987, and reductions in spending combined with a range of tax increases (higher sales, franchise, and motor vehicle taxes) were implemented to compensate for the loss of oil and gas revenues. Declining oil revenues have seriously eroded the ad valorem tax base, the main revenue source for many of the Texas' cities, counties, school districts, and water districts. 
Figure II-3

\section{Texas Producing Wells (1960 - 1991)}

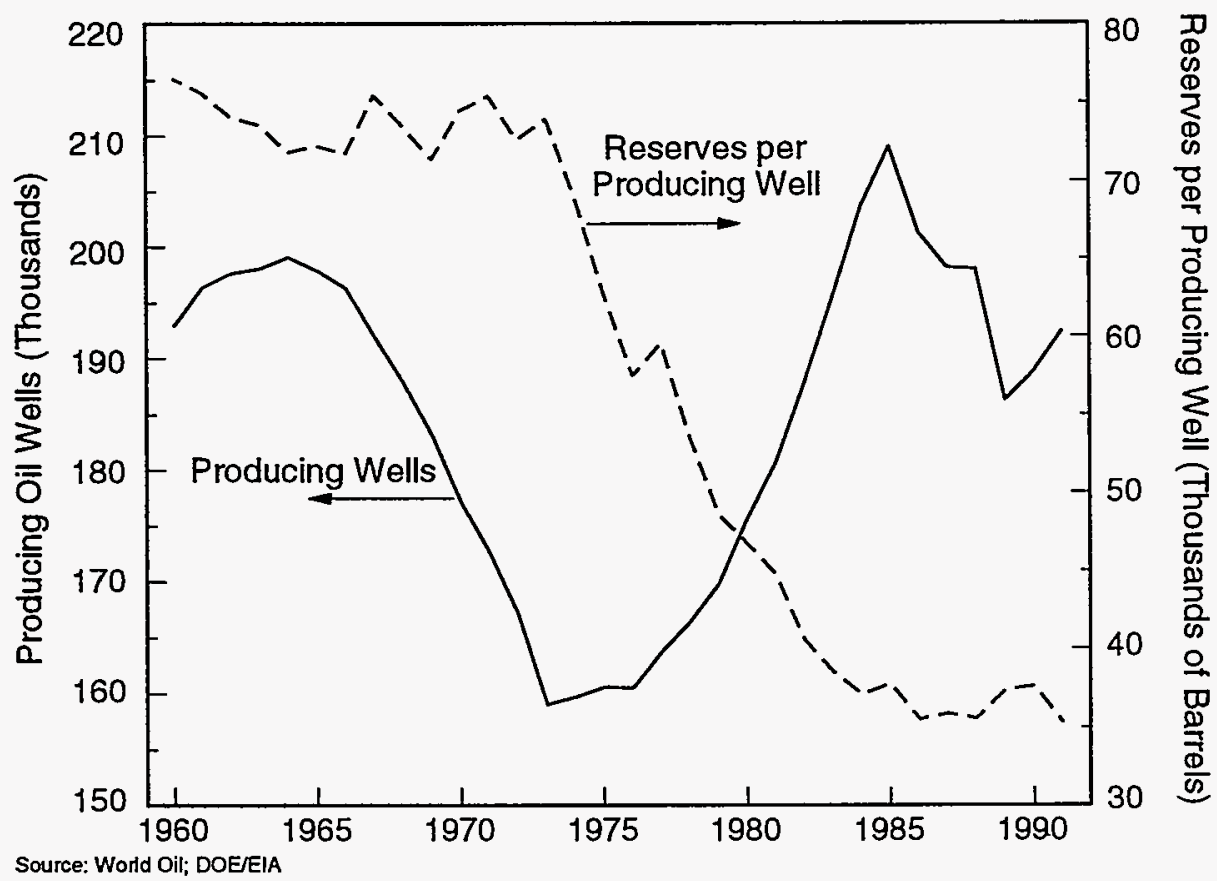

Figure II-4

\section{Texas Stripper Well Production and Abandonments}

(1970 - 1990)

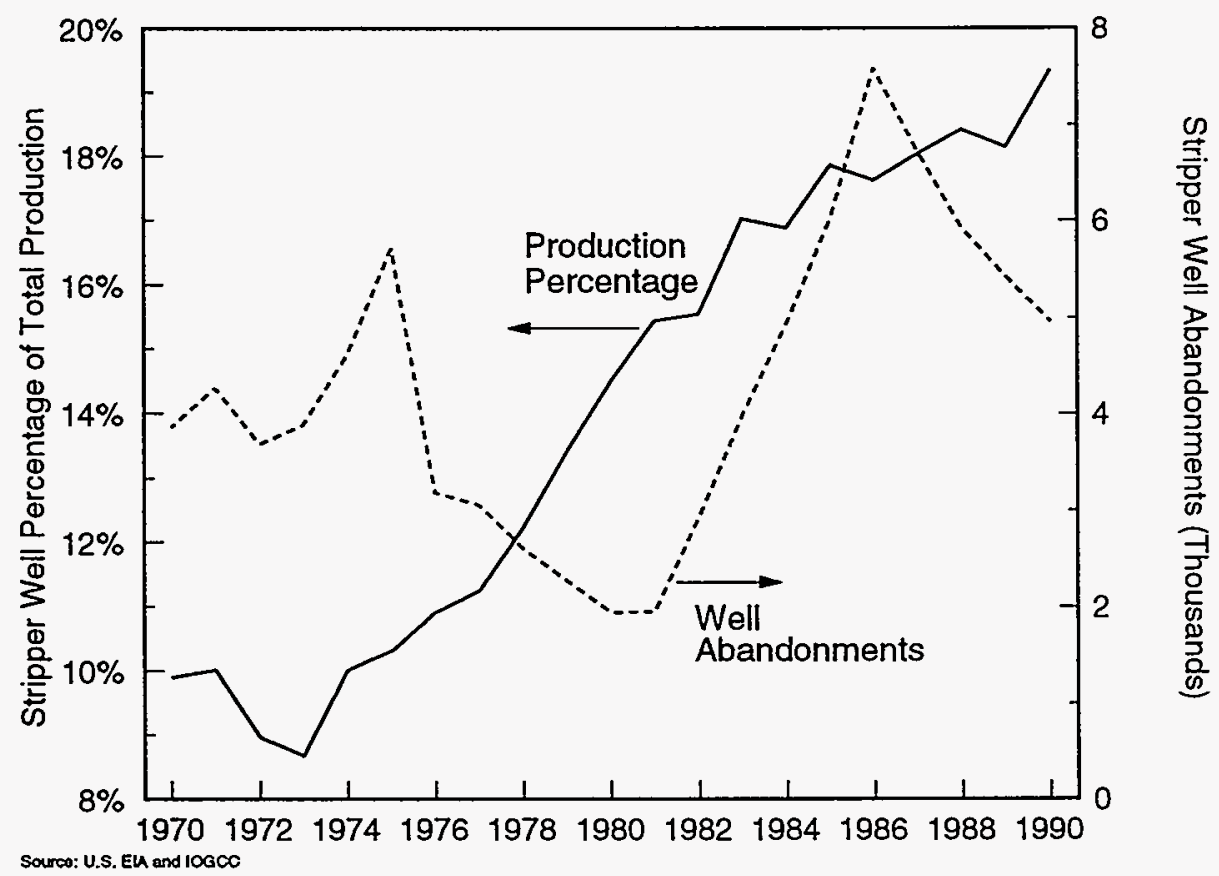


Figure II-5

Total Oil and Gas Employment in Texas (1970 - 1991)

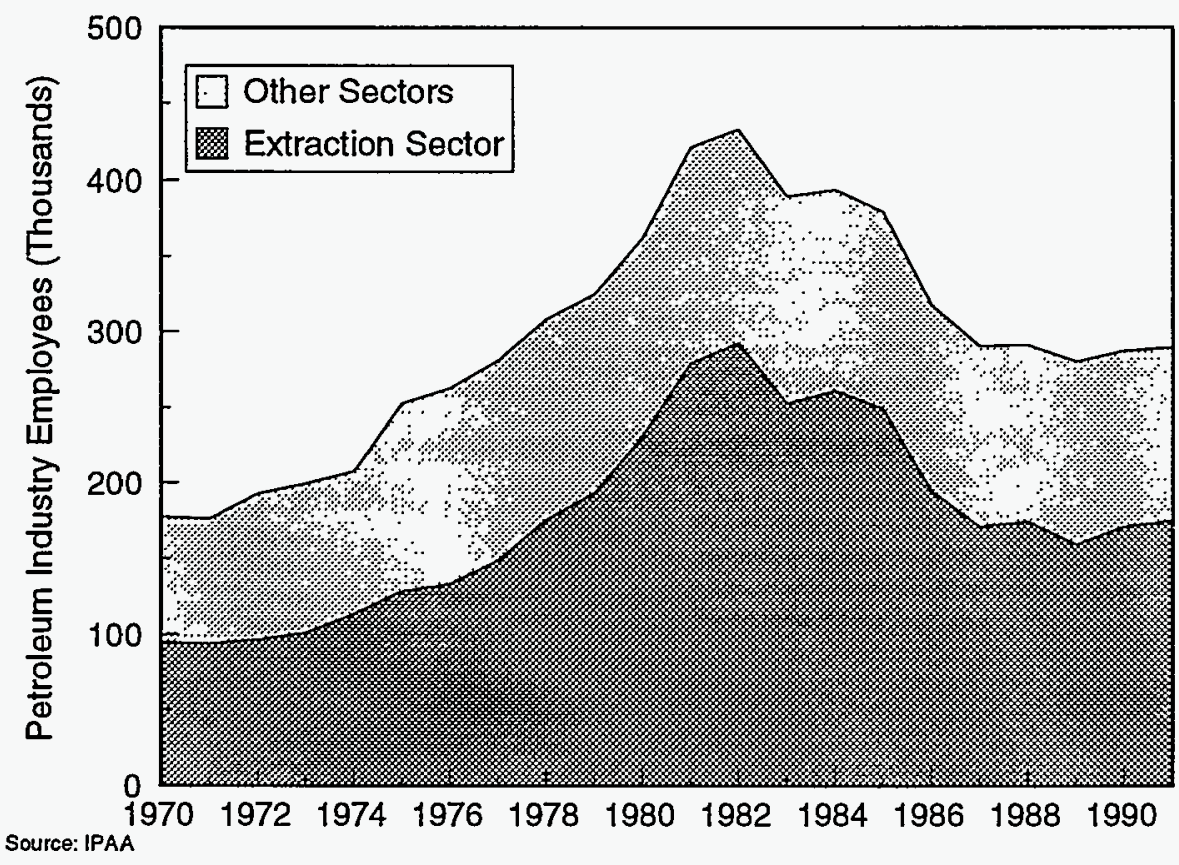

Figure II-6

\section{Annual Wellhead Value of Texas Oil and Gas Production (1961 - 1991)}

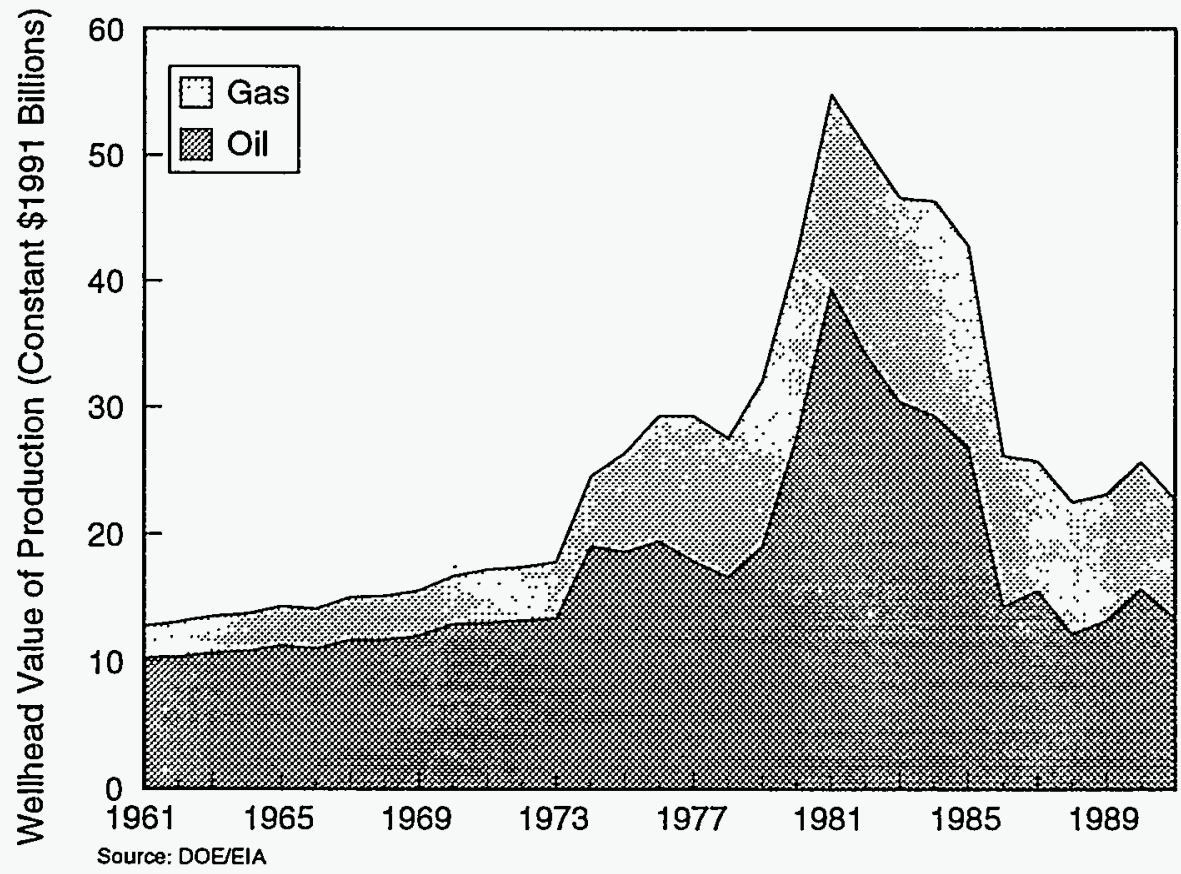


Figure II-7

Texas Oil and Gas Severance Taxes (FY1971 - 1992)

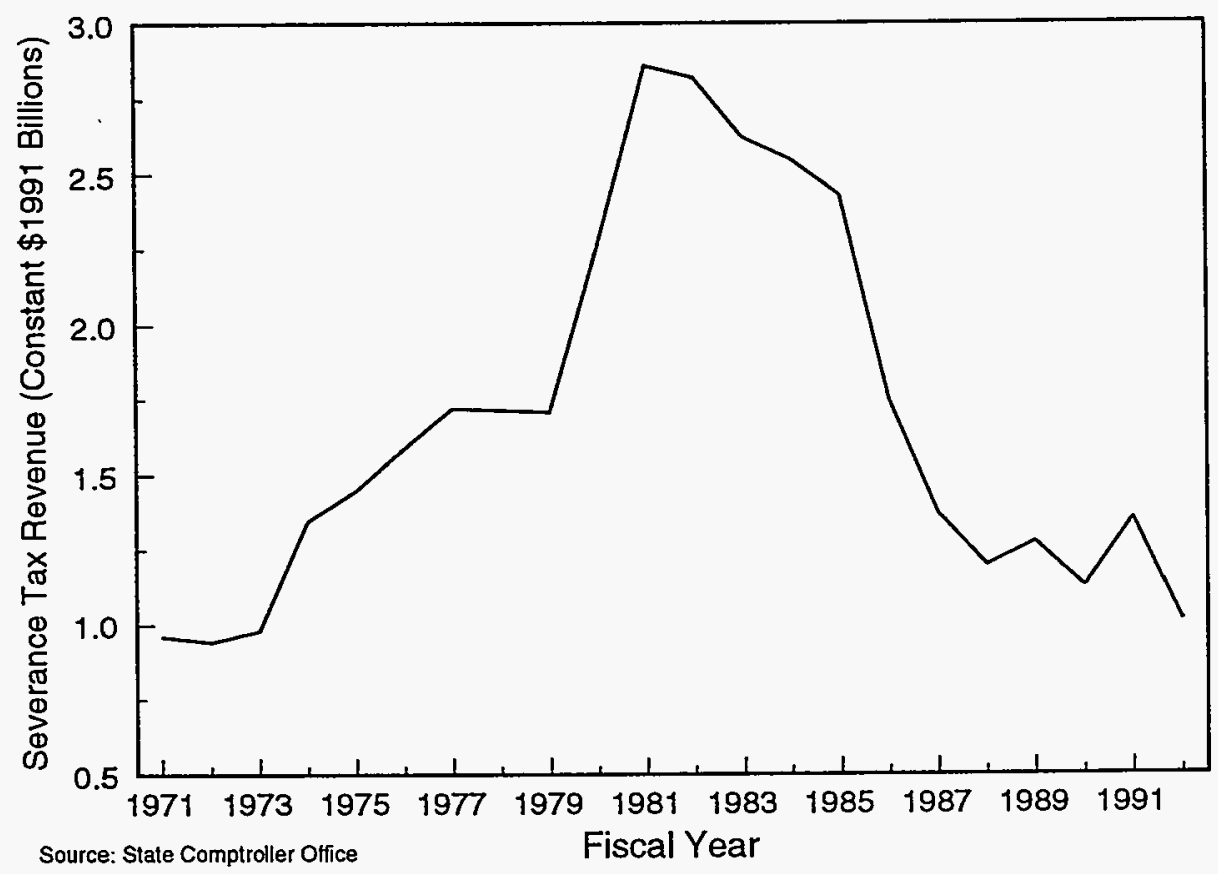

Figure II-8

Texas Oil and Gas Severance Taxes as a Percent of Total State Taxes (FY1971 - 1992)

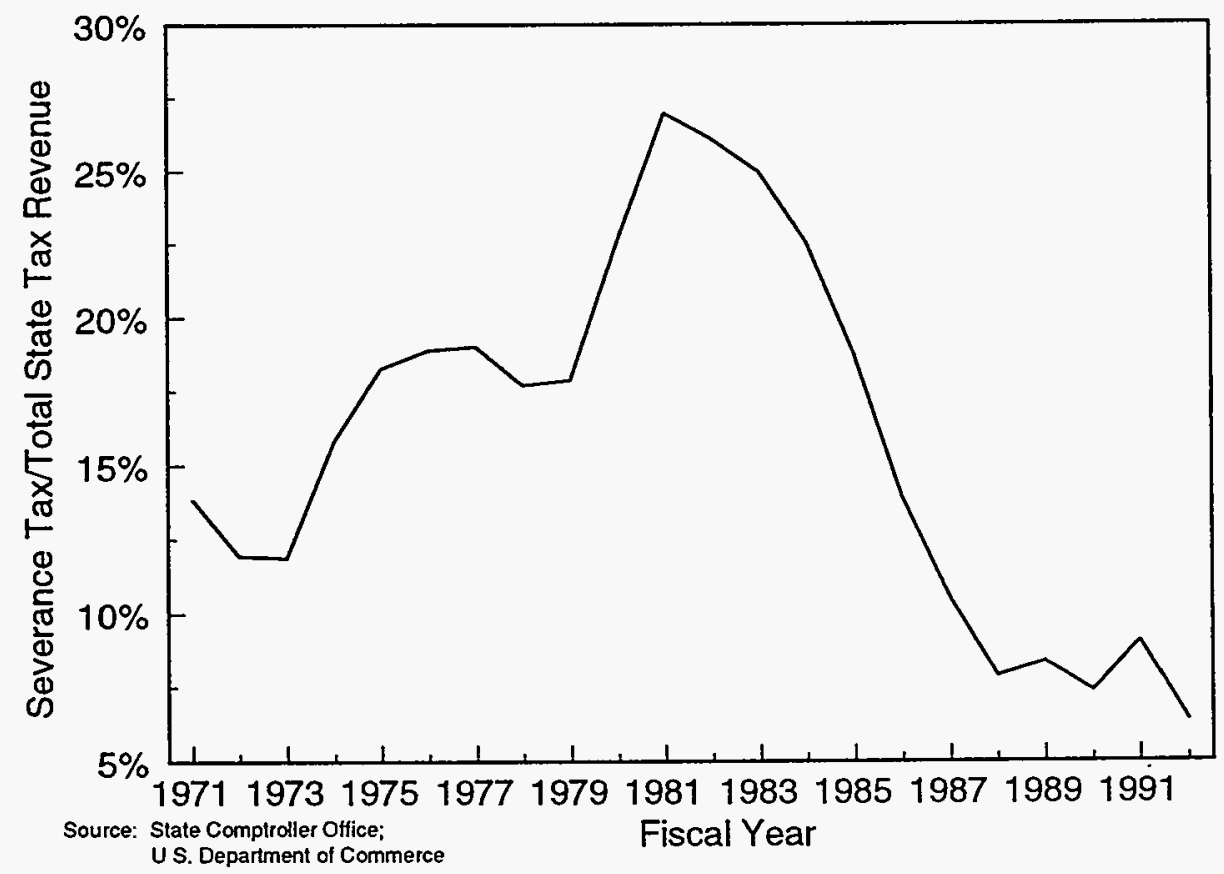


Despite significant revenue losses caused by the decline in oil and gas production, revitalization of the Texas economy is beginning to occur through diversification of the industrial base in the state. However, oil and gas production will continue to play a vital role in the state's economy, and development and testing of methods for extending the life of Texas' oil resource have high priority.

At the conclusion of conventional production operations, vast quantities of oil will still be unrecovered in Texas reservoirs (Figure II-9). The total known original oil-in-place (OOIP) in Texas is nearly 161 billion barrels. Of this, 54 billion barrels have been produced and roughly 7 billion barrels were recognized as proved reserves, for a total estimated ultimate recovery by conventional technology of over 60 billion barrels. After conventional recovery, 100 billion barrels, over three-fifths of the total known resource in Texas, will remain as a target for newer, more efficient extraction technologies.

Figure II-9

Texas Oil Resource

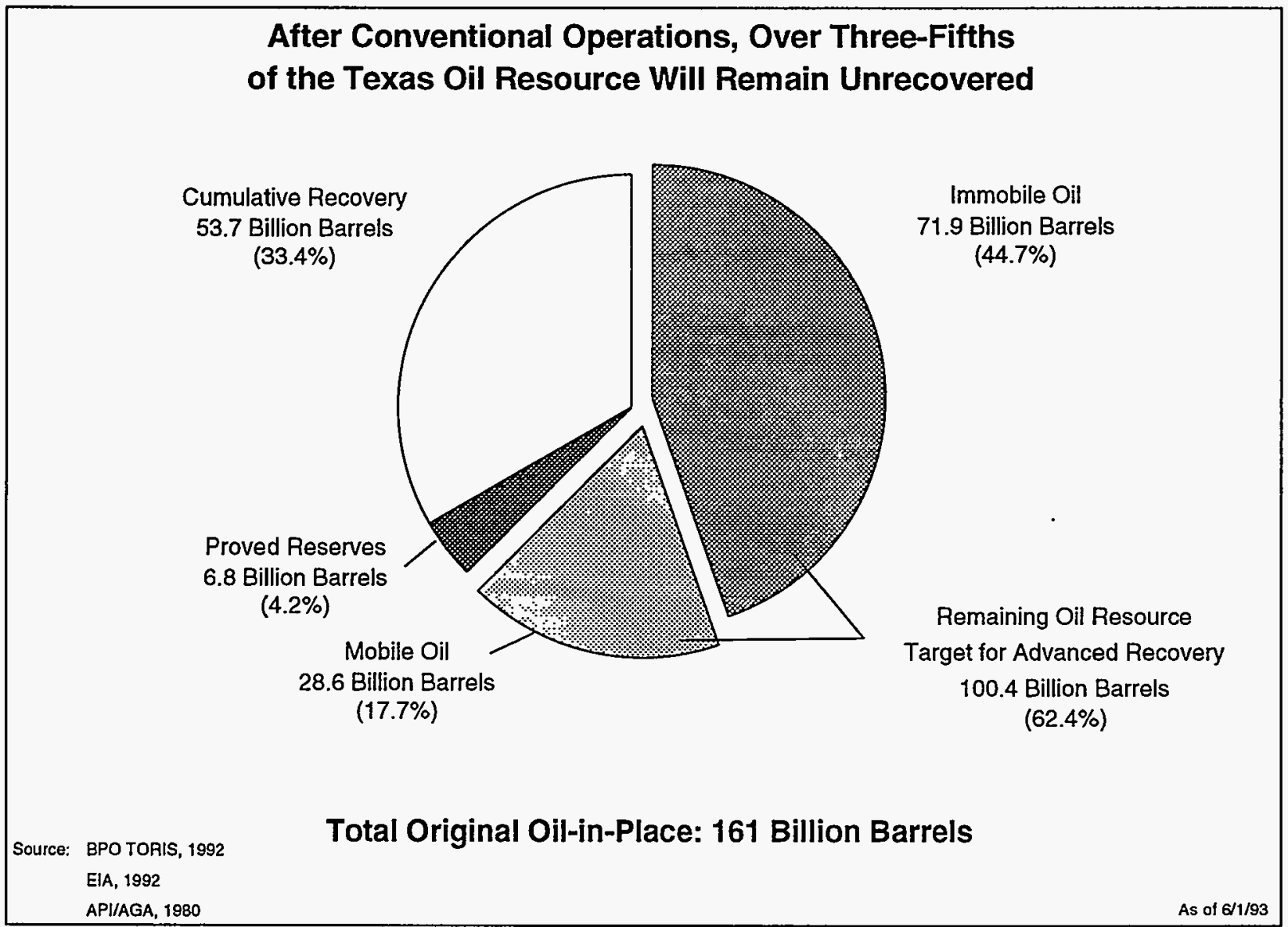


This unrecovered resource can be broken down into two main components: mobile and immobile oil. In Texas, 29 billion barrels of unrecovered mobile oil make up the target for a number of improved recovery processes -- polymer flooding, profile modification, and infill drilling -- collectively referred to as advanced secondary recovery (ASR). The 72 billion barrels of remaining immobile oil represent the target for a number of tertiary extraction technologies, defined generally as enhanced oil recovery (EOR). Recovery operations directed at each of these resources could play a critical role in sustaining the Texas oil industry and reducing the nation's dependence on imported oil. A brief overview of these recovery technologies is provided in Appendix A of Volume X.

\section{B. IMPROVED RECOVERY ACTIVITIES TARGETING THE REMAINING RESOURCE}

The oil remaining after conventional primary and secondary recovery lies in two defined regions within each reservoir: the swept and the unswept zones. In the swept zone of the reservoir, conventional operations have recovered a significant portion of the original concentration of oil. The oil remaining in this swept zone is trapped in the reservoir pore spaces or on the surface of the pores by capillary and surface tension forces. Additional flooding with water can produce very little of this oil; the swept zone is at the "waterflood residual" level of oil saturation.

In the unswept zone of the reservoir, conventional recovery processes have not swept the pore space, and the oil saturation can range from low to high, depending upon the efficiency of the primary recovery mechanism (e.g., high saturations for pressure depletion or lower saturations for natural water drive). The objective of many infill drilling programs, improved waterflooding projects (profile modification), and other reservoir management techniques is to contact the oil in the unswept zones.

\section{Enhanced Oil Recovery}

Proven enhanced recovery processes designed to displace the immobile oil target are classified into three categories: gas-miscible, chemical, and thermal. Miscible flooding, the most common and most promising means of enhanced recovery in Texas, dates back over 40 years. Many of the state's earliest EOR projects used flue gas or hydrocarbon injectants; a flue gas project began in ARCO's Block 31 Field (Crane county - Railroad Commission District 8) in 1949, and hydrocarbon miscible projects began in 1956 on Exxon's Bronte Field (District 7C), in 1957 at Humble's Seeligson Field, Zone 20B-07 (District 4), and in 1960 at Amoco's Midland Farms Field (District 8). Exxon operates two flue gas injection 
projects in the Hawkins Field in Wood County that began in 1977 and 1987. Active hydrocarbon miscible projects began in 1966 at Hunt's Fairway Field in Northeast Texas and Amoco's Levelland Field in Hockley County (District 8A). There have also been several nitrogen flooding projects in the western part of the state, including Texaco's Vealmoor East Field in Borden and Howard Counties (terminated) and Phillips' Andector Ellenburger Field in Ector County. ${ }^{1}$

Carbon dioxide $\left(\mathrm{CO}_{2}\right)$ is the state's most common tertiary injectant, used in nearly all of the largest EOR projects in the state (those with incremental production of over 1,000 barrels per day). $\mathrm{CO}_{2}-$ miscible flooding is the dominant EOR process used in the Permian Basin of West Texas (especially District $8 \mathrm{~A}$ ). This EOR method is prevalent in this region of the state for several reasons. The limestone and dolomite reservoirs of this area are especially well suited to the injectant, and below-average conventional recovery efficiencies have spurred operators to implement enhanced recovery projects to contact and produce the large volumes of remaining oil. In addition, the region is well located in relation to several major natural sources of $\mathrm{CO}_{2}$ and is serviced by three large trunklines and several distribution lines that cross the area. Two 500 million cubic feet per day capacity pipelines from Sheep Mountain, Colorado and Bravo Dome, New Mexico and a 650 million cubic feet per day pipeline from McElmo Dome, Colorado supply gas to West Texas, terminating in the Denver City area; the McElmo Dome pipeline may ultimately be expanded to 1 billion cubic feet per day.

There are 30 carbon dioxide floods currently underway in Texas. Twenty-two of these are in Permian or Devonian age carbonate reservoirs in West Texas. The majority of these projects were initiated in the high oil price years of the early 1980s, although new $\mathrm{CO}_{2}$ injection projects have been initiated or expanded in West Texas reservoirs even recently. The state's largest single $\mathrm{CO}_{2}$ project, Chevron's SACROC unit located in Scurry county (District 8A), began in 1972 and is now producing over 20,000 barrels per day. More than 33,000 acres (with 2.1 billion barrels OOIP) are being flooded with $\mathrm{CO}_{2}$. Other notable $\mathrm{CO}_{2}$ injection projects include the Wasson, Slaughter, Seminole, Dollarhide, Twofreds, Ford Geraldine and North Ward Estes fields. At the Wasson Field, Amoco, ARCO, Exxon, Mobil, and Shell are injecting $\mathrm{CO}_{2}$ into their respective units. Shell's Denver Unit project, the largest at almost 28,000 acres, was recently expanded. ${ }^{2}$ Chevron's North Ward Estes field, one of the most

1 IOGCC, "An Evaluation of the Known Remaining Oil Resource in the State of Texas", November 1989.

2 "Shell Presses Expansion of $\mathrm{CO}_{2}$ Operations", Oil and Gas Journal (June 10, 1991), 22. 
recently initiated $\mathrm{CO}_{2}$ projects, began in 1988 and is expected to recover 65 million barrels of incremental oil and 32 billion cubic feet of natural gas. ${ }^{3}$ Texaco also announced the beginning of a $\mathrm{CO}_{2}$ flood at the Mabee Field in late 1991. Taken together, the ongoing miscible projects in Texas are expected to ultimately recover 1.2 billion barrels of oil. Of this, 200 million barrels have been produced by 1991 . In typical West Texas reservoirs, combined primary and secondary recoveries range from $35-40 \%$ of OOIP. Carbon dioxide injection projects typically recover an additional 8-15\% of the original oil-in-place over a typical 15 to 20 year project life. Successful $\mathrm{CO}_{2}$-miscible projects can be expected to require 3 to 11 thousand cubic feet of $\mathrm{CO}_{2}$ per barrel of recovered incremental oil ${ }^{4,5}$. Where $\mathrm{CO}_{2}$ breaks through into producing wells, the gas-to-oil ratio in those wells rises and eventually the separated gas must be treated to remove the $\mathrm{CO}_{2}$, which can then be reinjected to reduce costs and improve project economics. Typically, around $60 \%$ of the injected gas is purchased, while $40 \%$ is collected, repressurized, and reinjected over the life of most large miscible floods.

Although there are no large scale chemical floods currently underway in Texas, several projects have been undertaken in the past. Mobil operated a surfactant project in Wichita County Regular Field (District 9) from 1973 to 1982, recovering about 3\% of the OOIP. Exxon conducted a surfactant flooding mini-test in Borregos Field (District 4), recovering $12 \%$ of the OOIP. ${ }^{6}$ Several alkaline flooding projects were initiated in the late 1970 s and early 1980s, but most have been discontinued. Among the projects were Unocal's South Van and Carroll Units in Van Zandt County (District 5). There have also been several micellar-polymer projects throughout the state, such as Mitchell Energy's Wizard Wells Field (Jack County, District 9), but they also have been discontinued.

Although several steam projects are underway in Texas, thermal recovery projects are not nearly as prevalent in the state as either miscible or chemical projects. Steam projects in Northeast Texas include Texaco's Sour Lake Field (terminated) and Mobil's Saratoga Field, both in Hardin County (District 3), as well as Enercap's Camp Hill Field in Anderson County (District 6). Greenwich Oil operates a

3 "Chevron Log Production Kick in N. Ward Estes $\mathrm{CO}_{2}$ project," Oil and Gas Journal (September 11, 1989), 22.

4 Martin, F.D., and Taber, J.J., "Carbon Dioxide Flooding", JPT (April 1992), 396-400.

5 Holm, L.W., "Evolution of the $\mathrm{CO}_{2}$ Flooding Processes," JPT (November 1987), 1337-1342

6 Kuuskraa, Vello A., "The Potential and Performance of Enhanced Oil Recovery," November, 1985. 
combustion project in its Forest Hill Field (Wood County - District 6), but development of in-situ combustion projects is still somewhat constrained by a limited understanding of the process in the reservoir. Although its further application to Texas reservoirs may be limited compared to the other EOR processes, thermal recovery remains the predominant EOR technique in the U.S. and could, ultimately, have wider applications in Texas.

\section{Advanced Secondary Recovery}

Mobile oil remains in the reservoir after conventional recovery for a variety of reasons. Foremost of these is reservoir heterogeneity, the complex variation of rock properties among zones in the producing interval. Reservoirs may consist of a large number of individual compartments, reflecting internal heterogeneity. These compartments are formed by depositional processes that originally formed the reservoir, or by diagenesis or tectonic activity that later altered the rock bodies. Exceedingly complex reservoirs may have compartments formed by all of these processes. At a given well spacing, some compartments containing oil are not in pressure or fluid communication with existing producing wells. At wide well spacings, much of the rock volume in a heterogeneous reservoir will not be contacted by existing wells, leaving large volumes of oil at or near original pressure and saturation. These compartments provide a major target for infill drilling and future recovery operations conducted at closer well spacing.

Mobile oil also remains in reservoir compartments that have been contacted, but inefficiently swept by secondary recovery methods that utilize existing well configurations. At wide well spacings, significant volumes of oil are areally bypassed due to small-scale variations in reservoir continuity, to the higher viscosity of oil than injected water, and to permeability variations within the reservoir. The effectiveness of water injection is further limited by vertical layering in the reservoir. Water preferentially enters the more permeable layers of the reservoir, leaving the less permeable rock layers unswept at relatively high remaining oil saturations.

Several geologic factors influence the volume, distribution, and potential future production of unrecovered mobile oil (UMO). A major factor commonly influencing recovery potential is reservoir genesis, or the type of system that originally deposited the reservoir rock. Internal reservoir architecture is profoundly affected by the depositional system of the initial reservoir sediment, which controls the distribution of different types of rock "packages," and by the pore structure that plays host to later 
diagenetic rock and fluid alterations. Other important geologic factors include trap style and source rocks. Reservoirs that have common depositional histories may have very similar internal reservoir architecture, but will be modified by post-depositional diagenesis. This modification will vary from basin to basin depending on geohistory.

Recovery of remaining mobile and immobile oil from known fields is a highly cost effective method for increasing oil production and reserves. Over $80 \%$ of reserve additions in Texas since 1979 have come from the intensive development of older fields. A large portion of these new reserves have resulted from improved primary and secondary recovery methods, including implementation of waterflooding and pressure maintenance programs, drilling of additional wells to improve reservoir contact, and selective recompletion of existing wells to improve performance. Several distinct methods for producing UMO have emerged: infill drilling to tap uncontacted reservoir compartments, recompletion of production and injection wells to contact and sweep previously bypassed portions of the reservoir, polymer flooding to overcome unfavorable waterflood injection fluid characteristics, and profile modification to reduce the permeability contrast between reservoir layers. These techniques are all tested and proven methods for producing mobile oil remaining in the reservoir.

The effectiveness of infill drilling has been demonstrated in many Texas reservoirs. Exxon recently drilled a significant number of new wells in the Robertson Clear Fork Unit ${ }^{7}$ and the Means San Andres Unit. ${ }^{8}$ Several publications have also discussed the large potential of infill drilling in specific reservoir settings. ${ }^{9}$ In some cases, infill drilling to close spacing can double the reservoir volume effectively contacted at conventional spacing, if economics will support the cost of the relatively large number of wells required.

$\wedge \mathrm{A}$

7 Barbe, J.A., "Quantitative Analysis of Infill Performance: Robertson Clear Fork Unit," JPT, December 1987.

8 Magruder, et al., "A Review of the Means San Andres Unit Full-Scale $\mathrm{CO}_{2}$ Tertiary Project," SPE Paper No. 17349, April 1988.

9 Gould, et al., "Infill Drilling for Incremental Recovery," JPT, March 1989. 
The potential benefits of geologically targeted infill drilling have been assessed by several studies. $^{10,11,12}$ The process has been evaluated in detail by the Bureau of Economic Geology (BEG) at the University of Texas at Austin. The evaluation in Dune Field ${ }^{13}$ indicates the substantial recovery potential and economic enhancement possible through targeted drilling.

Portions of oil that have been bypassed at current spacing can be recovered by well-designed, advanced waterflooding techniques, and significant portions of this oil could be recovered with the combined application of both polymer injection or profile modification with infill drilling. Over 30 polymer projects are currently in operation throughout Texas, including Salt Creek Field (Mobil) in District $8 \mathrm{~A}$, which currently produces over 2,800 barrel per day due to this improved recovery technique.

Taken alone, infill drilling, polymer flooding, and profile modification are effective processes for producing mobile oil; they are often even more effective when applied in combination, which allows the processes to complement one another. For example, polymer injection and profile modification can be used to increase the waterflood sweep efficiency not only in previously contacted compartments, but also in compartments newly contacted by infill drilling. These synergies maximize the cost-effectiveness of mobile oil recovery and encourage the coordinated, multiple application of techniques in selected reservoir settings.

There are several other processes and recovery techniques which were not included in this analysis and may have potential in Texas. Application of these techniques would further increase potential recovery and add to the estimates contained in this analysis. Immiscible gas and nitrogen gas EOR

10 ICF Resources Incorporated and the Bureau of Economic Geology, University of Texas at Austin, Producing Unrecovered Mobile. Oil: Evaluation of Potential Economically Recoverable Reserves in Texas, Oklahoma, and New Mexico, prepared for: U.S. Dept. of Energy/Office of Planning and Environment/Office of Fossil Energy and Bartlesville Project Office, 1989.

11 Fisher, W.L., "Can the U.S. Oil and Gas Resource Base Support Sustained Production?" Science, Volume 236, No. 4809, 26 June 1987, 1631-1636.

12 Tyler, et al., Oil Accumulations, Production Characteristics, and Target for Additional Recovery in Major Oil Reservoirs in Texas, the Bureau of Economic Geology, The University of Texas at Austin, Geological Circular 84-2, 1984.

13 Bebout, et al., Characterization of the Grayburg Reservoir, University Lands Dune. Field, Crane. County, Texas, the University of Texas at Austin, Bureau of Economic Geology, Report of Investigations, No. 168, 1987. 
projects could enhance Texas oil recovery. In addition, improvements in reservoir management and improvements in waterflood patterns, waterflood rates of injection, and the timing of inception of waterfloods show significant potential as recovery techniques. To the extent that these techniques and others currently being transferred (i.e., injection water compatibility) improve potential oil recovery, the results presented in this report will be understated.

\section{OBJECTIVES OF THE PRESENT STUDY}

The present study analyzes the incremental reserves, public sector revenues, and statewide economic activity that could result from the implementation of the improved EOR and ASR techniques described above. The potentials for EOR and ASR production are evaluated separately, and each is considered for two technology levels: implemented technology, which assesses recovery potential given the statewide application of currently available technology, and advanced technology, which assesses the impact of the statewide application of potential technological advances. Comparison of the results of these two evaluations provides the basis for assessing the benefits of improved technology provided by RD\&D. All of the analyses are conducted over a range of crude oil prices from $\$ 16$ to $\$ 36$ per barrel (in constant 1991 dollars). This price range encompasses the long-term prices likely to prevail over approximately the next 30 years.

Eight hundred and fifty-three reservoirs, accounting for nearly 128 billion barrels of original oil-inplace (nearly $80 \%$ of the total known resource in Texas), were included in this analysis. These reservoirs contain approximately 78 billion barrels of remaining oil resource (Figure II-10). The 23 billion barrels of UMO is the target for application of ASR processes and 55 billion barrels is the target for application of EOR processes. To achieve the required level of application, and therefore receive the maximum benefits of both levels of technology assessed in this report, it is critical that the state of Texas, the Federal government, and the oil industry work collaboratively to: (1) effectively transfer currently available technology (implemented technology to operators), and (2) develop a focused RD\&D program to improve recovery methods (advanced technology) and subsequently transfer those methods to a broad audience. The results and conclusion will provide valuable insights for state and Federal policy makers in their efforts to maximize Texas oil production and improve the nation's energy security. 
Figure II-10

\section{Texas Remaining Oil Resource After Conventional Recovery Operations}

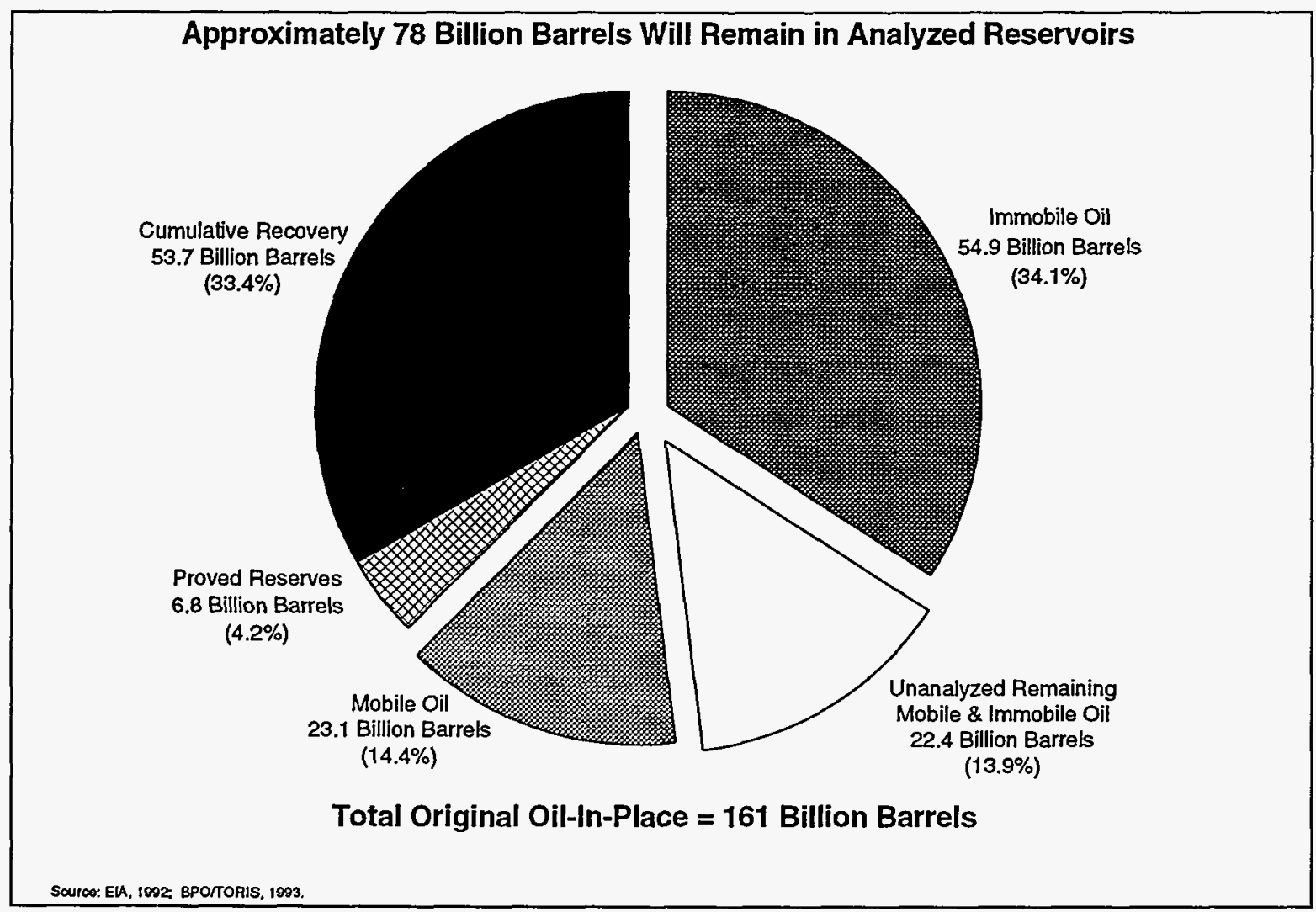




\section{APPROACH TO THE ANALYSIS}

\section{A. INTRODUCTION}

This analysis was performed using the Department of Energy's Tertiary Oil Recovery Information System (TORIS) developed for the 1984 National Petroleum Council (NPC) analysis of the nation's enhanced oil recovery (EOR) potential. ${ }^{1}$ Although TORIS was originally designed to evaluate EOR potential only, the system's capabilities have since been expanded to incorporate evaluations of the unrecovered mobile oil (UMO) resource, the target for advanced secondary recovery (ASR). The upgraded TORIS system assessed the recovery potential of immobile oil and UMO in the United States. The following sections in this chapter will briefly discuss the:

- Development of TORIS;

- $\quad$ Enhancement of TORIS to evaluate the UMO resource;

- $\quad$ Scope of the current analysis;

- $\quad$ Adaptations to TORIS for this analysis;

- Estimation of benefits, costs, and economic impacts; and

- Limitations of the analytical approach.

\section{B. GENERAL METHODOLOGY: THE NPC BASIS}

In March 1982, the U.S. Secretary of Energy requested the NPC to prepare a report on the nationwide potential and the economics of incremental EOR. The NPC is the official petroleum industry advisory committee to the Secretary. Members of NPC, who are appointed by the Secretary, represent all segments of petroleum interest, such as production, refining, marketing, and environmental, and include many chief executive officers. The NPC is supported entirely by the voluntary contributions of its members.

In response to the Secretary's request, the NPC mounted a two-year effort that consumed more than 50 professional man-years and nearly $\$ 7$ million of in-kind services. EOR experts from industry (majors, independents, service companies and consulting firms), universities, govermment, and private, non-profit organizations participated. The NPC EOR study committee utilized and built upon data bases

1 National Petroleum Council, Enhanced Oil Recovery, Washington, DC, 1984. 
of individual reservoir characteristics and computer models that were under development by the U.S. Department of Energy's (DOE), Office of Fossil Energy. After augmentation, adaptation and validation, the data bases and models were remanded to the DOE's Bartlesville Project Office (BPO) for maintenance, updating, and subsequent application. These data bases and models are components of a larger system, the Tertiary Oil Recovery Information System (TORIS).

By the agreement of the Assistant Secretary for Fossil Energy, the present study enjoys access to TORIS and the assistance of BPO, although its participation is limited strictly to providing the data base, models, and assistance for the technical analysis. The BPO and DOE neither contribute to nor endorse the study design or the interpretations presented in this report. The approach used by the NPC and in the present study to evaluate the EOR resource consists of the major phases listed below.

1. Reservoir Data Compilation. Detailed data describing the properties of the individual, significant oil reservoirs are compiled. Numerous public and private sources of information are consulted to complete and validate the reservoir data base. The principal elements of the TORIS data base are displayed in Table III-1. Representatives of the operating; companies review the data elements of each reservoir at least three times for consistency and accuracy; automated validity checks are performed on the entire data base.

2. Resource Screening Models. Each reservoir is subjected to a screening process designed to identify the technical applicability of the respective EOR processes under what the NPC defined as "implemented", or currently available, technology. The specific criteria applied to screen each EOR process are shown in Table III-2. In addition, the reservoirs are screened under what the NPC defined as "advanced" technology, available through concerted research and development. Table III-3 displays the technical criteria for "advanced" EOR technology.

3. Process Performance Models. Each reservoir that satisfies the technical criteria is then analyzed by a detailed process performance model at each level of technical applicability. The models for each process have been previously reviewed in detail and calibrated to actual field results. NPC study committees review and test this calibration. The models are reservoir-specific and, therefore, estimate incremental oil production from EOR as a function of reservoir properties and process design for each reservoir independently. Incremental production is that which is recovered in excess of production by conventional primary and secondary techniques at current field conditions.

4. Economic Evaluation. Each reservoir is then evaluated for its economic feasibility by estimating the income attributable to the incremental EOR production and the investment, operating costs, and taxes required to support the implementation of the process as designed and installed in the field. Detailed costing algorithms reflect EOR design (both "implemented" and "advanced"), reservoir depth, region, and other factors. The energy component of each cost element is adjusted to reflect the oil price being analyzed. A 
Table III-1

\section{Key Elements in the Current TORIS* Reservoir Data Base}

- Original Volumetrics

-- Original Oil-in-Place

-- Reservoir area

-- Net thickness

-. Porosity

-- Initial water saturation

- Initial oil saturation

-. Initial formation volume factor

- Current Volumetrics

-- Current oil saturation (swept zone)

-- Current formation volume factor

- Fluid Data

-- Oil gravity and viscosity

-- Connate water viscosity

-- Connate water salinity

-. Initial GOR

-- Current GOR

-- Injection water salinity

-- Crude oil fractions \& properties (being added)
- Geologic Variables

-- Lithology

-- Depth

-- Temperature

-- Original and current pressure

- Permeability

-- Permeability variation index

-- Clay content

-- Gross thickness

-- Dip angle

- Geologic age code

-- Presence of gas cap, faults, shale breaks

-- Geologic play, depositional system, trap type

-- Areal and vertical heterogeneity descriptors

-- Pay continuity (estimated)

- Development \& Performance Data

-- Recovery efficiency

-- Cumulative production

-- Annual production

-- Current injection rate

-- Cumulative volume of injectant by type

-- Well spacing

-- Number of producing \& injecting wells

-- Water cut

*Tertiary Oil Recovery Information System, maintained and operated by the Bartlesville Project Office of the U.S. Department of Energy 
Table III-2

\section{Screening Criteria for EOR Candidates-Implemented Technology Case}

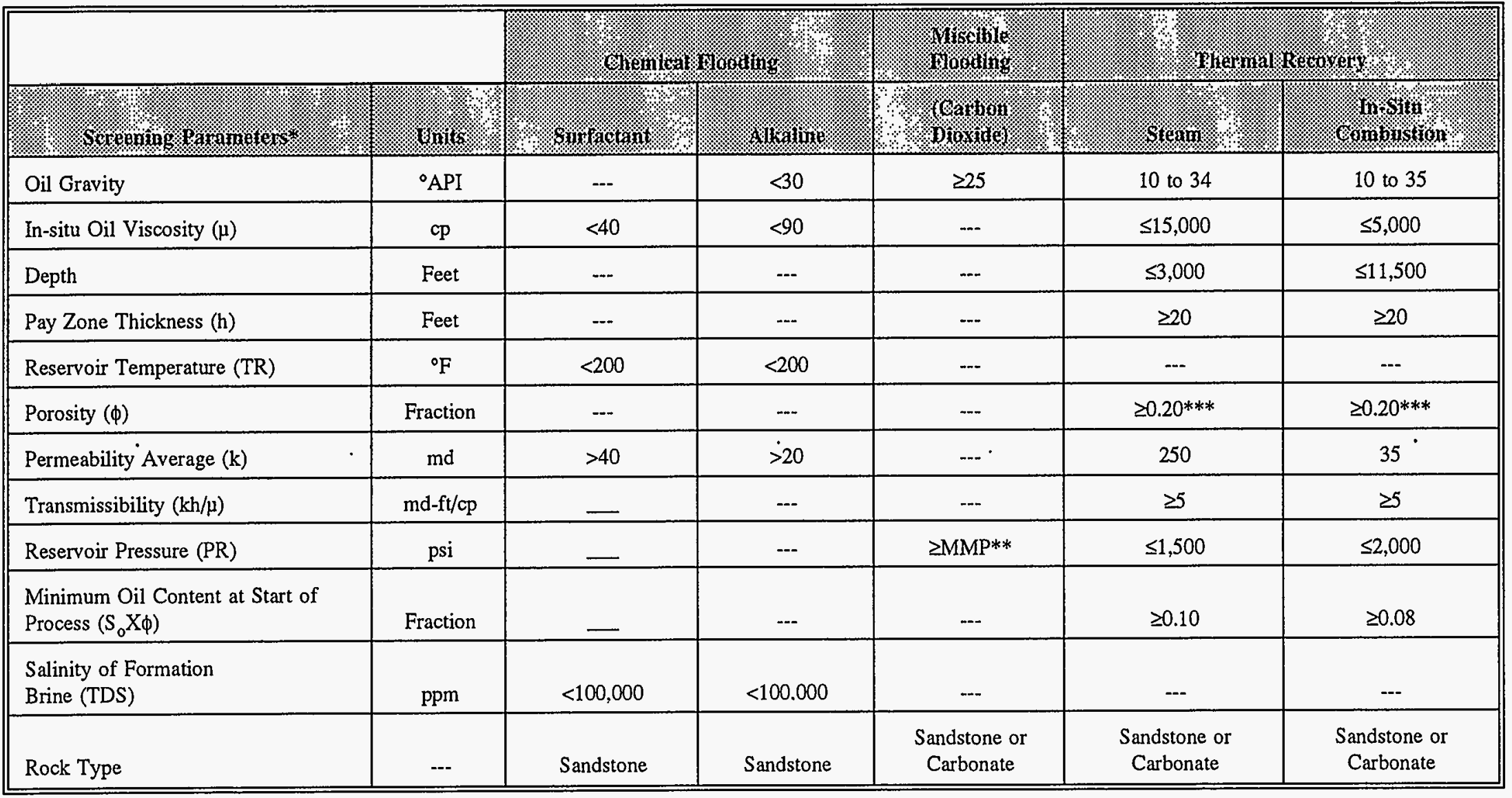

* Other criteria of a geological and depositional nature were also considered. Generally, reservoirs with extensive faulting, lateral discontinuities, or overlying gas caps are not prime candidates for field-wide EOR application. These factors were considered during the manual screening step when they could be identified.

** MMP denotes minimum miscibility pressure, which depends on temperature and crude oil composition.

*** Ignored if oil saturation $\left(S_{0}\right) \mathrm{X}$ porosity $(\phi)$ criteria are satisfied.

Source: NPC, 1984. 


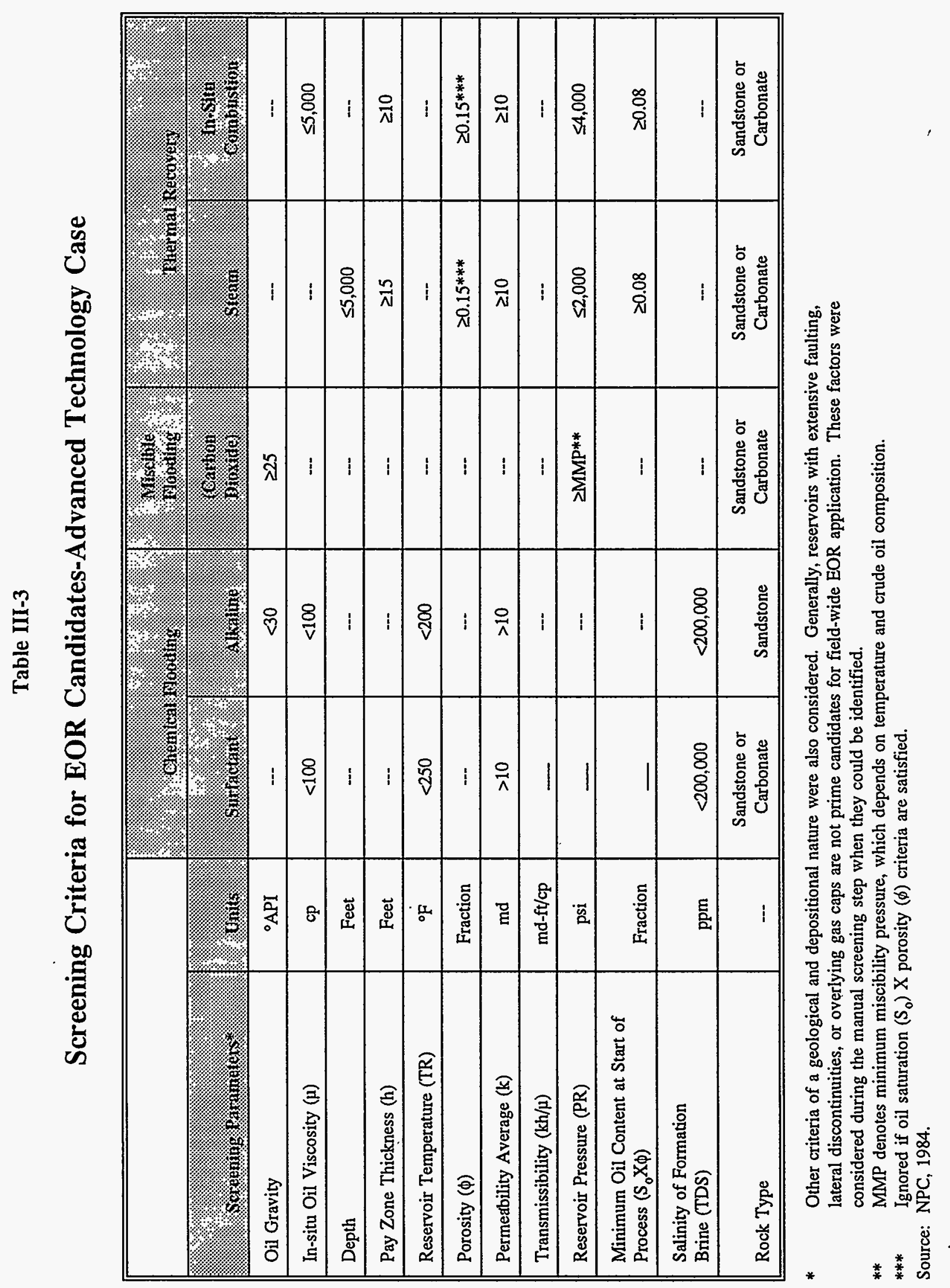


discounted cashflow analysis is performed for each reservoir at a number of oil prices and minimum rates of return.

5. Technology Development. For each reservoir that is determined to be economic at a given price, the performances of the applicable EOR processes are compared. Each reservoir is then assigned the process producing the greatest quantity of incremental oil. In the NPC assessment, the reservoirs are then scheduled for development on the basis of their relative economic attractiveness and time-phased against a series of supply and environmental constraints. This procedure is modified somewhat in the present study, as described below.

The NPC reported its findings on a national basis for four oil prices, ranging from $\$ 20$ to $\$ 50$ per barrel, three minimum rates of return (zero, ten, and twenty percent), and two levels of technology performance -- "implemented," meaning available at present, and "advanced," meaning available in the future due to successful completion of currently ongoing RD\&D. The present study uses the NPC reservoir data base, models, and methodology just as the NPC developed them, except as described in sections $\mathrm{C}$ and $\mathrm{E}$. The NPC methodology is described at length in its final report. ${ }^{2}$

\section{BUILDING ON TORIS: THE EVALUATION OF UNRECOVERED MOBILE OIL RESOURCES}

TORIS evaluations have historically focused on the recovery of immobile or waterflood residual oil. In 1988, TORIS' capabilities were expanded to include an evaluation of the unrecovered mobile oil (UMO) resources in Texas. ${ }^{3}$ This expansion was accomplished by enlarging the system to consider the recovery potential of extended primary and secondary recovery operations in unswept portions of the reservoir, in a manner consistent with the current capabilities to analyze the tertiary recovery target (residual oil in previously swept zones). The system development and initial limited applications that were completed under the DOE UMO study are reported in detail in a topical report by the DOE. ${ }^{3}$

2 Ibid.

3 ICF Resources Incorporated and the Bureau of Economic Geology, University of Texas at Austin, Producing Unrecovered Mobile Oil: Evaluation of Potential Economically Recoverable Reserves in Texas, Oklahoma, and New Mexico, prepared for: U.S. Dept. of Energy/Office of Planning and Environment/Office of Fossil Energy and Bartlesville Project Office, 1989. 
Since 1989, the TORIS ASR models have been upgraded to more accurately describe and evaluate the UMO resources. The enhancements included the following:

- Development of an infill drilling model which processes five-spot waterflood to five-spot infill as well as five-spot waterflood to nine-spot infill;

- Development of a methodology to determine key reservoir heterogeneity elements needed for modeling infill drilling potential. The heterogeneity elements are "reservoir continuity" and "Vertical Permeability Stratification Index" (Dykstra-Parson coefficient). The methodology relies on the history match of production data to determine the heterogeneity elements;

- Validation of the infill drilling model and history match methodology on nine actual field results as well as results of a black oil simulator;

- Integration of a newly developed infill model with other models in TORIS to process infill drilling in combination with polymer flooding or profile modification; and

- Validation of criteria for implemented as well as advanced technology infill drilling.

A preliminary draft report of all developmental work is available through the U.S. Department of Energy, Bartlesville Project Office. The draft report is currently being finalized, and it will be available to the general public in a very near future.

UMO, the target for advanced primary and secondary recovery operations, consists of oil that is uncontacted or bypassed during conventional production that can be displaced from the reservoir by waterflooding. "Uncontacted oil" refers to oil trapped in isolated compartments in reservoirs uncontacted by wells at current spacing, while "bypassed" oil has been contacted by existing wells but unswept by secondary recovery processes. The volume, location, and properties of the UMO depend on the geologic history of the reservoir, the fluid characteristics of the oil, and the drilling and development history of the reservoir.

Potential incremental oil recovery and related economic benefits are estimated for the three processes currently used to improve mobile oil displacement. These processes are referred to as advanced secondary recovery (ASR) and include: infill drilling, profile modification treatments (permeability contrast reduction), and polymer-augmented waterflooding. A modified polymer-waterflood predictive model is used to evaluate each process. Selected combinations of these processes are also evaluated in this study. 
Consistent with TORIS EOR evaluations, the analysis of UMO considers both current technology and advanced technology. The advanced technology analysis estimates that the potential improvement in recovery is possible after successful research, development and demonstration (RD\&D). For polymer flooding and profile modification treatments, advances in technology are projected to increase both the reservoir temperature and the formation salinity thresholds that currently limit the application of these processes. Table III -4 shows the process technical screens that are used in evaluating reservoirs for polymer flooding and profile modification treatments under current and advanced technology scenarios.

Table III -4

\section{Screening Criteria for Advanced Secondary Recovery Processes}

\begin{tabular}{|c|c|c|c|c|}
\hline & \multicolumn{2}{|c|}{ Polymer ${ }^{*}$} & \multicolumn{2}{|c|}{ Profile Modification } \\
\hline & Current & Advanced & Current & Advanced \\
\hline $\begin{array}{l}\text { Reservoir Temperature } \\
\left({ }^{\circ} \mathrm{F}\right)\end{array}$ & $<200$ & $<250$ & $<180$ & $<250$ \\
\hline $\begin{array}{l}\text { Formation Brine } \\
\text { Salinity (ppm) }\end{array}$ & $<100,000$ & $<200,000$ & $<100,000$ & $<200,000$ \\
\hline Permeability (md) & $>20$ & $>10$ & $>20$ & $>10$ \\
\hline Oil Viscosity (cp) & $<100$ & $<150$ & $<100$ & $<150$ \\
\hline * Source: NPC, 1984 & & & & \\
\hline
\end{tabular}

Infill drilling potential is also evaluated under implemented and advanced technology scenarios. Current knowledge of reservoir heterogeneity limits drilling to highly favorable reservoirs where blanketpattern drilling at uniform spacing can yield a profit. Increased continuity in the implemented technology case is estimated by the reservoir-wide average improvement in continuity that is possible with a reduction in spacing to one-half the current level. The advanced technology scenario assumes that improved geologic description would target infill wells to more promising segments of each reservoir. The TORIS models represent this assumption by dividing the reservoir into two parts, a more continuous (homogeneous) region and a less continuous (heterogeneous) region. Each region is then separately 
analyzed to determine its economic potential for infill drilling at subsequent one-half reductions in well spacing down to five acre spacing, or one-eighth of current spacing, the maximum reduction evaluated in this study. The specific criteria for both the implemented technology and the advanced technology infill drilling is shown in Table III-5. The entire methodology (data, models, highgrading, and analytical systems) was developed and implemented in a manner fully compatible with the existing TORIS structure.

Table III-5

Screening and Approach for Advanced Technology Infill Drilling

\begin{tabular}{|c|c|}
\hline teechinology\% & (4) \\
\hline Implemented & $\begin{array}{l}\text { 5-spot waterflood to 5-spot infill } \\
\text { - } \quad 15 \% \text { minimum real rate of retum } \\
\text { - } \quad \text { Minimum well spacing of } 10 \text { acres before infill drilling } \\
\text { - } \quad \text { One drill down }\end{array}$ \\
\hline Advanced & $\begin{array}{l}\text { - } \quad \text {-spot waterflood to 5-spot infill } \\
\text { - } \quad 10 \% \text { minimum real rate of retum } \\
\text { - } \quad \text { Highgrade into homogenous and heterogeneous portions } \\
\text { - } \quad \text { One drill down in homogeneous portion } \\
\text { - Up to three drill downs in heterogeneous portion } \\
\text { - } \quad \text { Well spacing after infill greater than } 5 \text { acres }\end{array}$ \\
\hline
\end{tabular}

\section{SCOPE OF THE ANALYSIS}

The cases selected for this analysis include six oil price assumptions and two levels of technology application. The cases are run, first incorporating either EOR or ASR processes individually, and then in combination. TORIS selects from five EOR recovery methods and five ASR methods for each reservoir in the database. A reservoir could be assigned only one EOR process and/or one ASR method for each case considered.

The nominal crude oil prices (West Texas intermediate adjusted for transportation costs and gravities less than $40^{\circ} \mathrm{API}$ ) range from $\$ 16 / \mathrm{B}$ to $\$ 36 / \mathrm{B}$ in $\$ 4$ increments, all stated in constant 1991 dollars. The prices are selected to bracket the likely prices over the next 30 years. A minimum real (after inflation) rate of return of $10 \%$ is used to estimate discounted cash flows and project profitability for all analyses. In addition, a risk premium is also considered depending on the EOR/ASR process and the level 
of technology. The risk premium is mrdeled as an increase in the hurdle rate as shown in Table III- 6 . The risk premium was recommended by the TORIS peer review committee.

Table III-6

Risk Premium For Implemented and Advanced EOR and ASR Processes

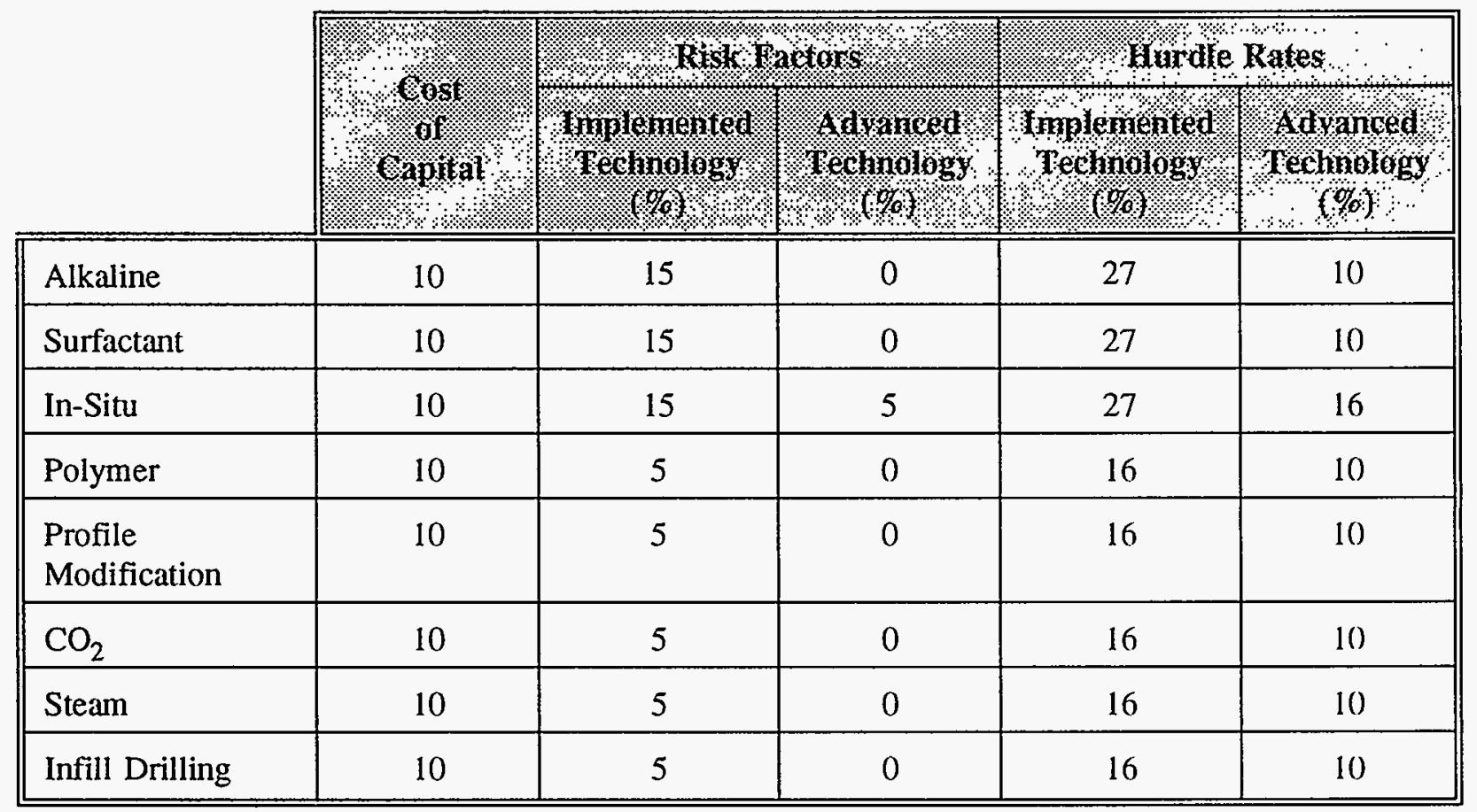

At each oil price, two technology cases are analyzed; the "implemented" and the "advanced" case. Implemented technology reflects the applicability and level of performance of the respective processes (EOR or ASR) which are currently available. Advanced technology considers the likely improvements in process performance and applicability that can be achieved within the next decade if a focused, effective $R \& D$ program is successfully completed.

All cases are analyzed in detail to examine their impact on estimated oil reserves, oil production, state and Federal revenues, and the state and national economies. The results of these analyses, addressing the benefits from incremental production, are reported in Chapters IV and V which discuss the effects of EOR and ASR processes for implemented technology and advanced technology, respectively. 


\section{E. ADAPTATIONS FOR THE PRESENT STUDY}

Several adaptations to the NPC approach were necessary to conduct the present analysis. None is a significant departure from the NPC methodology.

\section{Data Editing and Additions}

Based on a lengthy data search using state and library sources, the NPC reservoir data have been reviewed and updated for 853 of the largest Texas reservoirs, accounting for nearly $80 \%$ of estimated original oil-in-place (OOIP) in Texas. The reservoirs represented in the data base include oil zones in every region of the state. The largest reservoirs are more completely represented in the data, but reservoirs as small as 5 million barrels are also analyzed in the study. The data base is, therefore, believed to be representative of the diverse oil producing formations across Texas. Data from the Energy Information Administration on the production of oil, gas, and water from 1970 to 1992 has been added for all reservoirs, thereby permitting decline curve analyses (used in the timing algorithm, discussed below) and validation of the estimated ultimate conventional recovery.

\section{2. $\quad$ State and Federal Taxes}

The present study uses current tax structure along with the actual tax rates in the TORIS economic models. The Federal taxes are estimated based on the new corporate tax rules established by Congress in the Tax Reform Act of 1986 and signed into law in October 1986. This law provides for a 34\% marginal rate on corporate income taxes and changes the depreciation schedules and expense rules. In addition, the present study includes the new Federal EOR tax credit as passed by Congress in FY91. The new Federal EOR tax credit provides a credit equal to $15 \%$ of all qualified enhanced oil recovery costs on projects that began or were significantly expanded after December 31, 1990. The "qualified enhanced oil recovery costs" are defined as tangible property investments, intangible drilling and development costs, and purchase costs of tertiary injectants. The tax credit is contingent upon professional certification, in advance, that the EOR project is capable of producing more than an insignificant increase in ultimate recovery. Because the goal of the incentive is to make the application of EOR techniques economic at lower oil prices, where project economics are most impacted, the incentive is gradually phased out at oil

prices above $\$ 28 / \mathrm{B}$. For every $\$ 1 / \mathrm{B}$ that the average benchmark price for the preceding year exceeds 
$\$ 28 / \mathrm{B}$, the incentive is reduced by 2.5 percentage points for the subsequent year, so that a complete phasing out of the incentive would occur at an oil price of $\$ 34 / \mathrm{B}$.

The study also accounts for the current state tax incentive in Texas. This incentive reduces the severance tax on incremental production to $2.3 \%$ for the first ten years for all qualified EOR and ASR projects.

\section{Cost and Price Data}

An informal survey of industry representatives has determined that the NPC costing algorithms for investments are still valid for the present study, provided that the analyzed prices are consistent with the year of the cost data. The only exception to the use of the NPC's cost algorithms is the cost of enhanced recovery injectants delivered to the field. The NPC assumed a $\mathrm{CO}_{2}$ purchase price in the Permian Basin of West Texas and Eastem New Mexico of $\$ 1.25$ per thousand standard cubic feet (Mcf) at an oil price of $\$ 30 / \mathrm{B}$. The NPC adjusted for changes in oil price using the equation:

$$
\mathrm{CO}_{2} \text { Price }(\$ / \mathrm{Mcf})=\$ 0.50+\$ 0.025 \mathrm{X} \text { Oil Price }(\$ / \mathrm{B}) .^{4}
$$

However, the base price and adjustment equation were established at higher oil prices and before the completion of major $\mathrm{CO}_{2}$ pipelines or significant $\mathrm{CO}_{2}$ deliveries to the region. An informal poll of pipeline and field operators suggests that the $\mathrm{CO}_{2}$ prices at present and into the near future will be lower (relative to oil prices) than the NPC had assumed. The $\mathrm{CO}_{2}$ purchase price in West Texas has been adjusted for changes in oil price using the equation:

$$
\mathrm{CO}_{2} \text { Price }(\$ / \mathrm{Mcf})=\$ 0.50+\$ 0.02 \times \text { Oil Price }(\$ / \mathrm{B})
$$

This equation results in a $\mathrm{CO}_{2}$ price of $\$ 0.90 / \mathrm{Mcf}$ at the $\$ 20 / \mathrm{B}$ oil price. $\mathrm{CO}_{2}$ prices in other regions of the state are assumed to be double the West Texas price, based on previous NPC surveys.

Chemical injectant costs have also been adjusted based on a survey of operators and suppliers. Polymer costs, assumed to be $\$ 1.60$ per active pound by the NPC, have been reduced to $\$ 1.33$ per active

4 National Petroleum Council, Enhanced Oil Recovery, Washington, DC, 1984. 
pound based on the current cost of low temperature, low salinity polymers. The cost is increased where oil and reservoir properties dictate the use of high molecular weight polymers. Surfactant costs used by the NPC were based on a primary surfactant cost of $\$ 0.32$ per active pound and a secondary surfactant cost of $\$ 0.44$ per active pound. The surfactant slug cost based on these components was $\$ 7 / \mathrm{B}$. Prices paid by operators in recent field tests show this cost to be too low. Survey information shows that primary surfactant costs are higher (\$0.63/active pound), resulting in a $\$ 10.17 / \mathrm{B}$ surfactant slug cost at a $\$ 30 / \mathrm{B}$ oil price. ${ }^{5}$ Chemical costs have been adjusted for oil price changes as had been done in the NPC analysis, based on the energy component of the chemicals for different oil prices.

\section{Benefits Estimation}

The NPC did not calculate all of the individual items used in the present study's estimation of benefits. Special algorithms have been developed to estimate the number of jobs created, wages paid, and personal income taxes collected based on other elements already contained in the economic model. These algorithms are discussed further in Section $\mathrm{F}$ of this chapter.

\section{5. $\quad$ Project Timing}

The NPC's national perspective permitted a timing algorithm based principally on the assumption that the most economically attractive reservoirs would be developed first, given some broad constraints. A more detailed timing approach for both EOR and ASR was used in the present study. Timing for the application of EOR recovery techniques is estimated in two steps. First, project starting dates for EOR that are documented in the literature are used to time recently started operations. Second, when project start up dates are not available, the year that average well abandonment will occur for each reservoir under conventional recovery is estimated. This abandonment date is based on the projected rate of decline and economic limit of conventional recovery for each reservoir. EOR recovery is then phased in to occur reservoir-wide, at the latest, by three years following the estimated abandonment date. Projects that are not timed in by this data are assumed abandoned and are excluded from the analysis. The timing of ASR reserves development and production was accomplished using the Crude Oil Policy Model (COPM) because the TORIS timing model was not suited for ASR for technical reasons. COPM simulates the

5 Ray, et al., Potential Crude Oil Production from Enhanced Oil Recovery, U.S. Department of Energy, Bartlesville Project Office, 1986. 
development of an aggregate resource as a function of project economics, while simultaneously accounting for abandonment of the undeveloped portion of the resource and technology transfer constraints. Inputs to COPM include the total resource potential, development and production costs, technology availability dates, technology penetration rates, abandonments rates, and reserves development rates. Outputs from the model include annual production, reserve additions, abandonments, development costs, operating costs, wages, and taxes. Reserves estimates were supplied by TORIS.

Total reserves were disaggregated into two categories, reserves available with implemented technology and incremental reserves available through the application of advanced technology. Appropriate model parameters were selected for each of these resource categories. The technology availability dates were set to 1993 for implemented technology and 2000 for advanced technology. Technology penetration rates were set at $75 \%$ in 12 years for implemented technology and $75 \%$ in 8 years for advanced technology, with the advanced technology case representing an aggressive technology transfer effort. Abandonment rates for both implemented and advanced technology were set to $3 \%$ of the undeveloped resource per year prior to technology availability and $1.5 \%$ per year after technology becomes available. Reserves development rates corresponded to typical field development profiles.

\section{F. ESTIMATION OF BENEFITS, COSTS, AND ECONOMIC IMPACTS}

The NPC study analyzed each reservoir from the perspective of the operator deciding whether to implement advanced oil recovery processes. The present study does the same in evaluating the economic viability of each reservoir. Thus, the benefits and costs to the operators are explicitly captured in the net cash flow calculations of individual projects. Under each of the various cases analyzed, projects yielding a net present value greater than the hurdle rate are assumed to be developed. This assumption is the basis for the projection of potential incremental production and reserves.

The incremental benefits and costs of EOR and ASR are estimated and reported on an annual as well as a cumulative basis. As previously discussed, reservoir timing is based on the estimated abandonment of the resource due to production decline, except for major reservoirs in which activity suggests earlier project start dates. Projects are phased in over a 5- to 10-year period to achieve full project development before this abandonment would occur. Annual estimates of benefits are based on the total economic resource produced in a given year. These annual values are reported for a twenty-seven year period, 1993 to 2020 . Cumulative benefits include the sum of the annual benefits plus any additional 
benefits that would accrue after 2020. The total length of time for the life of all projects varies considerably depending on the process, oil price, and tax treatment. The vast majority of cumulative production and benefits occur in the twenty-seven year period of focus in this study. The additional benefits that occur after 2020 are small relative to the total benefit, but important to the overall aggregate analysis.

\section{Benefits to State and Local Treasuries}

The benefits to Texas state and local treasuries from advanced oil recovery processes are the additional tax revenues attributable to implementation of the projects. These taxes include gross production taxes on oil and sales tax on equipment and material purchases. The State of Texas does not have an income tax. Evaluating these benefits under the current tax structure involves estimating the sum of these revenues as they apply to the development of the projects and the activities associated with the incremental production from improved recovery projects.

\section{Direct State Economic Effects}

The effect on the state's treasury is only one segment of the benefits of advanced oil recovery processes. The citizens of Texas also gain from the increased economic activity. Only the direct effects of the incremental activity are included, not the economic "multiplier" or indirect "ripple effect" activities (e.g., pipeline construction, retail sales, etc.). The direct impact on the state economy is defined as the sum of net revenues to the state and local treasuries (as presented above); royalties to individuals, corporations, and the state; expendable (intangible) drilling materials and services; and operating costs excluding injectant purchases. It is assumed that these funds flow predominantly to the state of Texas and its citizens.

Excluded from this state economic activity definition are cashflows that generally benefit citizens of other states in larger proportion than they benefit citizens of Texas. These include costs for tubular steel products installed in wells, injection and production equipment, purchased tertiary injectants, and other oil field materials typically manufactured out-of-state. To the extent that these goods are marketed by distributors in Texas, the direct benefits of these "retail pass-through" to the state are omitted from the estimates of direct state economic activity. Similarly, while it is recognized that a portion of tertiary injectants, especially chemicals, may originate in Texas (generating royalties, employment, taxes, and/or 
other economic activity), estimating these quantities is outside the scope of the present study. Other excluded items include Federal taxes, corporate debt service, and return on capital. While the citizens of Texas obviously benefit from these excluded elements as U.S. citizens, or as employees and stockholders of companies providing services, they share them with a much larger population. Thus, the definition used for direct economic effects understates the actual benefits to the state of Texas and its citizens.

The additional jobs, wages, and benefits created by advanced oil recovery are also estimated. Labor costs (wages and fringe benefits) are calculated by isolating the labor component of all major cost elements. Table III-7 summarizes the major cost elements and their respective labor and material components. Labor costs are converted into estimated numbers of jobs by dividing total wages by the average oil field wages (including benefits) reported by the U.S. Department of Labor. ${ }^{6}$ Sales tax revenues are calculated based on the materials component of these costs, assuming purchasers would pay the appropriate state tax on these goods.

\section{National Effects}

The Federal government benefits substantially, both directly and indirectly, from increased recovery of the Texas oil resource. Direct Federal taxes total 5\% to $20 \%$ of the value of each barrel of oil recovered. Each additional barrel of Texas oil produced can replace a barrel of imported oil. Therefore, each dollar used to purchase the incremental barrels of oil that would otherwise pay for imports is, potentially, a dollar reduction in the trade deficit. ${ }^{7}$ To estimate the direct effects on import replacement (i.e., excluding multiplier effects), the gross revenue from the additional production is used. This measure of gross revenue incorporates direct in-state economic activity and excludes elements discussed in the section above. In this sense, the estimated increase in import replacement represents a more complete measurement of direct economic impacts, excluding multiplier effects. In addition, corporate and individual Federal income taxes are estimated to assess the direct effects of incremental Texas oil recovery on the Federal treasury.

6 U.S. Department of Labor, Bureau of Labor Statistics, 1985.

7 Although constraints caused by limited financial or personnel resources may result in delayed national benefits due to short-term deferral of projects in other states, the aggregate benefits to the nation should be achieved as all economic projects will ultimately be developed. 
Table III-7

\section{Labor and Materials as Percentage of Total Cost in EOR Projects}

\begin{tabular}{lccc}
\hline \multirow{2}{*}{ Investments } & \% Labor & \% Materials & \% Other \\
\cline { 2 - 4 } Drilling Wells & 18 & 55 & 27 \\
Work-overs & 15 & 63 & 22 \\
Equipping Wells & 10 & 50 & 40 \\
Pipe Installation & 10 & 50 & 40 \\
Plant Installation & 16 & 46 & 38 \\
& & & \\
Expenses & & & \\
Field Operations & 33 & 58 & 9 \\
Plant Operations & 38 & 57 & 5 \\
Production Treating & 0 & 100 & 0 \\
Overhead & 100 & 0 & 0
\end{tabular}

Sources:

Investments

Drilling and Work-overs

-. NPC, 1984

-. $\quad$ EIA, 1984

-- $\quad$ Professor Neil J. Dikeman, University of Oklahoma, 1986

- $\quad$ Equipping Wells

-- Industry estimate

- $\quad$ Pipe Installation

-- Industry estimate

- $\quad$ Plant Installation

-- $\quad$ Modern Cost Engineering Technologies, Herbert Popper, page 82-83

Expenses

- $\quad$ Field Operations

-- EIA, 1984

- $\quad$ Plant Operations

-- NPC, 1984

-- EIA, 1984 (power and chemicals)

- $\quad$ Production Treating

-- $\quad$ By definition

Overhead

-- NPC, 1984 


\section{G. LIMITATIONS TO THE ANALYTICAL APPROACH}

The approach followed by this study has limitations that should be considered in utilizing its results. Some of these follow from the adoption of the NPC methodology; others result from the need to limit the scope of the present effort. It is also important to note that the results of this analysis are not forecasts of future oil recovery; they are estimates of the recovery potential of selected EOR and ASR processes.

The NPC approach, while the most credible and flexible methodology available, has certain distinct limitations. One problem is the reliance on averaged reservoir and fluid properties. Oil reservoirs are actually highly heterogeneous, with erratic properties throughout the field. The use of averaged properties belies the fact that portions of an individual reservoir could be highly attractive as an advanced technology oil recovery prospect even if the whole reservoir, on average, is not economic. Given the present methodology, reservoirs must be economically accepted or rejected as whole units, unless advanced geoscientific knowledge allows the reservoir to be evaluated in segments. The methodologies of both the present study and the NPC assume that the least favorable 20 percent of any reservoir would not be developed under EOR or ASR operations.

A second limitation is the use of regional costing algorithms. Although developed from the best available data and explicitly adjusted for variations in energy costs and specific reservoir characteristics, they do not reflect site-specific cost variations applicable to specific operators. Thus, this study does not necessarily use the actual costs of individual projects. To the extent that the average costs used understate or overstate the true project costs, the actual results will be higher or lower than the analysis estimates.

A third limitation is the use of simplified process performance models. While the models used in this project are extensively calibrated, they are designed to analyze large numbers of individual reservoirs quickly and simultaneously. Therefore, while they incorporate all the relevant reservoir engineering concepts, they are relatively simplified and generalized. In this simplified state, the models cannot be as accurate as highly detailed reservoir simulators in which very specific reservoir features and process designs may be evaluated (such as assessments used in the actual design of specific projects). The present study assumes these models are appropriate for aggregate analyses but not necessarily for

individual reservoirs. Further, these models are explicitly designed to estimate only incremental recovery resulting from advanced oil recovery processes after completion of conventional production operations. 
Laboratory and limited field data suggest that application of some of these techniques before the economic limit of conventional recovery could yield more than the sum of conventional and advanced oil recovery, but this is not reflected in the models.

An additional limitation arises from the methodological convention of "constant price" analysis. The use of this convention is consistent with the NPC's original nationwide study, conducted during a period of relatively stable, rising oil prices, and differentiates the effect of oil price from other effects. It can, however, cause a distortion, especially in times of declining or radically changing oil prices. The "hidden" assumption of this convention is that each of the respective oil prices analyzed must be attained by the time (and be expected to continue at that level after) the decision to commit specific reservoirs to enhanced recovery or advanced mobile oil recovery operations is made. This decision is generally made several years before the reservoir's final, actual economic limit is reached under conventional technology. To the extent this condition is not met, existing wells reaching their economic limits at lower prices will be shut-in and abandoned, making them unavailable for use in advanced oil recovery projects, as assumed. The economic model assumes that all existing wells will be utilized in future operations, although older wells may require workovers. Should "premature" abandonments occur, these wells would need to be redrilled, resulting in additional incremental investment not included in this analysis (although necessary workovers are included in the assumed cost). Redrilling would result in substantially increased costs and would thus increase the minimum oil price at which advanced oil recovery processes are profitable for certain reservoirs. The net effect of this analytic convention could overstate the economic reserves and production and the corresponding economic benefits. Under these conditions, the "constant price" convention introduces an optimistic bias to the present analysis.

Finally, the analysis follows the NPC approach, which assumed that project operation would be conducted by an integrated major oil company. This approach, in most cases, presents the least favorable corporate tax treatment for investments and revenues from advanced oil recovery projects and assumes a relatively high overhead on operations. Independent producers operate with a different corporate structure, tax situation, and overhead rate. Because most costs used in this analysis are not affected by total project size and some non-integrated operators would enjoy more favorable tax treatment, smaller independent producers should receive the same benefit as a major oil company from application of advanced oil recovery processes, possibly even at lower oil prices than projected in this evaluation. 
None of the above limitations invalidate the results of this analysis. Given the uncertainty of the size and combinations of the optimistic and pessimistic biases introduced by these limitations, it is assumed that the approach is valid and the resulting projections are reasonable. To avoid misinterpretation of particular reservoirs, and to respect the confidence in which some project and reservoir data were obtained, no reservoir specific date is provided in the reports generated from this analysis. However, in cases where the results seemed unusual, the modeling specifications for specific reservoirs were examined in-depth to ensure the validity of the results. 


\section{INCREASED RECOVERY FROM THE KNOWN REMAINING OIL RESOURCE IN TEXAS UNDER IMPLEMENTED TECHNOLOGY}

\section{A. INTRODUCTION}

This chapter discusses the post-conventional reserve additions and potential economic impacts attributable to the application of currently available (implemented technology) oil recovery methods in analyzed Texas reservoirs. Chapter $\mathrm{V}$ discusses the incremental reserves and benefits under advanced technology methods attainable through RD\&D. The TORIS reservoirs analyzed in this study are individually modeled to evaluate their potential for incremental production and reserves by tertiary and advanced secondary recovery techniques under a variety of oil prices and economic conditions. Some key technical assumptions and considerations regarding the analysis in this report are:

- The incremental production and reserves refer to future recovery estimated for the analyzed EOR and ASR techniques. Such production and reserves are above and beyond the recovery attainable by primary and secondary recovery techniques.

- Both light oil (API $>20$ degree) and heavy oil (API $\leq 20$ degree) resources are considered in this analysis.

- $\quad$ All EOR and ASR recovery potential evaluated in this report reflect future new projects only, and they do not include incremental reserves from existing (ongoing) EOR and ASR projects. However, the expansion to the ongoing projects, if technically and economically feasible, are evaluated as part of future new projects in this report.

All reservoirs are screened for technical criteria and are analyzed in detail using the process performance and economic models described in Chapter III. The results are based on the evaluation of 853 reservoirs for their EOR and ASR potential. No effort is made to extrapolate the results of this analysis to the rest of the reservoirs making up the Texas resource.

\section{B. RECOVERY OF THE REMAINING IMMOBILE OIL RESOURCE}

\section{1. $\quad$ Production and Reserves}

Over the price range analyzed, EOR processes (carbon dioxide $\left(\mathrm{CO}_{2}\right)$ miscible, chemical, and thermal) could stimulate between 170 million and 2.4 billion barrels of incremental reserves under 
implemented technology (Figure IV-1A and Table IV-1A). The outside potential represents a $36 \%$ increase in the state's current proved reserves (6.8 billion barrels). At oil prices between $\$ 16 / \mathrm{B}$ and $\$ 20 / \mathrm{B}, 170$ million to 880 million barrels of incremental reserves could be economically producible. However, a small increment in price to $\$ 24 / \mathrm{B}$ could stimulate 644 million barrels of oil for a total of 1.5 billion barrels. As price rises above $\$ 24 / \mathrm{B}$, implemented technology EOR processes could become increasingly prolific, and substantial incremental reserves could become economically attainable. An additional $\$ 4 / \mathrm{B}$ increase in the oil price to $\$ 28 / \mathrm{B}$ could add another 560 million barrels of incremental EOR reserves for a total of over 2 billion barrels. As oil prices increase to $\$ 36 / \mathrm{B}$, EOR techniques could generate upside potential reserve additions of 2.4 billion barrels.

Among the currently implemented EOR processes considered in this analysis, $\mathrm{CO}_{2}$-miscible flooding generates the largest incremental reserves at all oil prices. The relatively inexpensive supply of $\mathrm{CO}_{2}$ that is available in West Texas gives this technique an economic advantage over other implemented technology EOR processes, particularly at lower oil prices. At an oil price of $\$ 16 / \mathrm{B}$, miscible flooding would account for all $E(\mathrm{R}$ reserve additions. At $\$ 20 / \mathrm{B}$ and $\$ 24 / \mathrm{B}$, miscible flooding would account for $99 \%$ and $91 \%$ of the estirnated incremental reserves from EOR, respectively. At higher prices, other EOR processes, particularly chemical flood, become more attractive, but at the upside potential $(\$ 36 / \mathrm{B})$, miscible flooding would still contribute $94 \%$ of the total potential incremental reserves from the analyzed Texas reservoirs. Given oil prices at or above $\$ 32 / \mathrm{B}, \mathrm{CO}_{2}$-miscible floods could recover over 2.1 to 2.2 billion barrels, over $30 \%$ of Texas' current proved reserves. In addition to the results from this analysis, the ongoing Texas $\mathrm{CO}_{2}$-miscible projects have potential recovery of 1.2 billion barrels of oil.

The recovery potential of other EOR processes is more limited in Texas. As currently implemented, chemical flooding has some potential at higher oil prices. Chemical flooding could stimulate up to 120 million barrels to Texas proved reserves at oil prices over $\$ 28 / \mathrm{B}$. At lower oil prices, however, the high cost of injectants limits the potential of chemical flooding potential under implemented technology; a threshold price of at least $\$ 20 / \mathrm{B}$ is needed to make chemical flooding minimally costeffective. The application of thermal techniques is also limited due to the small volumes of heavy oil (reservoirs with oil gravities of API $\leq 20$ degrees) in Texas, but thermal processes could yield 33 million barrels of incremental reserves at a $\$ 28 / \mathrm{B}$ oil price and above.

Table IV-1B shows the number of EOR projects that could be implemented at different oil prices. Of the 853 reservoirs evaluated in this analysis, all of which are technically amenable to one or more EOR 
Table IV-1A

\section{Incremental Reserves from EOR by Process Implemented Technology \\ (Million Barrels)}

\begin{tabular}{|c|c|c|c|c|}
\hline 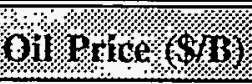 & 8.0, & ryoniningar & 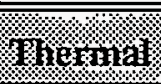 & 1. \\
\hline$\$ 16$ & 172 & 0 & 0 & 172 \\
\hline$\$ 20$ & 872 & 9 & 0 & 881 \\
\hline$\$ 24$ & 1,391 & 117 & 17 & 1,525 \\
\hline$\$ 28$ & 1,930 & 120 & 33 & 2,083 \\
\hline$\$ 32$ & 2,149 & $117^{* \prime}$ & 33 & 2,299 \\
\hline$\$ 36$ & 2,270 & 120 & 33 & 2,423 \\
\hline
\end{tabular}

- Decline in resource between $\$ 28 / \mathrm{B}$ and $\$ 32 / \mathrm{B}$ reflects the impact the phase out of the Federal EOR tax credit.

Table IV-1B

\section{Estimated Number of Economic EOR Projects by Process Implemented Technology \\ (Project Counts)}

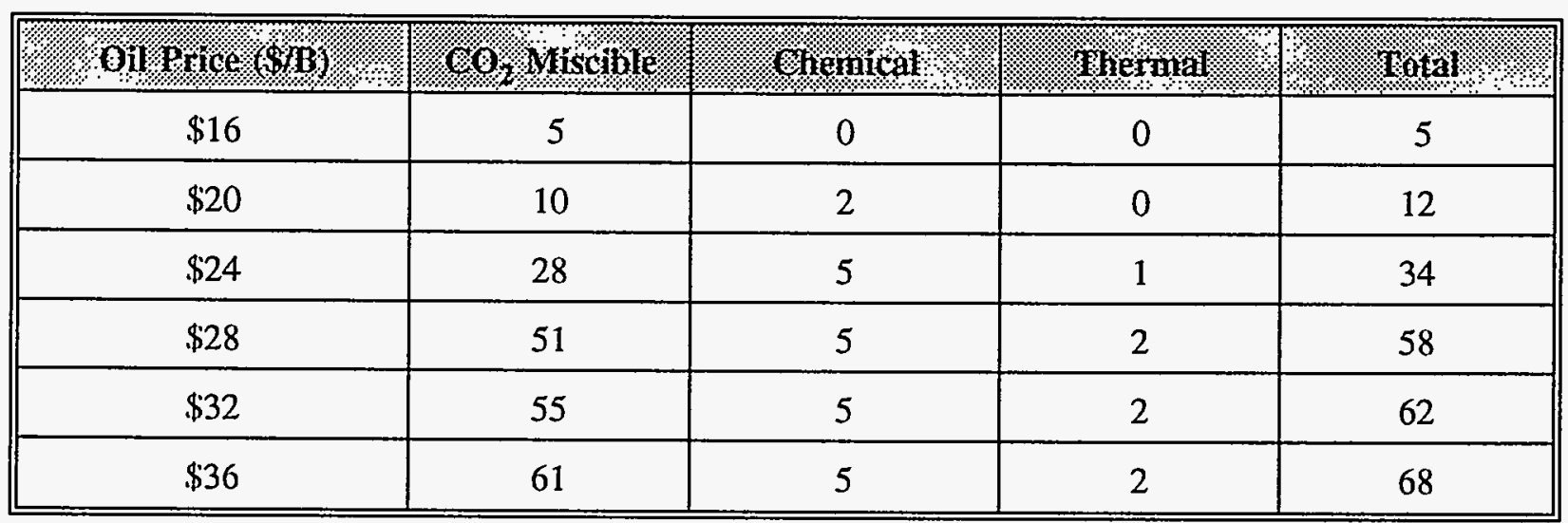


process, only $8 \%$ would be economic to develop with current EOR technology, even at oil prices of $\$ 36 / \mathrm{B}$. Gas-miscible floods account for about $90 \%$ of the EOR projects considered economic in the price range evaluated. At oil prices of $\$ 20 / \mathrm{B}$ or less miscible floods account for all but two economic Texas EOR projects. In most cases, the economic projects are in the large reservoirs, but size alone is not a major determinant of EOR economics.

The timing of project initiation in each reservoir that is economic at a specific price is scheduled according to that reservoir's projected decline rate. The annual incremental production resulting from EOR is determined by phasing in economic projects based on the demonstrated production decline and economic limit of conventional operations as discussed in Chapter III. Figure IV-1B shows the expected annual production from all EOR processes at oil prices of $\$ 16$ and $\$ 32$ per barrel. The timing of EOR production from economically feasible projects is governed by:

- $\quad$ Availability of the reservoir for tertiary activities, based on production decline estimates. The reservoir is available when an economic limit (itself a function of price) is reached.

- $\quad$ Physical constraints on services, such as drilling and workovers, as well as on the supply of tertiary injectants.

- Economic constraints, principally on the availability of investment capital.

At $\$ 16 / \mathrm{B}$, EOR production could peak at 7.5 million barrels per year in the year 2003 . The peak at $\$ 32 / \mathrm{B}$ would occur in the same year at nearly 72 million barrels per year, $11 \%$ of current production rates in Texas.

2. Increases in State and Local Revenues

EOR operations could also increase state and local revenues by production taxes and by sales taxes on purchased materials used in the projects (Texas has no state income tax). The estimated revenues are aggregated directly from analysis of oil production or operations in the sample of reservoirs. Direct state and local revenues generated over the life of the EOR projects vary considerably with oil prices, as shown in Figure IV-2. A significant portion of these revenues result from production taxes. At $\$ 20 / \mathrm{B}$, about $\$ 930$ million in incremental revenues could be generated, with production taxes contributing over $71 \%$ of the total and sales tax revenues accounting for the remainder. At $\$ 24 / \mathrm{B}$, EOR could yield $\$ 1.8$ billion in revenues for the state, $\$ 1.3$ billion from production tax revenues plus over $\$ 510$ million in sales tax 
Figure IV-1

\section{Reserves and Production Response from EOR Techniques \\ Implemented Technology}

A) Incremental Reserves by EOR Process

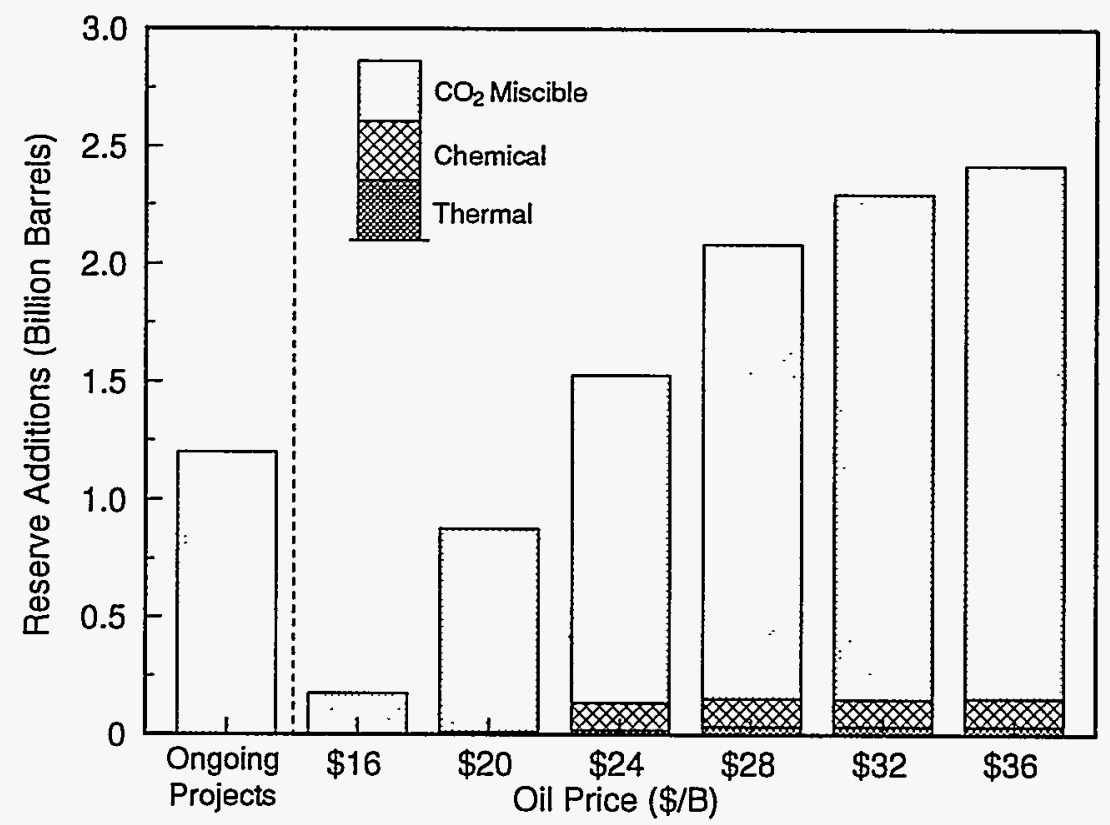

B) Annual Production from EOR

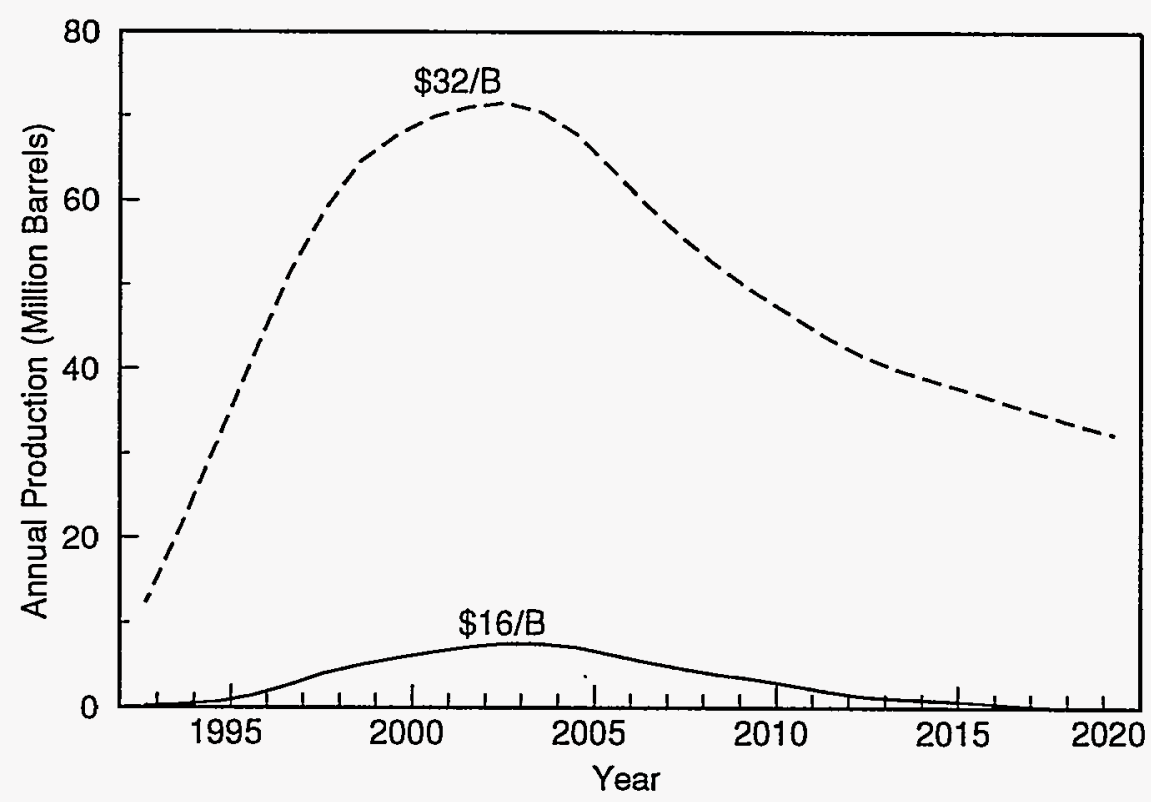


Figure IV-2

\section{Direct State and Local Revenues from EOR Production Implemented Technology}

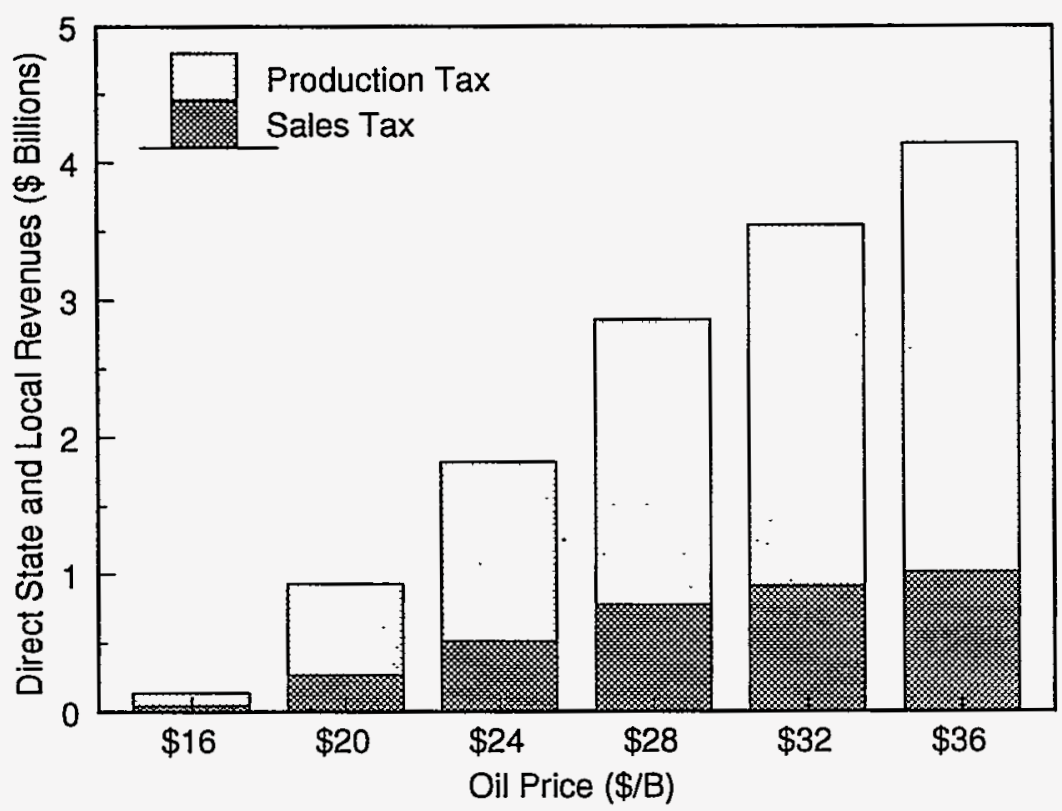

receipts. At $\$ 28 / \mathrm{B}$, additional tax revenues could total $\$ 2.9$ billion, while at the highest price case of $\$ 36 / \mathrm{B}, \$ 4.1$ billion of additional state and local revenues could be generated by EOR activities. Production taxes constitute a slightly larger share of the total revenues at these higher oil prices.

\section{Effects on the State Economy}

In addition to the incremental state and local revenues, EOR activities would benefit Texas by increasing economic activity and by creating new jobs. The effects of EOR on the state economy are estimated conservatively: (1) only direct effects are included (i.e., no economic multiplier due to secondary effects); and (2) the direct effects are limited to benefits believed to accrue predominantly to the state of Texas and its citizens. Only intangible drilling costs, royalties, state and local taxes (as defined and estimated in the previous section), and operating costs, exclusive of purchased injectants, are included in the calculation of state economic activity. Tubular steel products, injection and production equipment, purchased EOR injectants, corporate return on capital, and Federal taxes are all excluded from this definition of state economic activities. Royalties may be overstated as some portion is paid to the Federal government (i.e., production from Federal lands). While the excluded elements undoubtedly aid Texas' citizens to some degree, a substantial portion of the benefits will be enjoyed by citizens of other 
states. However, to the extent that local manufacture or retail sales of these items provide economic benefits within Texas, injectants produced or manufactured in Texas are employed, or economic "multipliers" occur, the calculated economic effects are understated.

Figure IV-3 displays the total direct economic gains for the state over the oil price range analyzed. In all cases, operating costs would account for between $65 \%$ and $68 \%$ of these economic effects; state taxes represent around $8 \%$; intangible investment is about $3 \%$; and royalties would be $19 \%$ to $22 \%$ of the total. At $\$ 16 / \mathrm{B}$, incremental benefits to the state economy could exceed $\$ 1.6$ billion. A substantial increase in economic activity occurs at oil prices above $\$ 20 / \mathrm{B}$; over $\$ 21$ billion and $\$ 33$ billion would be generated within the Texas economy at the oil prices of $\$ 24 / \mathrm{B}$ and $\$ 28 / \mathrm{B}$, respectively. At the upside potential ( $\$ 36 / \mathrm{B}$ ), an estimated $\$ 47$ billion of statewide direct economic activity could be stimulated by EOR projects.

Successful EOR projects could add a substantial number of jobs statewide, as shown in Figure IV-4. The number of additional jobs created or maintained due to new EOR projects during peak years could reach from over 430 to nearly 6,900 per year, depending on the oil price. Total annual wages paid could peak between $\$ 19$ and over $\$ 290$ million, again depending on the oil price.

\section{Effects on the National Economy and Budget}

Increased oil recovery from EOR in Texas would benefit the nation as a whole. National benefits would accrue in several ways: replacement of oil imports, increased Federal corporate and personal income tax revenues, increased energy security and independence, and a reduced trade deficit. The addition of as much as 2.4 billion barrels of reserves in Texas would expand the nation's proved reserve base. Since an additional barrel of domestic oil production replaces a barrel of imported oil, the nation's energy security would be enhanced through the implementation of EOR in Texas.

EOR activity in Texas contributes to the Federal treasury through personal income taxes on wages paid and corporate income taxes on project profits. As shown in Figure IV-5A, increases in Federal revenues attributable to EOR could range from $\$ 150$ million at $\$ 16 / \mathrm{B}$ to more than $\$ 11$ billion at $\$ 36 / \mathrm{B}$ over the life of the projects. At oil prices ranging from $\$ 20 / \mathrm{B}$ to $\$ 28 / \mathrm{B}$, EOR activities could generate nearly $\$ 1.0$ billion to over $\$ 4.4$ billion in additional Federal revenues. 
Figure IV-3

\section{Direct State Economic Activity* from EOR Production}

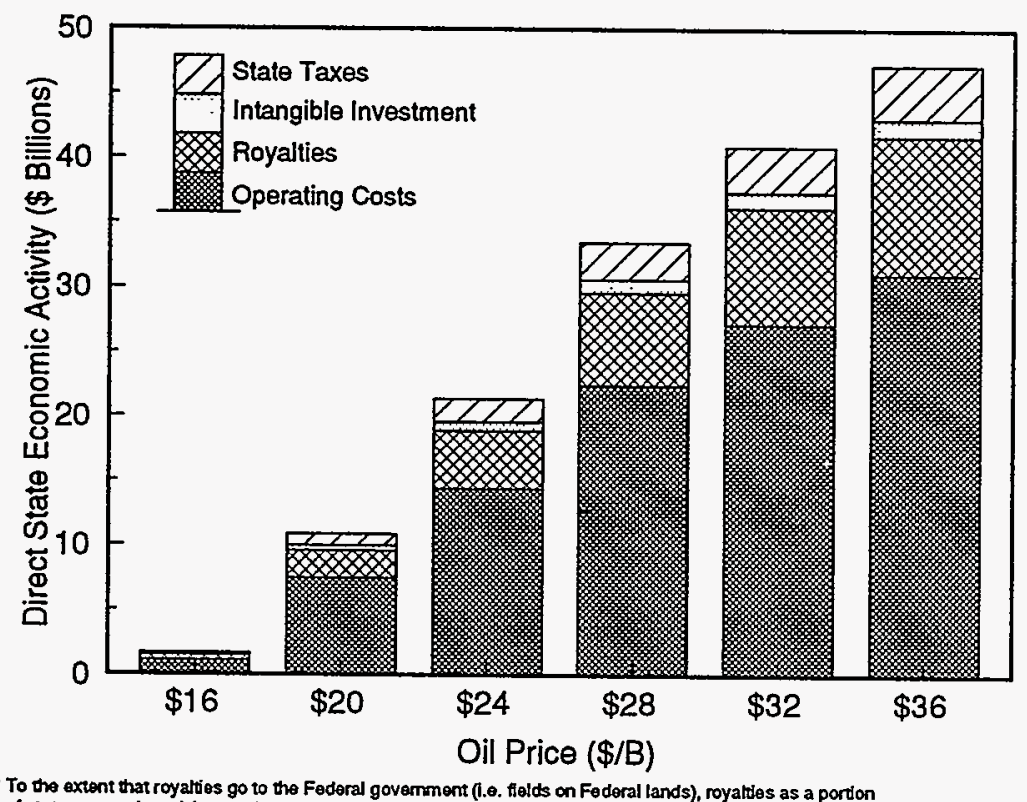

on Fedoral lands), royaltes as a portion of state economic activity may be overstated.

Figure IV-4

Jobs and Wages from EOR Production

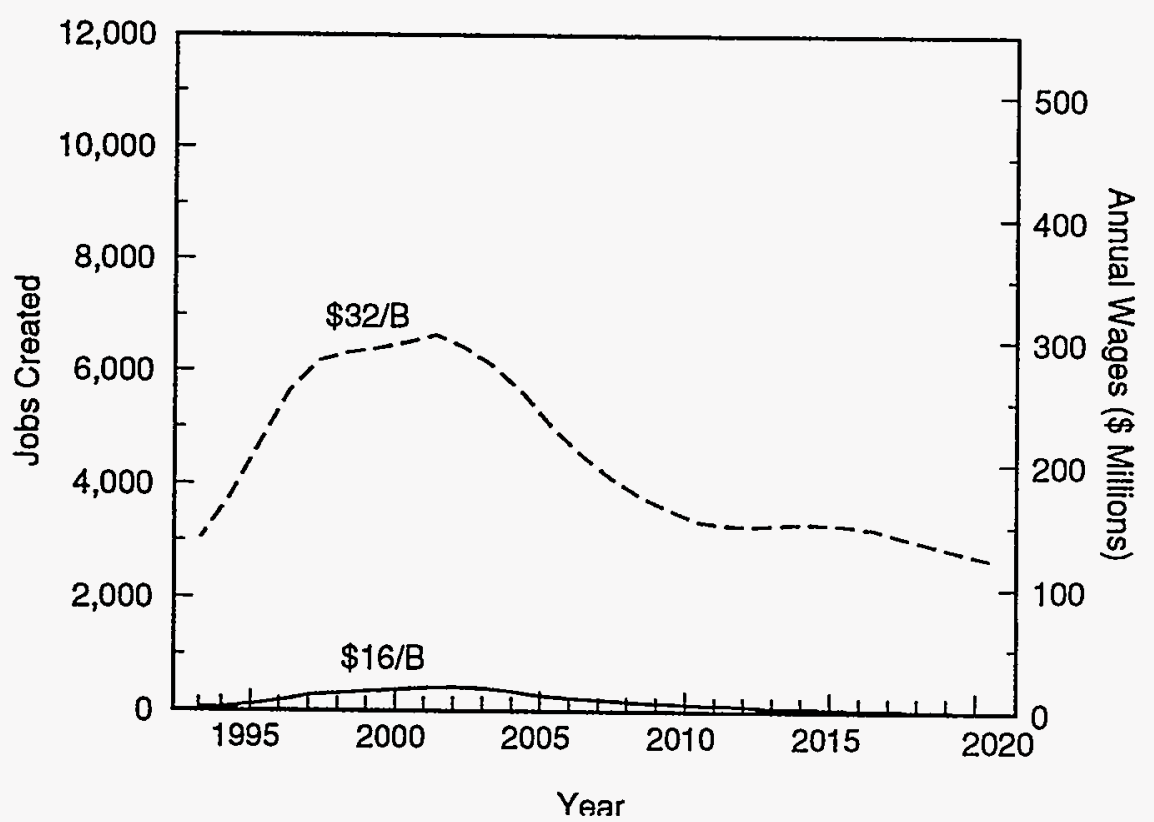


Increases in Texas oil production would directly replace imports, thus reducing the merchandise trade deficit by the direct value of the avoided imports (reserves multiplied by the effective wellhead oil price). At oil prices of $\$ 20 / \mathrm{B}$ to $\$ 28 / \mathrm{B}, \$ 17$ billion to $\$ 57$ billion in avoided imports could be recirculated within the U.S. economy. This money, instead of flowing to oil exporting countries to pay for oil imports would help enhance U.S. national energy security. At $\$ 36 / \mathrm{B}$, EOR production could result in over $\$ 85$ billion of avoided imports (Figure IV-5B).

\section{RECOVERY OF THE REMAINING MOBILE OIL RESOURCE}

The previous section focused on the potential impact of implemented EOR (tertiary) processes in selected Texas reservoirs which target immobile oil. This section will discuss the application of currently available advanced secondary recovery (ASR) technology, which target mobile oil, on the same set of reservoirs. These recovery technologies are distinct, and, since they focus on mutually exclusive resource targets, the amounts of oil recoverable from each are additive. Both technologies could be implemented in individual Texas reservoirs and, if so, the benefits (resource, revenues, economic activity, etc.) would also be additive. There are some potential synergies due to economic efficiencies associated with simultaneous employment of the EOR and ASR technologies; thus, there is the possibility that economic benefits could be even greater than the sum of the benefits from this separate analysis of EOR and ASR technologies.

\section{Production and Reserves}

Depending on the oil price, ASR technology applied in the reservoirs analyzed could stimulate between 1.9 billion and 2.6 billion barrels of incremental reserves in Texas (Figure IV-6A). ASR techniques are less costly to implement than EOR recovery processes, and therefore most of potential incremental reserves from ASR could be economic in the near-term at oil prices close to current levels. At the lowest oil price analyzed, $\$ 16 / \mathrm{B}$, about 1.9 billion additional barrels could be produced. At $\$ 20 / \mathrm{B}$, incremental ASR reserves could amount to nearly 2.1 billion barrels, which is nearly $81 \%$ of the ASR potential economically producible at $\$ 36 / \mathrm{B}$.

This analysis evaluates three categories of ASR processes: polymer flooding and profile modification, infill drilling, and combinations of infill drilling with polymer flooding and profile modification (combination processes). As shown in Figure IV-6A and Table IV-2A, infill drilling, both 
Figure IV-5

\section{National Impact of EOR Production}

\section{Implemented Technology}

A) Direct Federal Revenues

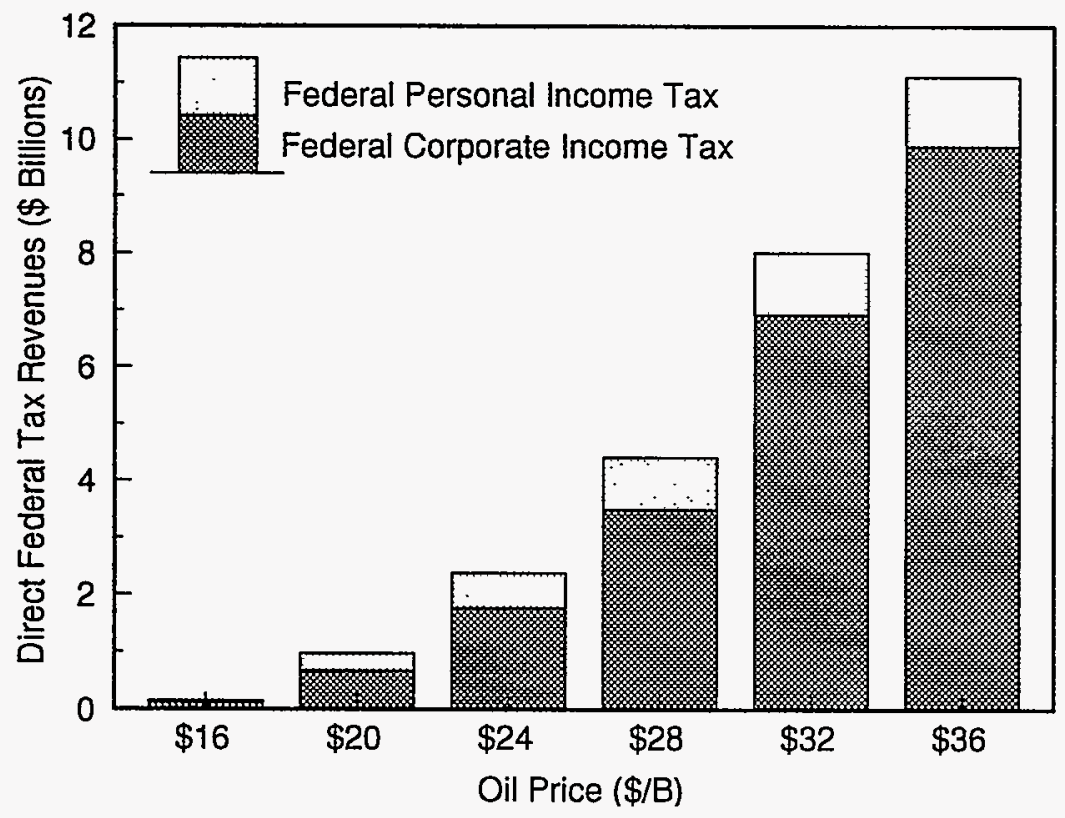

B) Imports Avoided*

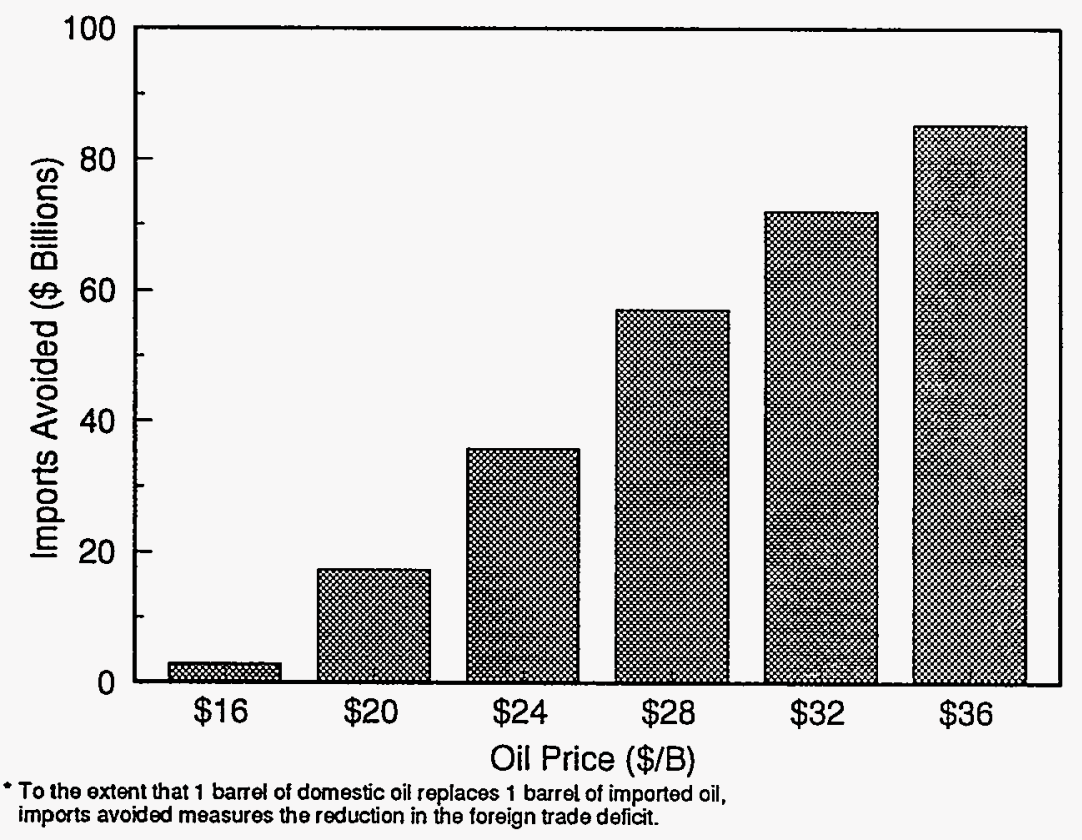


by itself and in combination with other processes, could play a predominant role in ASR, accounting for the bulk of the incremental reserves at all prices. At an oil price of $\$ 16 / \mathrm{B}$, the combination processes could contribute about 1.2 billion barrels of incremental reserves, while infill drilling alone could yield about 410 million barrels. At oil prices between $\$ 16 / \mathrm{B}$ and $\$ 20 / \mathrm{B}$, the percentage of incremental reserves stemming from infill drilling, either alone or in combination with other processes, would be about $89 \%$ of the total ASR potential. As oil prices increase, infill drilling would become more economical, since revenues increase along with oil prices. At $\$ 28 / \mathrm{B}$, infill drilling by itself would contribute over $30 \%$ of the 2.3 billion barrels of incremental reserves, while $58 \%$ of these reserve additions would come from the combination processes.

Polymer flooding and profile modification, applied alone, could contribute around 226 to 258 million barrels of incremental reserves across all oil prices considered in this analysis (about $10 \%$ of the ASR potential). As the oil price rises, thereby justifying the more expensive infill drilling and combination projects, reservoirs that were utilizing polymer or profile modification projects at lower oil prices switch to the now economically feasible, more prolific techniques. Therefore, polymer flooding and profile modification potential does not necessarily increase with price.

Table IV-2B shows the number of projects expected to be economic at each price for each recovery method. At all prices, the number of polymer or profile modification projects could be large (and at low prices higher than infill drilling). As oil price increases, infill drilling projects, applied alone and in combination with other processes, could become more prevalent due to improved project economics.

As shown above, the dominant ASR technique is infill drilling either alone or in combination with other processes. As such, ASR reserve additions require a considerable amount of drilling. ASR must compete for drilling infrastructure capacity (rigs, crews, investment dollars) with other oil industry activities such as domestic exploration, gas drilling and international ventures. Some portion of the potential ASR resource, therefore, is at risk of abandonment prior to the availability of drilling resources for its development. As much as $24 \%$ of the target resource could be abandoned over the life of the analyzed ASR projects.

Annual production from incremental ASR reserves at an oil price of $\$ 16 / \mathrm{B}$ would build gradually to a peak of 59 million barrels in 2016 and average about 34 million barrels per year over the 1993 to 
Table IV-2A

\section{Incremental Reserves from ASR by Process Implemented Technology \\ (Million Barrels)}

\begin{tabular}{|c|c|c|c|c|}
\hline (1.:. & 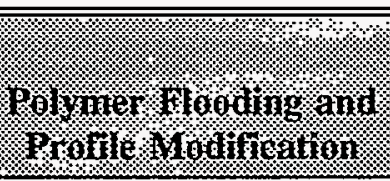 & : & 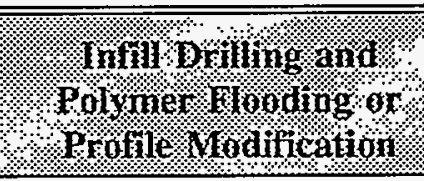 & \%ol. \\
\hline$\$ 16$ & 226 & 410 & 1,220 & 1,856 \\
\hline$\$ 20$ & 224 & 584 & 1,295 & 2,103 \\
\hline$\$ 24$ & 253 & 624 & 1,326 & 2,203 \\
\hline$\$ 28$ & 260 & 691 & 1,336 & 2,287 \\
\hline$\$ 32$ & 261 & 855 & 1,340 & 2,456 \\
\hline$\$ 36$ & 258 & 913 & 1,399 & 2,570 \\
\hline
\end{tabular}

Table IV-2B

Estimated Number of Economic ASR Projects by Process Implemented Technology

(Project Counts)

\begin{tabular}{|c|c|c|c|c|}
\hline 3ing & 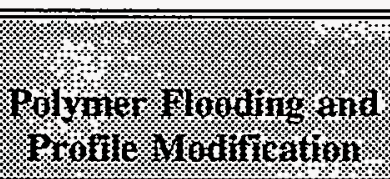 & \&. & 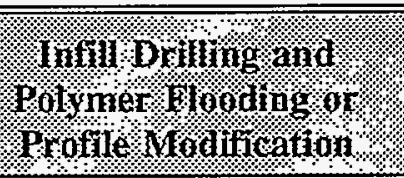 & Hotal \\
\hline$\$ 16$ & 55 & 44 & 140 & 239 \\
\hline$\$ 20$ & 56 & 56 & 160 & 272 \\
\hline$\$ 24$ & 56 & 65 & 169 & 290 \\
\hline$\$ 28$ & 57 & 76 & 172 & 305 \\
\hline$\$ 32$ & 64 & 87 & 171 & 322 \\
\hline$\$ 36$ & 59 & 99 & 177 & 335 \\
\hline
\end{tabular}


Figure IV-6

Reserves and Production Response from ASR

Implemented Technology

A) Incremental Reserves by ASR Process

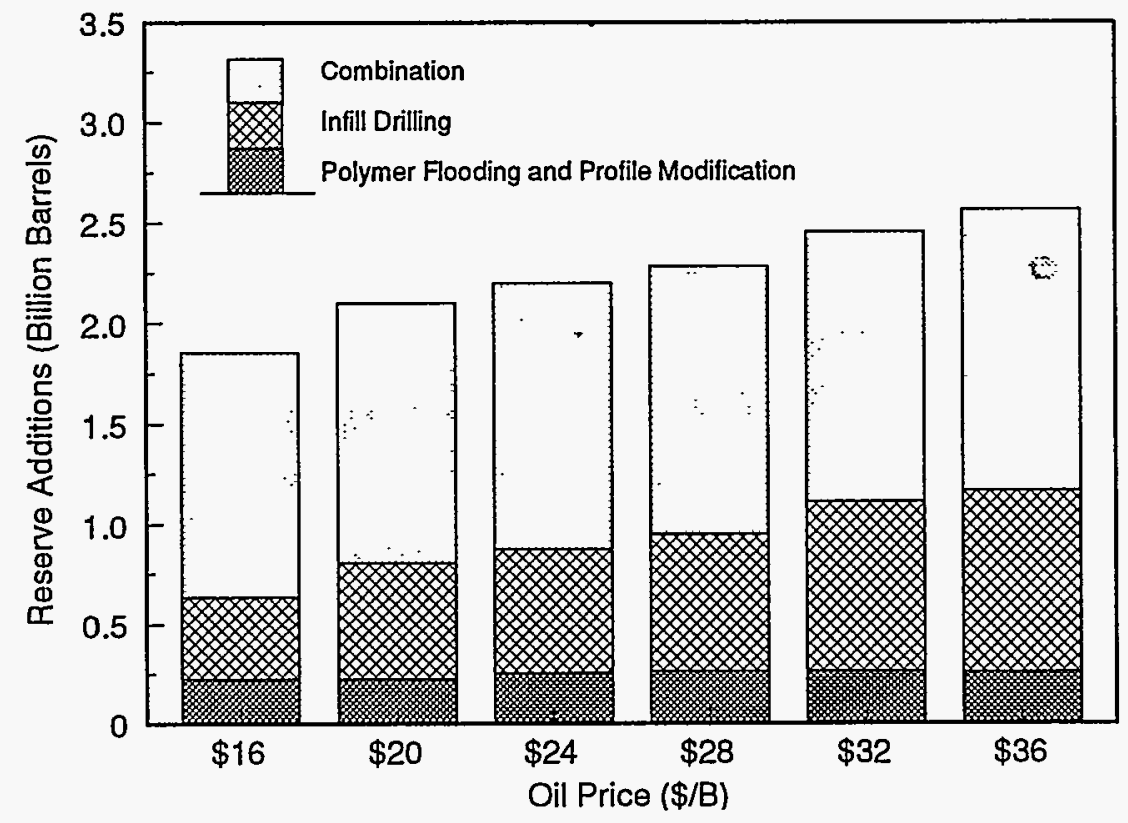

B) Annual Production from ASR

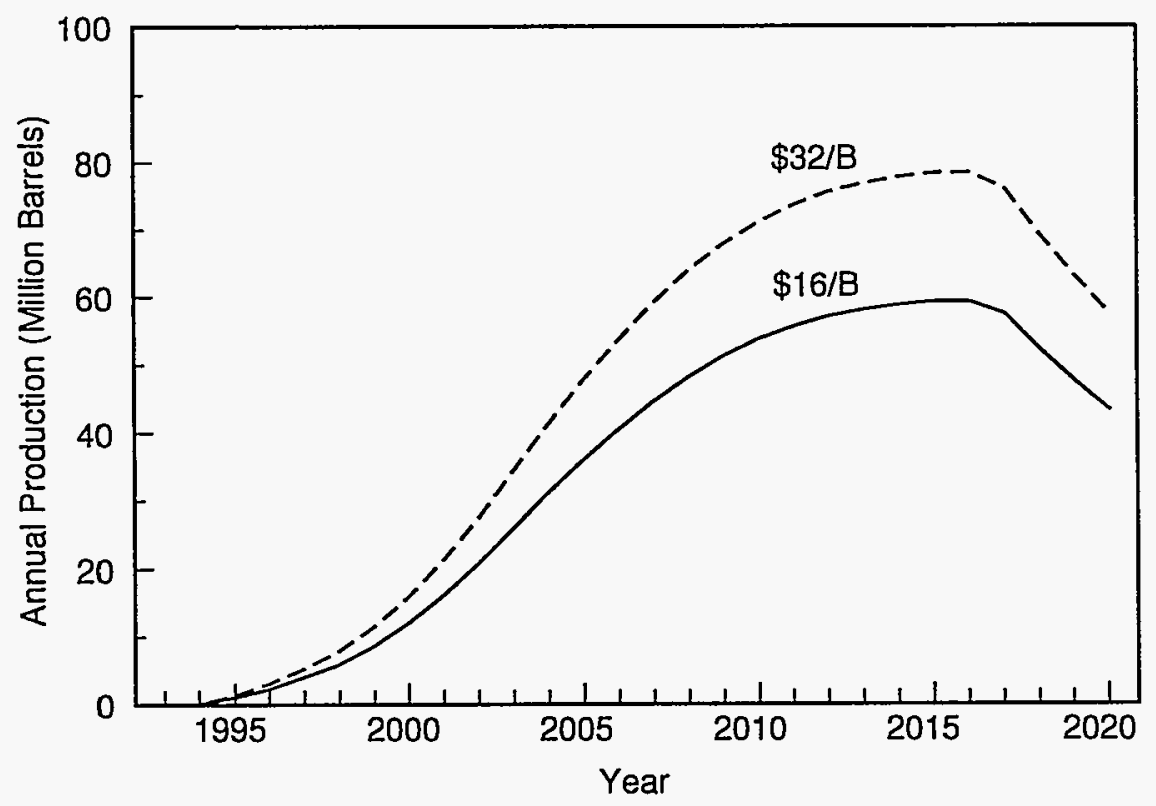


2020 period (Figure IV-6B). At an oil price of $\$ 32 / \mathrm{B}$, annual production would also rise gradually to a peak of over 78 million barrels in 2016 and average 45 million barrels per year over the same period. To put the potential contribution of ASR into perspective, 45 million barrels per year would add about $7 \%$ to current onshore Texas annual production.

\section{Increases in State and Local Revenues}

Figure IV-7 shows the expected growth in direct state and local revenues from ASR production and the proportional contributions of production and sales taxes to the total. Production tax receipts account for the largest portion of total state revenues from ASR production over all prices considered. Production taxes could generate $\$ 750$ million of the $\$ 1.1$ billion in potential revenues for the state at $\$ 16 / \mathrm{B}$. At $\$ 36 / \mathrm{B}, \$ 3.0$ billion could be generated for the state through $\mathrm{ASR}$, with $80 \%$ of that amount from production taxes. Over the moderate oil price range ( $\$ 20 / \mathrm{B}$ to $\$ 28 / \mathrm{B}$ ), ASR production could result in $\$ 1.5$ billion to $\$ 2.1$ billion in additional state and local revenues.

Figure IV-7

\section{Direct State and Local Revenues from ASR Production Implemented Technology}

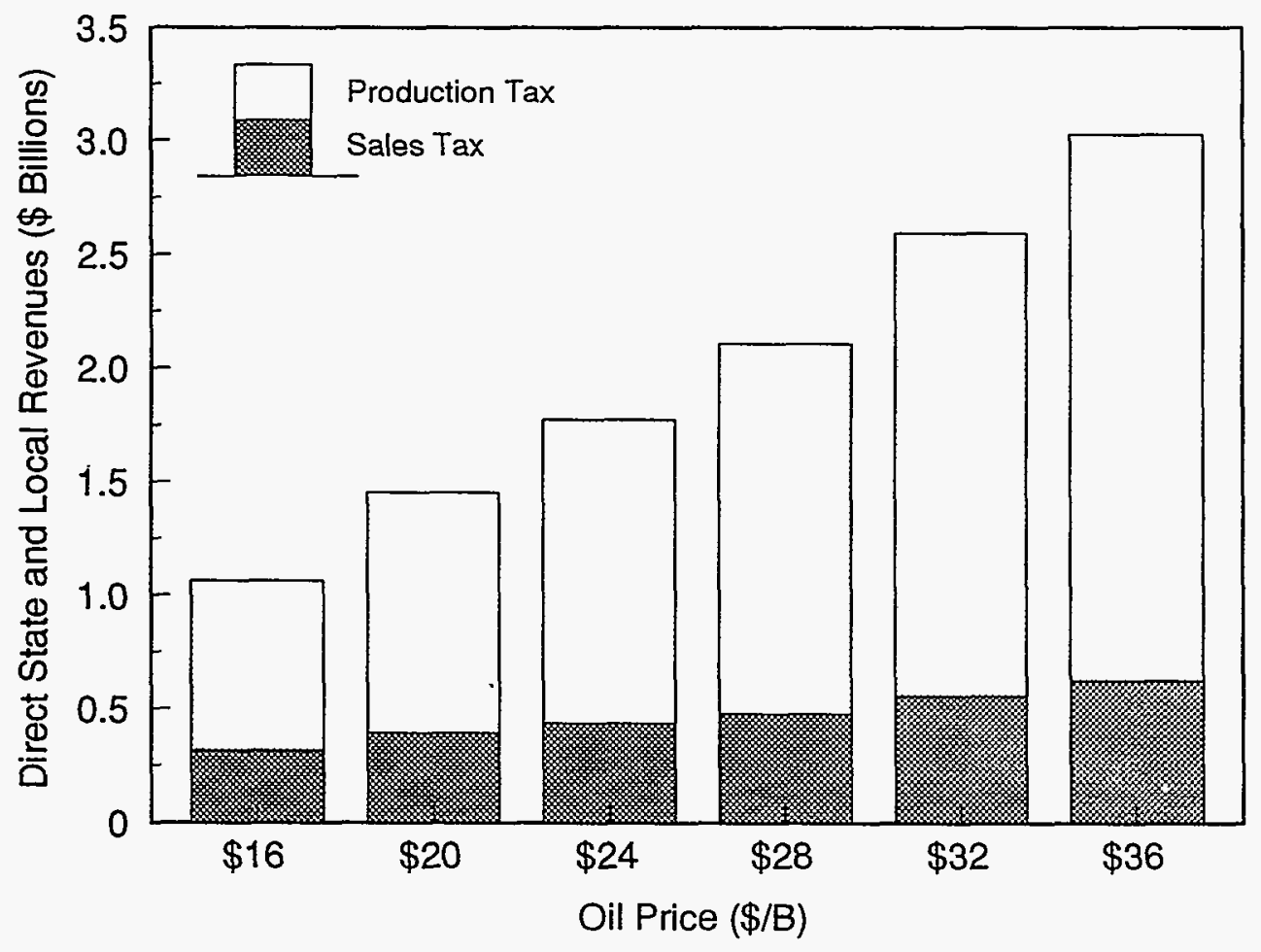




\section{Effects on the State Economy}

Figure IV-8 displays the total direct state economic activity associated with potential ASR production. Total state economic activity from the processes could range from $\$ 17$ billion at $\$ 16 / \mathrm{B}$ to $\$ 43$ billion at $\$ 36 / \mathrm{B}$. At intermediate oil prices, implemented technology ASR could stimulate nearly $\$ 23$ billion at $\$ 20 / \mathrm{B}$ and $\$ 31$ billion at $\$ 28 / \mathrm{B}$. Due to the predominance of infill drilling (alone or in combination), intangible costs would be the largest component of these increases in state economic activity, accounting for $36 \%$ to $39 \%$ of the total. These costs could approach $\$ 16$ billion at the $\$ 36 / \mathrm{B}$ oil price. Operating cost and royalties would be the next largest components of increased economic activity, averaging about $30 \%$ and $23 \%$, respectively, of the total activity across all oil prices. State taxes would contribute approximately $6 \%$.

The implementation of ASR techniques could significantly contribute to employment in the state of Texas. Figure IV-9 displays the annual number of jobs that could be created or maintained by ASR projects. At an oil price of $\$ 16 / \mathrm{B}$, jobs would peak in the year 2016 at around 1,950 , and decline to about 1,400 in the year 2020. At $\$ 32 / \mathrm{B}$, the number of jobs created or maintained would peak at 3,700 in the year 2016 and decline to about 2,700 by the year 2020 . At this price, as much as $\$ 167$ million in wages could be paid in the peak employment year.

\section{Effects on the National Economy and Budget}

Figure IV-10 shows the national benefits of ASR production in Texas. Federal revenues from ASR production could range from about $\$ 3.7$ billion to more than $\$ 16.7$ billion over the price range analyzed. At moderate oil prices, $\$ 5.8$ billion to over $\$ 10$ billion in additional direct Federal revenues could be generated by the analyzed ASR projects. As shown in Figure IV-10A, nearly all of these revenues would stem from corporate income taxes.

As the increased Texas production replaces oil imports, the U.S. trade deficit would be reduced and national security would be enhanced as the nation's vulnerability to future supply disruptions is diminished. Between $\$ 41$ billion and $\$ 63$ billion in imports avoided could be generated from ASR production at oil prices ranging from $\$ 20 / \mathrm{B}$ to $\$ 28 / \mathrm{B}$. At $\$ 36 / \mathrm{B}$, ASR projects could result in over $\$ 91$ billion in avoided imports. 
Figure IV-8

\section{Direct State Economic Activity* from ASR Production}

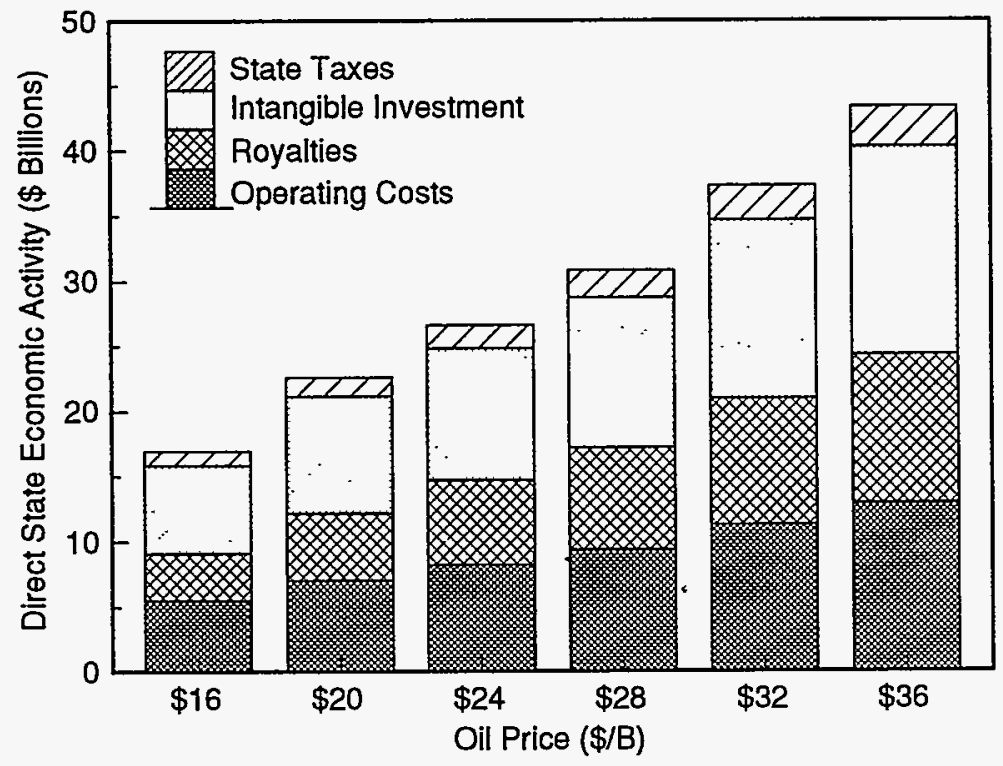

To the extent that royalties go to the Foderal govermment (l.e. fields on Foderal lands), royahies as a portion of state economic activity may be overstated.

Figure IV-9

Jobs and Wages from ASR Production

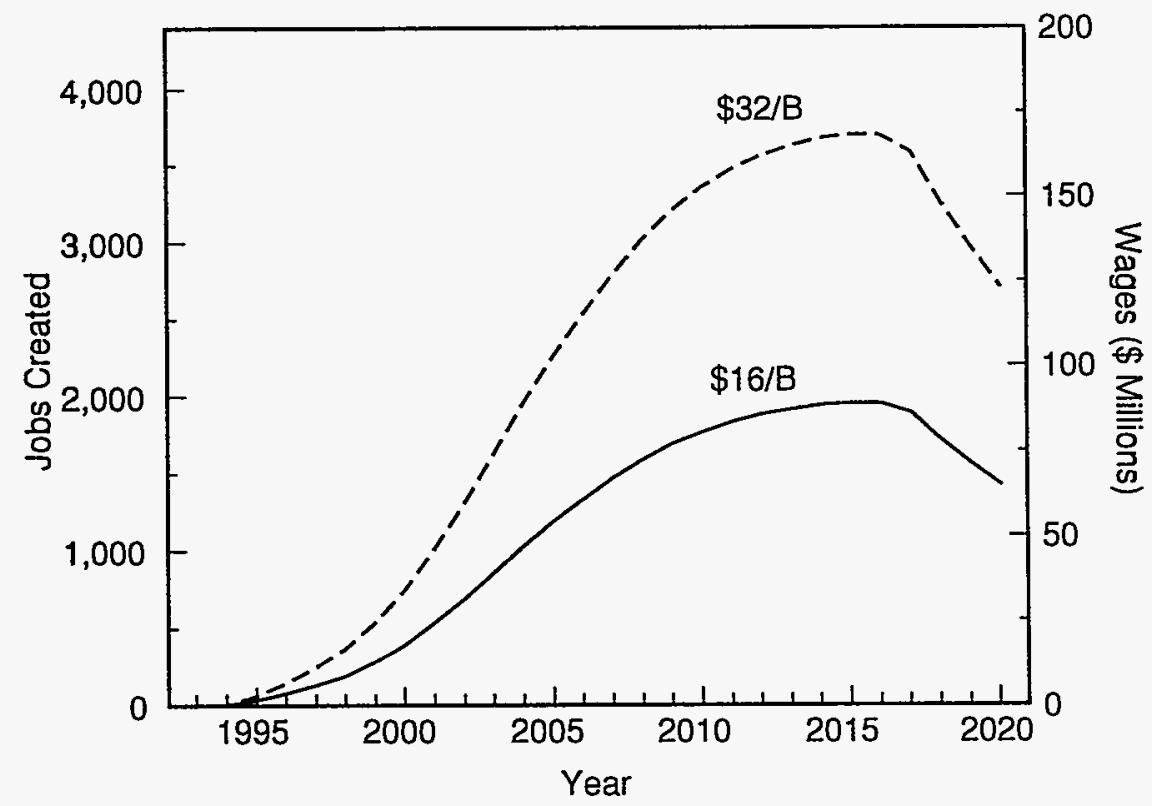


Figure IV-10

\section{National Impact of ASR Production}

\section{Implemented Technology}

A) Direct Federal Revenues

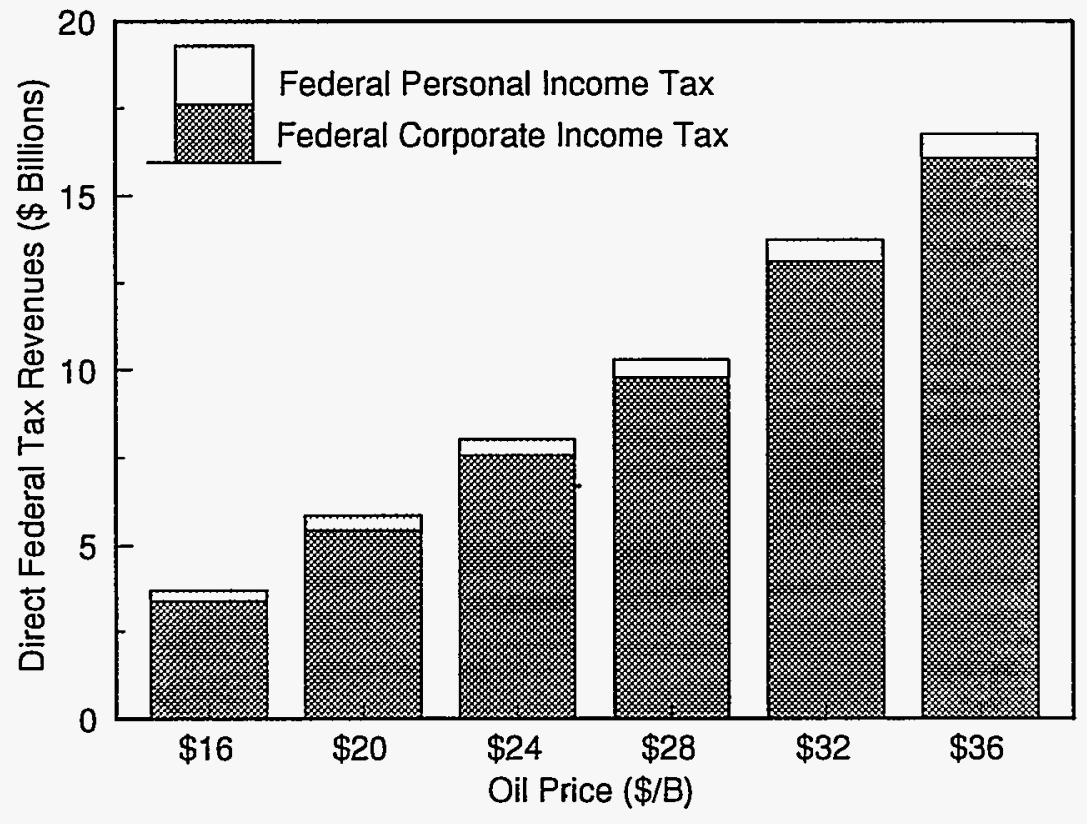

B) Imports Avoided*

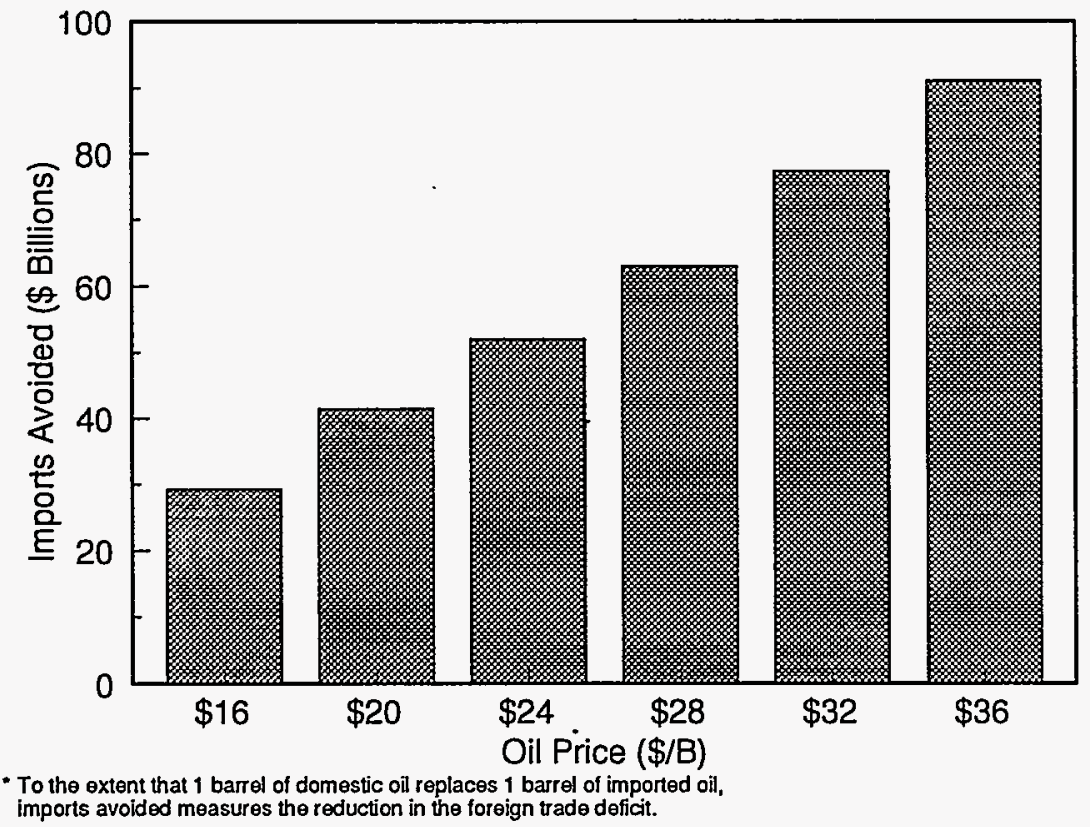




\section{CONCLUSIONS}

The existing level of EOR and ASR technologies could make substantial contributions to the reserve base and the Texas and national economies, as well as to domestic energy security. At a $\$ 20 / \mathrm{B}$ oil price, EOR processes could add 880 million barrels to Texas reserves while ASR techniques could add 2.1 billion barrels of oil. The application of current EOR and ASR technologies, in concert, could potentially add nearly 3.0 billion barrels of incremental reserves at this price, adding nearly half to Texas' current proved reserves. The higher production and increased reserves along with the associated economic benefits presented in this chapter are based on the application of currently available, state-of-the-art technology in the analyzed Texas reservoirs. As discussed in the next chapter, improved geoscientific understanding of reservoirs and enhanced process performance could increase these benefits if the required research can be cost effectively completed and transferred to the producers.

The state of Texas and its citizens stand to gain significantly from the increased production resulting from incremenial reserves. Production increases could generate $\$ 2.4$ billion to over $\$ 6.1$ billion in additional state and lecal revenues over the life of the analyzed improved recovery projects, assuming oil prices of $\$ 20 / \mathrm{B}$ to $\$ 32 / \mathrm{B}$. Total state economic activity could be boosted by $\$ 33$ billion to $\$ 78$ billion. Jobs could be created or maintained, and state economic activity could increase. The national economy could benefit through decreased oil imports, reductions in the trade deficit, and increased Federal corporate and personal income tax revenues. Maximizing recovery of the known oil resource in Texas should therefore be an important goal for state and Federal policy makers. While these benefits would be available using currently available technology, the true potential would not be realized without an aggressive program of technology transfer. The estimated potential assumes wide application of these technologies. A collaborative technology transfer effort between the public and private sectors is critical to the attainment of these estimated benefits.

As shown in Figure IV-11, the oil that will remain in the analyzed reservoirs after production by both current operations and by wide-scale application of currently available EOR and ASR processes, constitutes an important resource target for advanced-recovery technologies. Of the 55 billion barrels of immobile oil resource analyzed in this study, implemented technology EOR practices as defined in this report could produce an estimated 2.4 billion barrels at an oil price of $\$ 36 / \mathrm{B}$, leaving over 52 billion barrels of remaining immobile oil in these reservoirs. Of the 23 billion barrels of unrecovered mobile oil in the reservoirs analyzed, implemented technology practices could produce an estimated 2.6 billion barrels 
at $\$ 36 / \mathrm{B}$, leaving over 20 billion barrels of oil in these reservoirs. The extremely large size of the remaining resource clearly warrants a focused $R D \& D$ program that will test and speed the implementation of advanced technology to capture additional oil reserves.

Figure IV-11

\section{Texas Remaining Oil Resource After Implemented Technology Recovery}

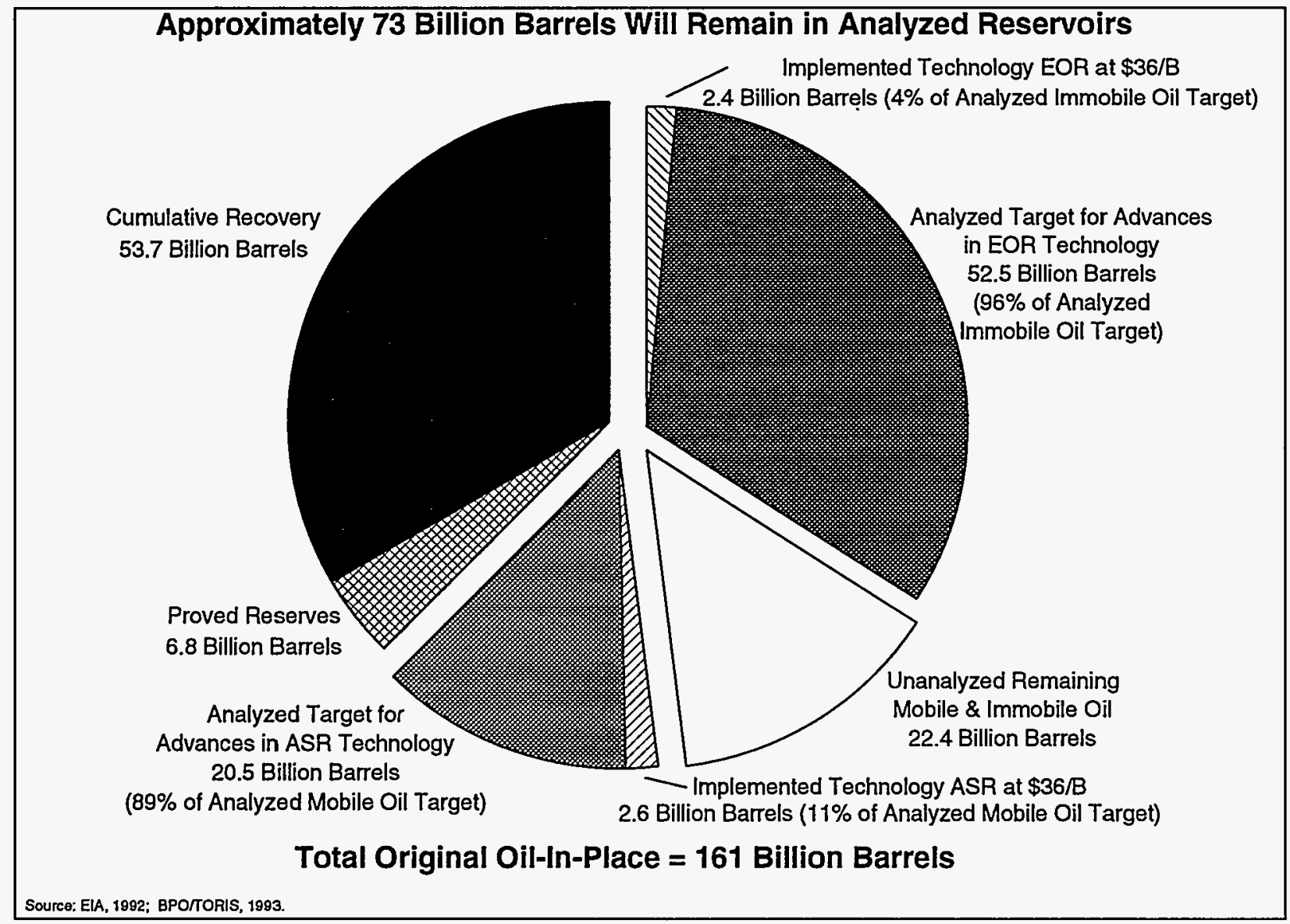




\section{BENEFITS OF INCREASED RECOVERY FROM THE KNOWN \\ REMAINING OIL RESOURCE IN TEXAS WITH \\ TECHNOLOGY ADVANCES}

\section{A. INTRODUCTION}

While currently available enhanced oil recovery (EOR) and advanced secondary recovery (ASR) techniques could contribute substantially to the Texas reserve base, technological advances in these processes resulting from a focus on RD\&D effort would have far more dramatic effects on the state's oil production. Development and wide-scale application of advanced methods could result in the recovery of a much greater portion of the remaining mobile and immobile oil resources in the state.

The present analysis evaluates the impact of advanced technology on oil recovery and the associated economic benefits. Evaluations of advanced technology EOR and ASR recovery potential in the state of Texas are presented separately. Given that the modeled advances in technology are conservatively defined, improvements in recovery processes resulting from research and development not envisioned in this report could add substantially to the estimated reserve potentials. However, well abandonments could limit access to the resource and increase project costs if EOR and ASR are not applied before conventional production ceases. Immediate actions are necessary to realize the economic benefits of these advanced processes.

\section{B. RECOVERY OF THE REMAINING IMMOBILE OIL RESOURCE}

\section{1. "Advanced" Technology Defined}

Enhanced oil recovery processes, as currently applied, have severe limitations. Some current EOR techniques can only be applied in a limited number of reservoirs with properties which fall within a narrow range of suitable values (temperature, salinity, oil viscosity, etc.). The sweep efficiency of EOR processes is often relatively poor; only a small portion of the residual oil remaining in the previously waterflooded zone is contacted. Injectants are expensive, often approaching the value of the oil they are designed to recover, which places a burden on project economics. The National Petroleum Council (NPC) predicted gradual improvements in EOR performance and project economics as current processes are 
improved and tested in the lab and field. These advanced processes are predicted to gain operator acceptance as the research and development efforts of oil companies, universities, geologic surveys, and the Federal government proceed and as field applications prove commercial viability. In this report, the IOGCC delayed the advanced technology availability date from the NPC's assumption of 1995 to the year 2000 , to reflect the slower pace of RD\&D activities in recent years caused by relatively low oil prices.

The major improvements in technology that are likely to impact Texas enhanced oil recovery will be advances in chemical enhanced oil recovery applications. For advanced technology thermal recovery, the NPC modeled the effects of an improvement in the ability to inject steam at greater depths and into thinner, lower permeability reservoirs. For advanced technology chemical flooding, the NPC modeled the effects of increasing the salinity and temperature tolerance of injectants, thus enabling them to be applied in a larger number of reservoirs. This study also assumes that advances in chemical flood technology would result in improvements in injection rate, interfacial tension reduction, lower costs, and reduced chemical retention, thereby improving the recovery and economics of chemical projects. Additionally, substantial reductions in the associated risk of EOR projects are modeled as a reduction in the minimum rate of retum, or hurdle rate, required for project implementation.

\section{2. $\quad$ Production and Reserves}

With technology advances, EOR could stimulate a substantial amount of incremental reserves over the analyzed oil price range. Figure V-1 and Table V-1A show the comparison between the incremental EOR reserves potentially generated through the application of advanced technology EOR processes and implemented technology EOR processes as discussed in Chapter III. At $\$ 20 / \mathrm{B}$, advances in EOR technology could add over 930 million barrels of incremental reserves, for a total EOR reserves potential of 1.8 billion barrels. Over the $\$ 24 / \mathrm{B}$ to $\$ 36 / \mathrm{B}$ price range, 2.3 billion to 3.3 billion barrels of incremental reseirves could be economically producible using advanced technology EOR, around $60 \%$ of which reflects the impact of a successful RD\&D effort. In general, prices at or above current levels are needed to begin seeing the potential impact of the advanced technology.

At $\$ 16 / \mathrm{B}$, advanced chemical flooding would be the primary source of incremental reserves, providing more than 320 million barrels of oil, all of which would be attributable to technology advances. At this low price, differences between advanced and implemented $\mathrm{CO}_{2}$-miscible flooding would be negligible. With implemented technology, thermal recovery would not be economic in Texas at oil prices 
Figure V-1

\section{Incremental Reserves by EOR Process Implemented Technology vs. Advanced Technology}

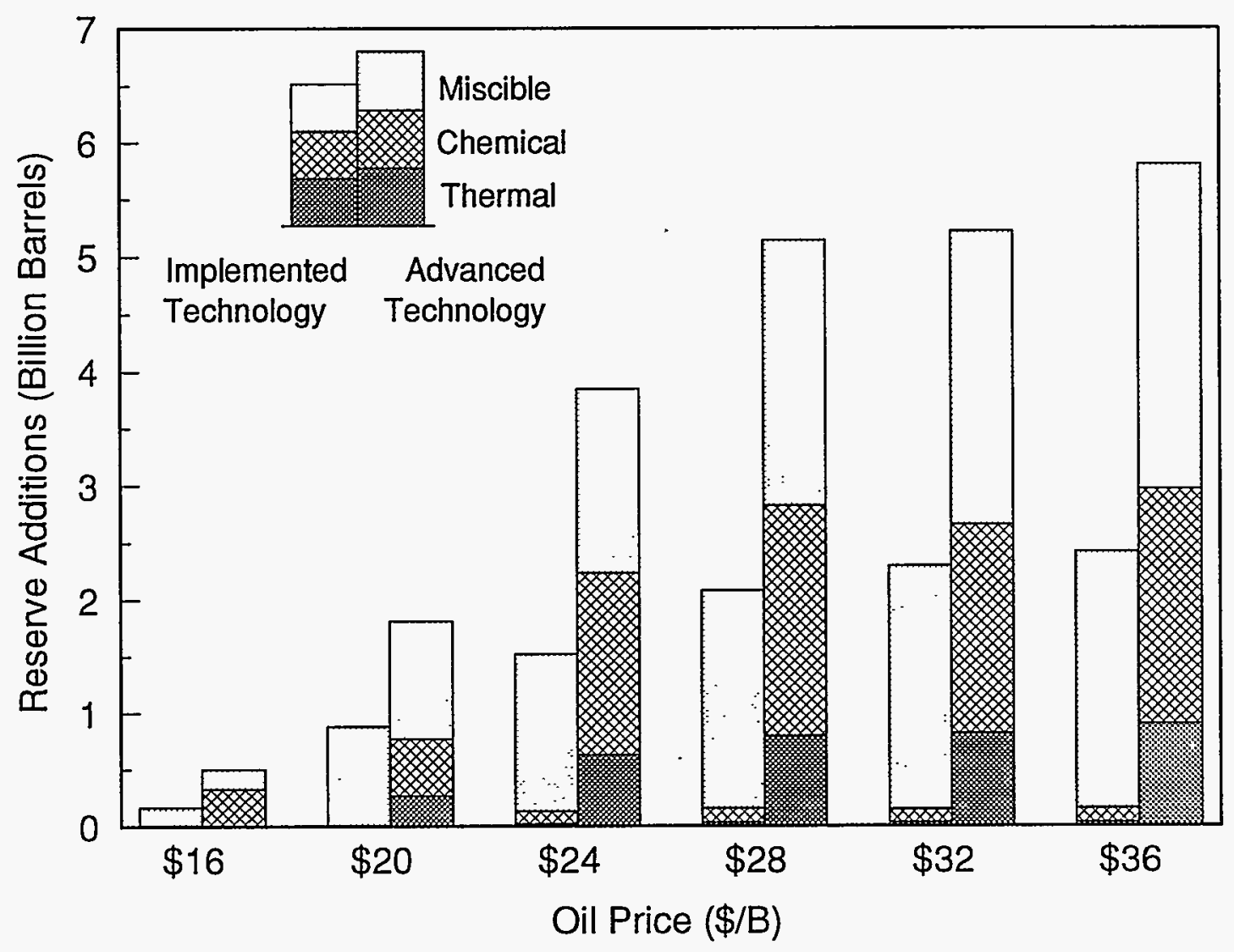

below $\$ 24 / \mathrm{B}$, although advanced technology thermal. EOR would recover 6 million barrels at the lowest oil price evaluated.

At $\$ 20 / \mathrm{B}, \mathrm{CO}_{2}$-miscible flooding could stimulate close to 1.1 billion barrels of incremental reserves under advanced technology, about 175 million barrels more recovery than is possible under the implemented case. Advanced chemical processes could contribute 500 million barrels of incremental reserves at this oil price; all but 9 million barrels would be due to technology advances attainable through RD\&D. At an oil price of $\$ 24 / \mathrm{B}, 1.7$ billion barrels of reserves could be stimulated by advances in chemical and $\mathrm{CO}_{2}$-miscible flooding technology, for a total potential from these processes of over 3.2 billion barrels. Each technique could contribute about 1.6 billion barrels, and thermal techniques could add nearly 630 million barrels. Virtually all of the incremental reserves from chemical EOR could be due to the technology advances, while $\mathrm{CO}_{2}$-miscible processes could generate over 220 million barrels more 
than implemented technology. Advanced miscible flooding processes represent the greatest absolute potential at all oil prices above $\$ 16 / \mathrm{B}$, stimulating up to 2.8 billion barrels of incremental reserves, $49 \%$ of the upside potential at $\$ 36 / \mathrm{B}$. At oil prices over $\$ 20 / \mathrm{B}$, advances in miscible flooding technology would generate from 200 to 500 million barrels of reserve additions over and above those economically feasible under currently implemented technology. Advances in the chemical flooding processes are even more effective at increasing oil recovery, and would add from 1.7 to 1.9 billion barrels more reserves than implemented technology at oil prices between $\$ 28 / \mathrm{B}$ and $\$ 36 / \mathrm{B}$. Although there is little potential in Texas for thermal processes as currently implemented, advanced technology could contribute nearly 270 million barrels of incremental EOR reserves at $\$ 20 / \mathrm{B}$. With increases in the oil price, the incremental reserves due to thermal techniques could increase to nearly 630 million barrels at $\$ 24 / \mathrm{B}$ and over 900 million barrels at $\$ 36 / \mathrm{B}$.

Table V-1B shows the number of EOR projects for each process type. The data on project counts illustrate the ways that technology advance yields benefits for all sectors of the US economy. Advances in technology may improve the efficiency of a given process (e.g., lower costs and/or increased production), in reservoir settings in which current technology is not economically feasible. The number of $\mathrm{CO}_{2}$-miscible projects remains relatively constant (or declines slightly) while 300 to 600 million barrels of new reserves are added, depending on price, demonstrating the increase in efficiency of $\mathrm{CO}_{2}$ projects due to technology advances. Advanced technology also permits cost-effective recovery from reservoirs which could not be tapped with current technology. In Texas, this is illustrated by the potential effects of new technology in additional reservoirs amenable to chemical and thermal techniques. With current technology and prices $(\$ 20 / \mathrm{B}$, implemented), only 2 chemical projects would be initiated, stimulating 9 million barrels of incremental reserves. At the same price, advances in chemical flooding would make the process feasible in 25 Texas reservoirs, yielding about 500 million barrels. The benefits of technology advances, including both increased efficiency and new resource targets, translate directly into more oil recovery at a given price.

Figure V-2 shows the expected annual production from incremental EOR reserves for oil prices of $\$ 16 / \mathrm{B}$ and $\$ 32 / \mathrm{B}$ for both the implemented and advanced technology cases. At $\$ 16 / \mathrm{B}$, production would peak at 14.3 million barrels per year in 2002 with application of advanced EOR. At $\$ 32 / B$, annual EOR production could reach 122 million barrels per year under advanced technology. Depending on price advanced technology could increase production by $10 \%$ to $33 \%$ over the implemented case. With high prices $(\$ 32 / \mathrm{B})$ and advanced technology, peak EOR production would be about $19 \%$ of Texas' current production of 635 million barrels. 
Table V-1A

\section{Incremental Reserves from EOR by Process \\ Implemented Technology vs. Advanced Technology (Million Barrels)}

\begin{tabular}{|c|c|c|c|c|c|c|c|c|}
\hline \multirow{2}{*}{$\begin{array}{c}\text { Oil } \\
\text { Price } \\
\text { (\$IB) }\end{array}$} & \multicolumn{2}{|c|}{$\mathrm{CO}_{2}$ Miscible } & \multicolumn{2}{|c|}{ Chemical } & \multicolumn{2}{|c|}{ uthermal } & \multicolumn{2}{|c|}{ Total } \\
\hline & Implemented & Advanced & Inplemented & Afpanced* & Implemented & Advanced* & Implemented & Advanced* \\
\hline$\$ 16$ & 172 & 173 & 0 & 324 & 0 & 6 & 172 & 503 \\
\hline$\$ 20$ & 872 & 1,050 & 9 & 500 & 0 & 268 & 881 & 1,818 \\
\hline$\$ 24$ & 1,391 & 1,613 & 117 & 1,606 & 17 & 629 & 1,525 & 3,848 \\
\hline$\$ 28$ & 1,930 & 2,315 & 120 & 2,032 & 33 & 796 & 2,083 & 5,143 \\
\hline$\$ 32$ & 2,149 & 2,565 & $117^{* \prime}$ & $1,838^{* \prime}$ & 33 & 821 & 2,299 & 5,224 \\
\hline$\$ 36$ & 2,270 & 2,843 & 120 & 2067 & 33 & 901 & 2,423 & 5,811 \\
\hline
\end{tabular}

\# Decline in resource between $\$ 28 / \mathrm{B}$ and $\$ 32 / \mathrm{B}$ reflects the phase-out of the Federal EOR tax credit.

* This is the total reserves with advanced technology -- implemented technology plus the increment due to technology advances.

Table V-1B

\section{Estimated Number of Economic EOR Projects by Process Implemented Technology vs. Advanced Technology (Project Counts)}

\begin{tabular}{|c|c|c|c|c|c|c|c|c|}
\hline \multirow{2}{*}{$\begin{array}{l}\text { Oil } \\
\text { Price } \\
\text { (\$M) }\end{array}$} & \multicolumn{2}{|c|}{$\mathrm{CO}_{2 \mathrm{M} \text { issible }}$} & \multicolumn{2}{|c|}{ - Otenolcai } & \multicolumn{2}{|c|}{$\diamond$ Thermal } & \multicolumn{2}{|c|}{ Total } \\
\hline & Implempentad & Aluanced & Implemented & Adyanced & Implemented & Advanced & Iinplemented & Advanced \\
\hline$\$ 16$ & 5 & 5 & 0 & 10 & 0 & 1 & 5 & 16 \\
\hline$\$ 20$ & 10 & 10 & 2 & 25 & 0 & 4 & 12 & 39 \\
\hline$\$ 24$ & 28 & 26 & 5 & 65 & 1 & 8 & 34 & 99 \\
\hline$\$ 26$ & 51 & 46 & 5 & 91 & 2 & 16 & 58 & 153 \\
\hline$\$ 32$ & 55 & 52 & 5 & $85^{* \prime}$ & 2 & 19 & 62 & 156 \\
\hline$\$ 36$ & 61 & 58 & 5 & 93 & 2 & 23 & 68 & 174 \\
\hline
\end{tabular}

\# Decline in resource between $\$ 28 / \mathrm{B}$ and $\$ 32 / \mathrm{B}$ reflects the phase-out of the Federal EOR tax credit. 
Figure V-2

\section{Annual Production from EOR}

\section{Implemented Technology vs. Advanced Technology}
A) At $\$ 16 / \mathrm{B}$

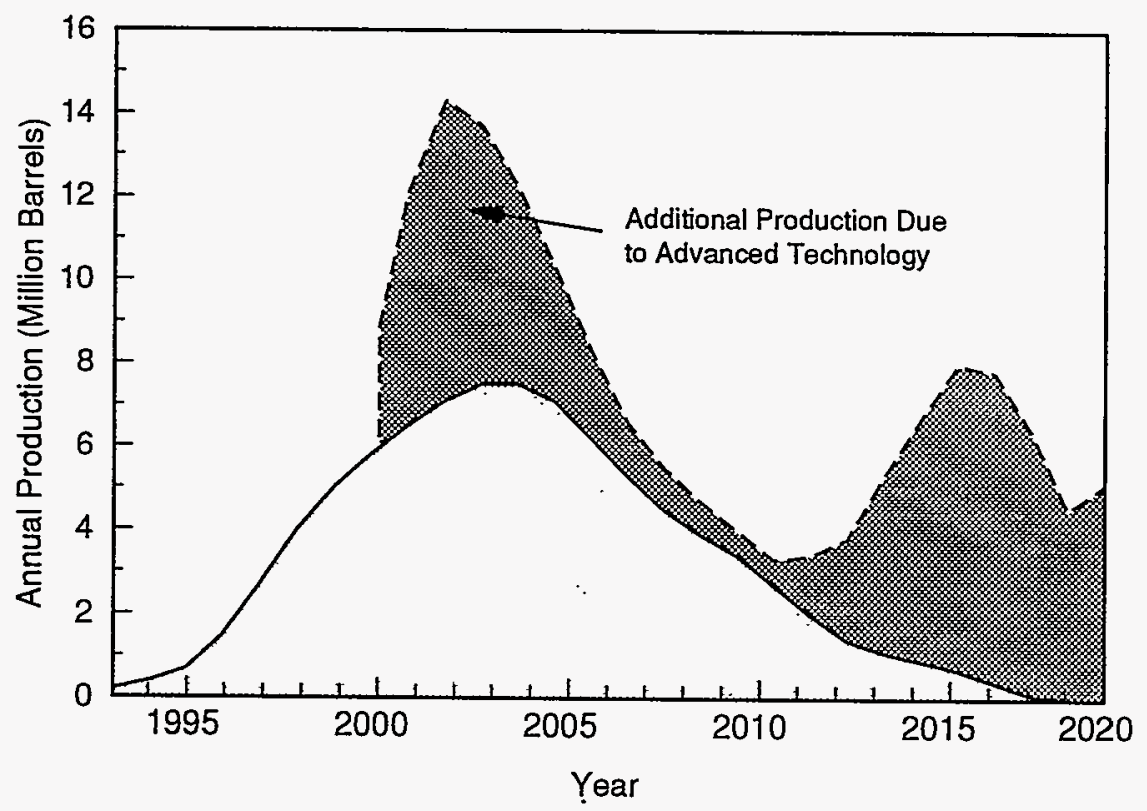

B) At $\$ 32 / B$

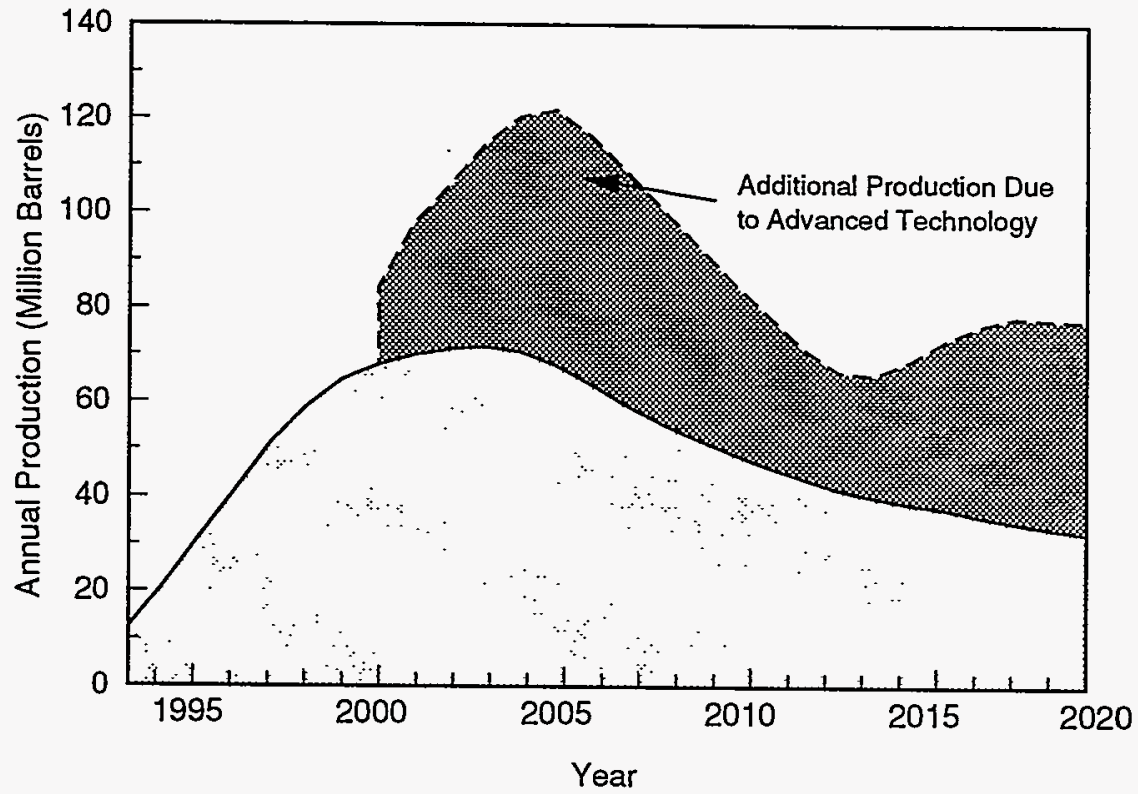




\section{Effects on State Revenues and Economic Activity}

Advanced EOR technology could dramatically increase the direct tax revenues to the state of Texas (Figure V-3A). At oil prices between $\$ 16 / \mathrm{B}$ and $\$ 20 / \mathrm{B}$, direct state and local revenues stimulated by advanced technology EOR could range from $\$ 340$ million to $\$ 1.8$ billion, $\$ 200$ million to $\$ 840$ million of which would be attributable to technology advances. At $\$ 24 / \mathrm{B}$, advances in EOR technology could increase implemented technology revenues by $\$ 2.4$ billion to over $\$ 4.2$ billion. At the higher oil prices of $\$ 28 / \mathrm{B}$ to $\$ 36 / \mathrm{B}$, direct state revenues from advanced technology EOR could range from $\$ 6.6$ billion to $\$ 9.3$ billion; technology advances could account for $52 \%$ to $56 \%$ of total potential revenues. Production taxes would contribute about $75 \%$ of the state's total direct revenues and sales tax receipts would constitute the remaining $25 \%$ over the price range analyzed.

Advanced EOR would also stimulate additional direct state economic activity in Texas, from noninjectant operating costs, intangible investments, royalty payments, and state tax revenues. Figure V-3B displays the potential incremental direct economic benefits to the state for both the implemented and advanced technology cases. The advanced technology case distribution of total economic benefits among the contributing components is similar to the trend shown for the implemented technology case. At $\$ 16 / \mathrm{B}$, the incremental state economic gain due to advanced EOR technology could be nearly $\$ 5.0$ billion, of which $\$ 3.4$ billion would be attributable to technology advances. Technology advances could increase implemented technology potential by nearly $\$ 12$ billion for a total of over $\$ 22$ billion in advanced technology direct state economic activity at an oil price of $\$ 20 / \mathrm{B}$. At $\$ 28 / \mathrm{B}$, the direct state-wide economic gain could increase by $\$ 58$ billion over implemented technology to nearly $\$ 87$ billion with full advanced EOR technology development. Clearly, the state of Texas could accrue substantial benefits from the development and application of advanced EOR technology at all of the oil prices considered.

Advanced technology would make a substantial impact on the state's employment. Even at a relatively low oil price of $\$ 16 / \mathrm{B}$, the application of advanced technology could create or maintain nearly 870 jobs by the year by 2001 (not illustrated). At the high oil price of $\$ 32 / B$, up to 9,800 jobs could be created or maintained by advanced technology EOR activities. 
Figure V-3

\section{State Impact of EOR Production}

\section{Implemented Technology vs. Advanced Technology}

A) Direct State and Local Revenues

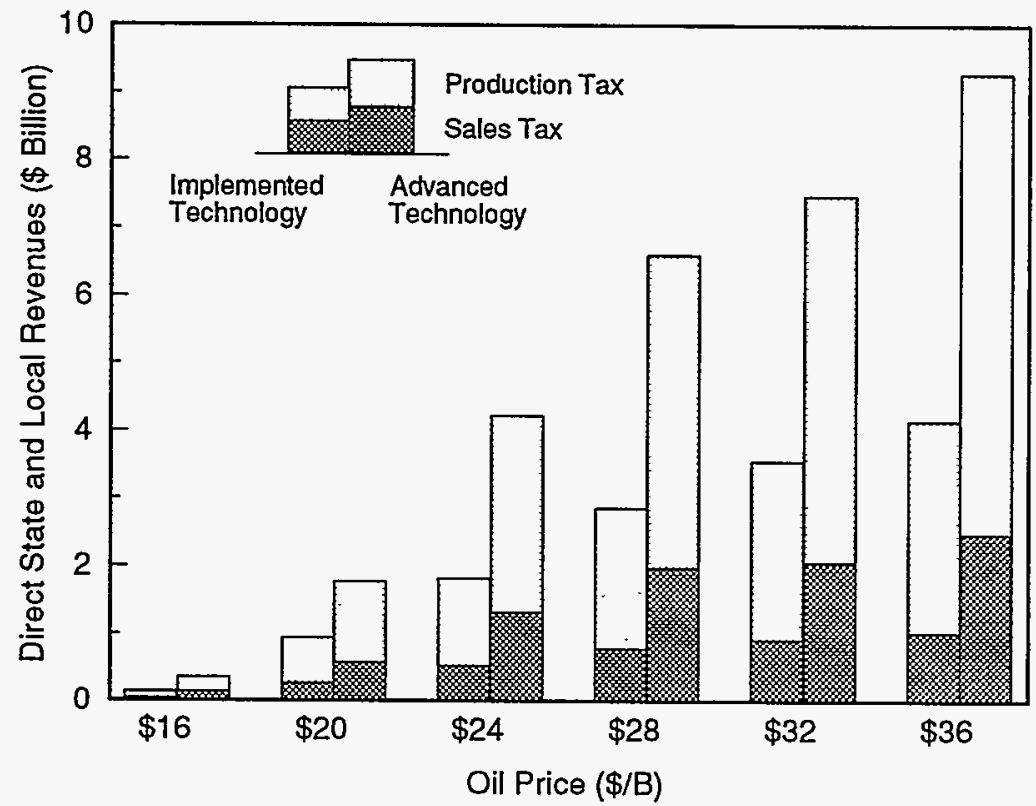

B) Direct State Economic Activity*

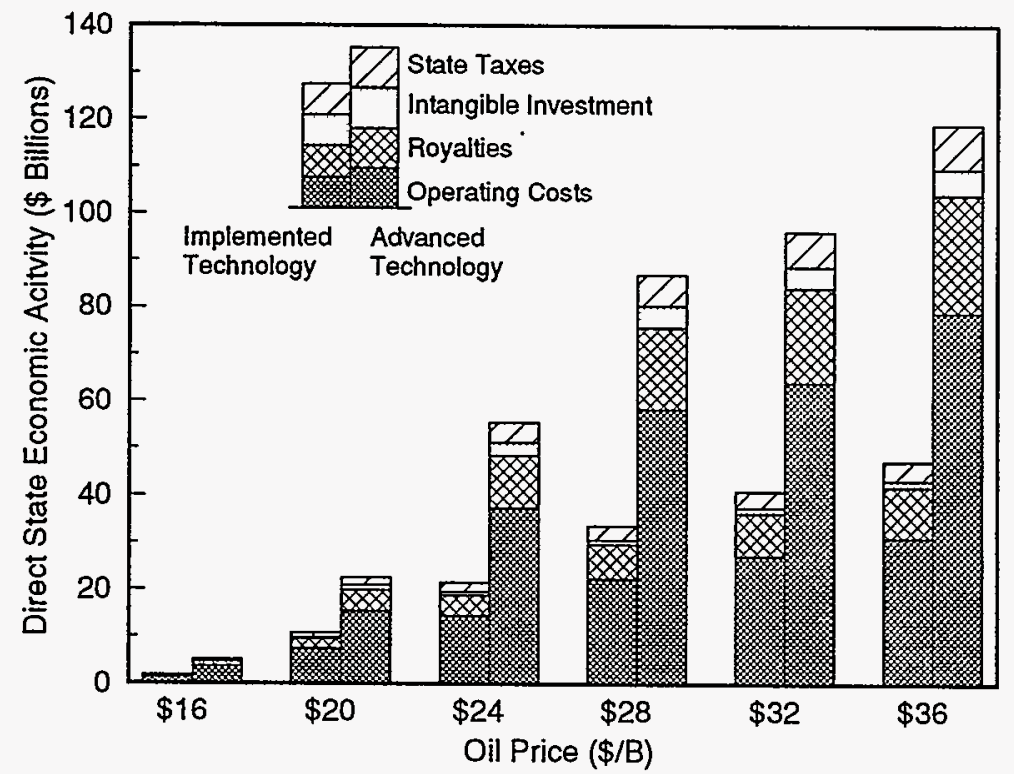

To the extent that royalties go to the Federal government (i.e. felds on Federal lands), royalties as a pornon of state economic activity may be overstated. 


\section{Effects on the National Economy and Budget}

Increased oil recovery in the state of Texas through EOR methods would also benefit all U.S. citizens by enhancing energy security, decreasing the trade deficit, replacing imports, and augmenting direct revenues to the Federal treasury. Advanced EOR technology could add up to 5.8 billion barrels of crude oil to proved reserves, 3.4 billion barrels of which would be due to technology advances. The additional reserves would increase energy security by reducing imports.

Direct Federal revenues could grow substantially due to the application of advanced technology EOR processes (Figure V-4A). At oil prices ranging form $\$ 20 / \mathrm{B}$ to $\$ 24 / \mathrm{B}$, technology advances could increase implemented technology revenues by $\$ 300$ million to $\$ 2.6$ billion, for a total potential of $\$ 1.3$ billion to nearly $\$ 7.0$ billion in additional direct Federal revenues. At prices above $\$ 28 / \mathrm{B}$, these increases could become more pronounced as the Federal EOR tax credit begins to phase out. At $\$ 36 / \mathrm{B}, \$ 11$ billion (50\%) of the $\$ 22$ billion in advanced technology Federal revenues could be attributable to technology advances. At all considered oil prices, corporate income taxes would make the largest contribution to the total Federal revenue potential.

As imports are replaced, the trade deficit would be improved by the direct value of the avoided imports (reserves multiplied by the effective wellhead oil price). The value of imports avoided would be circulated within the U.S. economy rather than paid to oil exporting countries for the oil imports. At moderate oil prices ( $\$ 20 / \mathrm{B}$ to $\$ 28 / \mathrm{B}$ ), $\$ 18$ billion to $\$ 82$ billion more in avoided imports could be generated by technology advances. The total potential of $\$ 35$ billion to nearly $\$ 139$ billion in imports avoided at these prices would be a significant reduction to the trade deficit. At $\$ 36 / \mathrm{B}, 58 \%$ of the $\$ 202$ billion in avoided imports could be attributable to technology advances (Figure V-4B).

\section{RECOVERY OF THE REMAINING MOBILE OIL RESOURCE}

\section{1. "Advanced" Technology Defined}

The unrecovered mobile oil (advanced secondary recovery) advanced case analysis, designed to reflect the potential technological improvements possible from a focused RD\&D program in geological reservoir characterization, is conducted in a manner consistent with the implemented technology case analysis. A major assumption is that RD\&D will allow geologic reservoir characterization techniques to 
Figure V-4

National Impact of EOR Production

Implemented Technology vs. Advanced Technology

A) Direct Federal Revenues

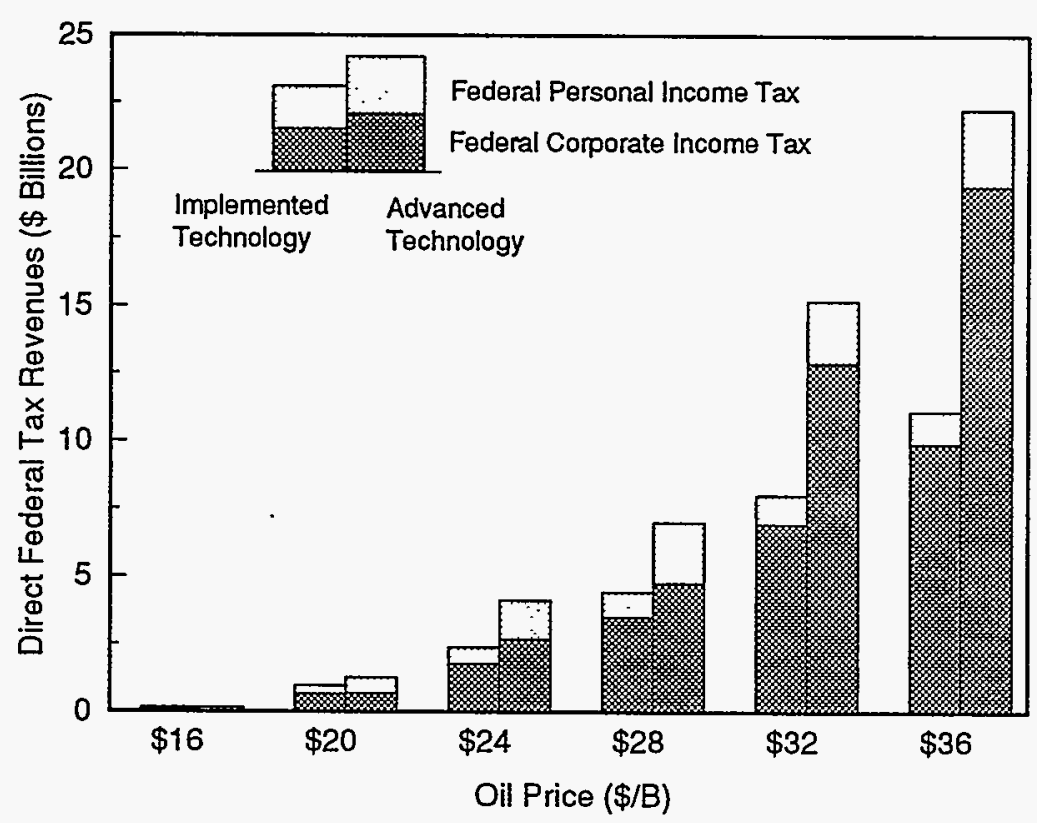

B) Imports Avoided*

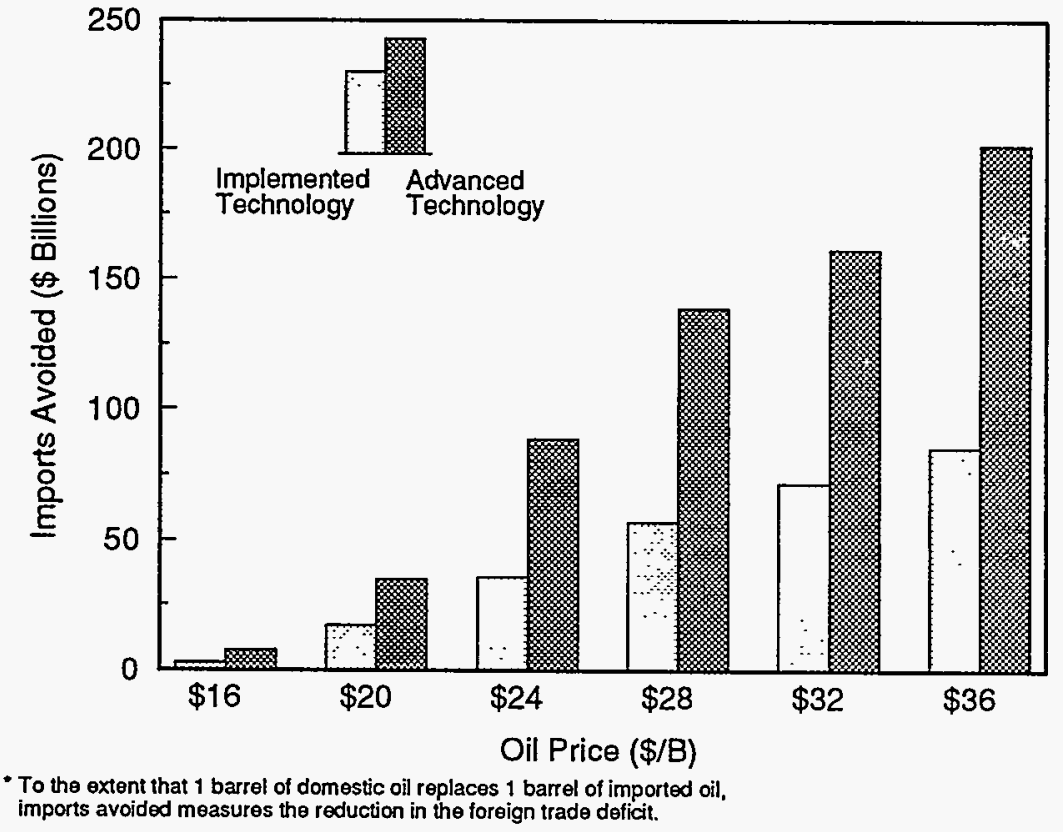


be widely applied, resulting in infill drilling that is targeted only into those portions of the reservoir where project economics will allow drilling at closer spacings. This will improve the project economics of advanced secondary recovery (ASR), resulting in more activity and much greater recovery under the advanced case than would be possible under the reservoir-wide, blanket drilling program assumed in the implemented technology case. Heterogeneous portions of reservoirs contain a proportionally larger amount of unrecovered mobile oil that is trapped in isolated compartments or bypassed by the injection fluids in conventional recovery operations. By contrast, the more homogenous portions of reservoirs exhibit more efficient conventional recovery and require less intensive drilling. In this study, infill drilling potential is evaluated by dividing each reservoir into two parts, a more continuous (homogeneous) segment and a less continuous (heterogeneous) segment. The economic recovery potential is evaluated independently in each segment, and the closest economic well spacing for each segment is independently selected.

The improved recovery methods discussed in this analysis could have a substantial impact on ASR reserve additions. Additional recovery could be stimulated as the chemical composition of polymer injectants is improved to withstand higher reservoir temperatures (up to $250^{\circ} \mathrm{F}$ ) and/or formation salinities (up to 200,000 parts per million). These improvements would increase the marginal impact of the profile modification and polymer flooding projected under the implemented technology case, whether they are applied alone or in combination with infill drilling. Additional benefits are estimated from the reduction of the associated risk (modeled as a reduction in hurdle rates) of ASR processes as currently implemented.

\section{Production and Reserves}

The development of advanced technology ASR recovery methods through RD\&D could significantly increase the state's oil reserves. The advanced technology ASR reserves are estimated at 2.9 billion to 3.8 billion barrels depending on oil price. The analyzed Texas reservoirs could therefore yield about 1.0 billion to 1.2 billion barrels more from application of advanced technology ASR than could result from implemented technology conditions (Figure V-5).

ASR offers the promise of significant low-cost incremental reserves. In contrast to EOR, about $76 \%$ of the total ASR reserve potential, nearly 2.9 billion barrels, could be added at oil prices of $\$ 16 / \mathrm{B}$. Almost 3.3 billion barreis, $48 \%$ of Texas' current proved reserves, could be added at $\$ 20 / \mathrm{B}$. Reserve additions for each $\$ 4 / \mathrm{B}$ increment above $\$ 20 / \mathrm{B}$ would average less than 130 million barrels, indicating the cost effectiveness of advanced technology ASR. Across the range of oil prices evaluated, $32 \%$ to $37 \%$ of total potential incremental reserves could be attributed to the impact of a successful RD\&D effort. 
Figure V-5

\section{Incremental Reserves by ASR Process Implemented Technology vs. Advanced Technology}

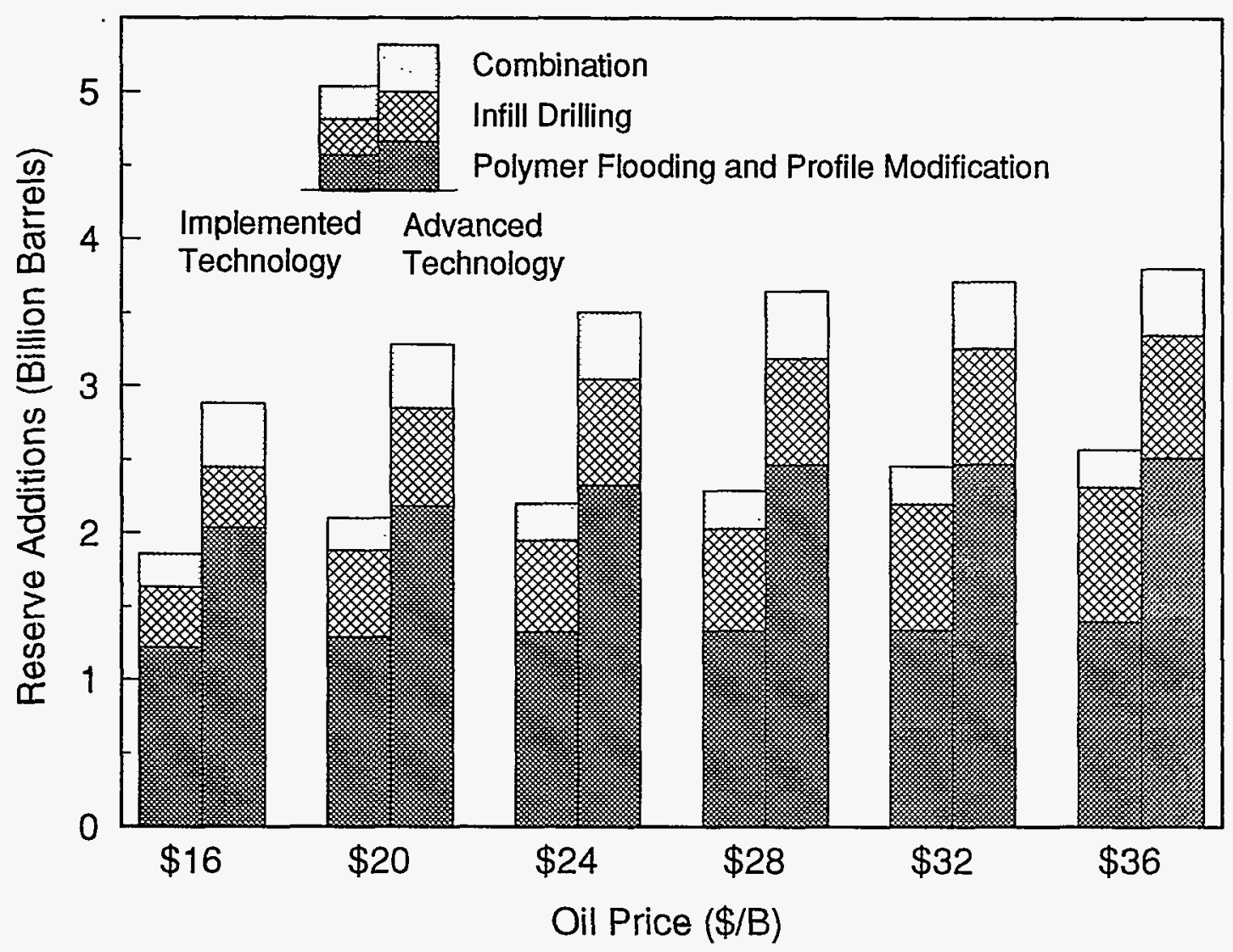

Table V-2A shows the distribution of incremental ASR reserves by process. Infill drilling in combination with profile modification or polymer flooding could be the most prolific recovery method, contributing from $66 \%$ to $71 \%$ of the total incremental reserves from ASR. Infill drilling by itself could generate between $14 \%$ and $21 \%$ of total incremental reserves. Polymer flooding and profile modification, applied alone, could contribute $8 \%$ to $20 \%$ of the total recovery in the advanced technology case, a smaller portion than under implemented technology.

Geologically targeted infill drilling, by itself or in combination with other processes, could generate between 800 million and 1.0 billion barrels of incremental reserves above those estimated in the implemented technology blanket infill drilling case at all oil prices evaluated. A total infill drilling reserves potential of 2.4 billion to 3.3 billion barrels of oil could be producible with a successful RD\&D effort. An improved understanding of reservoir architecture and the nature of heterogeneity would allow wells to be economically justified at much closer spacing than is currently possible. As these new wells 
contact additional volumes of oil, ultimate recovery would be improved. The ability to target infill wells would eliminate the unnecessary wells that would be drilled under a blanket infill drilling program. Targeting infill wells would reduce the front-end investment for each project undertaken, making some otherwise uneconomic projects cost-effective.

As under implemented technology, the contribution of polymer flooding and profile modification would not be price sensitive, yielding considerable benefits at low oil prices. Alone, these advanced waterflooding processes would yield between 430 and 460 million barrels at prices between $\$ 16 / \mathrm{B}$ and $\$ 20 / B$. As price increases, project economics would improve, allowing polymer flooding and profile modification to be used in conjunction with infill drilling. The number of projects relying on these techniques alone would therefore diminish.

Table V-2B shows the estimated number of economic ASR projects for both the implemented and advanced technology cases. Compared to implemented technology, advances in ASR technology would allow about 63 more projects to be started in Texas. About 36 of these new projects would be attributed to the effectiveness of targeting infill wells to the more prolific portions of the reservoir. The number of incremental projects is not particularly dependent on price, indicating that much of the benefits of advanced technology could be obtained at lower oil prices. The economics of most projects at these prices are favorably improved by advanced technology because a targeted infill drilling program would reduce the overall investment required in a given reservoir; capital that would have gone to drilling can be used for polymer floods and profile modification to further increase oil production and reserves. Twenty-seven additional polymer flooding and profile modification projects (alone and in combination with infill drilling) would be initiated under advanced technology, as a result of assumed improvements in the chemical composition of polymer solutions that allow these solutions to withstand more severe reservoir conditions.

As discussed in Chapter III, ASR techniques require considerable amounts of drilling and must compete with other activities (e.g., exploration) and other products (e.g., gas) for drilling rigs. Some portion of the reservoirs yielding ASR production could be abandoned before drilling capacity is available to drill the new infill wells. Since existing wells are assumed to be used as injection wells or, in some cases, producers at close spacing, abandonments could increase costs and decrease economic potential of Texas ASR, even under advanced technology. Between $28 \%$ and $32 \%$ of the potential resource could be abandoned over the life of the analyzed projects. 
Table V-2A

\section{Incremental Reserves from ASR by Process Implemented Technology vs. Advanced Technology (Million Barrels)}

\begin{tabular}{|c|c|c|c|c|c|c|c|c|}
\hline \multirow{2}{*}{$\begin{array}{l}\text { Oil } \\
\text { Price } \\
\text { (\$BB) }\end{array}$} & \multicolumn{2}{|c|}{$\begin{array}{l}\text { Rolymer Flondingand } \\
\text { Proflte Modification }\end{array}$} & \multicolumn{2}{|c|}{ Infill $\mathrm{Drming}$} & \multicolumn{2}{|c|}{ 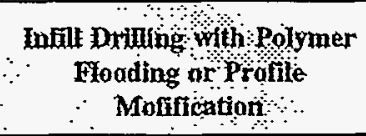 } & \multicolumn{2}{|c|}{ Total } \\
\hline & Implemented & Adyanced: & Implemented & Advanced- & Implemiented & Advanced* & Implemitented & Advanced* \\
\hline$\$ 16$ & 226 & 432 & 410 & 413 & 1,200 & 2,034 & 1,856 & 2,879 \\
\hline$\$ 20$ & 224 & 433 & 584 & 664 & 1,295 & 2,183 & 2,103 & 3,280 \\
\hline$\$ 24$ & 253 & 459 & 624 & 719 & 1,326 & 2,326 & 2,203 & 3,504 \\
\hline$\$ 28$ & 260 & 457 & 691 & 723 & 1,336 & 2,464 & 2,287 & 3,644 \\
\hline$\$ 32$ & 261 & 458 & 855 & 786 & 1,340 & 2,470 & 2,456 & 3,714 \\
\hline$\$ 36$ & 258 & 459 & 913 & 832 & 1,399 & 2,510 & 2,570 & 3,801 \\
\hline
\end{tabular}

* This is the total reserves with advanced technology -- implemented technology plus the increment due to technology advances.

Table V-2B

\section{Estimated Number of Economic ASR Projects by Process Implemented Technology vs. Advanced Technology (Project Counts)}

\begin{tabular}{|c|c|c|c|c|c|c|c|c|}
\hline \multirow{2}{*}{$\begin{array}{l}\text { On } \\
\text { Price } \\
\text { (\$in) }\end{array}$} & \multicolumn{2}{|c|}{ Polvoner Fraading and proftle } & \multicolumn{2}{|c|}{ Inifilontilig } & \multicolumn{2}{|c|}{$\begin{array}{l}\text { Itifil Driling thith Polymer } \\
\text { Foodingor Profile } \\
\text { Modiffation }\end{array}$} & \multicolumn{2}{|c|}{ Tatal } \\
\hline & Implemented & $\begin{array}{l}\text { Adpanced } \\
\text { a.... }\end{array}$ & Inplentented. & Adyanect: & Implemented & Advanced & Implementêd & Advanced \\
\hline$\$ 16$ & 55 & 81 & 44 & 27 & 140 & 193 & 239 & 301 \\
\hline$\$ 20$ & 56 & 84 & 56 & 39 & 160 & 218 & 272 & 341 \\
\hline$\$ 24$ & 56 & 84 & 65 & 46 & 169 & 232 & 290 & 362 \\
\hline$\$ 28$ & 57 & 80 & 76 & 48 & 172 & 249 & 305 & 377 \\
\hline$\$ 32$ & 64 & 93 & 87 & 55 & 171 & 248 & 322 & 396 \\
\hline$\$ 36$ & 59 & 84 & 99 & 61 & 177 & 253 & 335 & 398 \\
\hline
\end{tabular}


Figure V-6 displays the projected annual production from incremental ASR reserves for oil prices of $\$ 16 / \mathrm{B}$ and $\$ 32 / \mathrm{B}$ from the analyzed Texas reservoirs. In all cases, a significant amount of oil could be added to the state's production over the next 30. years. Production peaks at about 2016 after the advancement in technology becomes available in the year 2000 . At $\$ 16 / \mathrm{B}$, advanced case ASR production could reach 88 million barrels per year by the year 2016. At $\$ 32 / \mathrm{B}$ oil price, peak annual production of ASR in the advanced case would reach 113 million barrels per year by the year 2016. Advanced technology peak production rates could be $30 \%$ to $33 \%$ higher than those under implemented technology; the increase would be attributable to the impacts of successful RD\&D effort.

\section{Effects on State Revenues and Economic Activity}

At the outside potential of advanced ASR technology, Texas could receive up to $\$ 4.3$ billion in total additional revenues from production taxes and oil industry-related sales taxes (i.e., if oil prices reach $\$ 36 / B$ ). Over $\$ 1.3$ billion of the potential state revenue would be due to technology advances. As in the implemented technology case, the revenue is mostly generated from production taxes. These taxes account for over $80 \%$ of the direct state tax revenues added at each of the price levels considered in this analysis (Figure V-7A). At oil prices ranging from $\$ 20 / \mathrm{B}$ to $\$ 28 / \mathrm{B}$, application of ASR technology advances could increase implemented technology state revenues by $\$ 820$ million to nearly $\$ 1.3$ billion for a total of $\$ 2.3$ billion to $\$ 4.3$ billion in additional direct state revenues.

In addition to the increases in state and local revenues, Texas would benefit from the stimulation of economic activity and creation of new jobs. The advanced technology ASR projects could stimulate from $\$ 27$ billion to $\$ 64$ billion in new economic activity, depending on the oil price, 52\% to $67 \%$ of which would be attributable to technology advances. At $\$ 20 / \mathrm{B}$ to $\$ 28 / \mathrm{B}$, advances in ASR technology could generate $\$ 14$ billion to $\$ 21$ billion in additional state economic activity as an increment to implemented technology potential. The total potential of $\$ 37$ billion to $\$ 52$ billion would be a large increase in economic activity within the state of Texas. Operating costs, royalties, and intangible investment from ASR projects would all make substantial contributions to the state's economic activity. Direct state tax revenues would comprise the smallest portion of the increase (Figure V-7B).

A significant number of jobs could be created or maintained by the wide-spread application of advanced ASR technology in Texas (not illustrated). As oil prices rise, the total number of jobs created or maintained could grow substantially, with the incremental jobs stimulated directly by advanced 
Figure V-6

\section{Annual Production From ASR}

\section{Implemented Technology vs. Advanced Technology}

A) At $\$ 16 / B$

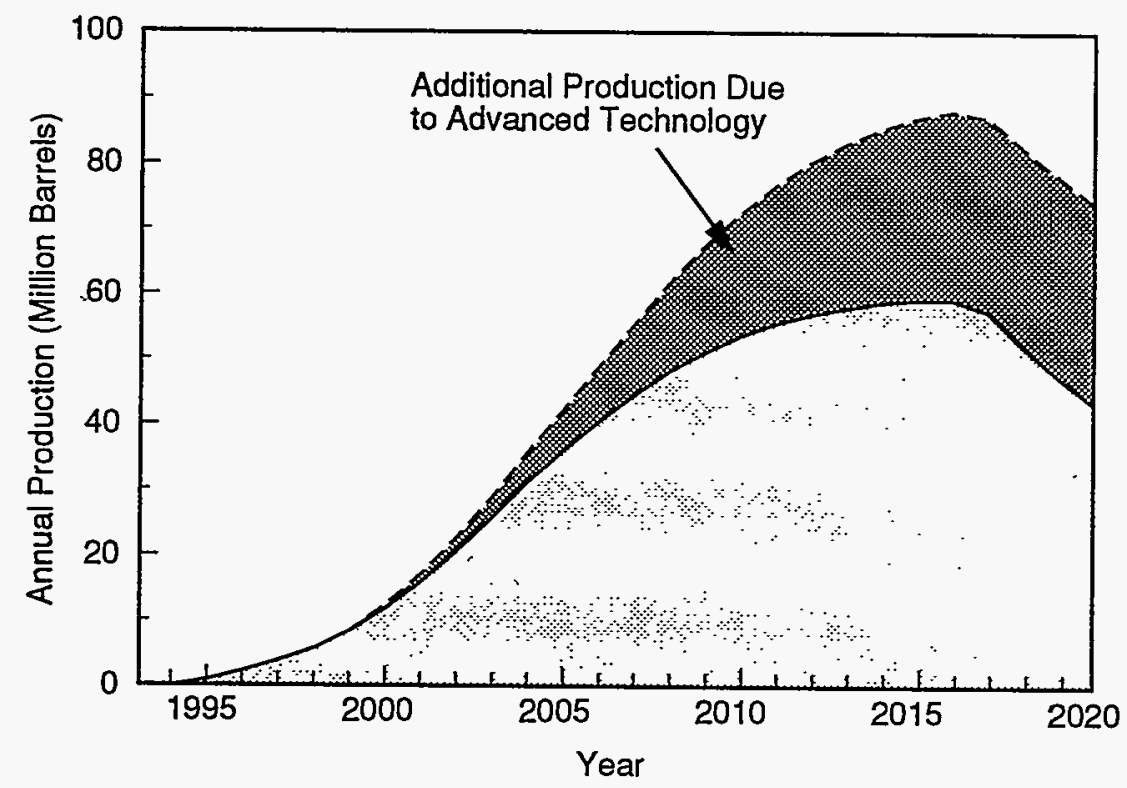

B) At $\$ 32 / B$

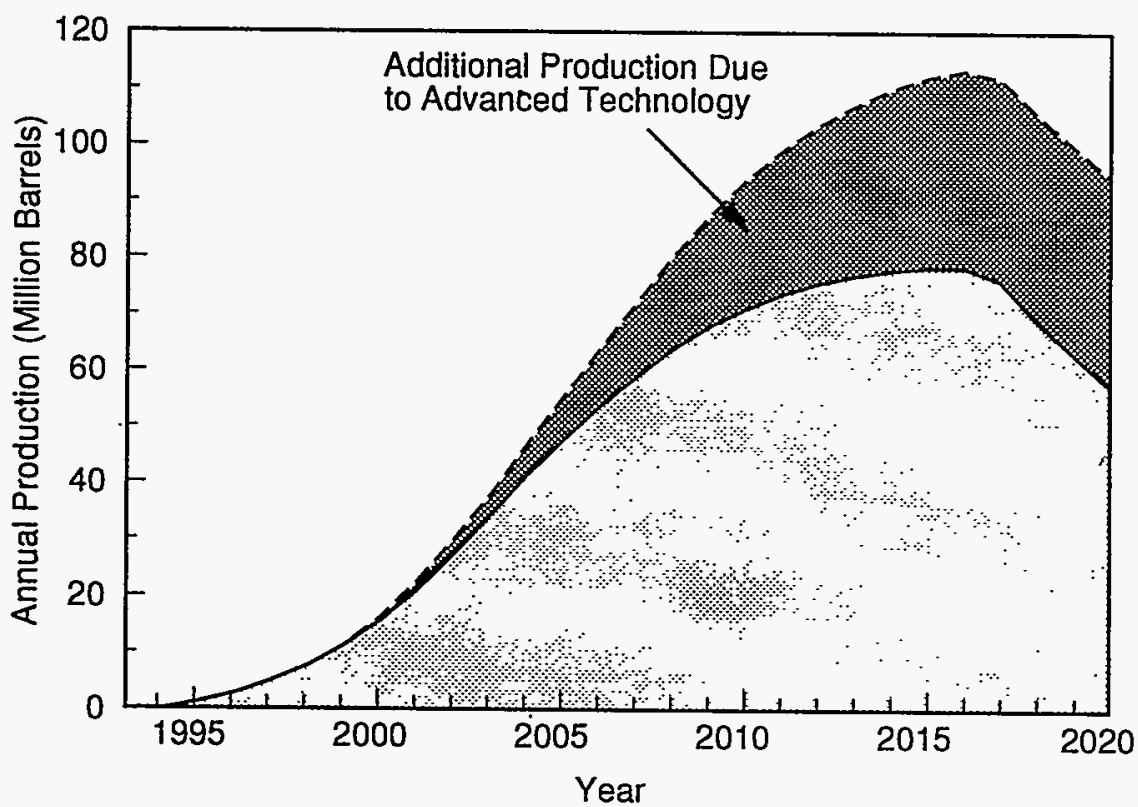


Figure V-7

State Impact of ASR Production

\section{Implemented Technology vs. Advanced Technology}

A) Direct State and Local Revenues

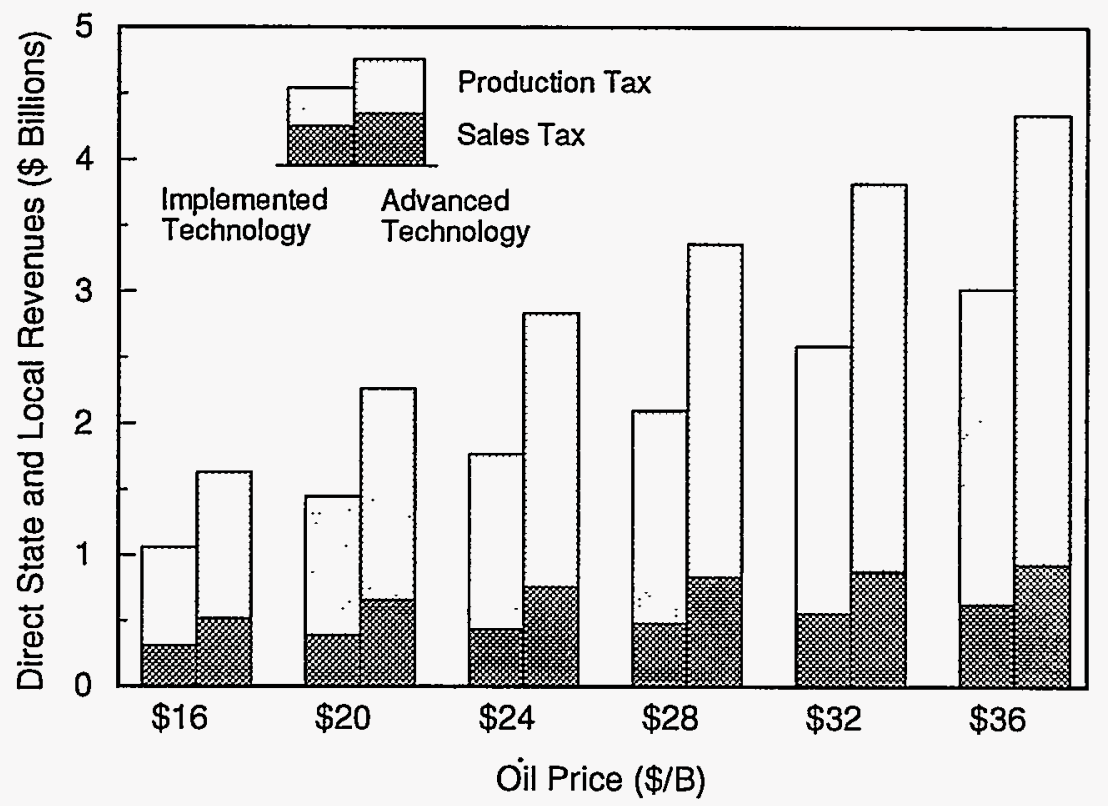

B) Direct State Economic Activity*

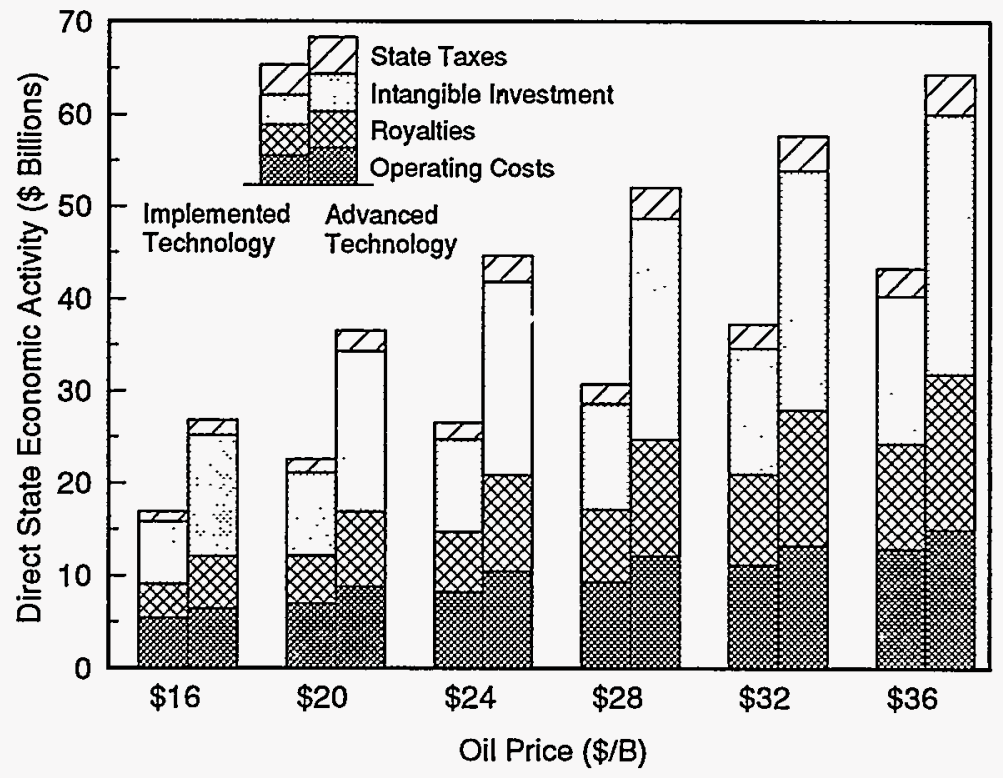

- To the extent that royalies go to the Foderal government (i.e. fields on Foderal lands), royalties as a portion of state economic aetivity may be overstated. 
technology accounting for much of the increase. In the peak year, advanced ASR technology could result in over 2,800 jobs annually at $\$ 16 / \mathrm{B}$ and 5,100 jobs per year at the $\$ 32 / \mathrm{B}$ oil price. Even at lower prices, the number of jobs created or maintained by advanced technology ASR projects would be highly beneficial to the Texas economy.

\section{Effects on the National Economy and Budget}

The application of advanced ASR technology in the state of Texas could also benefit the nation. Figure V-8A shows a dramatic increase in the incremental revenues to the Federal treasury from personal and corporate income taxes due to advanced technology ASR in analyzed Texas reservoirs. Total Federal revenues from advanced technology ASR could range from $\$ 5.2$ billion at the $\$ 16 / \mathrm{B}$ oil price to nearly $\$ 25$ billion at $\$ 36 / \mathrm{B}$. At oil prices from $\$ 20 / \mathrm{B}$ to $\$ 28 / \mathrm{B}$, technology advances could increase implemented technology potential revenues by $\$ 2.4$ billion to $\$ 4.3$ billion; $\$ 8.2$ billion to nearly $\$ 15$ billion of total potential Federal revenues from advanced technology ASR at these prices would be a significant addition to the Federal treasury.

As discussed in the previous chapter, the nation would also benefit from increased ASR production in Texas through enhanced energy independence and security, as the domestic resource base expands. Each barrel of reserves added through advanced technology ASR in Texas would replace a barrel of imported oil and reduce the nation's trade deficit. The value of the avoided imports would be recirculated through the U.S. economy rather than abroad. At moderate oil prices ( $\$ 20 / \mathrm{B}$ to $\$ 28 / \mathrm{B}$ ), technology advances could generate $\$ 23$ billion to $\$ 37$ billion of avoided imports over implemented technology. Total potential at these prices could range from over $\$ 65$ billion to $\$ 100$ billion in avoided imports. At $\$ 36 / \mathrm{B}$, $\$ 43$ billion (32\%) of the $\$ 135$ billion in imports avoided would be attributable to advances in ASR technology (Figure V-8B).

\section{CONCLUSIONS}

As discussed in Chapter III, currently available EOR and ASR technologies have the potential to significantly increase reserves and provide substantial economic benefits to operators, the state of Texas, and the nation. An aggressive and efficient technology transfer program in both the public and private sectors would bring these available technologies to operators and expedite their field applications. At an oil price of $\$ 20 / \mathrm{B}$, implemented technology EOR and ASR process could contribute nearly 3.0 billion 
Figure V-8

National Impact of ASR Production

Implemented Technology vs. Advanced Technology

A) Direct Federal Revenues

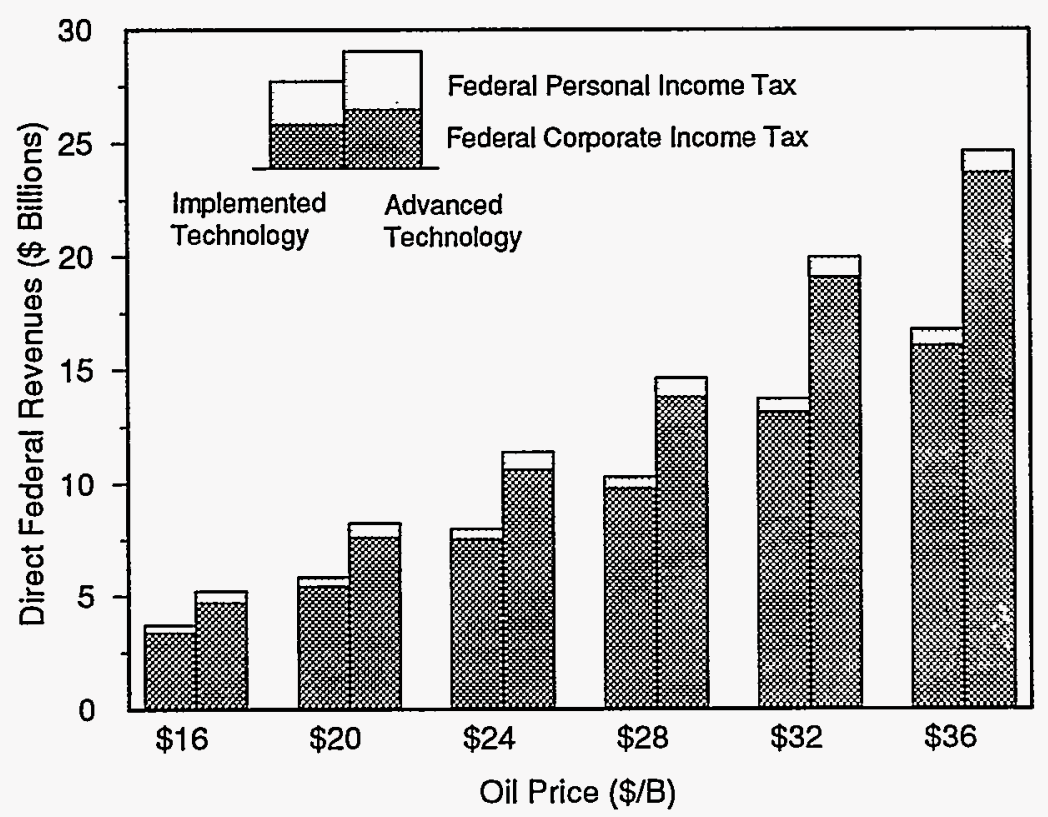

B) Imports Avoided*

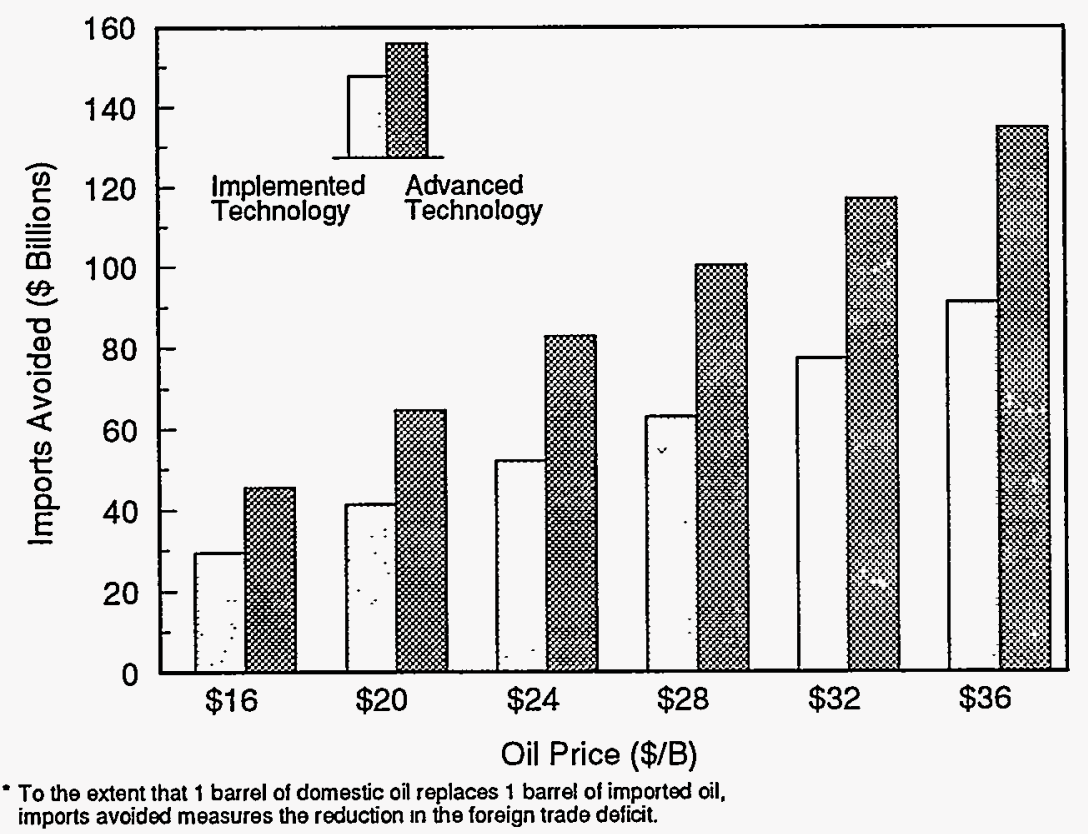


barrels of oil to Texas' reserves base. At $\$ 28 / \mathrm{B}$, potential reserves additions could reach almost 4.4 billion barrels.

Advances in technology could significantly increase the potential reserves and associated economic benefits which are possible using implemented technology EOR and ASR. Technology advances could increase implemented technology potential reserve additions by over 2.1 billion barrels of oil at an oil price of $\$ 20 / \mathrm{B}$. The total potential reserves at this price, over 5.0 billion barrels, is nearly $75 \%$ of Texas 1991 proved reserves. At an oil price of $\$ 28 / \mathrm{B}$, technology advances could add over 4.4 billion barrels of reserves additions for a total EOR and ASR reserve potential of nearly 8.8 billion barrels. If this potential were to be realized, advanced technology EOQR and ASR would more than replace Texas 1991 proved reserves.

The activities associated with advanced technology EOR and ASR would generate substantial direct state tax revenues. At $\$ 20 / \mathrm{B}$, nearly $\$ 1.7$ billion of the $\$ 4.0$ billion of potential direct state revenues are attributable to technology advances. At an oil price of $\$ 28 / \mathrm{B}$, over $50 \%$ ( $\$ 5.0$ billion) of the $\$ 10$ billion in total potential state revenues are due to advances in technology.

The potential benefits estimated in this analysis will not be possible, however, without effective technology transfer and RD\&D programs. Aggressive technology transfer needs to be undertaken by all oil-related entities (operators, producer associations, research universities, state geologic surveys, and state and Federal government agencies), in order to ensure that currently available technologies are disseminated in the oil patch and widely applied in the field. The significant additional benefits derived from technology advances clearly warrant a focused RD\&D program to improve advanced oil recovery technologies.

A collaborative effort between the public and private sectors is essential to pool resources and expertise while leveraging risk. Operators, oil companies, research universities, and state geologic surveys need to join with state and local governments and the Federal government to identify the highest priority problems in reservoirs with the largest remaining resources and the greatest threat of abandonment. A focused RD\&D effort targeting the identified problems needs to be undertaken. An RD\&D effort alone is not enough, however; the newly developed technologies need to be transferred to the field for widescale demonstration and application. The Department of Energy's Program Opportunity Notice (PON) process is currently applying some of these concepts. The PON process targets those classes of reservoirs 
with the largest potential resource and greatest threat of abandonments. Near- and mid-term RD\&D efforts, jointly funded by the Federal government and private industry, are directed towards the producing problems of these reservoirs. The results, once successfully developed and demonstrated, are to be transferred to other operators facing similar producing conditions. While they are a start, efforts like the PON process are not enough. A more aggressive and focused collaborative RD\&D effort will greatly increase domestic production, enhance national energy security, reduce imports, and increase economic benefits associated with oil recovery.

Even after the application of advanced technology EOR and ASR, large portions of the oil resource will remain unrecovered in the analyzed reservoirs (Figure V-9). At the improbably high oil price of $\$ 36 / \mathrm{B}$, total ASR reserves potential would be 3.8 billion barrels while EOR reserves potential would be 5.8 billion barrels. If this reserves potential were to be realized, over 19 billion barrels of mobile oil ( $84 \%$ of the mobile oil target) and 49 billion barrels of immobile oil ( $89 \%$ of the immobile oil target) would remain in analyzed reservoirs. In addition, over 22 billion barrels of remaining oil not included in this analysis and any newly discovered oil would still be unrecovered after application of advanced technology EOR and ASR. The known remaining oil-in-place of over 90 billion barrels is the target for further advanced in EOR and ASR technologies. 
Figure V-9

\section{Texas Remaining Oil After Advanced Technology Resource Recovery}

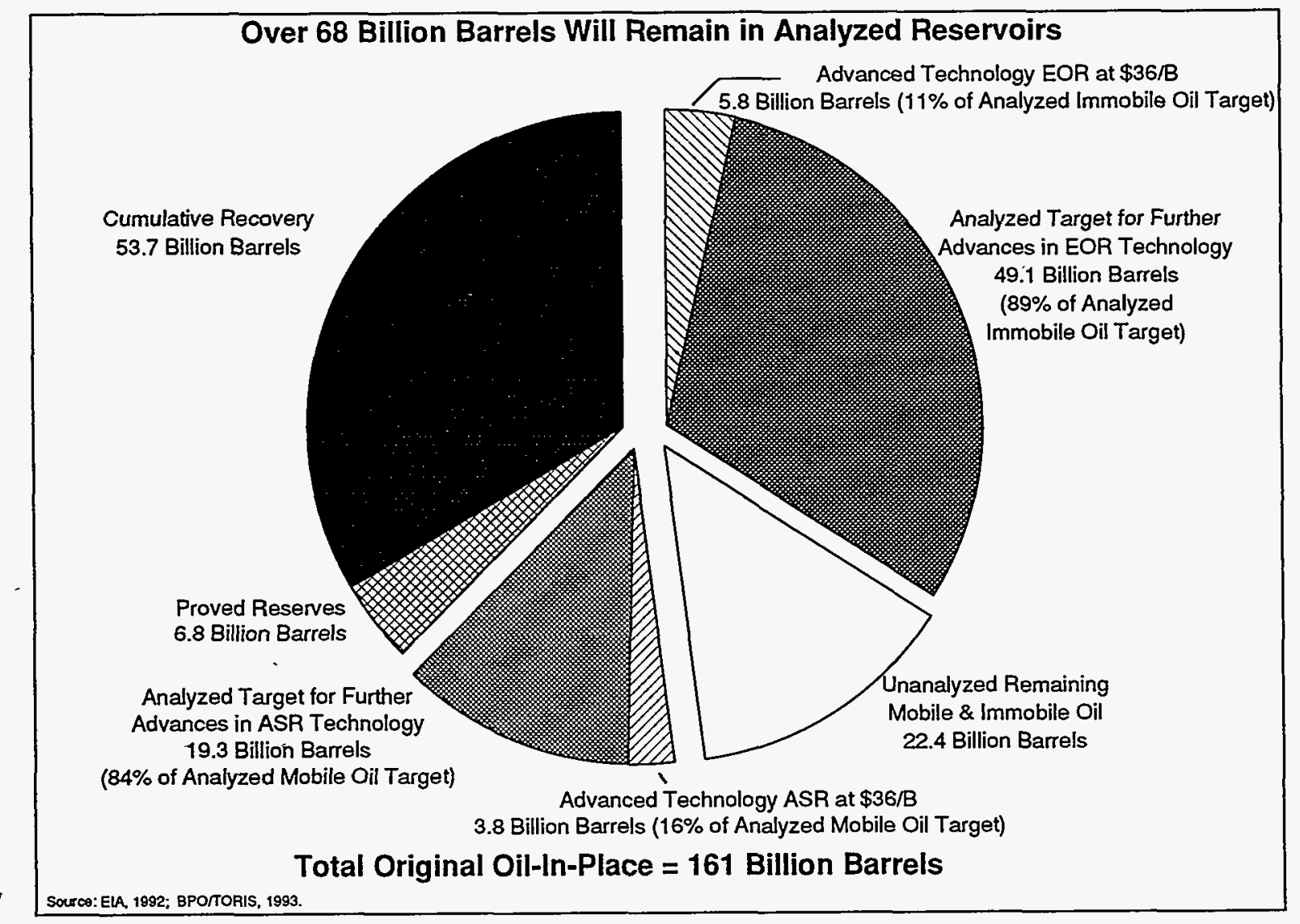

